\title{
PNL-607/
}

\section{EVALUATE AND CHARACTERIZE MECHANISMS CONTROLLING TRANSPORT, FATE, AND EFFECTS OF ARMY SMOKES IN THE AEROSOL WIND TUNNEL}

\author{
Transport, Transformations, Fate, and \\ Terrestrial Ecological Effects of \\ Red Phosphorus-Butyl Rubber and White Phosphorus \\ Obscurant Smokes
}

\section{Final Report}

\author{
Peter Van Voris \\ Michael W. Ligotke \\ Kris M. McFadden \\ Shu-mei W. Li \\ Berta L. Thomas
}

\author{
Dominic A. Cataldo \\ Thomas R. Garland \\ James K. Fredrickson \\ Roger M. Bean \\ David W. Carlile
}

\section{October 1987}

\author{
Supported by: \\ U.S. Army Medical Research \\ and Development Command \\ Fort Detrick, Frederick, MD 21701-5012
}

Project Order No. 84PP4819

Pacific Northwest Laboratory

Richland, Washington 99352

Operated for the U.S. Department of Energy

by Battelle Memorial Institute 


\title{
DISCLAIMER
}

This report was prepared as an account of work sponsored by an agency of the United States Government. Neither the United States Government nor any agency thereof, nor Battelle Memorial Institute, nor any of their employees, makes any warranty, expressed or implied, or assumes any legal liability or responsibility for the accuracy, completeness, or usefulness of any information, apparatus, product, or process disclosed, or represents that its use would not infringe privately owned rights. Reference herein to any specific commercial product, process, or service by trade name, trademark, manufacturer, or otherwise, does not necessarily constitute or imply its endorsement, recommendation, or favoring by the United States Government of any agency thereof, or Battelle Memorial Institute. The views and opinions of authors expressed herein do not necessarly state or reflect those of the United States Government or any agency thereof, or Battelle Memorial Institute.

\section{NOTICE}

\section{Disclaimer}

The findings in this report are not to be construed as an official Department of the Army position unless so designated by other authorized documents.

\section{Disposition}

Destroy this report when it is no longer needed. Do not return it to the originator.

\author{
PACIFIC NORTHWEST LABORATORY \\ operated by \\ BATTELLE MEMORIAL INSTITUTE \\ for the \\ UNITED STATES DEPARTMENT OF ENERGY \\ under Contract DE-AC06-76RLO 1830
}

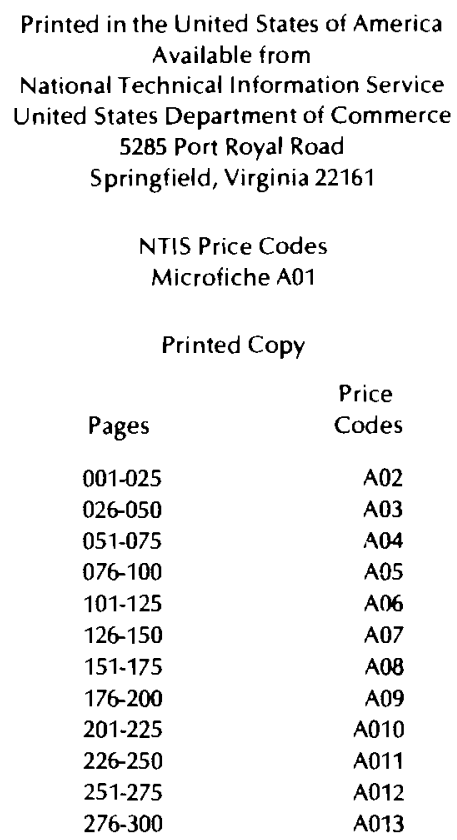


$A D$

PNL -6071

EVALUATE AND CHARACTERIZE MECHANISMS CONTROLLING TRANSPORT, FATE AND EFFECTS OF ARMY SMOKES IN THE AEROSOL WIND TUNNEL

Transport, Transformations, Fate, and Terrestrial Ecological Effects of Red Phosphorus-Butyl Rubber and White Phosphorus Obscurant Smokes

FINAL REPORT

\author{
Peter Van Voris \\ Michael W. Ligotke \\ Kris M. McFadden \\ Shu-mei W. Li \\ Berta L. Thomas
}

\author{
Dominic A. Cataldo \\ Thomas R. Garland \\ James K. Fredrickson \\ Roger M. Bean \\ David W. Carlile
}

OCTOBER 1987

Supported by:

U.S. ARMY MEDICAL RESEARCH AND DEVELOPMENT COMMAND

Fort Detrick, Frederick, MD 21701-5012

Project Order No. 84PP4819

Pacific Northwest Laboratory

Richland, Washington 99352

Operated for the U.S. Department of Energy

by Battelle Memorial Institute

Approved for public release;

distribution unlimited

The findings in this report are not to be construed as an official Department of the Army position unless so designated by other authorized documents 


\section{REPORT DOCUMENTATION PAGE}

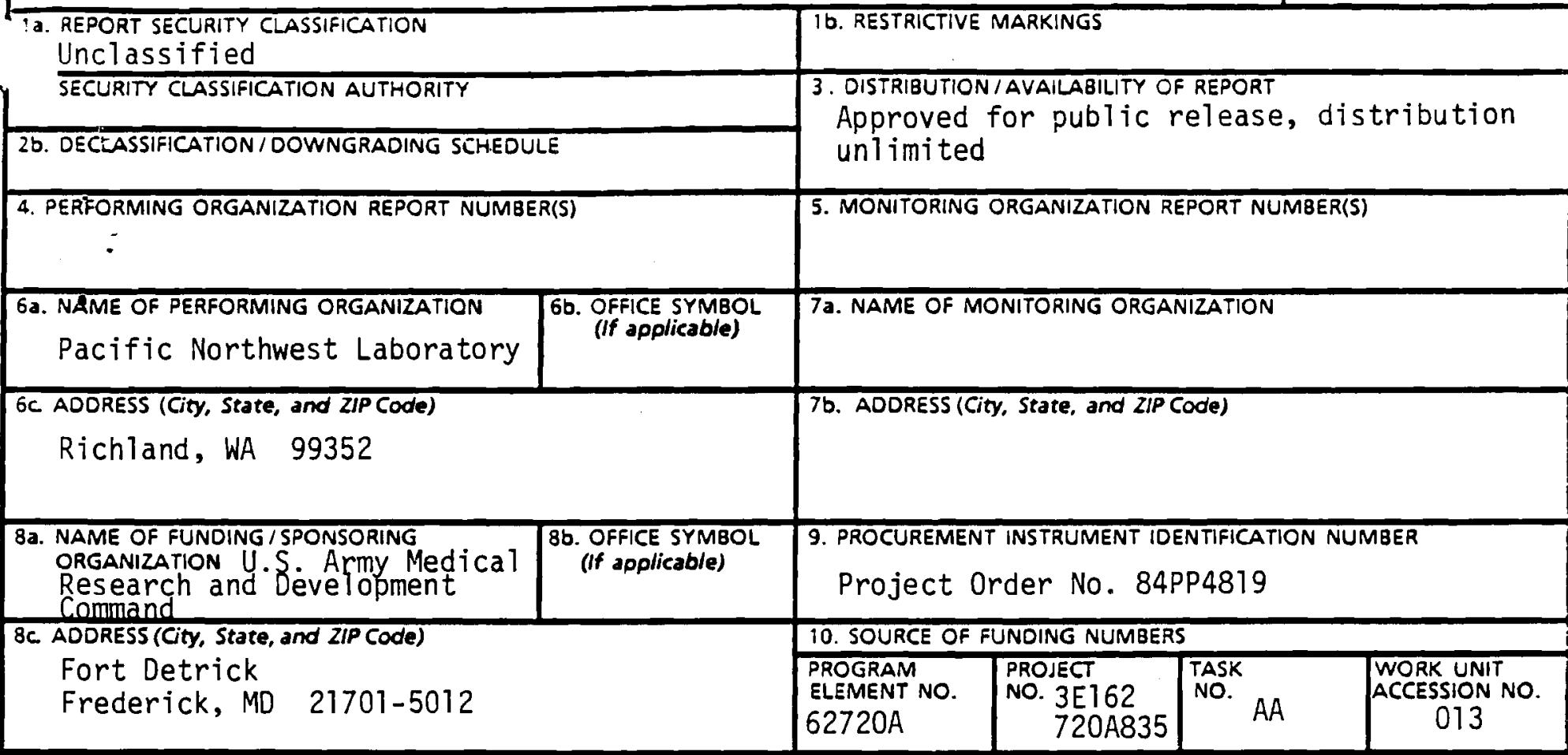

11. TITLE (Include Security Classification)

Evaluate and Characterize Mechanisms Controlling Transport, Fate and Effects of Army Smokes in the Aerosol Wind Tunnel

12 PERSONAL AUTHOR(s) P Van Voris, DA Cataldo, MW Ligotke, TR Garland, KM McFadden,

JK Fredrickson, SW Li, RM Bean, BL Thomas, and DW Carlile

\begin{tabular}{l|l|c|c|c}
\hline 13a. TYPE OF REPORT & 13b. TIME COVERED & 14. DATE OF REPORT (Year, Month, Day) \\
Fina 1 & FROM PAGE COUNT 1984 & OCtober 1987 & 202 \\
\hline
\end{tabular}

16. SUPPLEMENTARY NOTATION

Subtitle: Transport, Transformations, Fate, and Terrestrial Ecological Effects of Red Phosphorus-Butyl Rubber and White Phosphorus Obscurant Smokes

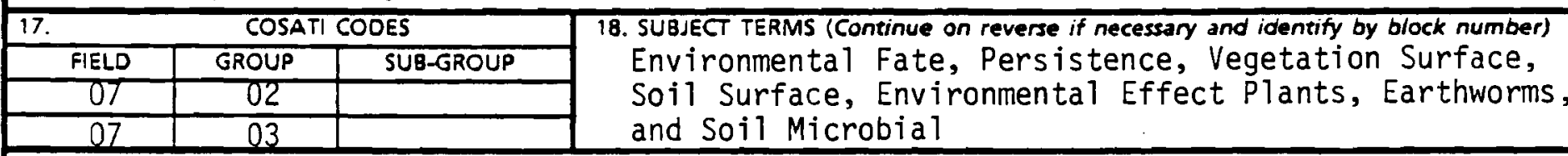

19. ABSTRACT (Continue on reverse if necessary and identify by block number)

See reverse.

20. DISTRIBUTION / AVAILABILITY OF ABSTRACT

XUNCLASSIFIED/UNLIMITED $\square$ SAME AS RPT.

22a. NAME OF RESPONSIBLE INOIVIDUAL

Judy Pawlus

21. ABSTRACT SECURITY CLASSIFICATION

Unclassified 


\section{ABSTRACT}

An evaluation of the terrestrial transport, transformations and ecological effects of phosphorus [red phosphorus-butyl rubber (RP/BR)] smoke obscurant was performed at. Pacific Northwest Laboratory. A similar evaluation using white phosphorus (WP) smoke/obscurant is currently proceeding. Future testing with other smokes are planned. The objective of this research program is to characterize the effects of smokes and obscurants on: (1) natural vegetation characteristic of U.S. Army training sites in the United States; (2) physical and chemical properties of representative of soils of those sites; and (3) soil microbiological communities. The influence and interactions of smoke/obscurant concentration, relative humidity $(25 \%, 60 \%, 90 \%$ and simulated rain) and wind speed of 0.22 to $4.45 \mathrm{~m} / \mathrm{s}$ by smoke is assessed. Five plant species and four soils were exposed to both single and repeated doses of RP/BR smokes in the Pacific Northwest Laboratory "P-3" rated recirculating environmental wind tunnel. Detailed results for RP/BR and limited results for WP are presented.

Toxicity symptoms for plants exposed for $2,4,6$, and 8 hours to concentrations of $R P / B R$ ranging from $200 \mathrm{mg} / \mathrm{m}^{3}$ (equivalent to a mass loading of $40 \mu \mathrm{g} \mathrm{P} / \mathrm{cm}^{2}$ to $250 \mu \mathrm{g}$ $\mathrm{P} / \mathrm{cm}^{2}$ ), either repeatedly or as a single exposure, included leaf tip burn, leaf curl, leaf abscission and drop, floral abortion, chlorosis, neucrotic spotting, wilting, desication and dieback. Of the plant species tested (i.e., ponderosa pine, short needle pine, sagebrush, a native grass [Blando Brome], and bushbean) the grass and bushbean were the most sensitive to RP/BR smoke. The intensity and duration of these effects vary depending on species, whether there was a post-exposure simulated rainfall treatment, and whether the exposure was a single high dose or a series of lower concentration repeated doses. Additionally, both relative humidity and wind speed affect the intensity of the plant effects. Soils effects data suggest that there is an increase in the mobility of selected trace elements after exposure; however, this effect appears to be ameliorated with time. This phenomenon is influenced by soil type, which is a reflection of the buffering capacity of the exposed soil (i.e., Burbank, Quallayute, Shawano, and Yamac) as well as the concentration and duration of exposure. Increased mobility of trace elements is also evidenced in. the trace element content of plants grown on soils after exposure to RP/BR. smoke. Soil Microbial community effects show a reduction in the production of nitrate after soil is exposed to RP/BR smoke. This indicates a reduction in ammonium oxidizing bacterial populations, specifically Nitrosomonas and probabiy Nitrobacter. For the most part, it appears that most of the plant, soil and soil microbial effects are transient in nature and are somewhat less intense resulting from repeated exposures; however, there is evidence that some of these environmental impacts may be persistent. 


\section{EXECUTIVE SUMMARY}

This report provides detailed information regarding wind tunnel evaluations of the formation, transport, atmospheric transformation, environmental fate, and terrestrial ecological effects of red phosphorus/ butyl rubber (RP/BR) and white phosphorus (WP) smokes/obscurants. These

- phosphorus based smokes are used in the L8A1 smoke grenade, the XM819 81-mm mortar, and the XM803 $155-\mathrm{mm}$ howitzer shell to mask troop and vehicle movement during combat training throughout the United States.

The primary objective of this research program is to characterize the ecological response of:

- Natural terrestrial vegetation representing Army training sites;

- Physical and chemical properties of several different soils; and

- Soil microbiological and invertebrate activities,

to these two obscurant smokes. Within the framework of the experimental design, we evaluated the influence of concentration of the smoke as well as two primary environmental variables, relative humidity $(20 \%, 60 \%, 90 \%$, and simulated rain) and wind speed $(0.5,2,4,6$, and $10 \mathrm{mph})$, on the ecological effects induced by these smokes. The second objective was to provide the detailed data necessary to establish frequency of usage criteria for training areas based on dose response and response surface characterization. As part of the overall research effort, considerable attention was given to the detailed physical and chemical characteristics of the smokes. This was done in order to provide source terms for exposure models for concerns associated with health effects on troops training at various sites, local residents, as well as domestic and wildlife animal populations.

The research was performed in the Pacific Northwest Laboratory Aerosol Research Facility which contains a specially designed recirculating wind tunnel. This wind tunnel was used to simulate a broad range of environmental conditions, varying smoke concentration, relative humidity, and wind speed, to allow extrapolation of laboratory test data to various Army training installations throughout the U.S.

Toxicity symptoms resulting from RP/BR or WP exposures for five plant species (i.e., ponderosa pine, short needle pine, sagebrush, blando brome [a grass], and bushbean) varied depending on species, smoke concentration, duration of exposure, relative humidity, and wind speed. The primary symptoms appearing included leaf tip burn, leaf curl, leaf abscission and drop, floral abortion, chlorosis, neucrotic spotting, wilting, desiccation, and dieback. Exposures lasted for 2, 4, 6, and 8 hours at concentrations that ranged from $200 \mathrm{mg} / \mathrm{m}^{3}$ to $5,600 \mathrm{mg} / \mathrm{m}^{3}$. Of the plant species tested, the grass and bushbean were most sensitive to both RP/BR and WP. The duration and intensity of the effects also varied depending on whether 
there was a post-exposure simulated rainfall treatment, or the exposure was a single high "acute" dose or a series of lower "chronic" repeated doses. Regrowth of grasses after exposure as well as the germination of seed after soil exposure was also adversely impacted.

Effects of RP/BR and WP on the four soils tested (i.e., yamac, burbank, shawano, and quillayute) suggest that there is a potential for increased mobilization of trace elements (i.e., $\mathrm{Al}^{+}$). However, the effects appear to be ameliorated with time and are strongly influenced by the buffering capacity of the soil as well as the concentration and duration of exposure. This increased trace element mobility is also evidenced in the trace element content of plants grown on exposed soil.

Soil microbial community effects show a reduction in the production of nitrate, and nitrite as we 11 as effects on soil dehydrogenase activity, and phosphatase activity. These effects indicate a reduction in ammonium oxidizing bacterial populations as well as other soil microbial populations.

For the most part, it appears that the plant, soil, and soil microbial effects are transient in nature. However, the grass regrowth test series data indicate that some of the environmental impacts may be persistent.

In this study we also attempted to integrate and interrelate those processes (atmospheric, environmental, and biological) thought to be important in defining the interaction of phosphorus smokes with receptor surfaces in the environment. The dose based on mass loading was quantified and the responses based on individual variables were evaluated to provide a bas is for extrapolating laboratory data to field situations. In addition, we present examples of three dimensional data extrapolation for the toxicity response of both ponderosa pine and sagebrush to phosphorus smokes, against a series of variables. The variables include mass loading, relative humidity and post-exposure simulated rainfall. From the response surface, it is clear that foliar mass loading is a major factor in toxicity. At a given mass loading, high and low levels of relative humidity have an adverse effect on the response, probably because of speciation of the phosphorus, while precipitation events (i.e., rainfall) can ameliorate the intensity of the adverse effects. It is also apparent that morphologic characteristics of the leaf surface can play a role in limiting or ameliorating the intensity of the impact.

The ease with which this type of response surface characterization can be applied to field scenarios depends on the basis used for establishing dose/response relationships. In this study, we have generated values for deposition velocity based on air concentration and mass loading (foliar and soil) that can be applied readily to the field situation. For example, the length of time a smoke test could be conducted without adversely impacting a stand of ponderosa pine located $8-\mathrm{km}$ downwind could be readily calculated based on the air concentration at that point, the deposition velocity for that canopy type, relative humidity, and wind speed. It is this predictive approach based on precise laboratory or field data that will be most useful in the future. 


\section{FOREWORD}

Citations of commercial organizations and trade names in this report do not constitute an official Department of the Army endorsement or approval of the products or services of these organizations. 


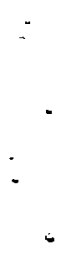

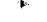




\section{TABLE OF CONTENTS}

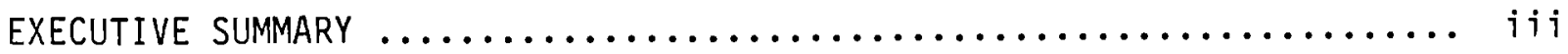

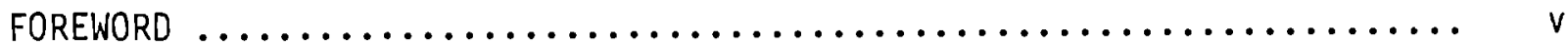

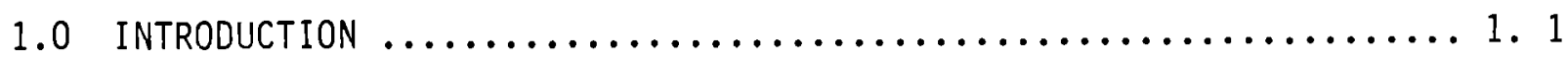

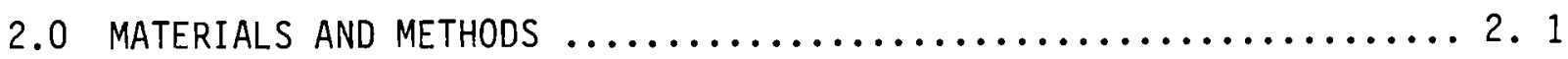

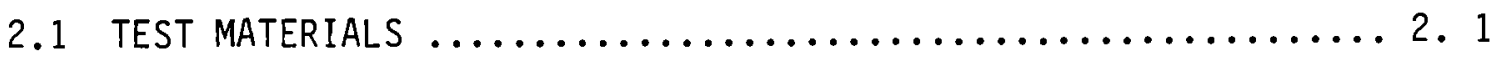

2.1.1 Smoke Substrate Characteristics ................. 1

2.1.2 Plant and Soil Selection ....................... 3

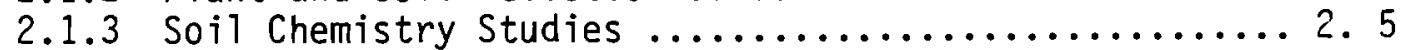

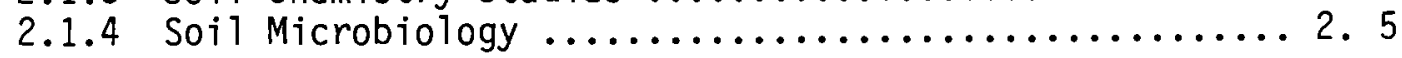

2.2 WIND TUNNEL FACILITIES AND EQUIPMENT $\ldots \ldots \ldots \ldots \ldots \ldots \ldots \ldots .6$

2.2.1 Description of Wind Tunnel Test Section .......... 2. 7

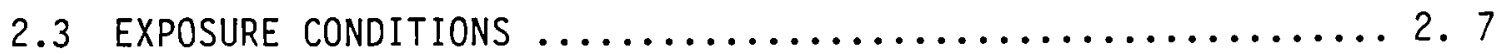

2.3.1 Exposure Environment and Test Conditions ..........2. 8

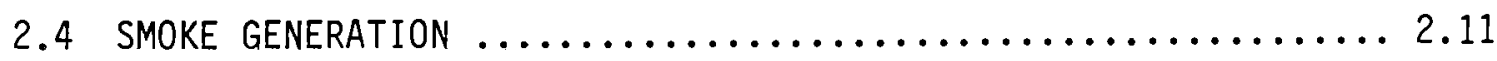

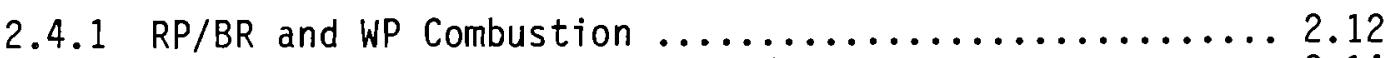

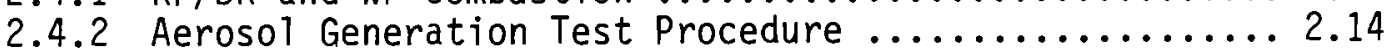

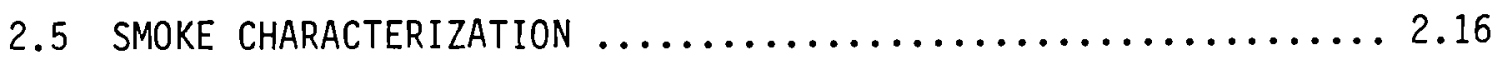

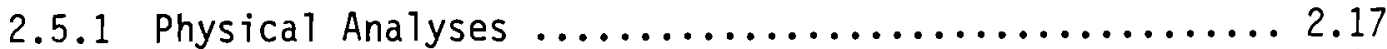

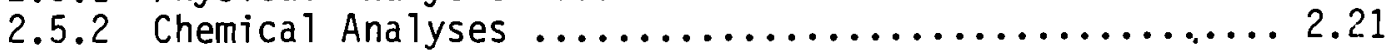

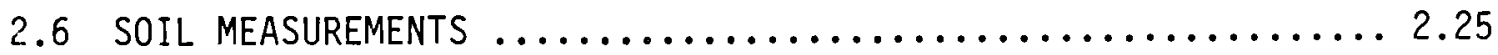

2.7 SOIL MICROBIOLOGICAL AND INVERTEBRATE MEASUREMENTS $\ldots \ldots \ldots 2.26$

2.7.1 Soil Microbiological Measurements ............. 2.26

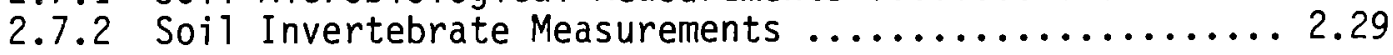

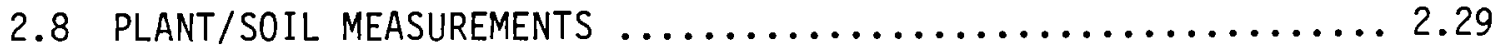

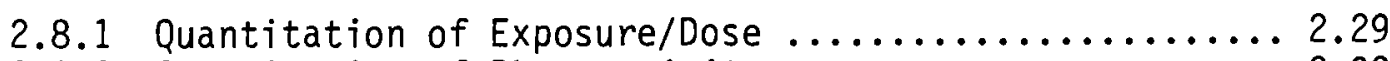

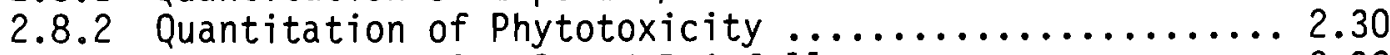

2.8.3 Post-Exposure Simulated Rainfal1 .....................

3.0 RESULTS AND DISCUSSION $\ldots \ldots \ldots \ldots \ldots \ldots \ldots \ldots \ldots \ldots \ldots \ldots \ldots \ldots \ldots \ldots \ldots \ldots \ldots$ 
TABLE OF CONTENTS (Cont.)

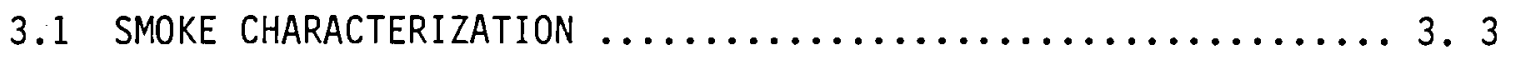

3.1.1 Physical Characteristics ......................... 3. 3

3.1 .2 Chemical Characteristics $\ldots \ldots \ldots \ldots \ldots \ldots \ldots \ldots \ldots \ldots \ldots \ldots .13$

3.2 TRANSPORT, FATE, AND EFFECTS OF PHOSPHORUS SMOKE DEPOSITION

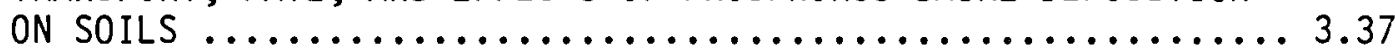

3.2.1 Soil-Phosphorus Background .................. 3.37

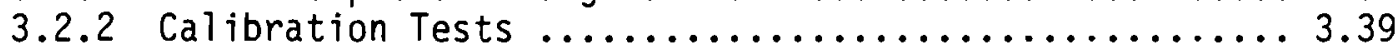

3.3 INTERACTIONS AND EFFECTS OF PHOSPHORUS SMOKES ON VEGETATION • 3.55

3.3.1 Deposition Velocities for Phosphorus Smokes to

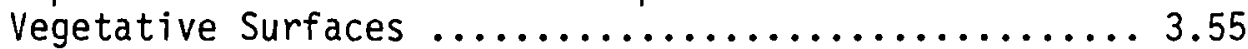

3.3.2 Mass Loading to Vegetative Surfaces and Influence of Post-Exposure Simulated Rainfall ................. 3.66

3.3.3 Direct Phytotoxicity of Phosphorus Smokes ............ 3.73

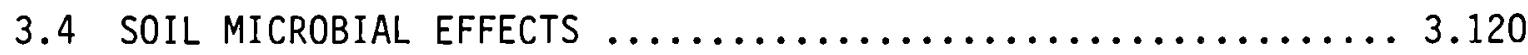

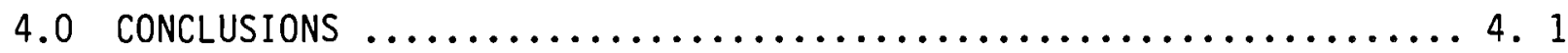

4.1 PHYSICAL AND CHEMICAL CHARACTERISTICS OF AIRBORNE

PHOSPHORUS SMOKES $\ldots \ldots \ldots \ldots \ldots \ldots \ldots \ldots \ldots \ldots \ldots \ldots \ldots \ldots . \ldots \ldots . \ldots \ldots$

4.2 IMPACT OF PHOSPHORUS SMOKES ON SOIL CHEMISTRY $\ldots \ldots \ldots \ldots \ldots . .2$

4.3 IMPACT OF PHOSPHORUS SMOKES ON SOIL MICROFLORA $\ldots \ldots \ldots \ldots \ldots, 2$

4.4 FOLIAR CONTACT TOXICITY: DIRECT EFFECTS $\ldots \ldots \ldots \ldots \ldots \ldots \ldots . . \ldots$

4.5 RESIDUAL AND INDIRECT SOIL/PLANT EFFECTS $\ldots \ldots \ldots \ldots \ldots \ldots .4 .4$

4.6 EXTRAPOLATION OF LABORATORY DATA TO FIELD SCENARIOS:

PREDICTIVE CAPABILITIES $\ldots \ldots \ldots \ldots \ldots \ldots \ldots \ldots \ldots \ldots \ldots \ldots, 4 . \ldots \ldots$

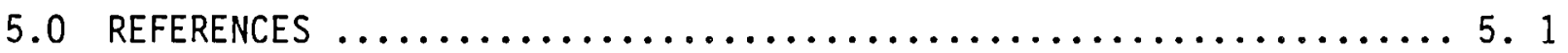




\section{LIST OF FIGURES}

2.1 Pacific Northwest Laboratory Special Recirculating Environmental

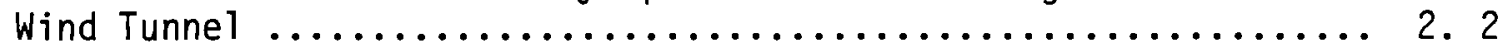

2.2 Computer Controlled Smoke Generation System ................ 2.13

2.3 Detailed Arrangement of Combustion System for RP/BR ......... 2.13

2.4 Wind Tunnel Smoke Generation, Injection, Bypass, and Baffle System ............................................... 2.14

2.5 Detailed Arrangement for Combustion of White Phosphorus ....... 2.15

2.6 Laser Transmissometer Used to Measure Smoke Mass Concentration

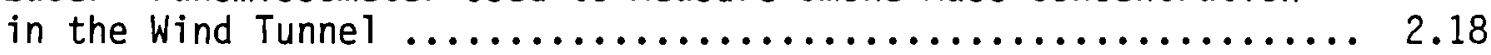

2.7 Post-Exposure Simulated Rainfal1 System ................. 2.32

3.1 Mass Concentration Versus Time for RP/BR Range-Finding Test A2 .. 3. 6

3.2 Mass Concentration Versus Time for the Fifth of Nine RP/BR Cumulative Dose Exposure Tests $\ldots \ldots \ldots \ldots \ldots \ldots \ldots \ldots \ldots \ldots \ldots . \ldots \ldots .6 .6$

3.3 Mass Concentration Versus Time for RP/BR Test Series D6

(Relative Humidity was 25\% for the First 2-hr Exposure and

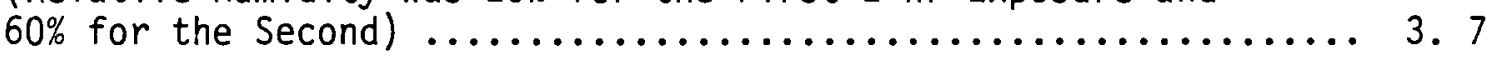

3.4 Mass Concentration Versus Time for WP Test E1 ............. 3. 7

3.5 Average Mass Concentration for Each Series B RP/BR Exposure .... 3. 8

3.6 Particle Size Distribution for RP/BR Test Series D6 Based on Anderson Cascade Impactor Samples ....................... 3.10

3.7 Mass Median Aerodynamic Particle Diameter (MMAD) Versus Age

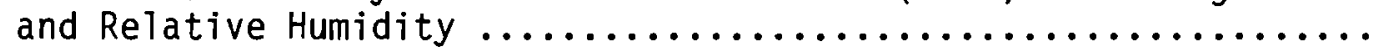

3.8 Chemical Composition of Airborne Particles: Percent Phosphorus by Mass in Various Aerosols Generated from Both RP/BR and WP .... 3.17

3.9 Hydroloys is of Phosphorus Compounds in RP/BR Smoke-Dosed

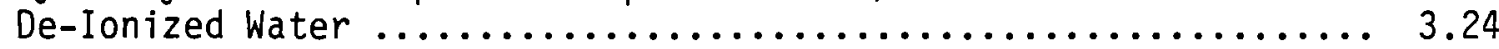

3.10 Phosphorus Speciation of RP/BR Aerosol Versus Humidity at $0.9 \mathrm{M} / \mathrm{S}$ (2 mph) Wind Speed and $22^{\circ} \mathrm{C}$ : Aqueous Impinger Samples $(\mathrm{N}=1) \ldots$ 


\section{LIST OF FIGURES (Cont.)}

3.11 Phosphorus Speciation of WP Aerosols Versus Humidity at $0.9 \mathrm{M} / \mathrm{S}$ Wind Speed and $22^{\circ} \mathrm{C}$ : Aqueous Impinger Samples $(\mathrm{N}=1) \ldots \ldots \ldots \ldots .31^{\circ}$

3.12 Behavior of Soluble Al from Burbank Soil After RP/BR Exposure ... 3.44

3.13 Behavior of Soluble Al from Quillayute Soil After RP/BR Exposure 3.44 .

3.14 Behavior of Soluble Al from Shawano Soil After RP/BR Exposure ... 3.45

3.15 Behavior of Soluble Al from Yamac Soil After RP/BR Exposure .... 3.45

3.16 Concentration of Soluble P Versus Exposed Soil Depth Ratio ..... 3.48

3.17 Concentration of Dissolved Organic C Versus Exposed Soil Depth

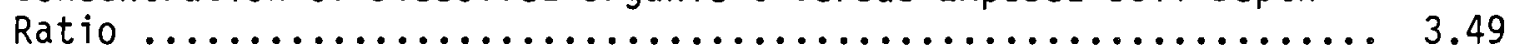

3.18 Concentration of Soluble Iron Versus Exposed Soil Depth Ratio ... 3.50

3.19 Percent of Total Soluble Phosphorus as Phosphate Versus Exposed

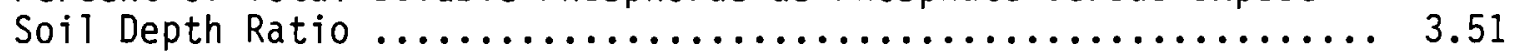

3.20 Influence of Relative Humidity on Deposition Velocities for Foliar Surfaces Following Exposure to RP/BR Smokes ............... 3.59

3.21 Influence of Relative Humidity on Deposition Velocities for Foliar Surfaces Following Exposure to WP Smokes ................. 3.62

3.22 Relationship Between Wind Speed and Deposition Velocities for Ponderosa Pine and Blando Brome Foliage Exposed to RP/BR and WP

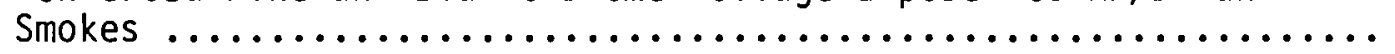

3.23 Influence of Exposure Duration on Mass Loading RP/BR Smokes to

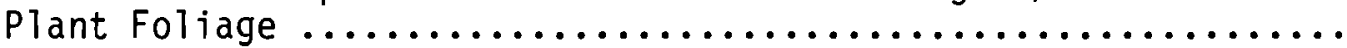

3.24 Influence of Foliar Mass Loading and Post-Exposure Leaching on Contact Toxicity of RP/BR Smokes to (a) Short Needle Pine, (b) Sagebrush, (c) Bushbean, (d) Blando Brome, and (e) Pondersoa

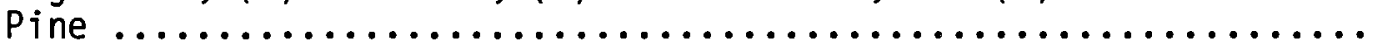

3.25 Overall Impact of Relative Humidity and Rainout on the Phytotoxicity of RP/BR (Top) and WP (Bottom) ................ 3.95

3.26 Scanning Electron Micrographs of Ponderosa Pine ( $A$ and $B$ ) and Short-Needle Pine Needles ( $C$ and $D)$. Magnifications are 100 Times and 2000 Times, Respectively 


\section{LIST OF FIGURES (Cont.)}

3.27 Scanning Electron Micrographs of $B$ lando Brome ( $A$ and $B$ ) and Bushbean Leaves ( $C$ and $D)$. Magnifications are 100 Times and 2000 Times, Respectively .............................. 3.101

3.28 Scanning Electron Micrographs of Sagebrush Leaves ( $A$ and $B$ ). Magnifications are 100 Times and 2000 Times, Respectively ...... 3.102

3.29 Residual Effects of Foliar Contamination with RP/BR and WP (Smokes on First and Second Harvest Biomass Production for Blando Brome)

3.30 Indirect Effects of Soil Deposited RP/BR Smokes on Growth of Blando Brome on Burbank Silt-Sand and Maxey Flats ............. 3.108

3.31 Plant Tissue Concentrations of Divalent Cations for Plants Grown in Maxey Flat Soil and Exposed to RP/BR .................... 3.113

3.32 Elemental Composition of Plant Tissue for Plants Grown in Burbank Soil

3.33 Response Surface for Soil Phosphatase Activity Resulting from $60 \%$

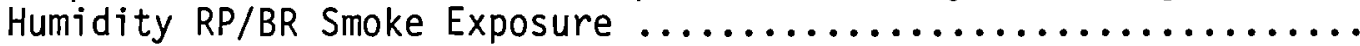

3.34 Response Surface for Soil Dehydrogenase Activity (in Glucose Amended Soi1) Resulting from 60\% Humidity RP/BR Smoke Exposure ..

3.35 Response Surface for Soil Dehydrogenase Activity (in Casamino Acids Amended Soil) Resulting From 60\% Humidity RP/BR Smoke Exposure

3.36 Response Surface for Soil Nitrification Activity Resulting from $60 \%$ Humidity RP/BR Smoke Exposure $\ldots \ldots \ldots \ldots \ldots \ldots \ldots \ldots \ldots \ldots . \ldots \ldots . . .136$

4.1 Response Surface for Ponderosa Pine (Top) and Sagebrush (Bottom). 4. 6 


\section{LIST OF TABLES}

2.1 Selected Properties of Test Soils ....................... 6

2.2 Exposure Conditions for the RP/BR Range-Finding Test (RFT) .... 2. 9

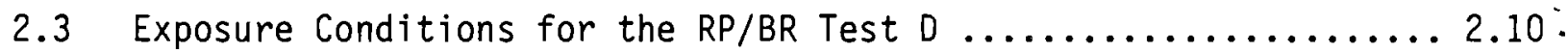

2.4 Exposure Conditions for the WP Test E $\ldots \ldots \ldots \ldots \ldots \ldots \ldots \ldots . .11$

2.5 Physical and Chemical Variables of RP/BR Smoke Tests for the Studies of Microbiological Effects ...................... 2.28

2.6 Coding for the Modified Daubenmire Rating Scale and Associated Phytotoxicity Symptoms .................................. 2.31

3.1 Aerosol Mass Concentration Results for the RP/BR Range-Finding Test $(R F T)$, Series A .................................. 4

3.2 Aerosol Mass Concentration Results for the RP/BR Range-Finding Tests (RFT), Series B ................................. 4

3.3 Aerosol Mass Concentration Results for the RP/BR Test D ....... 3. 5

3.4 Aerosol Mass Concentration Results for the WP Test E .......... 3. 5

3.5 Particle Size and GSD Versus Test, Age, and Relative Humidity. Results for Each Test Were Derived From Analys is of Single Cascade Impactor Samples ................................ 3.11

3.6 Summary of Particle Size Versus Age and Relative Humidity [Mass Median Aerosol Diameter Versus Relative Humidity and Aerosol Age for RP/BR and WP Aerosols (GSD $=1.60 \pm 0.1$ (Maximum observed Deviation from Average) Number of Impactor Samples Shown

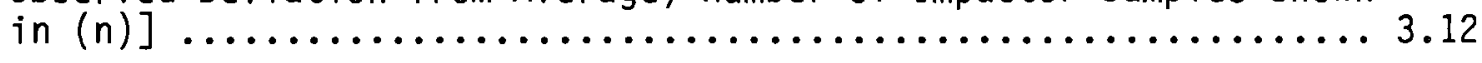

3.7 Ratio of Dried/Actual and Phosphorus/Actual Particulate Mass ... 3.16

3.8 Deposition Velocities of RP/BR Smoke Particles Under Varying Experimental Conditions $\ldots \ldots \ldots \ldots \ldots \ldots \ldots \ldots \ldots \ldots \ldots \ldots \ldots \ldots \ldots \ldots \ldots \ldots \ldots .18$

3.9 Deposition Velocities of RP/BR Smoke Particles on Wet and Dry Surfaces ...................................... 3.19

3.10 Deposition Velocities of WP Smoke Particles on Wet and

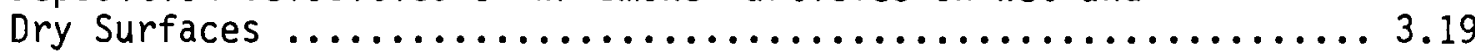

3.11 Hydrolysis Versus Age Prior to Water Leach $\ldots \ldots \ldots \ldots \ldots \ldots . . . \ldots 3.20$

3.12 Phosphate Contribution Versus Particle Size for RP/BR Aerosols at Three Humidities and Wind Speeds 


\section{LIST OF TABLES (Cont.)}

3.13 Phosphate Contribution Versus Particle Size for WP Aerosols at Three Humidities and Wind Speeds $\ldots \ldots \ldots \ldots \ldots \ldots \ldots \ldots . . . . .22$

3.14 Aging of RP/BR Aerosol at Constant Humidity $(\mathrm{N}=1) \ldots \ldots \ldots \ldots .23$

3.15 Speciation Versus Humidity in Fresh RP/BR Aerosol (Aqueous

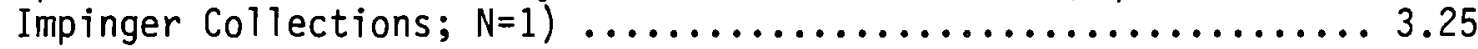

3.16 Phosphorus Speciation of RP/BR Aerosols Versus Humidity at $0.9 \mathrm{M} / \mathrm{S}$ (2 mph) Wind Speed and $22^{\circ} \mathrm{C}$ : Static Deposition

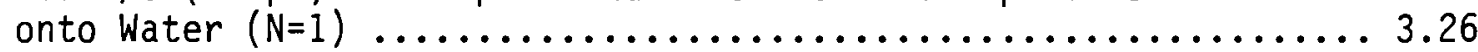

3.17 Phosphorus Speciation of WP Aerosol Versus Humidity at 0.9 $\mathrm{M} / \mathrm{Sec}$ Wind Speed $(2 \mathrm{mph})$ and $22^{\circ} \mathrm{C}$ : Static Deposition onto Water $(\mathrm{N}=1)$

3.18 Phosphorus Speciation of RP/BR Aerosol Versus Humidity at $0.9 \mathrm{M} / \mathrm{S}$ (2 mph) Wind Speed and $22^{\circ} \mathrm{C}$ : Aqueous Impinger Samples $(N=1)$

3.19 Phosphorus Speciation of WP Aerosols Versus Humidity at 0.9 $\mathrm{M} / \mathrm{S}$ Wind Speed and $22^{\circ} \mathrm{C}$ : Aqueous Impinger Samples $(\mathrm{N}=1) \ldots \ldots .30$

3.20 Phosphorus Speciation Versus Humidity in Steady-State

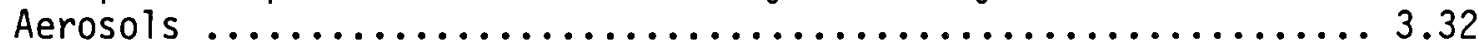

3.21 Phosphorus Speciation of RP/BR Aerosol (Test D4) Versus Particle Size at $9.0 \mathrm{M} / \mathrm{S}$ Wind Speed and $22^{\circ} \mathrm{C}$, and $87 \%$ Relative Humidity $(\mathrm{N}=1)$

3.22 Phosphine $\left(\mathrm{PH}_{3}\right)$ Concentrations in WP Aerosols During WP-E Test Series

3.23 Concentration of $P_{4}$ in Aerosol Bubbler Samples: WP-E Test Series $(N=1)$

3.24 Concentration of $P_{4}$ Following Static Deposition Water

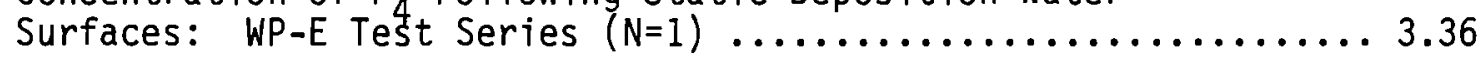

3.25 Interaction of RP/BR Smoke with Soil: 0.5-CM Depths

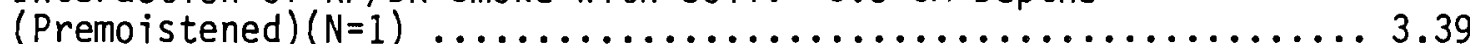

3.26 Mean Soluble Metal Concentrations Over Time from Sandy Loam Soi 1 After RP/BR Smoke Deposition Followed By Water Extraction ( $N=2)$.. 3.40

3.27 Comparison of Soluble Components Released from Soils Affected by RP/BR Smoke Deposition After 0.8-Day Incubation with water ... 3.41 


\section{LIST OF TABLES (Cont.)}

3.28 Comparison of Soluble Components Released From Soils Affected by WP Smoke Deposition After 0.8-Day Incubation With Water ..... 3.42

3.29 Soluble Components Released from Soils by WP Smoke Deposition Versus $\mathrm{H}_{3} \mathrm{PO}_{4}$ Leaching at 0.8 Day ....................

3.30 Effect of RP/BR-Exposed Soil Depth on Soluble Species After 5 -Day Incubation .................................... 3.47

3.31 Effect of Soil Type and Leaching Time of $\mathrm{PO}_{4}^{-} \mathrm{P}$ and Total Soluble Phosphorus Following RP/BR Aerosol Exposure .......... 3.53

3.32 Effect of Soil Type and Leaching Time on P04 $3^{-} P$ and Total Soluble Phosphorus Following WP Aerosol Exposiru ............. 3.54

3.33 Change in Phosphorus Speciation with Time after RP/BR

Deposition on Water and on Thin Layer of Sandy Loam Soil

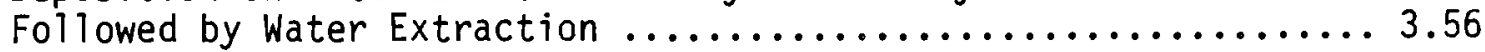

3.34 Deposition Velocities for Plant Species Exposed to a

Constant Air Concentration of RP Smoke ....................... 3.58

3.35 Influence of Relative Humidity on Deposition Velocities for $\mathrm{RP} / \mathrm{BR}$ Deposition to Vegetative Surfaces $\ldots \ldots \ldots \ldots \ldots \ldots \ldots \ldots . . \ldots \ldots$

3.36 Deposition Velocities for WP to Foliar Surfaces as a Function of Relative Humidity and Plant Species ............. 3.61

3.37 Influence of Wind Speed on Deposition Velocity of RP/BR Smokes to Foliage of Ponderosa Pine and Bland Brome ........... 3.63

3.38 Influence of Wind Speed on Deposition Velocity of WP Smokes

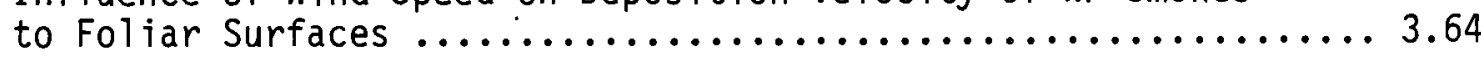

3.39 Mass Loading of RP/BR Smokes to Plant Foliage as a Function of Exposure Duration (Range-Finding Test), and Influence of Post-Exposure Simulated Rainfall on Retention of Phosphorus ...................................... 3.67

3.40 Influence of Relative Humidity and Simulated Rainout on Foliar Mass Loading of RP/BR Smokes on Plant Foliage ............... 3.70

3.41 Mass Loading Levels of WP to Foliar Surfaces as a Function of of Relative Humidity and Plant Species, and the Influence of Post-Exposure Simulated Rainfall on Foliar Retention of

Phosphorus 


\section{LIST OF TABLES (Cont.)}

3.42 Influence of Wind Speed on Mass Loading of RP/BR Smokes to

Foliage of Ponderosa Pine and BTando Brome $\ldots \ldots \ldots \ldots \ldots \ldots \ldots .72$

3.43 Influence of Wind Speed on Mass Loading of WP Smokes to

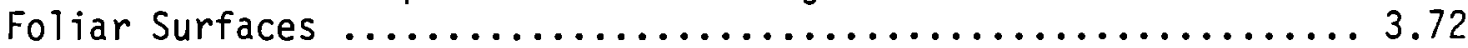

3.44 Coding for the Modified Daubenmire Rating Scale and

Associated Phytotoxicity Symptoms ........................... 3.75

3.45 Phytotoxic Responses Observed for Plants Exposed to RP/BR

Smokes for 2, 4, 6, and 8 Hours. Comparison of Plants

Exposed Without Post-Exposure Treatment and Plants Subjected to a Post-Exposure Simulated Rainfa11 ..................... 3.76

3.46 Exposure Frequencies and Time-Weighted Exposure Levels for RP/BR Smokes in the Cumulative Dose Test $\ldots \ldots \ldots \ldots \ldots \ldots . . . . . .3 .81$

3.47 Estimated and Measured Mass Loading Rates to Foliage for the Cumulative Dose Test $\ldots \ldots \ldots \ldots \ldots \ldots \ldots \ldots \ldots \ldots \ldots \ldots \ldots \ldots \ldots \ldots . .62$

3.48 Tabulated Phytotoxicity Data for the Repetitive Low and High Exposure Dose Treatments from the Cumulative Dose Test (These Data are Compared with Plant Effects, Foliar Mass Loading, and Time-Weighted Exposure Levels for the RP/BR Smoke Range-Finding Test) $\ldots \ldots \ldots \ldots \ldots \ldots \ldots \ldots \ldots \ldots \ldots \ldots \ldots \ldots . . .63$

3.49 Comparison of Gross Phytotoxicity Observed 14 days Post-Exposure for Each Plant Species Based on Treatments Employed in the Relative Humidity Test Series

3.50 Comparison of the Influence of Relative Humidity, PostExposure Simulated Rainfall, and Rainout on Phytotoxic Responses of Ponderosa Pine to RP/BR Smokes

3.51 Comparison of the Influence of Relative Humidity, PostExposure Simulated Rainfall and Rainout on Phytotoxic Responses of Short-Needle Pine to RP/BR Smokes .............. 3.88

3.52 Comparison of the Influence of Relative Humidity, PostExposure Simulated Rainfall and Rainout on Phytotoxic Responses of Sagebrush to RP/BR Smokes

3.53 Comparison of the Influence of Relative Humidity, PostExposure Simulated Rainfall and Rainout on Phytotoxic Responses of Bushbean to RP/BR Smokes 


\section{LIST OF TABLES (Cont.)}

3.54 Comparison of the Influence of Relative Humidity, PostExposure Simulated Rainfall and Rainout on Phytotoxic .

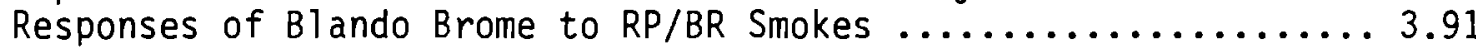

3.55 Influence of Relative Humidity and Post-Exposure Simulated Rainfall on Phytotoxicity of White Phosphorus Smokes to Ponderosa Pine ................................... 3.92

3.56 Influence of Relative Humidity and Post-Exposure Simulated Rainfall on Phytotoxicity of White Phosphorus Smokes to Short-Needle Pine

3.57 Influence of Relative Humidity and Post-Exposure Simulated Rainfall on Phytotoxicity of White Phosphorus Smokes to Sagebrush

3.58 Influence of Relative Humidity on Phytotoxicity of White

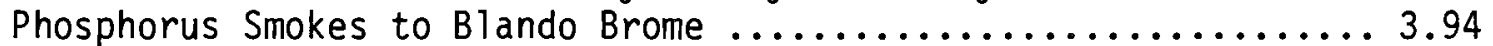

3.59 Influence of Relative Humidity and Post-Exposure Simulated Rainfall on Phytotoxicity of White Phosphorus Smokes to Bushbean

3.60 Influence of Wind Speed on the Phytotoxicity of RP/BR and WP

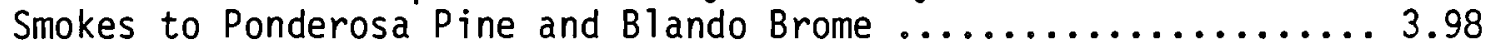

3.61 Residual Effects of Foliar-Deposited Phosphorus Smokes on

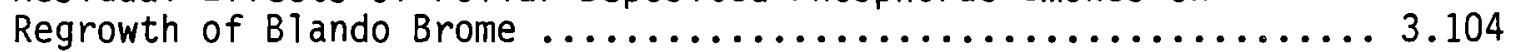

3.62 Effect of Soil-Deposited RP/BR Smokes on the Growth of Blando Brome Seeded Post-Exposure. Soils Were Exposed Either for 2, 4,6 , or 8 Hours in RFT-A, or to Consecutive Doses in the CDT

3.63 Influence of Relative Humidity and Rainout on Growth of Blando Brome Grown on Soils Contaminated with RP/BR Smokes, Exposure Series D

3.64 Availablility of Soil Elements for Plant Uptake Following Contamination of Soils with RP/BR Smokes for 2 to 8 Hours

3.65 Availability of Elements Following Cumulative Dosing with

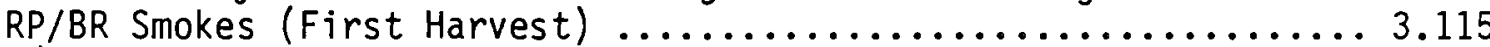

3.66 Availability of Elements Following Cumulative Dosing with RP/BR Smokes (Second Harvest) 


\section{LIST OF TABLES (Cont.)}

3.67 Plant Availability of Elements from Burbank Silt-Sand Following Contamination with RP/BR Smokes at a Range of Relative Humidities and Under Rainout Conditions

3.68 Plant Availability of Elements from Maxey Flats Silt-Loam Soil Following Contamination with RP/BR Smokes at a Range of Relative Humidities and Under Rainout Conditions

3.69 Changes in the Shoot Content of Several Elements Following Regrowth of Blando Brome, Foliarly Exposed to RP/BR Smokes

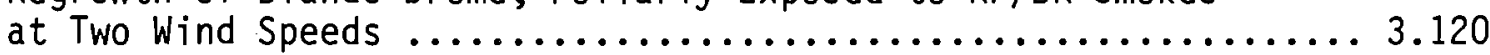

3.70 Physical and Chemical Variables of RP/BR Smoke Tests for the Study of Microbiological Effects ....................... 3.122

3.71 Effect of RP/BR Smoke on the Microbiological Conversion of

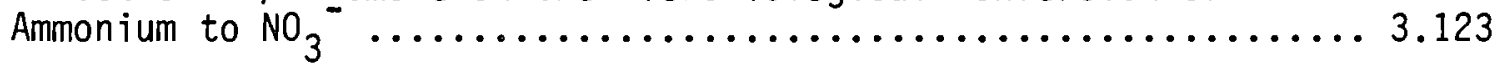

3.72 Effect of RP/BR Smoke on the Microbiological Conversion of

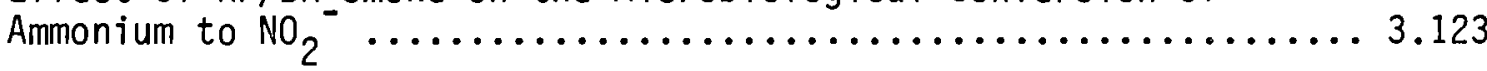

3.73 Effect of RP/BR Smoke on Nitrite Production ................ 3.124

3.74 Effect of RP/BR Smoke on Nitrate Production ................ 3.125

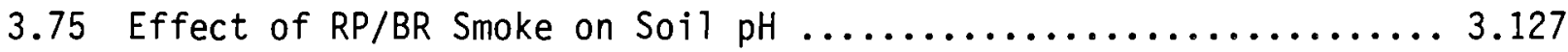

3.76 Effects of RP/BR Smoke on Soil Enzyme Activity .............. 3.128

3.77 Effect of RP/BR Smoke on Soil Dehydrogenase Activity

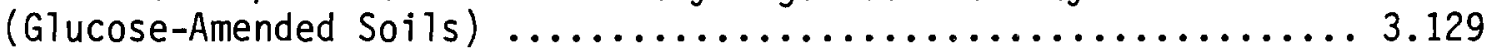

3.78 Effect of RP/BR Smoke on Soil Dehydrogenase Activity

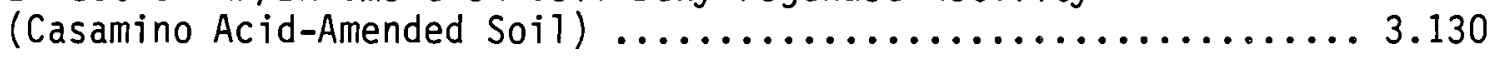

3.79 Effect of RP/BR Smoke on Soil Phosphatase Activity ........... 3.131 


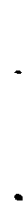




\subsection{INTRODUCTION}

The U.S. Army has developed smokes and obscurants to mask visually the movement of troops and vehicles during combat. Effective training scenarios for our armed forces require that troop maneuvers simulate, as closely as possible, the conditions most likely to be encountered under live combat situations (e.g., hardware, weapons fire, terrain, weather, vegetation, and smoke concentrations). Within the framework of the training operations, the Army has a regulatory responsibility to ensure that the use of smokes and obscurants does not adversely affect the health of local residents, or the environment, both on and near the training sites. The environments of these training centers range from high deserts to semitropical forests, thus complicating this responsibility.

The Health Effects Research Division of the U.S. Army Biomedical Research and Development Laboratory (USABRDL) has been assigned the responsibility of determining the potential environmental effects associated with the use of smokes and obscurants in training and testing. As part of USABRDL's planned program in response to this concern, the U.S. Department of Energy's (DOE's) Pacific Northwest Laboratory (PNL) was assigned to evaluate the transport, the chemical transformation, and the terrestrial ecological effects of several of the smokes currently used in training throughout the United States. PNL was assigned this task for two reasons. First, smoke and obscurant testing could be conducted within a special recirculating wind tunnel that ensures containment of the smoke and enables researchers to simulate a variety of environmental conditions (i.e., varying wind speeds, relative humidities, temperatures and lighting conditions). Second, PNL researchers have unique expertise in evaluating the interactions of plants and soils with aerosols and gases under controlled environmental conditions.

The objective of this report is to present detailed results associated with the formation, transport, atmospheric transformation, deposition, and terrestrial ecological effects of two obscurant smokes. The two smokes tested were red phosphorus-butyl rubber (RP/BR) and white phosphorus (WP). Effects of these smokes on three primary ecosystem components were evaluated:

1) natural terrestrial vegetation characteristic of U.S. Army training sites in the United States,

2) physical and chemical properties of soils at those sites, and

3) Soil microbiological and soil invertebrate communities.

Within the framework of the experimental design, we evaluated the influence of two primary environmental variables, relative humidity $(20 \%$, $60 \%, 90 \%$, and simulated rain) and wind speed ( 2 to $10 \mathrm{mph}$ or 0.90 and 4.5 $\mathrm{m} / \mathrm{s})$, on the ecological effects induced by these smokes. The second objective was to supply detailed data on the physical and chemical 
characteristics of these smokes for use by USABRDL in predicting dose associated with human health risk assessment models and for future assessments with regard to effects on wildlife and domestic animals.

It should be noted that the health and environmental effects of Army smokes and obscurants have been studied intensively over the past 30 years; these research efforts have recently been compiled and reviewed by Shinn et a). (1985). In general, research into the effects of obscurant smokes has concentrated on animal and aquatic toxicity, with relatively little effort being expended in understanding soil/plant or ecological effects. The vast majority of these previous efforts used direct artificial dosing of organisms or aqueous amendments of suspected toxicants. While this may be appropriate and necessary in many instances, it may not be appropriate in developing an understanding of the potential impact of the recurrent use of obscurant smokes at heavily used training sites. This is mainly because there is no established correlation between airborne smoke concentration, deposition on soils and plants (duration and physical parameters affecting deposition), and the ultimate effect, environmental deterioration. 


\subsection{MATERIALS AND METHODS}

A11 phosphorus smokes testing was conducted at the Aerosol Research Facility at Pacific Northwest Laboratory (PNL). This facility (Figure 2.1), which is located on the U.S. Department of Energy's (DOE) Hanford Site in southeastern Washington, contains an environmental wind tunnel suitable for testing obscurant smoke under a wide variety of environmental conditions. The facility and supporting laboratories are used for research involving generation, transport, deposition, and characterization of aerosols and gases in complex atmospheric environments. A more detailed description of the wind tunnel is provided in Section 2.2 and additonal information can be found in Van Voris et a1. (1985), Van Voris et al. (1986), and Ligotke et al. (1986).

\subsection{TEST MATERIALS}

Red phosphorus/butyl rubber (RP/BR) and white phosphorus (WP) smokes were tested in this project. The effects of these smokes on soil chemistry, microbially mediated soil processes, select invertebrates inhabiting the soil, and five plant species representing various geographic regions of the contential United States were evaluated.

\subsubsection{Smoke Substrate Characteristics}

Both RP/BR and pure WP were burned to generate obscurant smokes. Sixty-four kilograms of RP/BR, packaged in three small drums, were obtained from the U. S. Army at Aberdeen Proving Ground in Maryland. The material consisted of amorphous red phosphorus granules composed of a 95:5 ratio of red phosphorus to butyl rubber. The butyl rubber reduces the cloud-pillar effect often found with pure RP obscurant munitions. Approximately $1 \%$ of the RP/BR mixture was mineral oil (a die extrusion lubricant) and $1 \%$ was talc, in accordance with military specifications (DOD-P-51463(EA), 1960). The talc optimizes break up and improves dispersion pattern uniformity. The RP/BR used in this study was similar to that used in the L8AI grenade, XM819 81-mm mortar, and the XM803 155-mm howitzer. Approximately $20 \mathrm{~kg}$ of $\mathrm{RP} / \mathrm{BR}$ were used during the study.

Pure WP was purchased from a commercial supplier because distribution of the material in white phosphorus/felt (WP/F) munitions is not uniform (Spanggord et al. 1985). The white, or yellow, phosphorus was like wax in appearance and texture.

While RP/BR used in this study was, to our knowledge, identical to that used in several types of obscurant devices currently in the military inventory, the WP was pure rather than impregnated in a felt matrix (WP/F) as is typical of military inventory. Pure WP was used rather than WP/F because no significant effect on the formation or chemical speciation of the smokes was anticipated between pure WP and WP in a felt matrix. 


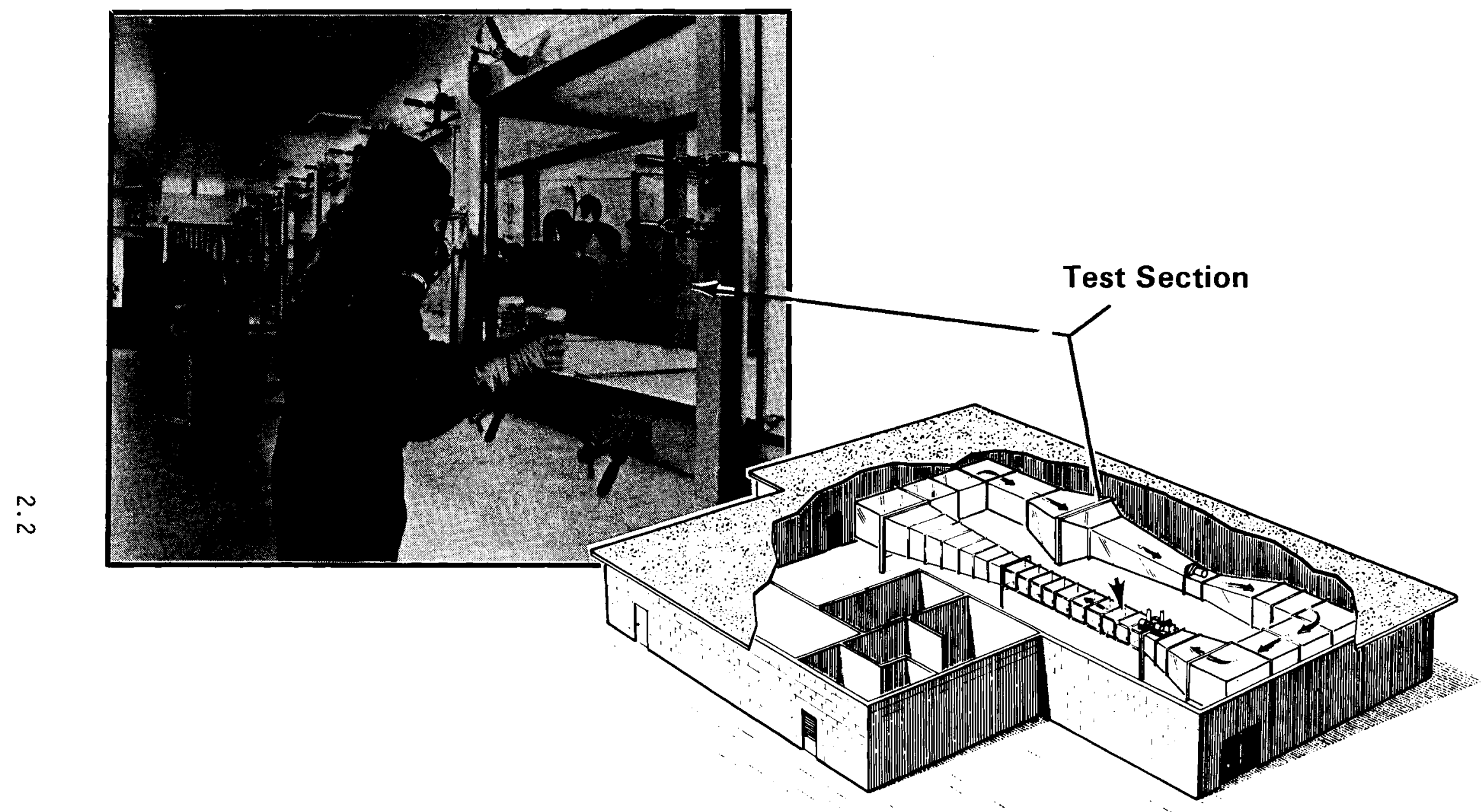

FIGURE 2.1 PACFIC NORTHWEST LABORATORY SPECIAL RECIRCULATING ENVIRONMENTAL WIND TUNNEL 
Red phosphorus melts in the range of $585^{\circ} \mathrm{C}$ to $600^{\circ} \mathrm{C}$. Several $X$-ray diffraction studies of liquid phosphorus derived from either RP or WP indicate that the phosphorus atoms are present in the liquid as symmetrical $\mathrm{P}_{4}$ tetrahedra. This $\mathrm{P}_{4}$ tetrahedron is the fundamental element in explaining the chemistry of phosphorus oxidation. Red phosphorus is an amorphous material, most likely made up of large random arrays of phosphorus atoms, in the form of connected tetrahedrons. Commercial RP is

- a moderately unstable material, reacting slowly with water vapor and air to form phosphine and various oxyacids of phosphorus at normal temperatures and humidities. These reactions may be slowed by reducing the temperature and by reducing the amount of certain metals (such as iron, copper and nickel) that may be found in commercial RP.

White phosphorus is a solid obtained by the condensation of phosphorus vapor to a liquid and then allowing the phosphorus liquid to cool under water. Pure WP is a colorless waxy solid melting at $44^{\circ} \mathrm{C}$ to a clear liquid. The major impurities in commercial white phosphorus are arsenic (usually less than $0.02 \%$ ) and traces of hydrocarbons. White phosphorus is made up of unpolymerized tetrahedra of phosphorus atoms (molecular formula $\left.P_{4}\right)$.

The major product of combustion of either of these phosphorus allotropes is phosphorus pentoxide. In the absence of sufficient quantities of oxygen, some of the lower oxides (particularly phosphorus trioxide) may form. The potential for formation of phosphorus trioxide is of special interest because it reacts with water to form phosphoric acid and phosphine, a very toxic gas:

$$
2 \mathrm{P}_{2} \mathrm{O}_{3}+6 \mathrm{H}_{2} \mathrm{O}=\mathrm{PH}_{3}+3 \mathrm{H}_{3} \mathrm{PO}_{4}
$$

Phopsphorus pentoxide also reacts with water and, as a result of this reaction, is one of the most effective drying agents known at normal temperatures. The reaction of phosphorus pentoxide with water produces a number of hydrolysis products, the relative amounts of each depending on the conditions at which the reaction is carried out. Thilo and Wieker (1954) studied the reaction in water at $0^{\circ} \mathrm{C}$, and found that $77 \%$ of the phosphorus pentoxide formed tetrametaphosphoric acid, $15 \%$ triphosphoric acid, and the remainder trimetaphosphoric acid, tetraphosphoric acid, and phosphoric acid. The three reaction products, tetrametaphosphoric acid, trimetaphosphoric acid, and triphosphoric acid, are reasonably stable compounds. Hydrolysis of the phosphorus pentoxide to these three species is rapid; further hydrolysis proceeds at a much slower rate. The hydrolysis scheme is discussed in detail in Van Wazer (1958).

\subsubsection{Plant and Soil Selection}

Five plant species, representative of a range of plant types, were used in these studies. The native species were representative of different training environments throughout the United States and included the following: 
- Big sagebrush (Artemisia tridentata, vaseyana). A medium-sized, perennial shrub found over vast expanses of the arid and semi-arid western states. It grows in relatively harsh environments on alkaline soils and at elevations from sea level to $7000 \mathrm{ft}$. Source: Native Plants Inc., Sandy, Utah. Age: 2-year-old seedlings.

- Ponderosa pine (Pinus ponderosa). A large coniferous forest species, common to western North America. It grows at a range of elevations and is relatively tolerant to drought. It requires moderate soil fertility. Source: MacHugh Nursery, Eltopia, Washington. Age: 2-year-old seedlings.

- Short-needle pine (Pinus echinata). A coniferous tree species indigenous to the southeastern U.S. This variety is used extensively in reforestation. Source: J.P. Rhody Nursery, Gilbertsville, Kentucky. Age: 2-year-old seedlings.

- Blando brome (Bromus mollis). A perennial, cool-season bunch grass that grows well on dry or wet, alkaline or acid soils. A rather ubiquitous range. Source: Native Plants, Sandy, Utah. Grown from seed.

- Bushbean (Phaseolus vulgaris, tendergreen). An agronomic species that is relatively sensitive to chemical insults, based on prior experience. Grown from seed.

These five plant species provided a range of canopy type, cuticular structure and thickness and were suitable for evaluating phytotoxic response to obscurant smokes and for evaluating deposition velocity under a range of environmental conditions. Ponderosa pine, short-needle pine, and sagebrush were maintained in the greenhouse prior to use. These species were allowed to go dormant in the fall of the year; in December, the greenhouse temperature was increased and photoperiod was artificially adjusted to break dormancy. Prior to their experimental use in the spring, groups of these plants were transferred to growth chambers and allowed to equilibrate for 30 days, where they were maintained at day/night temperatures of $32^{\circ} \mathrm{C} / 21^{\circ} \mathrm{C}$, a 16 -hour photoperiod (approximately $500 \mu \mathrm{E} \mathrm{m-2}$ sec-1, PAR, at leaf surface), and $50 \%$ relative humidity. Bushbean was planted and grown in growth chambers under the same conditions. Blando brome was grown from seed and maintained at day/night temperatures of $27^{\circ} \mathrm{C} / 15^{\circ} \mathrm{C}$, a 10-hour photoperiod (approximately $500 \mu \mathrm{E} \mathrm{m}-2 \mathrm{sec}-1$, PAR, at leaf surface), and $50 \%$ relative humidity.

Both pine species were grown on a commercially available loam soil, while the sagebrush, blando brome, and bushbean were grown on Burbank silt-sand. The latter were used to evaluate direct foliar contact toxicity, and at no time was the soil of these test systems exposed to phosphorus smokes. 
Two soils were used to evaluate indirect soil/plant effects. For this evaluation, soils were contaminated with phosphorus smokes prior to the seeding and growth of the grass species. The two soils used were Burbank (found at Hanford, Washington), an alkal ine silt-sand that readily supports the growth of the grass species; and Maxey Flats (found at Morehead, Kentucky), a silt-clay that is noncultivated, has low nutrient status, and will support marginal growth of the grass species. All soils were

- maintained at $50 \%$ to $66 \%$ of field capacity prior to and following experimental use.

\subsubsection{Soil Chemistry Studies}

Four well characterized soils (Table 2.1) representing a range of soil types that one might encounter on training sites were exposed to phosphorus smokes. The exposure was made on 40 grams of soil spread onto a $700 \mathrm{~cm}^{2}$ surface area. This method of exposure was chosen in order to evaluate changes occurring within the surface layer where the major microbial decomposition and metabloic processes occur. It is also the layer that is subjected to erosional forces (wind, water, runoff) which may impact adjacent surface or subsurface waters.

\subsubsection{Soil Microbiology}

The effects of RP/BR smoke exposure on soil microbiological health were evaluated for those processes that lead to the formation of mineral phosphorus and nitrogen, and to the decomposition of organic matter.

Nitrogen and phosphorus are considered macronutrients because plants require large quantities of these elements for growth. They are also important nutritional elements for the growth of soil microflora. Decomposition of organic matter (carbon mineralization) by the soil microbial population is critical for the cycling of important nutritional elements (nitrogen, phosphorus, sulfur, and some trace metals) and for the return of organic carbon as $\mathrm{CO}_{2}$ to the atmosphere. Carbon mineralization activity also detoxifies xenobfotic chemicals that may be released to the environment. Therefore, any physical or chemical perturbation on the soil system that disrupts these microbially mediated processes can indirectly influence plant growth, and directly affect the soil's ability to decompose organic matter and detoxify xenobiotics.

Soil organisms are also a source of food for the soil fauna (e.g., mites, arthropods, worms) and thus occupy an important position low in the food chain. A deleterious impact on the various soil microbial populations can affect soil invertebrate life and the soil-dwelling animals that depend on the populations for food.

Phosphatases are a broad group of enzymes that catalyze the hydrolysis of both esters and anhydrides of $\mathrm{H}_{3} \mathrm{PO}$. Phosphatase enzyme activity in soil is a contributing factor to organic phosphate mineralization and therefore was chosen as an assay to study the effect of phosphorus smoke on phosphorus cycling in soil. 
TABLE 2.1. SELECTED PROPERTIES OF TEST SOILS

\begin{tabular}{|c|c|c|c|c|}
\hline Soil Properties & Burbank & Quillayute & Shawano & $\underline{\text { Yamac }}$ \\
\hline $\mathrm{pH}$ & 7.43 & 4.74 & 4.82 & 8.43 \\
\hline Organic carbon (\%) & 0.52 & 12.5 & 13.5 & 0.74 \\
\hline Sulfur (\%) & 0.060 & 0.12 & 0.083 & 0.025 \\
\hline Nitrogen (\%) & 0.070 & 0.86 & 0.066 & 0.095 \\
\hline $\begin{array}{l}\text { Total phosphorus } \\
(\mu \mathrm{g} / \mathrm{g})\end{array}$ & 2400 & 3900 & 1440 & 716 \\
\hline $\mathrm{PO}_{4}^{3-}-\mathrm{P}$ & 4.8 & 0.13 & 7.6 & 6.7 \\
\hline \multicolumn{5}{|l|}{$(\mu g / g)$} \\
\hline $\begin{array}{l}\text { Fine and course } \\
\text { clay }(\%)\end{array}$ & 4.0 & 27.0 & 14.7 & 33.4 \\
\hline $\mathrm{CO}_{3}^{-}+\mathrm{HCO}_{3}^{-}(\%)$ & $<0.5$ & $<0.5$ & $<0.5$ & 4.65 \\
\hline $\begin{array}{l}\left.\mathrm{NH}_{4}^{+} \mathrm{N}\right) \\
(\mu \mathrm{g} / \mathrm{g})\end{array}$ & 6.1 & 36 & 45 & 99 \\
\hline
\end{tabular}

The conversion of organic nitrogen to available inorganic forms combines two distinct microbiological processes: ammonification, which converts organic nitrogen to ammonia and nitrification, which transforms ammonia to nitrate. Organic matter decomposition and carbon turnover occurs mainly through oxidative metabolism with the subsequent release of $\mathrm{CO}_{2}$.

\subsection{WIND TUNNEL FACILITIES AND EQUIPMENT}

Smokes were produced in the PNL Aerosol Research Facility using a variety of laboratory-scale generators and were maintained within the wind tunnel to approximate natural field concentrations. Aerosols were characterized using conventional and state-of-the-art instruments. Low-pressure cascade impactors were used to measure particle size distribution in dense aerosols, and laser particle analyzers were used to measure both particle size and the aerosol mass concentration of materials contained within the wind tunnel. Some of these instruments are remote, and were thus used for in situ measurement of aerosol characteristics; no probe disturbed the air flow and hazardous materials did not need to be 
removed from the wind tunnel for analysis. Most of the laboratory instrumentation is connected to a computer control and data acquisition system that improves quality control and allows a large number of experimental conditions to be measured efficiently.

\subsubsection{Description of Wind Tunnel Test Section}

Wind speed, humidity, temperature, and lighting are controlled within the $70-\mathrm{m}^{3}$ recirculating wind tunnel in the PNL Aerosol Research Facility (see Figure 2.1). The wind tunnel is constructed of stainless-steel to allow corrosive aerosols and gases to be tested, and is used to hold suspended materials in complete containment. A negative pressure is maintained during test sequences and all effluent is passed through liquid scrubbers and a series of high-efficiency particulate air (HEPA) filters prior to its release.

Plant and soil exposures were performed during this project in the 6.1-m-long by $0.4-\mathrm{m}^{2}$ test section of the wind tunnel (see Figure 2.1). Movable internal baffles were used to isolate the test section from the wind tunnel prior to and immediately following an exposure test, which allowed the exposure duration to be precisely controlled. Velocity and aerosol concentration profiles in the approach flow were uniform across the width and height of the test section. The test environment simulated natural environmental conditions. Humidity and wind speed were controlled and varied between tests, and uniform temperature was maintained. Adequate lighting was also provided to prevent reduced plant and soil respiration rates.

\subsection{EXPOSURE CONDITIONS}

Environmental parameters in the wind tunnel were controlled to closely match those existing in the field. Air temperature ranged from $20^{\circ} \mathrm{C}$ to $23^{\circ} \mathrm{C}$ for all tests. The relative humidity of the wind tunnel atmosphere was controlled and ranged from $20 \%$ to $90 \%$ depending on study conditions; water vapor was added to the system by a series of small boilers to maintain the higher humidities. A limited number of tests were performed at relative humidities of $5 \%$ and $98 \%$ for chemical analysis of the aerosol oniy. A v1-meter (40-inch) variable speed fan was used throughout each test to maintain a constant wind speed in the wind tunnel test section. Tests were performed at wind speeds of $0.22,0.90,1.8,2.0,2.7$, and 4.5 $\mathrm{m} / \mathrm{s}(0.5$ to $10 \mathrm{mph})$. Mean wind speed was measured by an anemometer using a mean velocity hot-wire probe.

The humidity of the wind tunnel atmosphere was typically measured at 5-minute intervals during each test using a diffusion sampling probe connected to a General Eastern Model 1500 Hygrocomputer. The hygrocomputer was also used to measure wind tunnel temperature. The probe was calibrated against a precision-controlled draft velocity sling psychrometer. The probe was required for measuring water vapor concentrations in the dense aerosols maintained within the wind tunnel during exposure tests. Sample 
air originated in the laboratory and was dried by passage through a silica gel column. The air was then brought to near equilibrium with the water vapor concentration in the wind tunnel by passing the air through a large-surface-area teflon membrane filter. Particle deposition on the outer filter surfaces was limited because very little air from the wind tunnel passed through it. Gaseous diffusion sufficed to equilibrate the sample flow with the water vapor concentration within the wind tunnel.

Test durations were typically $2,4,6$, or 8 hours. Tests consisted of either a single exposure or series of exposures to obscurant smoke in which the same sets of specimens were exposed nine consecutive times over 3 weeks. The aerosol mass concentration for RP/BR was controlled, and ranged between 200 and $6000 \mathrm{mg} / \mathrm{m}^{3}$ depending on the test; while WP concentrations aerosol mass was controlled within the range of 50 to $700 \mathrm{mg} / \mathrm{m}^{3}$ depending on study objectives. Aerosol mass concentrations above $2500 \mathrm{mg} / \mathrm{m}^{3}$ were produced during high-humidity tests when the available water vapor in the wind tunnel atmosphere contributed significantly to the total mass of particles suspended in the wind tunnel. Calculations to determine the availability of oxygen and water vapor to the combustion process or the evolution of phosphorus compounds in the wind tunnel showed that neither was limited any more than they would be in the field.

\subsubsection{Exposure Environment and Test Conditions}

Test codes, date of run, temperature, relative humidity, wind speed, and duration of exposure for each major RP/BR and WP test are presented in Tables $2.2,2.3$, and 2.4 . The relative humidity for the RP/BR range-finding tests, series $A$ and $B$, probably ranged between $20 \%$ and $30 \%$ because outdoor conditions influenced the water vapor content within the laboratory; however, measurements of relative humidity in the wind tunnel during these tests may have been subject to minor error. Wind speed was measured during the tests either by hot-wire anemometry or a Pitot-static tube procedure. The hot-wire probe was unavailable during most of the $\mathrm{RP} / \mathrm{BR}$ range-finding tests because it was returned to the manufacturer for repairs. Because the wind tunnel mean wind speed remained constant after it was initially set, measurements made at the beginning of each test were sufficient for verifying the wind speed throughout each test. The wind tunnel fan motor speed was not monitored to measure velocity because the frictional drag of the plant specimens in the test section varied from test to test, making a motor speed/wind speed calibration meaningless.

The duration of the exposure interval for each test was based on visual observation of the smoke density. Test start times were nearly instantaneous and thus easily estimated; however, approximately 5 minutes were required to remove the visible smoke from the test section at the end of each test. The end of the exposure interval was assigned to that time when the test section purge was one-half complete, which was typically 2 or 3 minutes following initiation of test section purging. 
TABLE 2.2. EXPOSURE CONDITIONS FOR THE RP/BR RANGE-FINDING TEST (RFT) ${ }^{(a)}$

\begin{tabular}{lcccc}
\hline Test & Date & $\begin{array}{c}\text { Temperature } \\
\left({ }^{\circ} \mathrm{C}\right)\end{array}$ & $\begin{array}{c}\bar{U} \\
(\mathrm{~m} / \mathrm{s})\end{array}$ & $\begin{array}{c}\text { Exposure } \\
\text { interva } \\
\text { [hours (minutes) }\end{array}$ \\
\hline RFT-A1 & $9 / 24 / 84$ & 23.5 & 0.90 & $\begin{array}{c}1039-1225(106) \\
1239-1427(214)\end{array}$ \\
RFT-A2 & $9 / 25 / 84$ & 23.5 & 0.90 & $0815-1400(345)$ \\
& & & & $1417-1600(448)$ \\
RFT-A3 & $9 / 26 / 84$ & 23.0 & 0.90 & $0905-1105(120)$ \\
RFT-B1 & $10 / 15 / 84$ & 22.7 & 0.90 & $0805-0940(95)$ \\
& & & & $1045-1445(240)$ \\
RFT-B2 & $10 / 17 / 84$ & 23.7 & $\sim 0.9$ & $1010-1250(160)$ \\
& & 24.6 & & $1317-1717(240)$ \\
RFT-B3 & $10 / 19 / 84$ & 23.9 & $\sim 0.9$ & $0805-1205(240)$ \\
& & & & $1220-1620(240)$ \\
RFT-B4 & $10 / 22 / 84$ & 22.8 & $\sim 0.9$ & $0940-1340(240)$ \\
& & & & $1345-1745(240)$ \\
RFT-B5 & $10 / 24 / 84$ & 22.3 & $0.9 \pm .1$ & $0906-1306(240)$ \\
& & & & $1316-1716(240)$ \\
RFT-B6 & $10 / 26 / 84$ & 22.2 & $\sim 0.9$ & $0810-1210(240)$ \\
& & & & $1224-1624(240)$ \\
RFT-B7 & $10 / 29 / 84$ & 19.6 & $\sim 0.9$ & $0837-1237(240)$ \\
& & 23.2 & $\sim 0.9$ & $1255-1655(240)$ \\
RFT-B8 & $10 / 31 / 84$ & 22.7 & 0.90 & $0705-1105(240)$ \\
& & & & $1125-1525(240)$ \\
RFT-B9 & $11 / 2 / 84$ & 22.8 & $0730-1130(240)$ \\
& & & 0.9 & $1150-1550(240)$ \\
\hline
\end{tabular}

(a) Relative humidity was within the range $15 \%<\mathrm{RH}<30 \%$ for all $\mathrm{RP} / \mathrm{BR}$ range-finding tests. 
TABLE 2.3. EXPOSURE CONDITIONS FOR THE RP/BR TEST D

\begin{tabular}{|c|c|c|c|c|c|}
\hline Test & Date & $\begin{array}{l}\text { Temperature } \\
\left({ }^{\circ} \mathrm{C}\right)\end{array}$ & $\begin{array}{l}\text { Relative } \\
\text { humidity } \\
(\%)\end{array}$ & $\begin{array}{c}\bar{U} \\
(\mathrm{~m} / \mathrm{s})\end{array}$ & $\begin{array}{c}\text { Exposure } \\
\text { interva1 } \\
\text { [hours (minutes)] }\end{array}$ \\
\hline 01 & $12 / 17 / 84$ & 21.6 & 53 & 0.90 & $1202-1602(240)$ \\
\hline $\mathrm{D} 2$ & $12 / 20 / 84$ & 22.1 & 60 & 4.5 & $1006-1408$ \\
\hline D3 & $12 / 27 / 84$ & 21.3 & 27 & 0.90 & $1402-1802(240)$ \\
\hline D4 & $1 / 3 / 85$ & 21.7 & 89 & 0.90 & $1145-1545(240)$ \\
\hline D5.1 & $1 / 8 / 85$ & 21.7 & 67 & 4.5 & $1255-1355(60)$ \\
\hline 05.2 & $1 / 8 / 85$ & 21.7 & 64 & 2.0 & $1408-1509(61)$ \\
\hline D5.3 & $1 / 8 / 85$ & 22.2 & 62 & 0.22 & $1523-1624(61)$ \\
\hline D6.1 & $1 / 22 / 85$ & 22.0 & 25 & 0.90 & $0955-1151 \quad(116)$ \\
\hline 06.2 & $1 / 22 / 85$ & 21.7 & 56 & 0.90 & $1220-1418(118)$ \\
\hline D7 & $1 / 23 / 85$ & 21.9 & 84 & 0.90 & $0923-1121$ (118) \\
\hline D8 & $1 / 25 / 85$ & 21.4 & 61 & 0.90 & $1000-1200(120)$ \\
\hline D8.1 & $1 / 25 / 85$ & 21.6 & 56 & 0.90 & $1000-1100(60)$ \\
\hline $\mathrm{D} 8.2$ & $1 / 25 / 85$ & 21.2 & 67 & 0.90 & $1100-1200(60)$ \\
\hline
\end{tabular}


TABLE 2.4. EXPOSURE CONDITIONS FOR THE WP TEST E

\begin{tabular}{lccccc}
\hline Test & Date & $\begin{array}{c}\text { Temperature } \\
\left({ }^{\circ} \mathrm{C}\right)\end{array}$ & $\begin{array}{c}\text { Relative } \\
\text { humidity } \\
(\%)\end{array}$ & $\begin{array}{c}\bar{U} \\
(\mathrm{~m} / \mathrm{s})\end{array}$ & $\begin{array}{c}\text { Exposure } \\
\text { interval } \\
\text { [hours (minutes)] }\end{array}$ \\
\hline E1 & $3 / 26 / 85$ & 21.3 & 57 & 0.90 & $0930-1330(240)$ \\
E2.1 & $3 / 28 / 85$ & 21.1 & 66 & 4.5 & $0935-1035(60)$ \\
E2.2 & $3 / 28 / 85$ & 21.3 & 61 & 2.7 & $1050-1150(60)$ \\
E2.3 & $3 / 28 / 85$ & 21.2 & 61 & 1.8 & $1205-1305(60)$ \\
E3 & $4 / 2 / 85$ & 21.4 & -35 & 0.90 & $0935-1335(240)$ \\
E4 & $4 / 4 / 85$ & 22.0 & $90 \pm 5$ & 0.90 & $0835-1235(240)$ \\
\hline
\end{tabular}

A steady-state smoke representative of field conditions was desired for the exposure tests. Measurements of relative laser transmittance and particle size distribution indicated that the obscurant aerosols attained a steady-state condition in the wind tunnel approximately one-half hour after the first portion of material was ignited. Plants and soils were exposed to the fresh smoke during the exposure tests for the RP/BR range-finding tests, series $A$ and $B$. During the RP/BR test $D$ and WP test $E$ exposures, the test section was isolated until a steady-state obscurant aerosol had evolved. The steady-state aerosols were described by the average age of the particles in suspension in the wind tunnel. The particle age was determined from the combustion sequence and the measured aerosol loss rate from the wind tunnel atmosphere as a result of deposition and vacuum removal. The steady-state aerosol was approximately 28 minutes in average age for the RP/BR test $D$ series and 22 minutes in average age for the WP test $E$ series. Assuming an average wind speed of $0.90 \mathrm{~m} / \mathrm{s}(2 \mathrm{mph})$ these steady-state aerosols would generally reflect the chemical characteristics of obscurant plumes between $1.2 \mathrm{~km}$ and $1.5 \mathrm{~km}$ downwind of a field source.

\subsection{SMOKE GENERATION}

The unclassified literature pertaining to the study was reviewed during the planning and early experimental stages of this project. In general, the references contained valuable information. However, adequate data concerning actual field environmental conditions (i.e., temperature, relative humidity and wind speed), aerosol concentrations, and aerosol chemical compositions would have been valuable for comparing the study results to field situations, although information from Shinn et al. (1985) was helpful in determining the average aerosol mass concentrations that were used in this project. 
An important aspect of this project was the attempt to recreate field conditions in a laboratory. Because physical and chemical characteristics of the aerosols changed as they aged following their generation by combustion, aerosols were introduced into the wind tunnel exposure chamber continuously during an exposure to simulate an actual field situation. Previous laboratory studies conducted in static test chambers tended to reproduce the obscurant aerosols under varying conditions. Therefore, it was difficult to obtain previously published information about the physical and chemical characteristics of aerosols generated and aged under simulated natural conditions over the expected aging period of field aerosols.

\subsubsection{RP/BR and WP Combustion}

Smokes were generated by the controlled burning of RP/BR or WP in a $2-m^{3}$ combustion chamber, then passing the product into the wind tunnel test chamber. Two other generation systems were investigated (DeFord et al. 1982, Holmberg and Moneyhun 1984); however, neither system was adequate for this study. A computer-controlled ignition chamber, shown in Figure 2.2, was designed and constructed such that it provided a nearly continuous source of smoke to the wind tunnel, allowing smokes of constant age and concentration to be maintained during test sequences. While individual portions of the RP/BR and WP were ignited sequentially, the combustion process duration was typically nearly equal to the time between successive ignitions, resulting in a nearly continuous production of obscurant smoke. The obscurant smoke thus produced was a combination of particles of various ages; however, due to the constant aerosol generation and removal rates, the obscurant smoke was at approximately steady-state conditions during each test. We believed this scenario best approximated a field situation, where obscurant munitions are deployed periodically for up to several hours.

As many as 22 individual portions of RP/BR or WP were ignited sequentially during each test to maintain approximately constant smoke concentrations within the test section (see Figure 2.2). The phosphorus materials were placed in shallow stainless-steel trays and connected to nichrome ignition wires prior to each test (Figure 2.3). The RP/BR was burned on a sand surfaces and the WP in ceramic cups. During RP/BR testing, air was passed through the combustion chamber directly from the wind tunnel. During WP testing, conditioned air was supplied to the combustion chamber from the laboratory. Fans vigorously stirred the air within the combustion chamber to ensure an adequate supply of oxygen and water vapor at the burn zone. The aerosol was passed from the chamber into the wind tunnel downwind of the test section, which allowed the fresh aerosol plume to mix completely and come to thermal equilibrium with the wind tunnel atmosphere prior to approaching the wind tunnel test section (Figure 2.4). No thermal stratification was observed and the approach flow to the wind tunnel test section was uniform in aerosol density. 


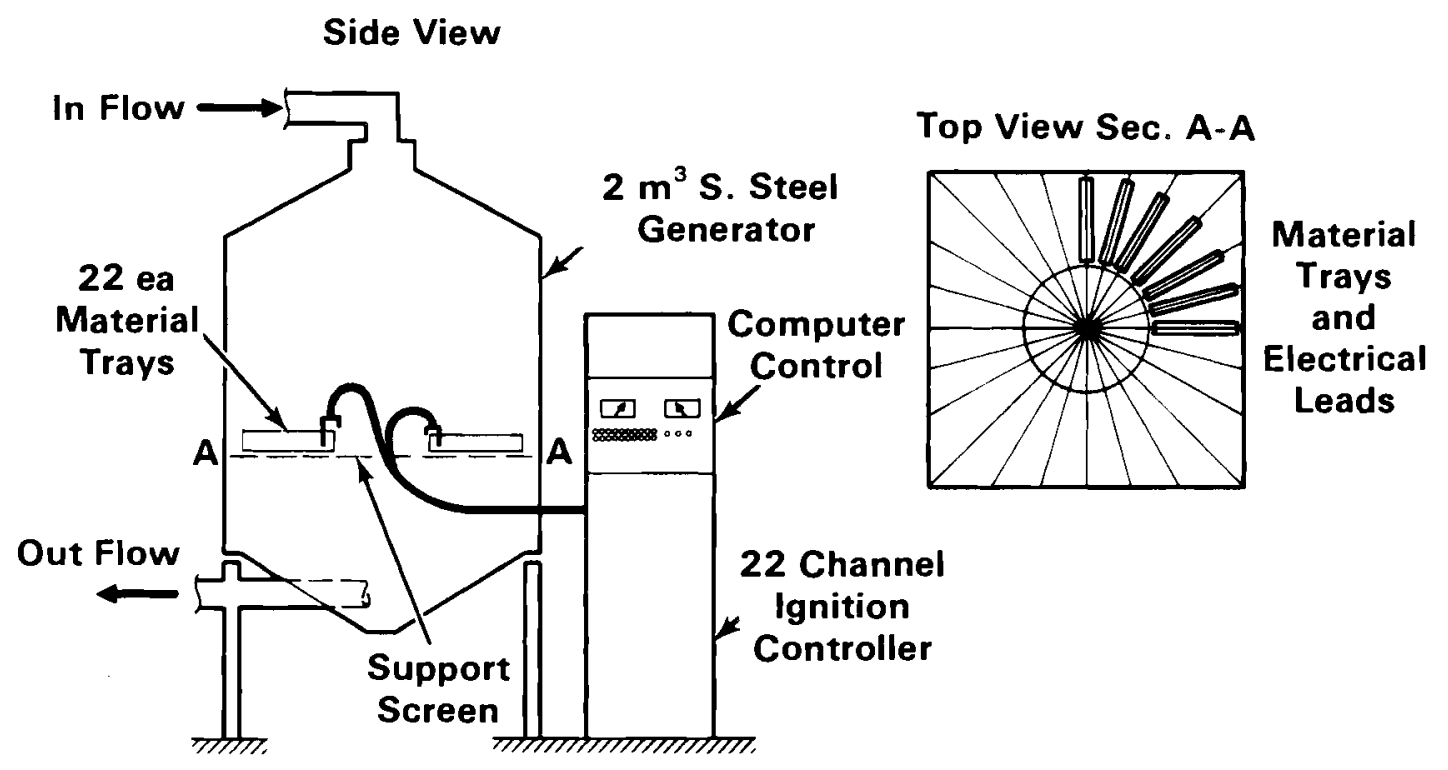

FIGURE 2.2. COMPUTER CONTROLLED SMOKE GENERATION SYSTEM

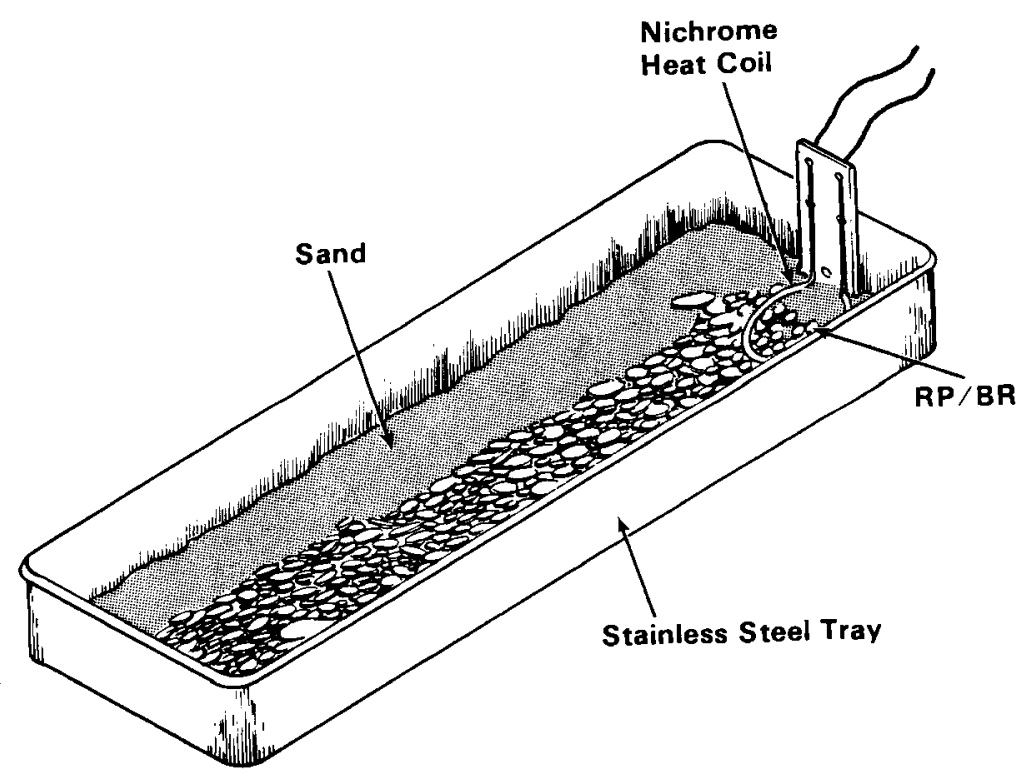

FIGURE 2.3. DETAILED ARRANGEMENT OF COMBUSTION SYSTEM FOR RP/BR 


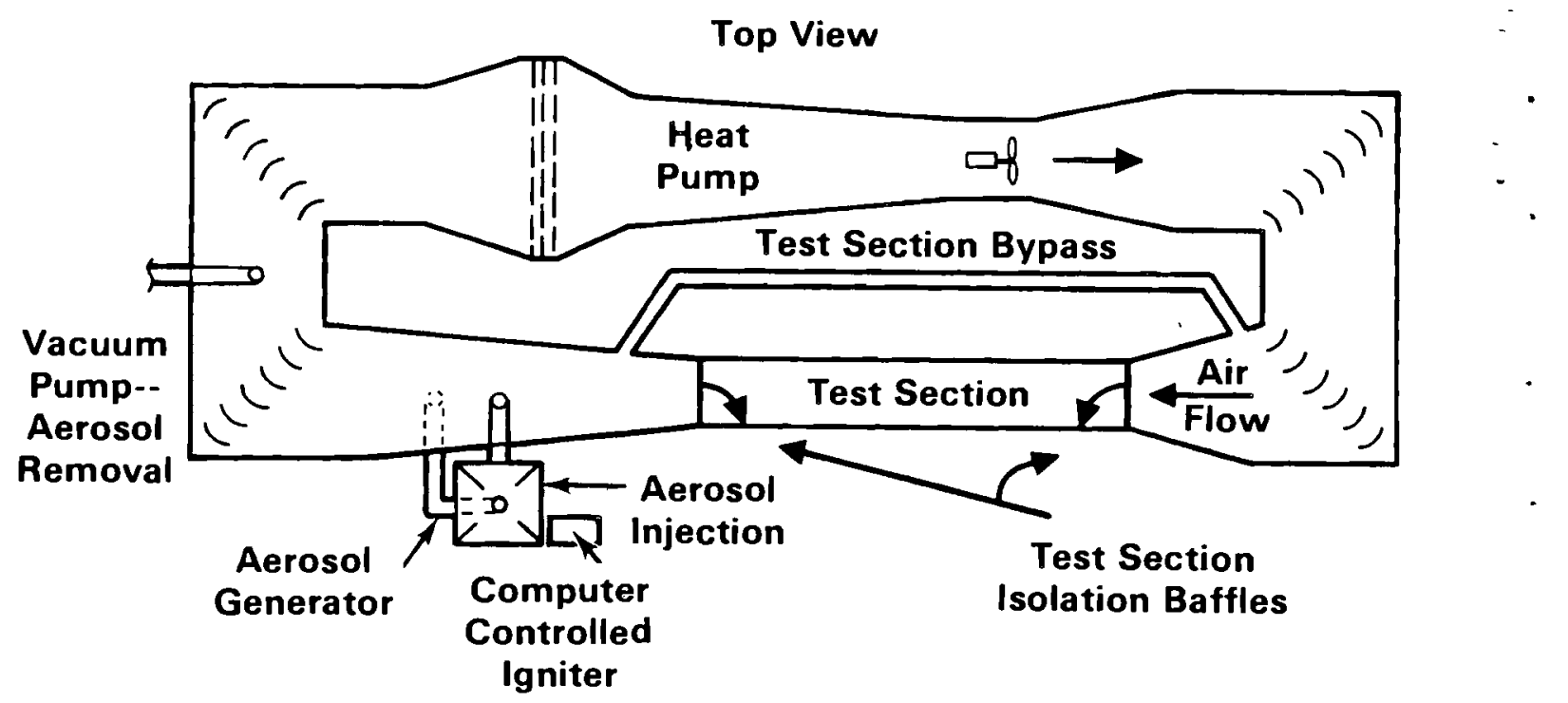

FIGURE 2.4. WIND TUNNEL SMOKE GENERATION, INJECTION, BYPASS, AND BAFFLE SYSTEM

Because the WP smoldered and eventually burst into flame when dry and in contact with air, a bath water system was used during all WP tests. The WP material was placed in small water-filled ceramic cups and aspiration tubes were placed in the cups (Figure 2.5). Each cup was then automatically aspirated just prior to combustion of the WP. The nichrome ignition wires were used to promote timely ignition.

\subsubsection{Aerosol Generation Test Procedure}

The amount of RP/BR or WP required for each test was calculated from target aerosol mass concentration requirements, the exposure duration, and experimentally determined relationships between mass burned and the resulting aerosol concentration in the wind tunnel. These relationships were a function of relative humidity; increased water vapor in the air greatly increased the mass concentration of the aerosol produced from RP/BR and WP combustion per unit volume of these materials. The first mass of WP ignited during each test was two to three times greater than the remaining masses to allow the WP concentration to be rapidly built in the wind tunnel. The remaining portions of WP were of equal mass and the aerosol produced by their combustion was used to replace the portion of the aerosol 


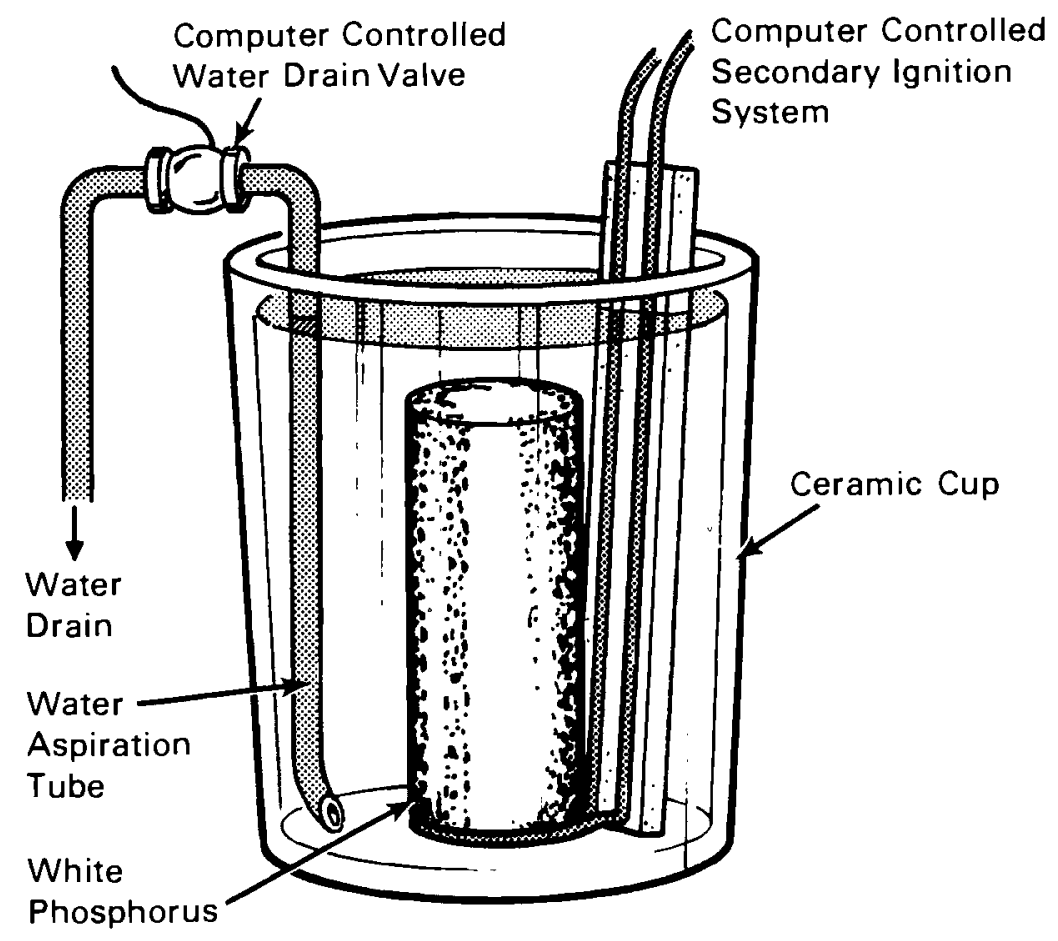

FIGURE 2.5. DETAILED ARRANGEMENT FOR COMBUSTION OF WHITE PHOSPHORUS

in the wind tunnel lost to deposition and removal in the wind tunnel effluent. The loss rate of aerosol to these removal mechanisms was typically on the order of $1 \%$ per minute.

A gravimetric procedure was used to portion the RP/BR into the individual combustion trays, and the WP was measured volumetrically prior to placement in the ceramic cups. The wind tunnel was sealed and its atmosphere conditioned to the appropriate relative humidity at room temperature, and the test section was isolated using the bafffles and bypassed (see Figure 2.4) prior to WP ignition. Throughout the test, the wind tunnel was maintained at 0.5 to 1.0 in. $-\mathrm{H}_{2} \mathrm{O}$ negative air pressure to ensure material containment. Air flow through ${ }^{2}$ the combustion chamber was verified and the chamber mixing fan turned on prior to initiating each test sequence. Using a preprogrammed test plan, the laboratory data acquisition and instrument control system initiated each combustion by aspirating the ceramic cup (WP only) and then heating the appropriate nichrome ignition wire (both RP/BR and WP). Obscurant smoke was allowed to circulate throughout the wind tunnel, bypassing the test section, for approximately 30 minutes during which time plants and soils were placed in the test section. After a 30-minute period the aerosol had aged to nearly a steady-state condition--a condition that remained approximately constant throughout the test--and the test section was opened to the wind tunnel and 
the exposure began. Aerosol generation continued until the test was finished, at which time the test section was again isolated and flushed with fresh air, then plants and soils were removed.

The aerosol generation procedures used were generally sufficient for maintaining steady-state aerosols in the wind tunnel. A few times during the exposure tests, a tray of phosphorus would fail to ignite; the resulting reduction in aerosol concentration would be observed in the output of a laser transmissometer.

A dark red-black residue remained following combustion of both RP/BR and WP material in the combustion chamber. Although this residue was dry, it occasionally appeared to be wet. The RP/BR material burned with a steady flame. Combustion of the WP began by melting the wax-like material, which burned with a sputtering flame for approximately the first $20 \%$ of the combustion period. A limited amount of sputtering continued throughout the WP combustion process.

\subsection{SMOKE CHARACTERIZATION}

Aerosols produced by the combustion of RP/BR and WP may evolve to phosphorus oxides. The oxide $\mathrm{P}_{4} \mathrm{O}_{10}$ was thought to be the primary chemical form present as a vapor in the combustion zone. A dense smoke formed as a result of condensation of the combustion products and water vapor as the vapor moved away from the combustion zone and cooled. Coagulation of the resulting highly concentrated primary droplets contributed to a rapid initial increase in particle size as the smoke left the combustion zone. Many different species of phosphorus anions were found in the resulting aerosol, indicating complex combustion reaction chemistry occurred during particle formation. It appeared that the frequency of occurrence of these species depended on the availability of water vapor. The characteristics of the phosphorus aerosols in the wind tunnel, and of the particles that were deposited, changed with age, as indicated by increasing particle size and mass. The change was possibly caused by absorption of water vapor and coagulation, and by changing chemical form from the decomposition of the high-order phosphorus anions.

In this study, the evolving state of the phosphorus aerosols was partialiy offset by the continuous generation of the aerosols in the wind tunnel. While the individual aerosol particles continued to age and their characteristics continued to change, the overall characteristics of the aerosol remained approximately constant throughout each exposure test. The steady-state aerosols were monitored during each test for mass concentration, particle size distribution, and various chemical composition parameters such as free water content, phosphate content, and phosphorus speciation. 


\subsubsection{Physical Analyses}

\subsubsection{Aerosol Mass Concentration}

Aerosol mass concentration, or the total mass of particles suspended per volume of air, is an important characteristic of aerosols that must be measured during particle deposition investigations. The mass concentration of suspended material is directly related to the amount of the material that eventually deposits on the ground, vegetation, and other surfaces, and is thus directly related to the effect that the deposited material may have. When aerosol mass concentration is compared to the mass loading on exposed surfaces, the rate at which particles deposit on a surface under specific environmental conditions, the particle deposition velocity, may be calculated.

\subsubsection{Aerosol Mass Concentration/Laser Transmissometer}

Aerosol mass concentration was monitored by measuring the transmittance of a helium-neon ( $\mathrm{He}-\mathrm{Ne}$ ) laser at intervals of 30 seconds to 2 minutes during each test. The subsequent data allowed the average aerosol mass concentration to be calculated for each exposure test. The laser transmissometer, shown in Figure 2.6, employed a $20-\mathrm{mW}$ He-Ne laser that was propagated horizontally through the transparent walls of the wind tunnel test section, perpendicular to the air flow. The intensity of the laser beam transmitted through the test section was affected by multiple-particle scattering of the beam by particles suspended in the wind tunne1. The inside surfaces of the test section remained unobstructed by periodic application of an antistatic agent, and the relative transmittance of the laser beam remained constant throughout nearly all of the exposure tests. Several different lasers were used during the RP/BR range-finding tests (RP/BR range-finding tests, Series A and B). The power output of these lasers became unstable after varying periods of use. The actual transmittance of these lasers in $\mathrm{mW}$ was calibrated to indicate the aerosol mass concentration in the wind tunnel test section.

A series of calibration curves were developed for the RP/BR range-finding tests. All calibration curves were obtained by comparing the transmittance of the various lasers to the actual aerosol mass concentration, which was determined by sampling the wind tunnel aerosol that had deposited on glass fiber filters. The laser calibration data for the three RP/BR range-finding test $A$ exposures (see Table 2.2 for a description of test conditions for all range-finding tests) were similar. A second laser was used for the first four exposure tests of range-finding test B. Calibration data from the first three of these exposure tests were similar and are described by one laser calibration curve. During the fourth exposure test the output of the laser increased and a distinct calibration curve resulted. A third laser was used for the last five exposures of the RP/BR range-finding test B. This laser was used throughout the remaining RP/BR and WP exposure tests. Other than the fifth exposure test and the low concentration half of the ninth exposure test, 


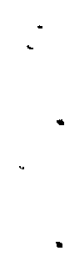




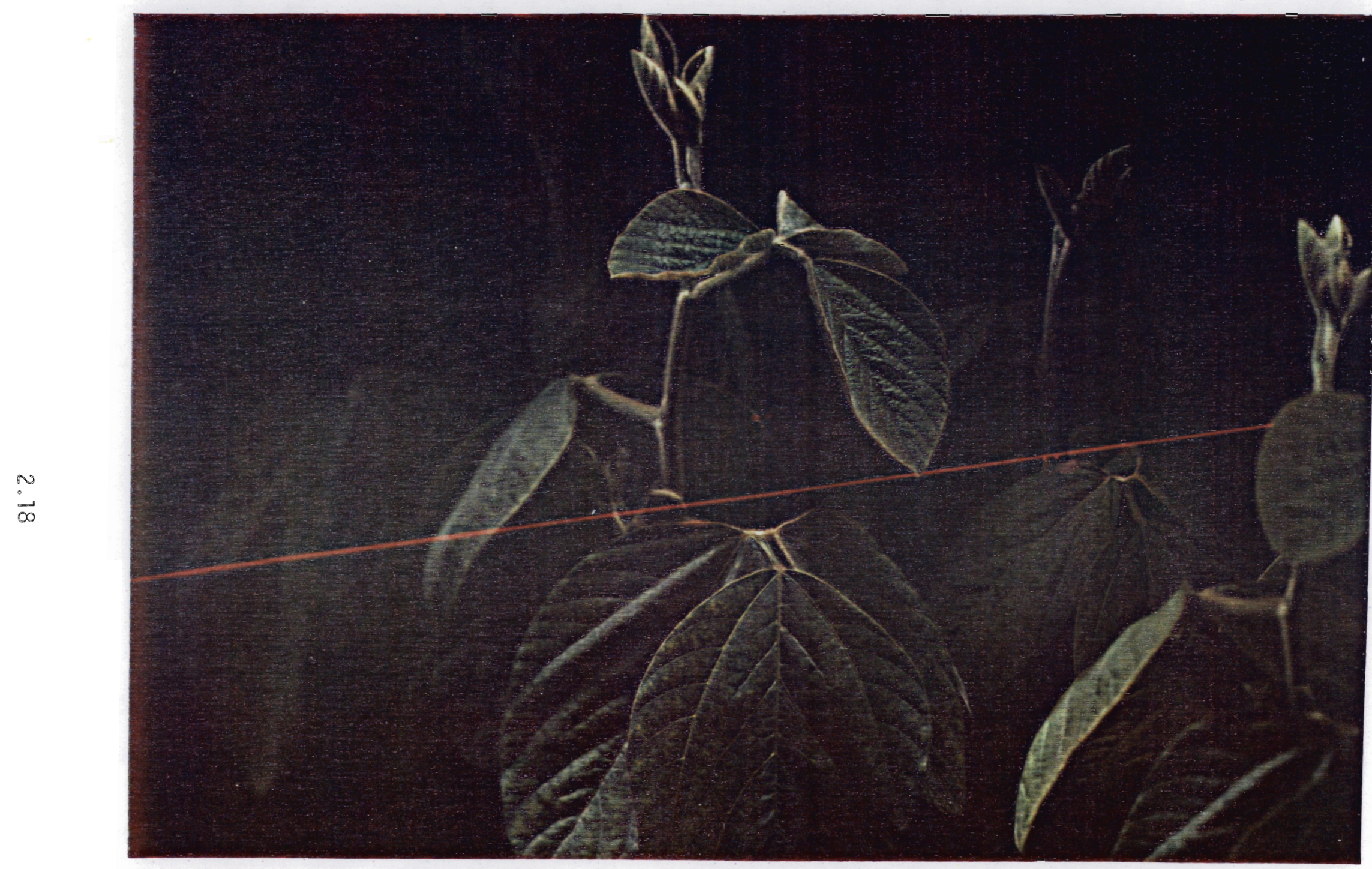

FIGURE 2.6. LASER TRANSMISSOMETER USED TO MEASURE SMOKE MASS CONCENTRATION IN THE WIND TUNNEL 
the laser calibration curves determined during the last five exposure tests of $R P / B R$ range-finding test $B$ were very similar. The deviations in the fifth and ninth exposures may have been caused by changes in the output power of the laser, or by differences in the characteristics of the particles suspended in the wind tunnel during these tests.

The third laser was used in conjunction with a reference laser power meter during RP/BR test $D$ and WP test $E$ (see Tables 2.3 and 2.4 for description of conditions for test series $D$ and $E)$. Prior to passing through the test section, the laser beam was split and one portion of it was monitored for actual laser output intensity. The intensity required monitoring because the average output intensity of the laser, Po, could change by as much as $10 \%$ in 4 hours. The intensity of the portion of the laser beam that was propagated through the wind tunnel was measured as Pt, the transmitted intensity. By comparing the ratio of Pt to Po with the actual mass concentration measured by an isokinetic sampling procedure, direct calibrations of aerosol mass concentration versus actual transmitted laser intensity were developed. These calibrations remained constant throughout each of the test series.

No differences in relative transmittance were observed between calibration data obtained at a relative humidity of $25 \%$ and that obtained at a relative humidity of $60 \%$. The relative transmittance of the laser beam at $90 \%$ relative humidity, however, may not be similar to that at the lower humidities, perhaps because of differing optical properties of the aerosol as a result of absorbed water vapor. The properties include mass concentration, particle size, and particle refractive index. The laser transmissometer calibration data that were obtained during the high humidity tests were included in determining the calibration curve for RP/BR test $D$ data because it was observed that very little overlap in aerosol mass concentration occurred between tests at high humidities and tests at low humidities. The WP test E calibration curve was modified to account for the altered obscurant properties at high humidities because the range of aerosol mass concentrations observed during the high humidity WP test overlapped those observed during the tests at lower humidity.

\subsubsection{Aerosol Mass Concentration/Filter Samples}

Samples of aerosol mass were collected periodically throughout each exposure test by drawing a $1.0-1 \mathrm{pm}$ flow rate of wind tunnel atmosphere through $25-\mathrm{mm}$ glass fiber filter pads. A sharp-edged, stainless steel nozzle oriented directly into the mean air flow direction was operated isokinetically for all the $0.9 \mathrm{~m} / \mathrm{s}$ wind speed tests (the velocity within the sampling nozzle was equal to the mean velocity of the wind tunnel air). Tests using the same nozzle and another isokinetic nozzle were performed at wind speeds of $4.5 \mathrm{~m} / \mathrm{s}$ to determine the accuracy of the sampling technique. These tests supported calculations indicating that errors resulting from nonisokinetic sampling procedures were insignificant. Thus, filter samples were obtained using the $0.9 \mathrm{~m} / \mathrm{s}$ isokinetic nozzle for all wind speeds. Some early filter samples of RP/BR aerosols were obtained using $25-\mathrm{mm}$ 
open-face filters; again, no sampling error resulting from subisokinetic conditions was found in later comparison tests.

Filter samples were analyzed gravimetrically for particulate mass immediately after they were obtained to reduce the potential for evaporative errors. The magnitude of an evaporative error was determined by measuring selected filter samples several times over a period of at least 30 minutes in the constant humidity of the laboratory. The results generally yielded an exponentially shaped curve of filter mass versus aging time for selected filter samples. This data was roughly linear when plotted on semilog graph paper, and the resulting linear curve of best fit was extrapolated to the time at which the sample was removed from the wind tunnel atmosphere. Results from several filters indicated that the total particulate mass that was lost may have been less than $2 \%$ at a relative humidity of $25 \%$, approximately $4 \%$ at a relative humidity of $60 \%$, and $8 \%$ at a relative humidity of $90 \%$. Laboratory humidity ranged between $30 \%$ and $50 \%$ during these measurements. The typical filter sampling duration was 5 minutes, although 10-minute samples were taken during some low concentration RP/BR tests. Select filters were immersed in de-ionized water, after gravimetric analysis, for later chemical analys is for phosphorus and phosphate. Other filters were desiccated for later determination of free, or unbound, water content of the phosphorus aerosols.

\subsubsection{Particle Size Distribution}

The size of particles that make up an aerosol often determine which forces, inertial or diffusive, control the transport and deposition phenomena. The deposition velocity of particles to surfaces varies with the particle size; typically, particles with aerodynamic diameters between 0.1 and $1 \mu \mathrm{m}$ deposit less quickly than smaller or larger particles. This difference results because smaller particles are strongly affected by diffusive forces and larger particles by inertial forces. Aerosols observed in the field are polydispersive; they are made up of particles of many different diameters. The size distribution of such aerosols is often log normal and may thus be well characterized by a mean or median size and a standard deviation.

Measuring the particle size distribution of an aerosol (the frequency of particle occurrence as a function of particle diameter) is important in describing an aerosol's physical characteristics. The particle size distribution of an aerosol may be based on particle number frequency, aerosol mass, or other parameters such as surface area or particle volume. The particle size distributions of the phosphorus aerosols generated in this study were characterized by aerodynamic diameter rather than actual physical diameter. Aerodynamic diameter includes the inertial characteristics of airborne particles in size distribution results. This method also accounts for the effects on particle transport caused by the shape of the individual particles that make up the aerosol. 
Particle size distributions of the phosphorus aerosols were measured during the exposure tests for the RP/BR test D Series and all WP test $E$ series. No measurements were made during the range-finding tests. Conventional Andersen cascade-type impactors were used to segregate the phosphorus aerosols into eight aerodynamic size ranges between 0.3 and $10 \mu \mathrm{m}$. These impactors were adequate for these aerosols as more than $98 \%$ of the particulate mass was observed to be made up of particles with diameters in the 0.3 to $10 \mu \mathrm{m}$ size range. Samples were drawn nonisokinetically from the wind tunnel approximately $6 \mathrm{~m}$ downwind of the test section. Because the mean wind speed in this location was always less than $0.75 \mathrm{~m} / \mathrm{s}$ and the suspended particles were small, no significant sampling errors were introduced by the nonisokinetic sampling procedure. Eight stages of the impactors were covered with a flat preweighed disk of aluminum foil and the last stage consisted of an 8-cm-dia. glass fiber filter. Particulate mass was collected on the aluminum foil disks and the filter and weighed immediately. Selected disks and filters were then immersed in de-ionized water for subsequent analys is for elemental phosphorus, phosphate, or phosphorus speciation. Particle size distributions derived from the gravitational procedure were compared to those derived from the chemical analysis procedures to reveal potential analysis errors and differences between the sizes in particle water content. A limited number of impactor samples were taken without aluminum foil disks in place on the stages and the particulate mass rinsed off the stages and analyzed for phosphorus to determine if the aluminum foil disks altered the operation of the impactors.

\subsubsection{Particle Deposition Velocity}

The rates at which the RP/BR and WP aerosols deposited to the plants and soils in the wind tunnel, or the deposition velocities, were determined as functions of the phosphorus mass concentration of the aerosols. The velocities were determined on this basis because phosphorus-specific analysis methods may be used in field measurements when obscurant smokes are sampled for assessing environmental dose. However, the deposition velocity of the particles will be more completely related to the actual particle mass, including phosphorus anions and free water. Deposition velocity results were compared for all three types of aerosol concentrations measured in this study.

\subsubsection{Chemical Analyses}

\subsubsection{Particle Composition}

The composition of the particles that made up the phosphorus obscurant aerosols was important both for describing the aerosols and for determining the major components of the aerosols, as the components differed under various environmental conditions. The aging process was also characterized for the freshly combusted vapors to the changing chemical form of the aerosol and finally to the well-aged deposits. 
In this study the bulk composition of the particles suspended in the wind tunnel was characterized in three ways. The first method was measurement of fresh, or actual, particulate mass determined by gravitational analysis of filter samples of the aerosol. The second method was measruement of desiccated, or dried, particulate mass determined by desiccating filter samples for 24 hours over a silica gel, then re-weighing the filters. The mass of phosphorus present in the aerosol was the third method and was determined by analyzing filter samples for total elemental phosphorus. The results of these measurements were expressed as the actual, dried, and phosphorus mass concentration of the aerosols in the wind tunnel. The relative magnitudes of these three particle composition measurements varied as the result of particle age and the relative humidity in the wind tunnel. Fresh mass concentration included all of the mass in the aerosol and was related to electromagnetic obscuration; therefore, this parameter resulted from the laser transmissometer measurements of the aerosols in the wind tunnel. Dried aerosol mass concentration was equal to the fresh mass concentration less all free, or not chemically bound, water present on the particles. Phosphorus mass concentration was measured because the mass loading of phosphorus to plants and soils may have a greater effect than the other mass concentrations.

\subsubsection{Total Phosphorus}

Concentrations of total phosphorus in solutions generated by burning $\mathrm{RP} / \mathrm{BR}$ or WP were determined by using an inductively coupled plasma (ICP) emission spectrometer. Aqueous samples were analyzed without modification and normally did not require filtration. The detection limit using the ICP spectrometer was $0.1 \mathrm{mg} / \mathrm{L}$ as phosphorus. Relative standard deviation was $50 \%$ at the detection 1 imit, $10 \%$ at 5 times the detection 1 imit, and $3 \%$ at 50 times the detection limit.

In addition to determining phosphorus concentrations, the ICP spectrometer could also determine up to 32 other elements in the solutions that were analyzed. Determining many elements that exist in a solution was previously useful in studies involving precipitation of phosphorus species from water matrices containing a range of chemical components (Poston et al. 1986), and provided invaluable chemical compositional data on soil leachates as they were affected by deposited phosphorus smoke particulate.

Routine analysis of total phosphorus, associated with soils, filters and plant tissues was analyzed using the colorimetric HPLC method of Yamaguchi et al. (1979), a high-pressure liquid chromatographic (HPLC) procedure. This method was effective in quantitation of monophosphates, linear, and cyclic phosphates associated with RP and WP smokes. Samples were extracted in $50 \mathrm{ml}$ of SRW for 30 minutes, mixed with $1 \mathrm{ml}$ of $3.45 \mathrm{M}$ $\mathrm{H}_{2} \mathrm{SO}_{4}$, vortexed, and heated in a water bath at $80^{\circ} \mathrm{C}$ for 30 minutes. The samples were then cooled to room temperature. Two milliliter of molybdate reagent (10-3 $\mathrm{M}$ ammonium molybdate in $0.6 \mathrm{M}$ sulfuric acid) and $1 \mathrm{ml}$ of ascorbic acid reagent ( $0.1 \mathrm{M}$ ascorbic acid in $5 \%$ acetone) were added, and 
the samples were vortexed and heated for 15 minutes at $80^{\circ} \mathrm{C}$. The samples were cooled to room temperature and absorbance read at $830 \mathrm{~nm}$ using a spectrophotometer. The working range of the assay was 0.5 to $15 \mu \mathrm{g} \mathrm{P} / \mathrm{ml}$; samples were diluted as necessary for analysis. This method was calibrated against ICP analyses, and was found to be valid for linear and cyclic polyphosphates.

\subsubsection{Reagents}

Several reagents were used for phosphorus species determenations. Phosphate, phosphite, hypophosphite, and pyrophosphite solutions were prepared from reagent-grade chemicals. Cyclic trimetaphosphate was prepared according to Ballou (1981). Tripolyphosphate was generously supplied by the Monsanto Company (St. Louis, Missouri). Tetrapolyphosphate, hexammonium salt, and the type 5-, 15-, and 25-polyphosphate giasses were obtained from Sigma Chemical Company (St. Louis, Missouri). A11 other chemicals were reagent grade.

\subsubsection{1P Species}

Phosphate $\left(\mathrm{PO}_{4}{ }^{3}-\right)$, phosphite $\left(\mathrm{HPO}_{3}=\right)$, and hypophosphite $\left(\mathrm{H}_{2} \mathrm{PO}_{2}{ }^{-}\right)$ were analyzed using an ion chromatograph (IC) equipped with an AGl guard and AS1 separator columns and a continually regenerated fiber suppressor linked to a conductivity detector. Eluent was $3 \mathrm{mM} \mathrm{NaHCO}_{3}$ plus $2.4 \mathrm{mM}$ $\mathrm{Na}_{2} \mathrm{CO}_{3}$. The detection limit for the $1 \mathrm{P}$ species was $0.3 \mathrm{mg} / \mathrm{L}$ as phosphorus. The stock and exposure solutions were continually analyzed, which resulted in a loss of column efficiency as a result of binding of the higher polyphosphates onto the column in the basic eluent system. Reasonable column recovery was attained by back flushing with a series of acid and base washes $\left(0.1 \underline{\mathrm{N}} \mathrm{H}_{2} \mathrm{SO}_{4}, 0.1 \underline{\mathrm{N} \mathrm{NaOH}}, 0.2 \underline{\mathrm{N}} \mathrm{Na}_{2} \mathrm{CO}_{3}\right)$.

\subsubsection{Speciation of Higher Poly- and Metaphosphates}

The separation scheme used for polyphosphates basically followed that of Yamaguchi et al. (1979). The procedure involves anion exchange using a high salt eluent gradient containing EDTA to complex any metals in the system, thereby slowing the depolymerization rate. A $1 \times 10-\mathrm{cm}$ glass column containing Hitachi 2630 resin (Mitsubishi Chemical Industries, LTD.) was used for all separations. Two Waters (Millipore Corp., Bedford, MA) Model $6000 \mathrm{~A}$ pumps with Model 660 solvent programmer-controlled delivery of eluent $A\left(0.22 \mathrm{M} \mathrm{NaCl}+5 \mathrm{mM} \mathrm{Na}{ }_{4}\right.$ EDTA) and eluent $\mathrm{B}\left(0.53 \mathrm{M} \mathrm{NaCl}+5 \mathrm{mM} \mathrm{Na}{ }_{4}\right.$ EDTA) under prógram 5. The separated condensed phosphates were then acid hydrolyzed and the resultant phosphate reacted to form a heteropoly blue complex with Mo(V-VI), detected at $660 \mathrm{~nm}$. Using a water bath at $94^{\circ} \mathrm{C}$ for both the acid hydrolysis and the color development loops resulted in good recovery of phosphorus species, based on total phosphorus using the analysis ICP spectrometer. The detection method as used could not oxidize phosphite and hypophosphite to phosphate. Tests showed that these species are easily oxidized by light. Since phosphite and hypophosphite would likely co-elute with phosphate during the HPLC procedure, could be analyzed 
by IC, and were minor components in the species distributions, addition of a UV oxidation step was not necessary.

\subsubsection{Phosphine}

Phosphine $\left(\mathrm{PH}_{3}\right)$ was sampled in the wind tunnel aerosol by attaching a gas sampling bottle directly to the wind tunnel and flushing the tunnel with at least 5 volumes of aerosol at a flow rate of $0.5 \mathrm{~L} / \mathrm{min}$ before collecting the actual volume to be analyzed. A Hewlett-Packard gas chromatograph (GC), equipped with a $5 \%$ pheny1, $95 \%$ methyl silicone-fused silica capillary (held at $100^{\circ} \mathrm{C}$ ), and a nitrogen/phosphorus detector, was used for phosphine analysis. Gas-tight syringes were used to sample the gas collection bottles. The detection limit varied with baseline stability, but was no less than $43 \mu \mathrm{g} / \mathrm{m}^{3}$ of aerosol.

\subsubsection{White Phosphorus}

Elemental WP $\left(\mathrm{P}_{4}\right)$ in the aerosol was trapped in $40 \mathrm{ml}$ of benzene in a gas wash bottle at a sampling rate of $150 \mathrm{ml} / \mathrm{min}$. The efficiency of benzene as extractant for WP has been noted previously (Lai and Rosenblatt 1977). We found benzene to be superior to isoctane, while hexane failed to hold dissolved WP for more than a few hours. Chloroform was a good trapping agent, but interfered with subsequent analyses. Estimated carryover to a backup trap was $<0.1 \%$. The entrained phosphorus oxy-anions did not interfere with the $P_{A}$ determination. A water rinse of the benzene layer and trap walls resulted in an essentially complete recovery of the polyphosphate fraction, giving a second check on the total aerosol collected in the bubbler. A GC equipped with a 4-ft glass column containing $5 \%$ OV 101 packing, at $100^{\circ} \mathrm{C}$ isothermal, and flame photometric detector with a phosphorus-specific filter was used for sample injections of up to $.01 \mathrm{ml}$ of benzene trap solution. The detection limit for WP in benzene was $1 \mathrm{ppb}$.

\subsubsection{Carbon Analysis}

Dissolved organic carbon (DOC) in solutions that were analyzed was determined by acidifying the solution to $\mathrm{pH}<2$ with phosphoric acid, sparging to remove inorganic carbon as $\mathrm{CO}_{2}$, and injecting the solution into a carbon analyzer, where $\mathrm{CO}_{2}$ is detected by nondispersive infrared (NDIR) detection. The total organic carbon (TOC) in solution was then determined by direct injection, with dissolved inorganic carbon then calculated by difference.

\subsubsection{Sampling Procedures for Phosphorus Speciation}

Aerosol mass samples collected on glass fiber filters were sonicated in de-ionized water for $\mathrm{pH}$, total phosphorus, and phosphate determinations. Aerosol samples taken at a flow rate of $150 \mathrm{ml} / \mathrm{min}$ through gas wash bottles containing 50-ml de-ionized water were analyzed for total phosphorus, phosphate, and polyphosphate distributions. Analys is for both 
total phosphurus and phosphate could be done fairly rapidly compared to speciation analyses, and such analysis was therefore employed as the overall sample-monitoring method. Select filter and cascade impactor samples were routinely flushed with de-ionized water for phosphorus analysis. Static deposition coupons and aerosol gas-washing bubblers used in speciation determinations required total phosphorus and $\mathrm{PO}_{4}-\mathrm{P}$ for mass balance and cross-checking ability. Phosphite was included in routine analysis, since it represented a minor but consistant contribution to phosphorus distribution, and was not detectable by the HPLC separation procedure. Hypophosphite levels were not considered significant and so were monitored but not reported. Since the phosphorus speciation procedure was time-intensive, speciation distribution tests were minimized by judicious choice of samples. Although Brazell et al. (1984) recommended inclusion of EDTA to inhibit breakdown of the higher polyphosphates, we found little change in either bubbler or static water deposition samples using de-ionized water when analyzed on the day of preparation.

Efforts to find the best surface for static deposition resulted in tests on various substrates including one surface (the GSWP filter) which seemed to attract the aerosol. Since comparisons of deposition loads on exposed soils and plants suggested that the empty polystyrene Petri dish cover was a reasonable estimation of plant loading, wet and dry Petri dishes were used routinely. Deposition on dry surfaces (150-mm polystyrene Petri dish cover) and wet surfaces (150-mm polystyrene Petri dish containing de-ionized water or speciation eluent $A$ solution) produced an estimate of the total deposition occurring during each of the 1-to 4-hour exposures. Phosphine was sampled in the gaseous state using a gas purge and trap bottles, while elemental WP was trapped in a gas wash bottle containing benzene.

\subsection{SOIL MEASUREMENTS}

An initial study of smoke deposition on three types of soils (sandy loam, silt loam, and high organic soil) was conducted during the initial test burns. For this test, soils were premoistened to approximately $70 \%$ field capacity and were placed in $140-\mathrm{mm}$ (nominal) polystyrene Petri dishes (surface area $154 \mathrm{~cm}^{2}$ ) to a depth of $0.5 \mathrm{~cm}$. Soil response to phosphorus smoke deposition was examined closely because of the dramatic increases in soluble aluminum and iron in this test.

Because of the large expense associated with running soil tests for all possible scenarios soil, exposures were performed at $0.9 \mathrm{~m} / \mathrm{s}(2 \mathrm{mph})$ and about $20 \%$ to $30 \%$ relative humidity. For the WP exposures, Burbank soil was used in conjunction with a silt-loam (Maxey Flats) soil that has not been fully characterized, but were chosen because these soils were the planting media for native plants used in exposures.

The basic exposure regime used in subsequent tests consisted of exposing air dried soils as thin lenses $\left(10 \mathrm{~g} / 165 \mathrm{~cm}^{2}\right)$ in polystyrene Petri dish covers. This exposure method was chosen to evaluate changes occurring 
within the surface layer where the major microbial decomposition and metabolic processes occur. It is also the layer most subjected to all erosional forces (i.e., wind, water, runoff) that may impact adjacent surface or subsurface waters.

Four surface soils representing a range of soil types (see Table 2.1) expected to be encountered under actual field conditions were exposed to a 2-hour RP/BR aerosol deposition (range-finding test A3). Duplicate soil lenses were exposed for a total of $40 \mathrm{~g}$ onto $660 \mathrm{~cm}^{2}$ surface area per sample. Additional soil aliquots were exposed and held for 2 to 21 days prior to water contact under a similar leaching program. For WP smoke aerosols, two surface soils were exposed during a 4-hour test (WP-E3). A separate test, designed to study the dilution effects of larger masses of soil, was conducted during a 2-hour RP/BR exposure (range-finding test B9.2, see Table 2.3), and consisted of a sandy loam (Burbank) soil exposed in varying thicknesses. Immediately after exposure soils were contacted with de-ionized water (10:1 water to soil ratio) and gently agitated (60 rpm) at $25^{\circ} \mathrm{C}$ under aerobic conditions. Solutions were sampled periodically over a 24-day interval, filtered $(<: 22 \mu \mathrm{m})$ and analyzed for $\mathrm{pH}$, solubilized organic and inorganic carbon, major anions $\left(\mathrm{SO}_{4}=, \mathrm{Cl}^{-}, \mathrm{NO}_{2}{ }^{-}\right.$, $\mathrm{NO}_{3}{ }^{-}, \mathrm{PO}_{4}{ }^{-}$) by ion chromatography (IC), macro elements ( $\mathrm{Na}, \mathrm{K}, \mathrm{Ca}, \mathrm{Mg}$ ), and trace elements ( $\mathrm{Al}, \mathrm{B}, \mathrm{Ba}, \mathrm{Cd}, \mathrm{Co}, \mathrm{Cr}, \mathrm{Cu}, \mathrm{Fe}, \mathrm{Li}, \mathrm{Mn}, \mathrm{Mo}, \mathrm{Sr}, \mathrm{Ni}$, Si, and $\mathrm{Zn})$ by ICP. Unexposed soil controls were leached under identical conditions. Select exposed soil lenses were held for varying lengths of time following exposure and prior to water contact to simulate dry deposition followed by delayed rain/runoff contact. After completion of the leaching period for RP/BR exposed soils, phosphoric acid (140 ppm phosphorus) was added to control soils at a level approximating the phosphorus levels deposited on exposed soils to distinguish the polyphosphate effects from the acidic phosphate effects. A fresh aliquot of air-dried Burbank (sandy-loam) soil was also contacted with dilute phosphoric acid (118 ppm phosphorus) and the effects noted. Evaporation during water contact averaged less than $0.2 \%$ per day and was not replaced or factored into calculations.

\subsection{SOIL MICROBIOLOGICAL AND INVERTEBRATE MEASUREMENTS}

\subsubsection{Soil Microbiological Measurements}

Sieved, air-dried Burbank sandy-loam soil was used to study microbiological effects. Because of the inherently low microbiological activity, organic material was added to the soil to enhance the microbial populations. A uniform mixture of air-dried soil (500 g) and ground alfalfa $(5 \mathrm{~g})$ were placed in a $1-\mathrm{L}$ Erlenmeyer flask and $50 \mathrm{ml}$ of distilled water was added to bring the soil to $60 \%$ of its moisture-holding capacity. The moist soil mixture was incubated in darkness for 6 days, after which the enriched soil was placed in a large Pyrex dish and air dried.

Enriched soil was evenly spread over the top surface of a 145-mm inside diameter (ID) polystyrene Petri dish. Petri dishes containing 10, 25,50 and 100 grams of soil, which represent soil depths of $0.4,1.0,2.0$ 
and $4.0 \mathrm{~mm}$, respectively, were placed in the wind tunnel for exposure to smoke. Table 2.5 lists smoke exposure conditions for microbiological studies. After exposure, the soil was mixed well and left covered (but not sealed) in the original Petri dish used during smoke exposure. Soil subsamples were then taken from these dishes at predetermined intervals for assay of enzyme activities.

To assay for nitrification activity, a separate aliquot of the exposed soil was mixed with water at 10:1 (volume/weight) water to soil ratio and incubated under aerobic conditions at $25^{\circ} \mathrm{C}$, in darkness, on an orbital shaker revolving at $150 \mathrm{rpm}$. A control that consisted of unexposed soil treated similarly was incubated under the same conditions. In one experiment, soil suspensions were amended with 50 or $500 \mathrm{ppm}$ of ammonium ion (as ammonium sulfate) to determine potential nitrification activities. Periodic measurements were made from the water extracts of soil for the soluble nitrite and nitrate as an indication of soil nitrification activities. Methods for nitrite and nitrate determination were the same as those described in the soil chemistry methods section.

Soil dehydrogenase activity was assayed by the methods of Klein et al. (1971), with modifications. Dehydrogenase assays were initiated by adding $0.5 \mathrm{ml}$ of $0.5 \%(\mathrm{w} / \mathrm{v})$ glucose or casamino acids solution to $25-\mathrm{ml}$ centrifuge tubes. The tubes contained one gram of smoke-exposed soil or control soil that had been amended with $0.2 \mathrm{mi}$ of a $3 \%(\mathrm{w} / \mathrm{v})$ solution of 2,3,4-triphenyltetrazolium chloride (TTC). The tubes were incubated at $27^{\circ} \mathrm{C}$ in darkness for 24 hours. After incubation, $10 \mathrm{ml}$ of methanol was added to each tube and the tubes were thoroughly mixed for about 10 seconds in a vortex mixer. After centrifugation at $12,000 \mathrm{~g}$ for 10 minutes to extract TTC-formazan formed during the incubation, the supernatant solution was decanted. Absorbance of the solution at $485 \mathrm{~nm}$ was determined with a colorimeter. Soil dehydrogenase activity expressed as milligrams of TTC-formazan produced per gram of soil per 24 hours was quantified by comparing absorbance values to a standard curve prepared with reagent grade TTC-formazan in the concentration range of 0 to $30 \mu \mathrm{g} / \mathrm{ml}$ methanol.

Soil phosphatase activity was measured by the procedure of Tabatabai and Bremner (1969), as modified by Klein et a1. (1979). One gram of soil was placed in 25-mi centrifuge tubes with $4 \mathrm{ml}$ of modified universal buffer (MUB), which consists of tris (hydroxymethy 1) amino methane, $3.025 \mathrm{~g}$; maleic acid, $2.9 \mathrm{~g}$; citric acid, $3.5 \mathrm{~g}$; boric acid, $1.57 \mathrm{~g} ; 1 \mathrm{~N} \mathrm{NaOH}$, $122 \mathrm{ml}$; in $250 \mathrm{ml}$ final volume, $\mathrm{pH} 8.65$. One $\mathrm{ml}$ of paranitrophenylphosphate ( $0.025 \mathrm{~N}$ prepared with MUB solution) was added to each tube. The tubes were swirled, stoppered and incubated for one hour at $37^{\circ} \mathrm{C}$. One $\mathrm{ml}$ of $0.5 \mathrm{~N} \mathrm{CaCl}{ }_{2}$ and $4 \mathrm{ml}$ of $0.5 \mathrm{~N} \mathrm{NaOH}$ were then added to stop the reaction. The mixtures were centrifuged a $\bar{t} 12,000 \mathrm{~g}$ for ten minutes. Supernatants were decanted into cuvettes and read at $400 \mathrm{~nm}$ with a colorimeter. Phosphatase activity was determined by comparing these values to a standard curve constructed with various concentrations of para-nitrophenol ( 0 to $50 \mu \mathrm{g}$ per $\mathrm{ml}$ MUB solution) and expressed as $\mu \mathrm{g}$ of para-nitrophenol released per gram of soil per hour. 

TABLE 2.5. PHYSICAL AND CHEMICAL VARIABLES OF RP/BR SMOKE TESTS FOR THE STUDIES OF MICROBIOLOGICAL
EFFECTS(a)

\begin{tabular}{|c|c|c|c|c|c|c|c|c|c|c|c|}
\hline \multirow[b]{3}{*}{ Test } & \multirow{3}{*}{ Date $^{\text {Te }}$} & \multirow{3}{*}{$\begin{array}{l}\text { mperatur } \\
\left({ }^{\circ} \mathrm{C}\right)\end{array}$} & \multirow{3}{*}{$\begin{array}{c}\text { Air } \\
\text { velocity } \\
\text { (mph) }\end{array}$} & \multirow{3}{*}{$\begin{array}{c}\text { Exposure } \\
\text { time } \\
\text { (hr) }\end{array}$} & \multirow{3}{*}{$\begin{array}{c}\text { Relative } \\
\text { humidity } \\
\text { (\&) }\end{array}$} & \multirow{3}{*}{$\begin{array}{l}\text { Deposition } \\
\text { velocity on } \\
\text { dry surface } \\
\left(\mathrm{cm} \mathrm{sec} \sec ^{-1}\right)\end{array}$} & \multirow{3}{*}{$\begin{array}{c}\text { Particle } \\
\text { size } \\
\text { distribution } \\
\text { MMAD ( } \mu \mathrm{m})\end{array}$} & \multicolumn{4}{|c|}{ Mass Concentration } \\
\hline & & & & & & & & \multicolumn{2}{|c|}{ Particles, $\mathrm{mg} / \mathrm{m}^{3}$} & \multicolumn{2}{|c|}{ Phosphorus $(\mathrm{b})$} \\
\hline & & & & & & & & Fresh & Dry & $\begin{array}{c}\text { Total } \\
m g-P / m^{3}\end{array}$ & $\frac{81 P}{P_{\text {tot }}}$ \\
\hline RFT-A3 $(c)$ & $9-26-84$ & 24.0 & 2 & 2 & 25 & 0.052 & 0.76 & $\begin{array}{l}1960 \\
2040\end{array}$ & $--(d)$ & $\begin{array}{l}520 \\
530\end{array}$ & $\ldots$ (d) \\
\hline D6.1 & $1-22-85$ & 22.0 & 2 & 2 & 25 & 0.031 & 1.56 & 2440 & 2290 & 630 & 30.0 \\
\hline D6. 2 & $1-22-85$ & 21.7 & 2 & 2 & $60^{(e)}$ & 0.043 & 1.60 & 3060 & 2040 & 597 & 21.3 \\
\hline D7 & $1-23-85$ & 21.9 & 2 & 2 & $90^{(e)}$ & 0.034 & 1.90 & 4440 & 1510 & 425 & 15.7 \\
\hline
\end{tabular}

(a) Compiled from data in monthly progress reports $\# 5,6,8,9$.

(b) P species measured by IC.

(c) Oniy one soil depth $(0.4 \mathrm{~mm})$ was exposed in this test.

(d) Data not available.

(e) Actual relatively humidity is $56 \%$ for Test $D 6.2$ and 848 for Test D7. 
A11 dehydrogenase and phosphatase activities were measured in three replicates and their calculated mean values were compared with that of the unexposed control soil and presented as percent of control.

\subsubsection{Soil Invertebrate Measurements}

An earthworm bioassay system was employed to elucidate the toxicity of the WP. The test was a soil test in which $80 \mathrm{~g}$ soil (placed in $100 \times 25 \mathrm{~mm}$ Petri plates), containing 5 worms (Eisenia fetida) each, were exposed to aerosols of WP during test series E. These were terminated after 14 days, and effects observed over this period. An artificial soil containing $350 \mathrm{~g}$ sand, $100 \mathrm{~g} \mathrm{Kaolin}$ and $50 \mathrm{~g}$ dried peat moss (adjusted to $\mathrm{pH} 6.5$ with $\mathrm{CaCO}_{3}$ ), was employed for the earthworm exposures. Worms were fed twice weekly with fermented alfalfa, and soil moisture adjusted to $35 \%$ of dry weight.

\subsection{PLANT/SOIL MEASUREMENTS}

In evaluating direct foliar contact toxicity, plant canopies were exposed to smokes under a range of concentration, time, and atmospheric conditions. In all cases, soils were isolated from canopies by bagging the soil containers at the lower plant stem to preclude any indirect effects arising from soil contamination. All foliar exposures were conducted in the illuminated portion of the wind tunnel test section. Indirect plant effects were evaluated by exposing Burbank and Maxey Flats soils to smoke aerosols. These soils (444 and $526 \mathrm{~g}$ dry weigh of Maxey Flats and Burbank, respectively) were brought to moisture level, placed into 4.5-in.-diameter by 4-in.-high pots, the surface leveled, and pots exposed to smokes. Four days after being exposed, the soils were seeded with 15 blando brome seeds. This approach resulted in contamination of only the soil surface; post-planting irrigation should result in some redistribution of smoke components down the soil profile. Details of the exposure regimes are presented in Section 3.0.

\subsubsection{Quantitation of Exposure/Dose}

The evaluation of plant toxicity responses to airborne contaminants requires a basis for intercomparison of treatments and variables. In all of the toxicity studies, the point of reference is the mass loading value or exposure dose, as opposed to air concentration or exposure duration, to provide a specific dose value for each plant. The mass loading rate is determined by chemical measurement of the amount of smoke deposited to a unit area or weight of foliage, and is an absolute index of dose. In the case of phosphorus smokes, total foliar phosphorus was determined by extraction of foliar samples with simulated rainwater (Cataldo et al. 1981). Initial studies showed the phosphorus concentration of leachates from control foliage ranged from 0.5 to $1.0 \mu \mathrm{g} \mathrm{P} / \mathrm{cm}^{2}$, and mass loading values were corrected as appropriate. Extraction efficiency was calculated at $98.5 \%$ based on phosphorus content of control and exposed/extracted tissues. Mass loading to soils was estimated based on loading to filter coupons, dry Petri dishes, and wet Petri dishes as noted earlier. Quantitation of interception efficiency based on type of receptor surface 
(namely the type of canopy structure) is based on computed deposition velocities. The velocities are calculated from the air concentration, exposure duration, and the quantity of smoke $(P)$ deposited per unit surface area.

\subsubsection{Quantitation of Phytotoxicity}

Toxicity responses arising from direct contact of smokes with foliage, . namely those that are readily visualized or phenotypic, were evaluated using a modified Daubenmire Rating Scale (Table 2.6). In addition, grasses that are harvested 3 to 4 weeks after exposure (direct canopy effects) were permitted to regrow through one or more subsequent harvests, and dry matter production was monitored. Regrowth and monitoring allows for evaluation of any residual plant effects resulting from foliar absorption and root accumulation of smoke components. Indirect plant effects resulting from smoke contaminants deposited to soils were determined by evaluating percentage germination and dry matter production using blando brome as a test species. As noted in Chapter 3.0 (Results and Discussion), in no case was germination affected by phosphorus smokes. Dry matter production for plants grown on contaminated soils was followed through two or more harvests. In addition, total elemental analysis of leaf tissue was performed for the first two harvests to determine whether phosphorus smokes affected the solubility of soil minerals and soluble elements. Finally, a series of Scanning Electron Micrographs (SEM) were taken of both exposed and control plants. The SEM photographs were then examined to identify the relationship of morphologic features with degree of effect.

\subsubsection{Post-Exposure Simulated Rainfall}

The intensity of phytotoxic responses to foliar contaminants can be modified by the presence or absence of surface moisture. Immediately following exposure, subsets of exposed plants were subjected to a simulated rainfall (Figure 2.7 ) equivalent to $1.0 \mathrm{~cm}$, as described in Cataldo et al. (1981). Simulated rainfall permitted evaluation of either the ameliorating effects of foliar surface wash-off, or any intensification of effects resulting from the presence of surface moisture and increased foliar uptake. 
TABLE 2.6. CODING FOR THE MODIFIED DAUBENMIRE RATING SCALE AND ASSOCIATED PHYTOTOXICITY SYMPTOMS

Symptom/intensity

Description

Modified daubenmire rating scale:

0

1

3

4

5

6

Phenotypic responses:

\section{$O G A$}

$N G A$

O\&NGA

TB

LBD

NS

LD

$\mathrm{Ch} 1$

$\mathrm{BD}$

LC

W

GD

D

F/SA

(value) no obvious effects over controls $<5 \%$ of plant foliage affected between $5 \%-25 \%$ of foliage affected between $25 \%-50 \%$ of foliage affected between $50 \%-75 \%$ of fol iage affected between $75 \%-95 \%$ of fol iage affected between $95 \%-100 \%$ of foliage affected old growth affected

new growth affected

old and new growth affected

tip or leaf edge burn

leaf burn and leaf drop

necrotic spotting

leaf abscission or needle drop

chlorosis

blade dieback

leaf curl

wilting

growing tip dieback

plant dead

floral or seed/fruit abortion

indicates the length in $\mathrm{cm}$ that needles or leaves exhibit dieback or burn 


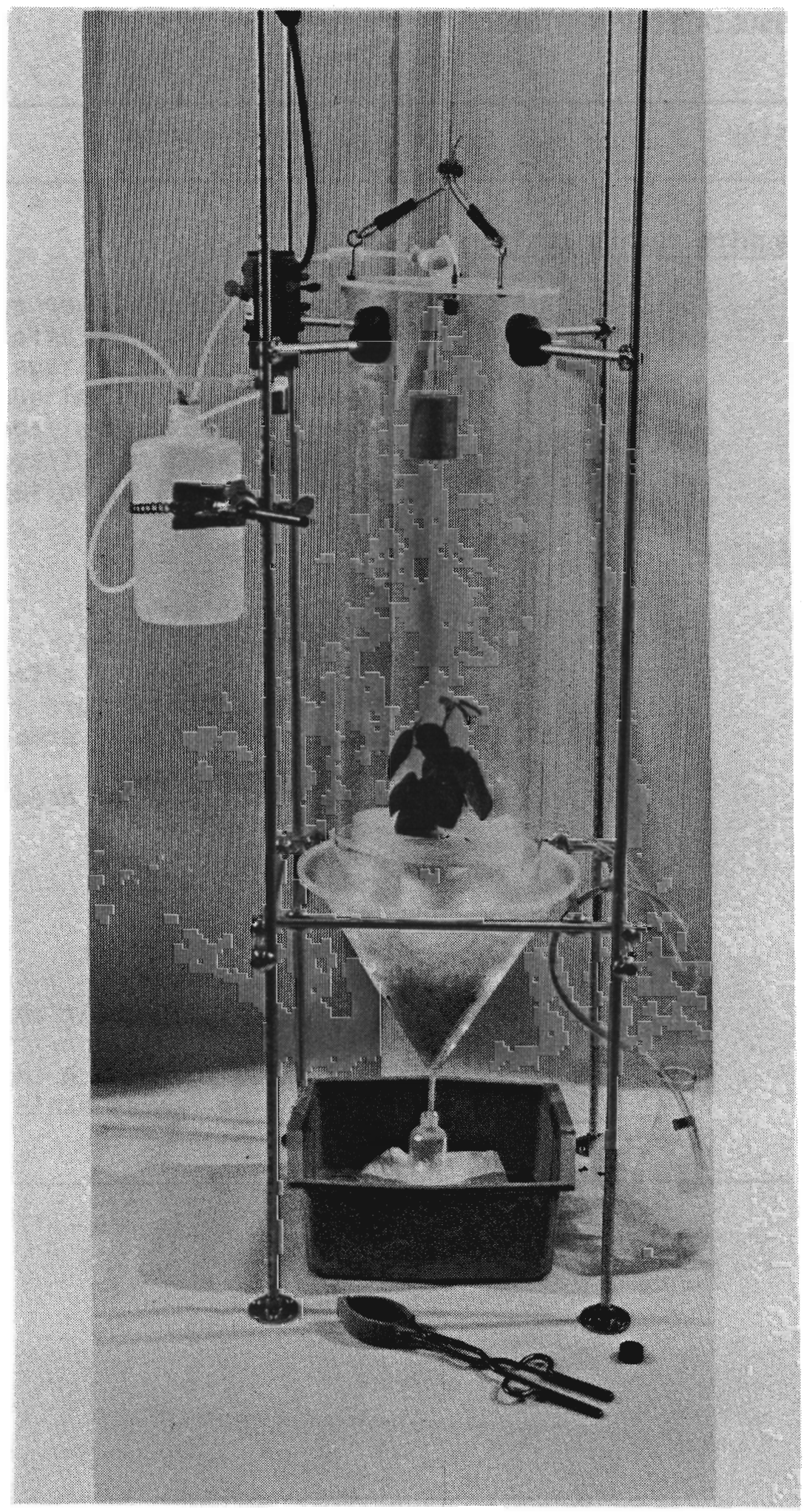

FIGURE 2.7. POST-EXPOSURE SIMULATED RAINFALL SYSTEM 


\subsection{RESULTS AND DISCUSSION}

The wind tunnel tests were conducted to establish a detailed data base from which one could predict the chemical transformations, transport, ecological effects, and potential long-term impact of red phosphorus/butyl rubber (RP/BR) and white phosphorus (WP) obscurant smokes on components of natural environments representative of a range of field training sites. The wind tunnel was used to simulate the environmental variables associated with airborne dissemination scenarios. The chemical and physical characteristics of the airborne smokes were monitored while they were in transit to determine the influence of those characteristics on the deposition of smokes to plant and soil surfaces. As part of the overall research effort, considerable attention was given to the detailed physical and chemical characteristics of the smokes. This was done in order to provide source terms for exposoure models for concerns associated with health effects on residents near various training sites as well as domestic and wildilfe animal populations.

Several aspects of the ecological effects of phosphorus smokes were considered:

1. Does a dose/response relationship exist for a given obscurant smoke, and can a dose/response relationship derived under laboratory conditions be used to determine the effects of smoke used under actual field conditions?

2. If a dose/response relationship exists, can it be affected by environmental factors or dosing conditions such as relative humidity, wind speed, or rainfall?

3. Once the effects of smokes are observed, how can they be compared or used to assess present and future impacts of obscurant smoke?

A point of reference must be established to answer these questions and predict long-term impacts at Army training sites.

Dosing levels (air concentration and duration) are inappropriate as a reference point for determining the effects of airborne contaminants on plant and soil systems. The physical processes (diffusional and gravitational fluxes versus impaction) that influence the transfer of airborne pollutants from the air column, through the boundary layers, to receptor surfaces where effects are induced are affected by a range of parameters. These parameters include atmospheric conditions and to some extent the chemical and physical structure of the receptor. Therefore, the only appropriate method for equating damages and effects to dose is to quantify the dose deposited to affected surfaces and/or soils. In this study the mass of phosphorus deposited per unit mass or area of surface exposed (mass loading) is quantified, which allows dose/response relationships to be compared, and allows the mass loading (ML) rate to be 
used in conjunction with air concentration and exposure time for computing deposition velocities $\left(V_{d}\right)$. The formula for calculation of $V_{d}$ is shown in Equation 1.

$$
V_{d}(\mathrm{~cm} / \mathrm{sec})=\frac{M L\left(\mathrm{mg} \mathrm{P} / \mathrm{cm}^{2}\right. \text { leaf) exposure time }}{\text { air concentration }\left(\mathrm{mg} P / \mathrm{m}^{3}\right)} \times(\mathrm{sec}) \times \mathrm{boo}^{3^{(1)}}
$$

Use of $V_{d}$ permits a comparison of desposition efficiency to various surfaces as influenced by physical and atmospheric variables such as relative humidity, wind speed, physical characteristics of the airborne smoke (i.e., particle size), and plant canopy and soil characteristics. By using this quantitative approach, the wind tunnel can be used to simulate the behavior and effects of obscurant smokes in the field. In addition, computed $V_{d}$ values based on a series of smoke and atmospheric variables can be used to estimate mass loading and, therefore, damage to components of the terrestrial ecosystem.

Because of the lack of detailed information and/or data on the effects of phosphorus smokes on plants and associated terrestrial components (Shinn et a1. 1985; Van Voris et al. 1985), an experimental approach was used in this study. The exposure tests were designed to determine the ecological effects of smokes and the influence of various environmental factors on those effects. The tests consisted of a range-finding test, a cumulative dose test, and a series of tests to evaluate the effects of atmospheric parameters on ecotoxicity. The latter primarily include tests to determine the effects of relative humidity, rainout, and wind speed.

The range-finding tests established a working air concentration for phosphorus smokes that induce a measurable degree of ecotoxicity. Plant canopies and soils were separately exposed to a single concentration of phosphorus smoke for $2,4,6$, and $8 \mathrm{hrs}$. Wind speed, relative humidity, and temperature remained constant during each exposure. As a result of the range-finding tests, a dose/exposure pattern was selected to evaluate ecological responses to obscurant smokes. The range-finding tests also included a post-exposure simulated rainfall treatment to plants to determine the ameliorating or intensifying influence of excess foliar surface moisture on phosphorus solubilization, foliar uptake, and subsequent toxicity.

The dose/exposure pattern established in the range-finding tests was subsequently used to study the effects of relative humidity and wind speed conditions on the phytotoxicity of phosphorus smokes. A dose level was also established to set limits for the cumulative dose test. The cumulative dose test consisted of nine consecutive exposures of individual plants to low and high, subtoxic, dose/exposure patterns. After the ninth exposure, the total dose received by each plant was compared to single dose exposure to evaluate the toxicologic responses and the mass loading levels of foliage from these two different exposure scenarios. From these tests it can be determined whether or not the ecotoxicity resulting from long-term, low-level exposures to obscurant smokes has a cumulative effect comparable to a single toxic dose having a comparable mass loading. 
Other effects of phosphorus smokes that were investigated include: 1) the influence of soil-deposited smokes on seed germination and plant growth, 2) the solubilization of soil elements and their accumulation in plants, and 3) the effects of smokes on microbial processes important to both soil genesis and plant growth.

\subsection{SMOKE CHARACTERIZATION}

\subsubsection{Physical Characteristics}

The rates of particulate mass loading to specific plants and soils were measured in a wind tunnel under a wide range of simulated natural conditions. This rate of mass loading, called the deposition velocity of the aerosol, could then be applied to estimate the total particulate mass loading in the field. Required field measurements would include exposure duration, aerosol mass concentration, wind speed, and particle size. For phosphorus obscurant aerosols, the particle size measurement requirement could be replaced with an ambient relative humidity measurement because the size of the particle is apparently determined by age and available water vapor.

\subsubsection{Aerosol Mass Concentration}

During each exposure test the average mass concentration of the obscurant smoke suspended in the wind tunnel was determined by converting the output of the laser transmissometer to aerosol mass concentration and averaging the resulting data over the duration of the test. This method resulted in actual aerosol mass concentration; the desiccated aerosol mass concentration and the concentration of phosphorus, by mass, were determined by multiplying the actual average mass concentration by the appropriate ratio. Tables 3.1 through 3.4 ist the average actual, desiccated, and phosphorus mass concentrations measured for each exposure test. Figures 3.1 through 3.4 are example recordings of smoke concentration versus time for each type of exposure test. These figures also show that the average smoke concentration was maintained at an approximately constant level throughout each test by a continuous series of RP/BR or WP ignitions.

The aerosol concentration record for $R P / B R$ range-finding test $A 2$ is shown in Figure 3.1. An average actual mass concentration of $1960 \mathrm{mg} / \mathrm{m}^{3}$ was measured for both the 6- and the 8-hour exposures. The rapid decreases in aerosol mass concentration at 14:00 and 16:00 resulted from isolating and purging the test section prior to removing exposed plants and soils. Figure 3.2 shows the double concentration exposures of RP/BR B series range-finding test. In the $B$ series test, one set of plants was repeatedly exposed (three times per week, nine times total) to a low concentration of the obscurant smoke and another set was exposed to a higher concentration. With the exception of range-finding test B1 and B2, the exposures were 4 hours long; the exposures for tests B1 and B2 were shorter because the aerosol mass concentration was markedly greater than the initial target of $200 \mathrm{mg} / \mathrm{m}^{3}$. The average concentration of the low concentration exposures was approximately $219 \mathrm{mg} / \mathrm{m}^{3}$ ( $\pm 30:$ standard deviation of 9 tests) and the average concentration for the high concentration exposures was $1140 \mathrm{mg} / \mathrm{m}^{3}$ ( \pm 130 : standard deviation of 9 tests), as shown in Figure 3.5 . 
TABLE 3.1. AEROSOL MASS CONCENTRATION RESULTS FOR THE RP/BR RANGEFINDING TEST (RFT), SERIES A

\begin{tabular}{lclc}
\hline Test/duration & $\begin{array}{c}\text { Relative } \\
\text { humidity } \\
(\%)\end{array}$ & $\begin{array}{l}\text { Aerosol mass concentration } \\
\text { Actual } \\
\left(\mathrm{mg} / \mathrm{m}^{3}\right)\left(\mathrm{mg} / \mathrm{m}^{3}\right)\end{array}$ & $\begin{array}{c}\text { Dhosphorus } \\
\left(\mathrm{mg} \mathrm{P} / \mathrm{m}^{3}\right)\end{array}$ \\
\hline RFT-A1, $2 \mathrm{hr}$ & $20(\mathrm{a})$ & $2070 \pm 85(49)$ & 560 \\
RFT-A1, $4 \mathrm{hr}$ & & $2030 \pm 125(49)$ & $550(\mathrm{c})$ \\
RFT-A2, 6 $\mathrm{hr}$ & & $1960 \pm 135(158)$ & $530(\mathrm{c})$ \\
RFT-A2, $8 \mathrm{hr}$ & & $1960 \pm 140(48)$ & $530(\mathrm{c})$ \\
RFT-A3,2 $\mathrm{hr}$ & & $2040 \pm 89(45)$ & 550 \\
\hline
\end{tabular}

(a) Relative humidity was within the range $15 \%<\mathrm{RH}<30 \%$ for all

(b) range-finding tests.

(c) $P$ =number of transmissometer samples

Calculated from results of chemical analysis of air sample filter pads.

TABLE 3.2. AEROSOL MASS CONCENTRATION RESULTS FOR THE RP/BR RANGEFINDING TESTS (RFT), SERIES B

\begin{tabular}{llll}
\hline Test & $\begin{array}{c}\text { Relative } \\
\text { humidity } \\
(\%)\end{array}$ & $\begin{array}{l}\text { Actual aerosol } \\
\text { Low dose } \\
\left(\mathrm{mg} / \mathrm{m}^{3}\right)\end{array}$ & $\begin{array}{c}\text { migh dose } \\
\left(\mathrm{mg} / \mathrm{m}^{3}\right)\end{array}$ \\
\hline RFT-B1 & $20(\mathrm{a})$ & $550 \pm 217(30)(\mathrm{b})$ & $877 \pm 138(94)$ \\
RFT-B2 & & $284 \pm 189(72)(\mathrm{c})$ & $1030 \pm 150(93)$ \\
RFT-B3 & $265 \pm 41(95)$ & $1140 \pm 107(95)$ \\
RFT-B4 & $213 \pm 28(95)$ & $1170 \pm 113(95)$ \\
RFT-B5 & $216 \pm 24(108)$ & $1100 \pm 133(108)$ \\
RFT-B6 & $279 \pm 34(95)$ & $1250 \pm 134(95)$ \\
RFT-B7 & $221 \pm 19(81)$ & $1210 \pm 140(95)$ \\
RFT-B8 & 197 & $1130 \pm 148(94)$ \\
RFT-B9 & $216 \pm 17(95)$ & $1330 \pm 117(95)$ \\
Average & $219(9)$ & $1140(9)$ \\
\hline
\end{tabular}

(a) Relative humidity was within the range $15 \%<\mathrm{RH}<30 \%$ for all $\mathrm{RP} / \mathrm{BR}$

(b) range-finding tests.

(c) $P=$ number of transmissometer samples.

$n(m): n=a c t u a l$ average concentration. 
TABLE 3.3. AEROSOL MASS CONCENTRATION RESULTS FOR THE RP/BR TEST D. (a)

\begin{tabular}{|c|c|c|c|c|}
\hline \multirow[b]{2}{*}{ Test } & \multirow{2}{*}{$\begin{array}{c}\text { Relative } \\
\text { humidity } \\
(\%)\end{array}$} & \multicolumn{3}{|c|}{ Average mass concentration } \\
\hline & & $\begin{array}{c}\text { Actua } 7 \\
\left(\mathrm{mg} / \mathrm{m}^{3}\right)\end{array}$ & $\begin{array}{l}\text { Dried } \\
\left(\mathrm{mg} / \mathrm{m}^{3}\right)\end{array}$ & $\begin{array}{l}\text { Phosphorus } \\
\left(\mathrm{mg} \mathrm{P} / \mathrm{m}^{3}\right)\end{array}$ \\
\hline D1 & & $2670 \pm 356(-)$ & 2170 & 673 \\
\hline D2 & 60 & $2890 \pm 170(-)$ & 2130 & 676 \\
\hline D3 & 27 & $2440 \pm 230(-)$ & 2030 & 612 \\
\hline D4 & 89 & $3130 \pm 332(129)$ & 1560 & 441 \\
\hline D5 & 67 & 2640 (D) & $(1690)^{(c)}$ & 591 \\
\hline D6 & 25 & $2440 \pm 212(156)$ & $2290^{\circ}$ & 630 \\
\hline & 56 & $3060 \pm 184(121)$ & 2040 & 597 \\
\hline D7 & 84 & $4440 \pm 553(153)$ & 1510 & $425(c)$ \\
\hline D8 & 56 & $3330 \pm 164(79)$ & $\begin{array}{l}2070 \\
1720\end{array}$ & $\begin{array}{l}(726)(c) \\
(707)(c)\end{array}$ \\
\hline & & $3 / 20 \pm 366(82)$ & $1 / 20$ & \\
\hline
\end{tabular}

\footnotetext{
(a) $P=$ number of transmissometer samples.

(b) Average of composite test.

(c) Estimated.
}

TABLE 3.4. AEROSOL MASS CONCENTRATION RESULTS FOR THE WP TEST E

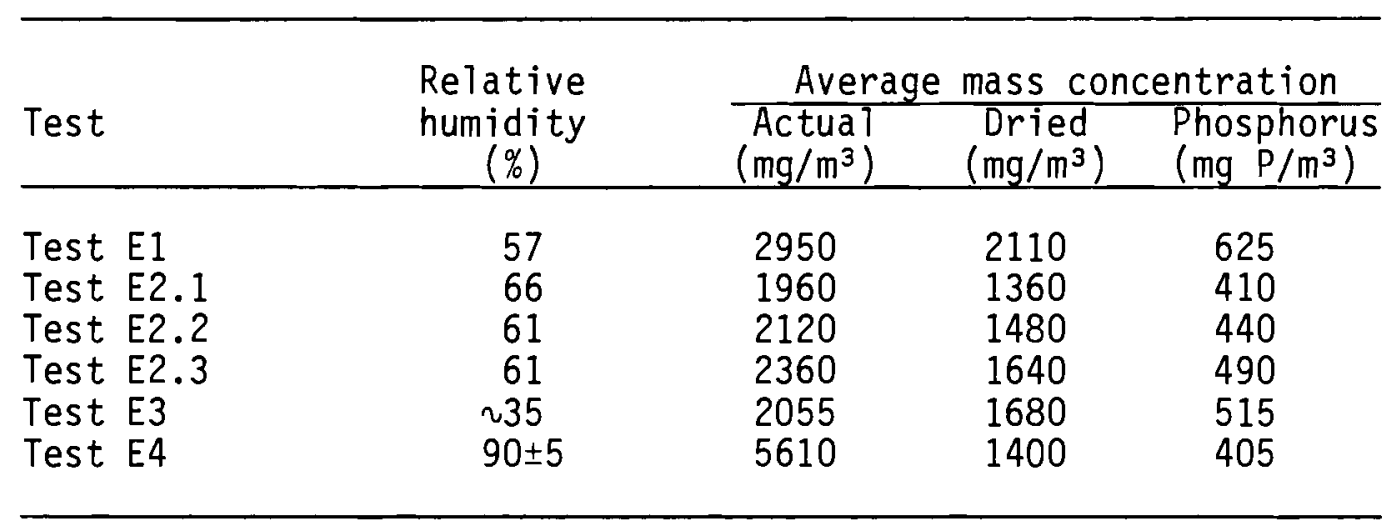




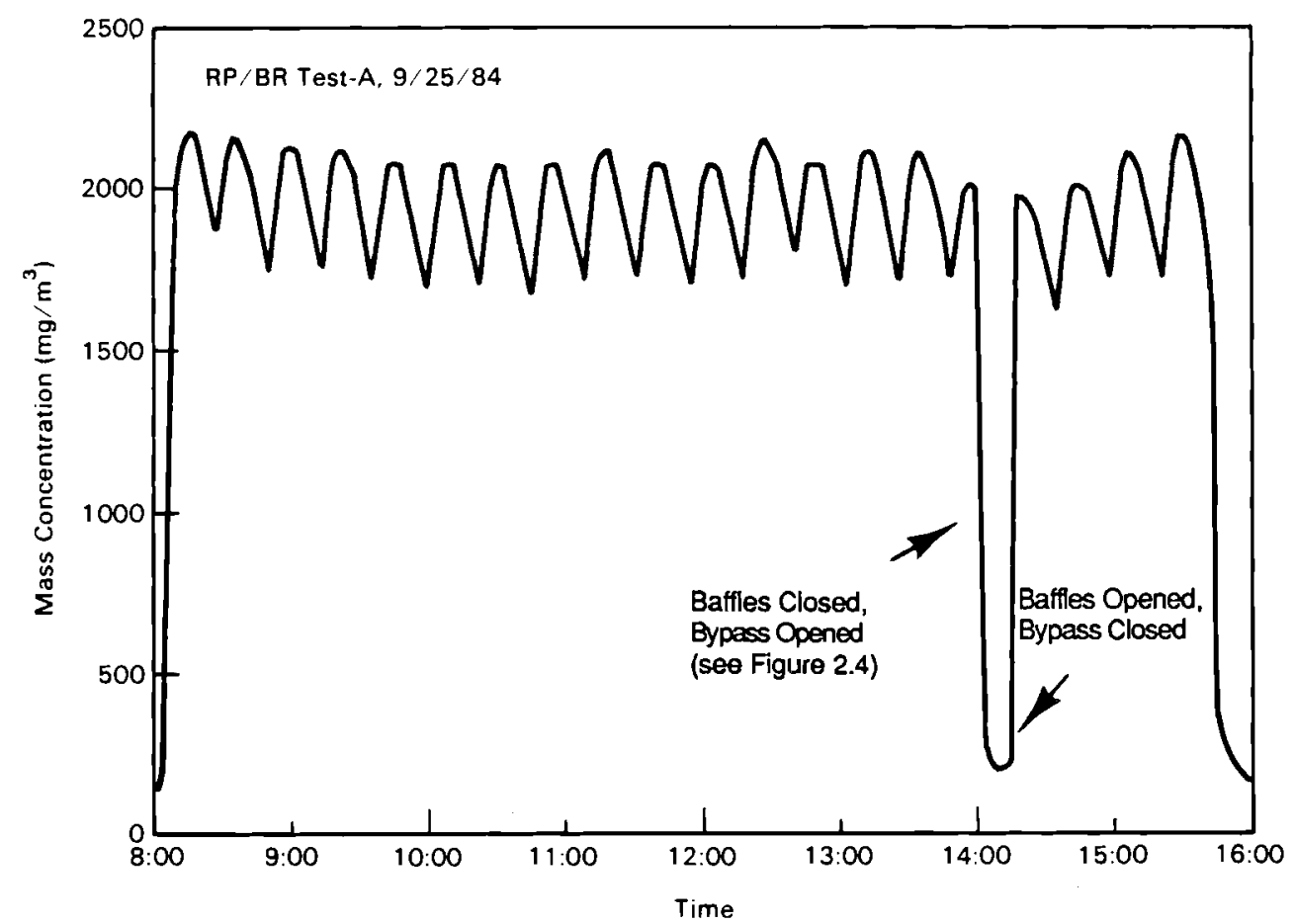

FIGURE 3.1. MASS CONCENTRATION VERSUS TIME FOR RP/BR RANGE-FINDING TEST A2

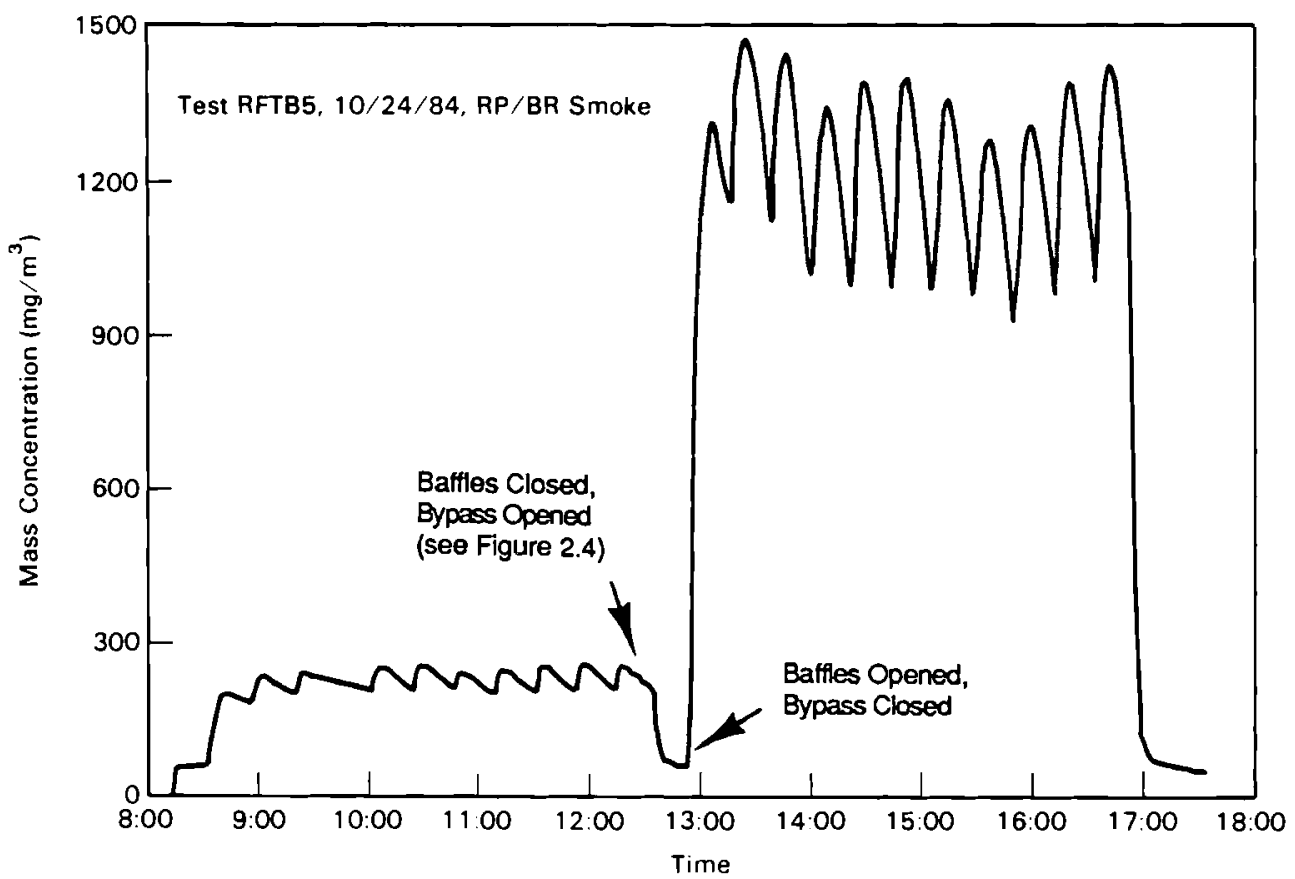

FIGURE 3.2. MASS CONCENTRATION VERSUS TIME FOR THE FIFTH OF NINE RP/BR CUMULATIVE DOSE EXPOSURE TESTS 


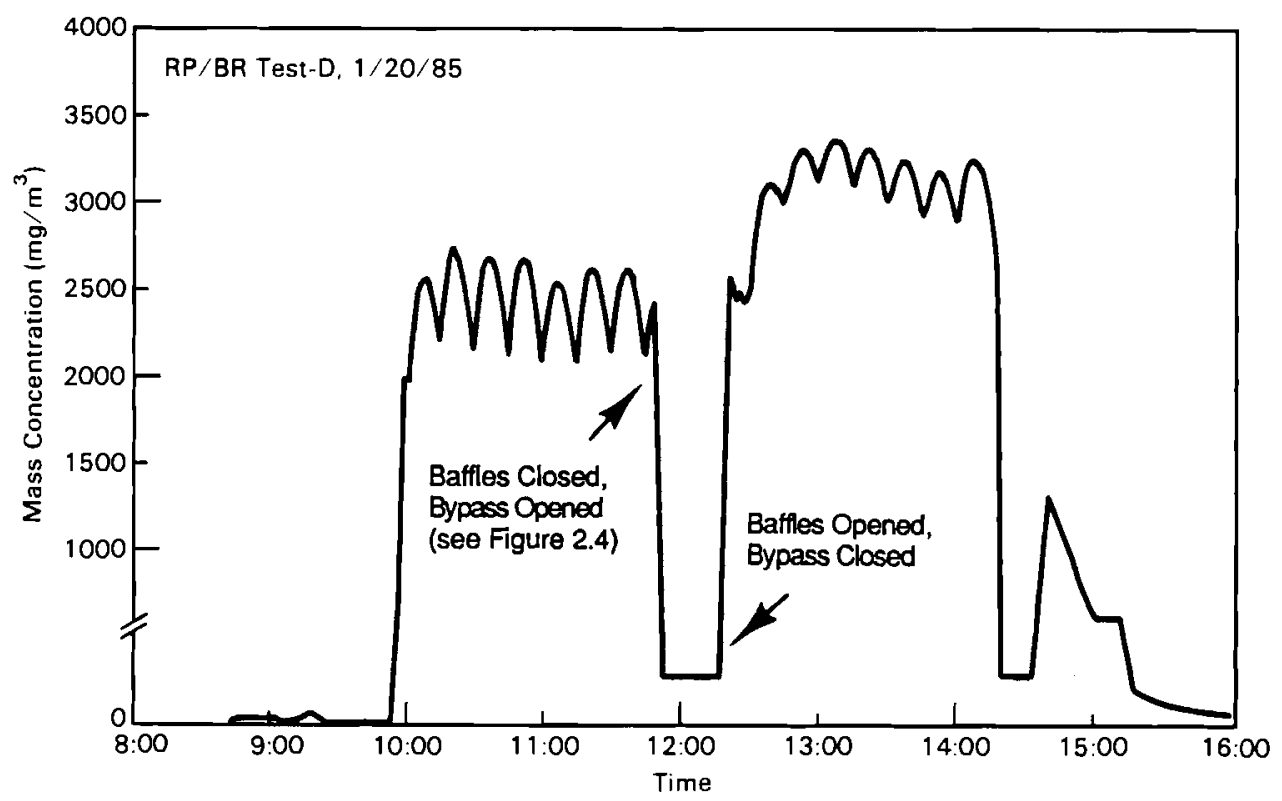

FIGURE 3.3. MASS CONCENTRATION VERSUS TIME FOR RP/BR TEST SERIES D6 (RELATIVE HUMIDITY WAS 25\% FOR THE FIRST 2-HOUR EXPOSURE AND $60 \%$ FOR THE SECOND).

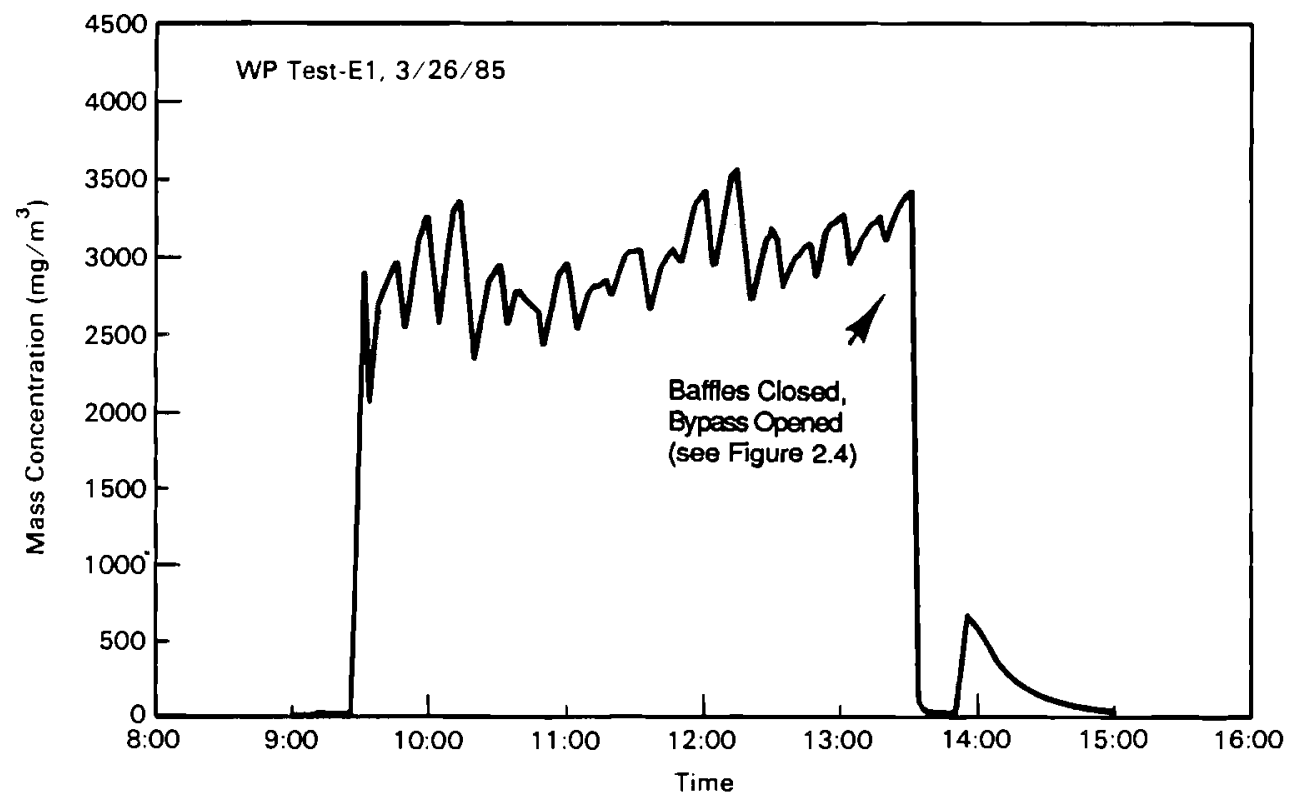

FIGURE 3.4. MASS CONCENTRATION VERSUS TIME FOR WP TEST E1 


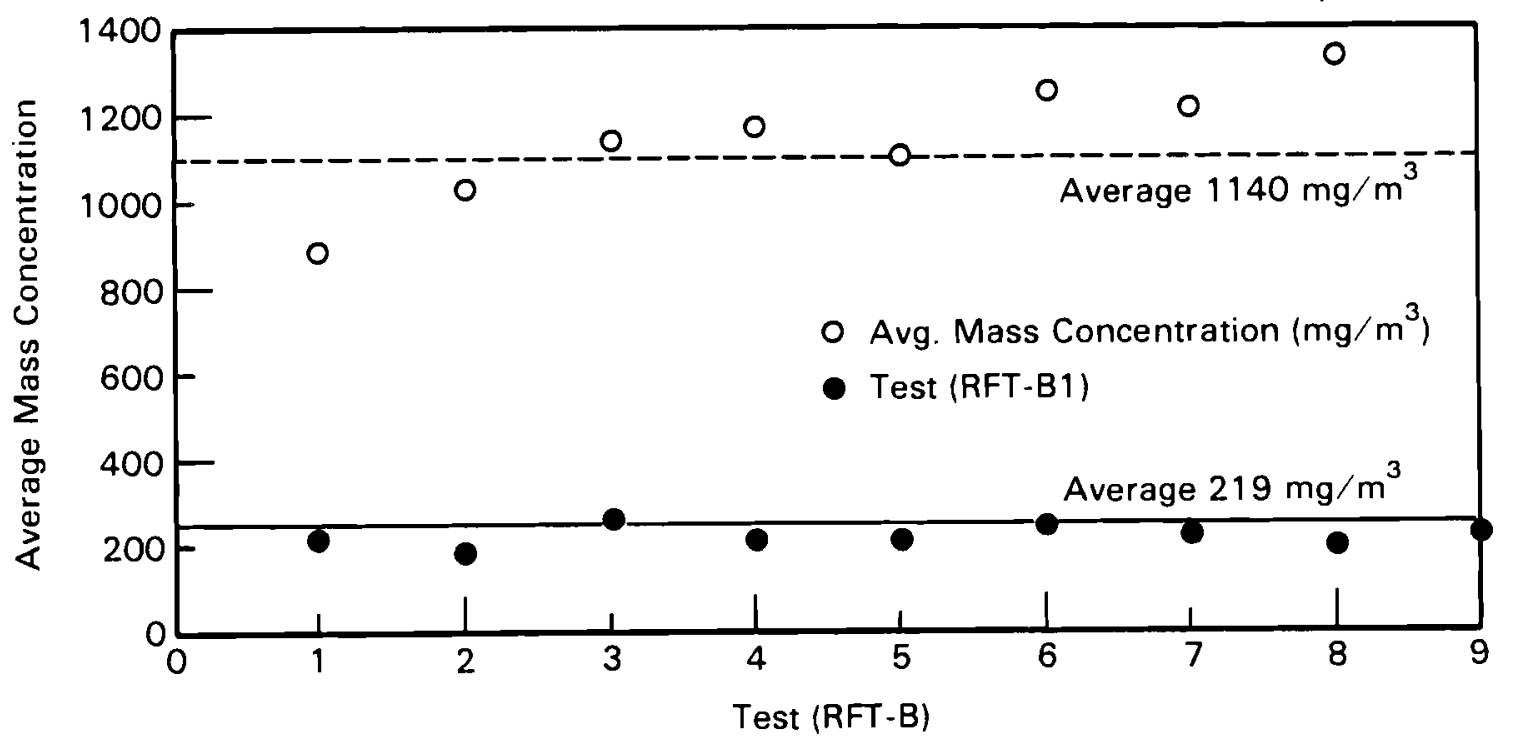

FIGURE 3.5. AVERAGE MASS CONCENTRATION FOR EACH SERIES B RP/BR EXPOSURE

The aerosol mass concentration for one of the RP/BR Test-D exposure tests are represented in Figure 3.3. This test series consisted of two 2-hour exposures. The combustion rate of RP/BR was constant throughout each test. The actual aerosol concentration during the second exposure was $25 \%$ greater than the concentration during the first exposure because the wind tunnel humidity was increased from $25 \%$ to $56 \%$ between the two tests, and this additional water vapor was absorbed by the particles. One of the six WP Test-E exposure tests is depicted in Figure 3.4. The shape of the aerosol concentration plot is less smooth than that for the RP/BR aerosols because of the more violent nature of the WP combustion process. Also shown are actual laser calibration data points obtained during the test. The average of the calibration data indicated an aerosol mass concentration $5 \%$ less than the $2950 \mathrm{mg} / \mathrm{m}^{3}$ indicated by analys is of the laser transmissometer. A one-to-one ratio between the two methods is not expected. The filter (calibration) data is less accurate because it cannot account for concentration fluctuations as can the laser transmissometer calibration; on the other hand, the transmissometer calibration may incorporate errors originating in the assignment of a curve-of-best-fit to the calibration data.

The air concentrations generated and maintained in the wind tunnel during exposure tests ranged from 200 to $4500 \mathrm{mg} / \mathrm{m}^{3}$ for $R P / B R$, and 2000 to $5600 \mathrm{mg} / \mathrm{m}^{3}$ for WP. These ranges tend to approximate the upper range field concentrations previously calculated for these two obscurants, 1 to 13,600 $\mathrm{mg} / \mathrm{m}^{3}$ for RP devices and 6 to $3400 \mathrm{mg} / \mathrm{m}^{3}$ for WP devices (Shinn et al. 
1985). These calculations were based on estimates of affected area and effective device fill weight. Actual field concentrations may often vary and the additional mass of absorbed atmospheric water vapor and oxygen will tend to significantly increase the field aerosol concentrations.

\subsubsection{Particle Size Distribution}

Particle size distributions of the obscurant aerosols dispersed into the wind tunnel were characterized by mass median aerodynamic diameter (MMAD) and geometric standard deviation (GSD). These two parameters adequately describe the aerosols measured during this study because the distribution of particle size was observed to be log normal. One particle size distribution, obtained during RP/BR test D6, is shown in Figure 3.6 .

The obscurant aerosols were log-normally distributed which was

demonstrated by the linearity of the majority of the cascade impactor data when plotted as particle aerodynamic size versus cumulative mass percentage on logarithmic-probability graph paper. Two impactors were used to sample the RP/BR aerosol during this exposure test. The first impactor, PNL No. 13, was operated without aluminum foil collection disks and was subsequently analyzed chemically. The second impactor, PNL No. 14, was operated with aluminum foil collection disks and analyzed both chemically and gravimetrically. As seen in Figure 3.6, neither the analys is method nor the presence of the aluminum foil collection disks biased the results. The aerosol MMAD was estimated to be $1.60 \mu \mathrm{m}$ with a GSD of 1.61 .

Aerosol size distributions measured during the RP/BR test $D$ series and WP test $E$ series are presented in Table 3.5. The analys is procedure was primarily gravitational; however, much of the data was chemically analyzed to check the analysis accuracy. Typically, two separate impactors were used to sample the obscurant aerosol during each test. One was used for sampling the steady-state aerosol and the other for sampling either the fresh aerosol prior to an exposure, the steady-state aerosol with aluminum foil collection disks, the steady-state aerosol as a reproduction of the first impactor, or the aged aerosol following the exposure.

The MMAD's measured for RP/BR and WP aerosols are grouped by relative humidity in the wind tunnel atmosphere in Table 3.6 and Figure 3.7. Particle growth was observed as the aerosols aged between 5 minutes and approximately 1 hour after combustion. At a relative humidity of $60 \%$, particle size apparently increased by 1.3 times in diameter and 2.0 times in volume. This increase was expected because it was assumed that the particles continued to grow by absorption of water vapor and, to a lesser extent, by coagulation as they aged. An even greater increase in the size of the particles as the aerosol aged may have been partially offset by preferential deposition of the larger particles to the wind tunnel and plant/soil surfaces. 


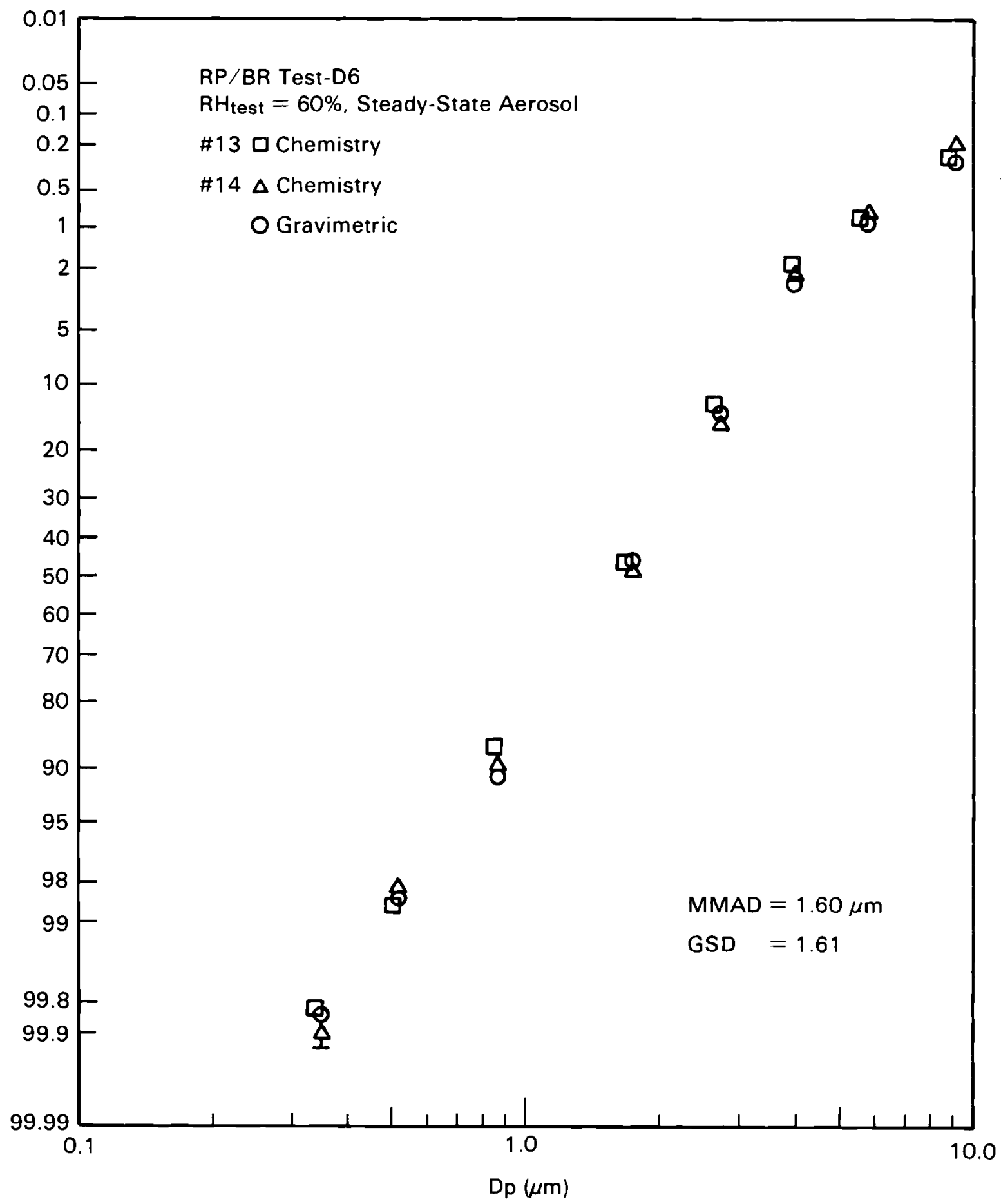

FIGURE 3.6. PARTICLE SIZE DISTRIBUTION FOR RP/BR TEST SERIES D6 BASED ON ANDERSON CASCADE IMPACTOR SAMPLES 
TABLE 3.5. PARTICLE SIZE AND GSD VERSUS TEST, AGE, AND RELATIVE HUMIDITY. RESULTS FOR EACH TEST WERE DERIVED FROM ANALYSIS OF SINGLE CASCADE IMPACTOR SAMPLES

\begin{tabular}{|c|c|c|c|c|c|}
\hline \multirow[b]{2}{*}{ Test } & \multirow[b]{2}{*}{$\begin{array}{c}\text { Relative } \\
\text { humidity } \\
(\%)\end{array}$} & \multicolumn{3}{|c|}{ MMAD } & \\
\hline & & $\begin{array}{l}\text { Fresh } \\
(\mu \mathrm{m})\end{array}$ & $\begin{array}{c}\text { Steady-state } \\
(\mu \mathrm{m})\end{array}$ & $\begin{array}{l}\text { Aged } \\
(\mu \mathrm{m})\end{array}$ & $\begin{array}{l}\operatorname{GSD}^{(a)} \\
(-)\end{array}$ \\
\hline
\end{tabular}

RP/BR tests

$\begin{array}{llcccc}\text { D1 } & 53 & 1.46 & 1.60 & - & 1.57 \\ \text { D2 } & 60 & 1.40 & 1.55 & 1.70 & 1.59 \\ \text { D3 } & 27 & 1.50 & 1.73 & - & 1.57 \\ \text { D4 } & 89 & 1.90 & 1.95 & - & 1.57 \\ \text { D5.1 } & 67 & - & 1.68 & - & 1.58 \\ \text { D5.2 } & 64 & - & 1.68 & - & 1.6 \\ \text { D5.3 } & 62 & - & 1.68 & - & 1.6 \\ \text { D6.1 } & 25 & - & 1.56 & - & 1.63 \\ \text { D6.2 } & 56 & - & 1.60 & 1.70 & 1.61 \\ \text { D7 } & 84 & - & 1.90 & - & 1.60 \\ \text { D8.1 } & 56 & - & - & - & - \\ \text { D8.2 } & 67 & - & 1.85 & - & 1.55\end{array}$

WP tests

$\begin{array}{llllll}\text { E1 } & 57 & - & 1.62 & - & 1.65 \\ \text { E2.1 } & 66 & - & 1.52 & - & 1.53 \\ \text { E2.2 } & 61 & - & 1.58 & - & 1.60 \\ \text { E2.3 } & 61 & - & 1.59 & - & 1.62 \\ \text { E3 } & 235 & \text { (b) } & 1.50 & - & 1.59 \\ \text { E4 } & 90 \pm 5 & \text { (b) } & 1.75 & - & 1.60\end{array}$

(a) Geometric standard deviation for steady-state particle size.
(b) Very fresh (age<5 minutes).

Particle size also increased with the availability of water vapor in the wind tunnel atmosphere. The particle aerodynamic diameter increased by 1.2 times as the relative humidity of the wind tunnel atmosphere increased from $20 \%$ to $90 \%$; this increase was equivalent to a particle volume increase of 1.7 times. The increase in particle size as the result of water vapor absorption occurred in the $60 \%$ to $90 \%$ range. For steady-state aerosols that resulted from RP/BR combustion (average particle age approximately 28 minutes), the MMAD was measured at $1.60 \mu \mathrm{m}$ at $25 \%$ relative humidity, 1.61 $\mu \mathrm{m}$ at $60 \%$ relative humidity, and $1.95 \mu \mathrm{m}$ at $90 \%$ relative humidity. The corresponding MMAD's for steady-state aerosols that resulted from WP 
TABLE 3.6. SUMMARY OF PARTICLE SIZE VESUS AGE AND RELATIVE HUMIDITY. [MASS MEDIAN AEROSOL DIAMETER VERSUS RELATIVE HUMIDITY AND AEROSOL AGE FOR RP/BR AND WP AEROSOLS [GSD $=1.60 \pm 0.1$ (MAXIMUM OBSERVED DEVIATION FROM AVERAGE) NUMBER OF IMPACTOR SAMPLES SHOWN IN $(n)]$.

\begin{tabular}{|c|c|c|c|c|}
\hline & Relative humidity $(\%)$ : & $225 \%$ & $\sim 60 \%$ & $290 \%$ \\
\hline \multirow[b]{3}{*}{$\mathrm{RP} / \mathrm{BR}$} & & \multicolumn{3}{|c|}{$\operatorname{MMAD}(\mu \mathrm{m})$} \\
\hline & $\begin{array}{l}\text { Steady-state aerosols }(a) \\
\text { Very fresh }(b)\end{array}$ & $\begin{array}{l}1.6(1) \\
--\end{array}$ & $1.61(5)$ & $1.95(2)$ \\
\hline & $\begin{array}{l}\text { Fresh }(c) \\
\text { Aged }(c) \\
\text { Simulated rain }\end{array}$ & $1.5(1)$ & $\begin{array}{l}1.40(2) \\
1.80(2)\end{array}$ & $\begin{array}{l}1.85(1) \\
-- \\
1.80\end{array}$ \\
\hline & $\begin{array}{l}\text { Steady-state aerosols }(a) \\
\text { Very fresh(b) }\end{array}$ & $\begin{array}{l}1.50(1) \\
1.15(1)\end{array}$ & $1.56(6)$ & $\begin{array}{l}1.75(1) \\
1.10(1)\end{array}$ \\
\hline WP & $\begin{array}{l}\text { Fresh (c) } \\
\text { Aged (d) } \\
\text { Simulated rain }\end{array}$ & -- & $\begin{array}{l}1.30(1) \\
1.62(1)\end{array}$ & $\begin{array}{l}-- \\
-- \\
--\end{array}$ \\
\hline
\end{tabular}

(a) Steady-state (time = approximately 28 minutes for RP/BR and 22 minutes

(b) for WP)

(b) Very fresh (time $=<5$ minutes)

(c) Fresh (time = approximately 10 minutes)

(d) Aged ( $t$ ime $=>50$ minutes)

combustion (average particle age approximately 22 minutes) were measured to be $1.50,1.56$, and $1.75 \mu \mathrm{m}$ for $25 \%, 60 \%$, and $90 \%$ relative humidty, respectively. The slightly smaller size of the WP aerosol particles may have been the result of the 6 minute difference in average particle age of the aerosol rather than a difference in the formation and evolution of the aerosols produced from the two phosphorus compounds. However, we did not investigate these differences any further.

Measured MMAD's of the steady-state phosphorus obscurant aerosols ranged between 1.50 and $1.95 \mu \mathrm{m}$. These measurements tend to be slightly larger than previously published values (Holmberg and Moneyhun 1982, Brazell et al. draft report, Spanggord et al. 1985, Gillespie and Johnstone 1955, and Katz et al. 1981) which range from 0.30 to $2.0 \mu \mathrm{m}$. However, when the age of the aerosols at the time of sampling is considered, most of the measurements that are substantially less than $1.50 \mu \mathrm{m}$ resulted from newly 


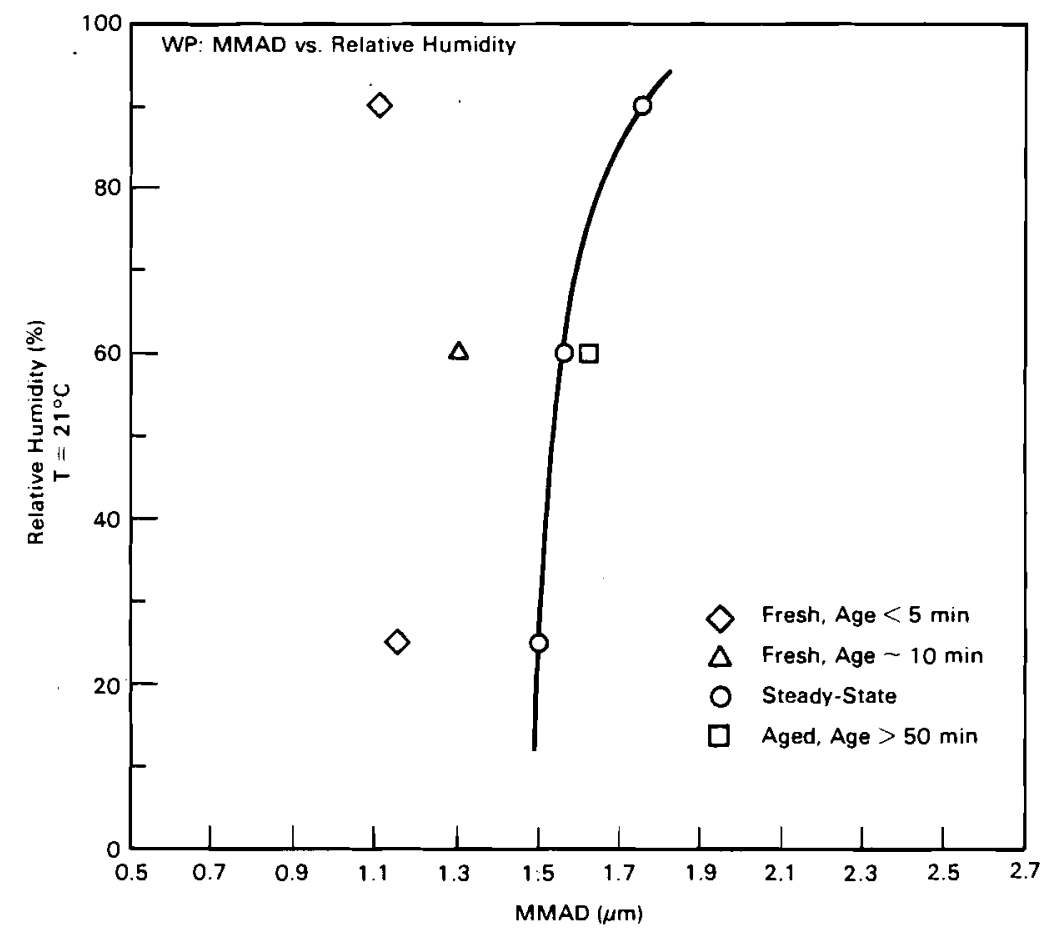

FIGURE 3.7. MASS MEDIAN AERODYNAMIC PARTICLE DIAMETER (MMAD) VERSUS AGE AND RELATIVE HUMIDITY

generated aerosol that is presumably in the initial rapid-growth stage. The measurements of Gillespie and Johnstone (1955) were for phosphoric acid aerosols and ranged between 1.0 and $1.5 \mu \mathrm{m}$. Perhaps the bimodal particle size distribution reported by Spanggord et a1. (1985), with a secondary particle size of approximately $5 \mu \mathrm{m}$, is an artifact. Even a single-mode, or log-normal, particle size distribution often appears bimodal at the extreme upper size range of particle sizing devices that use particle impaction for classifying sizes.

\subsubsection{Chemical Characteristics}

Literature on phosphorus chemistry is extensive and we11-reviewed (Haimann 1972, Riemann and Beukenkamp 1961, Van Wazer 1958). Phosphorus can form polymeric chain and ring compounds valued as softening, complexing, and solubility-controlling agents in fertilizer and detergent industries. Although early work with phosphorus smokes was based on the assumption that the combustion of phosphorus would yield $\mathrm{P}_{4} \mathrm{O}_{10}$, which would yield phosphoric acid upon contact with atmospheric humidity, it became apparent that phosphorus aerosol chemistry was more complex. Using Nuclear Magnetic Resonance (NMR) and gross titration data, Tarnove (1980) suggested the presence of tetrametaphosphoric and pyrophosphoric acid in the smoke at a $1: 6$ mole ratio and concluded that only $\mathrm{P}_{4} \mathrm{O}_{10}$ was formed in the combustion. However, the NMR scans were done on highly concentrated droplets of deposited aerosol which may be subject to marked acid 
hydrolysis, and no data was reported which could preclude tetra-

metaphosphate over trimetaphosphate. Spanggord et a1. (1985) reported that NMR resonances for tri-, tetra-, and hexametaphosphates were broad and virtually indistinguishable. Since the Tarnove (1980) titrations were only reported as totals to $\mathrm{pH} 9$, no estimate of numbers of end versus middle phosphorus groups or of average chain length could be calculated.

Determination of differences between first and second acid endpoint before and after acid hydrolysis and after addition of silver ion to displace the weak third hydrogen from phosphoric acid would have been required to better define the mixture of ortho and polyphosphates (Van Wazer et al. 1954).

Early phosphorus speciation analys is on WP/F aerosol was limited to analys is of only $1 P$ to $8 P$ species, and found over one third of the phosphorus to be in acids greater than 8P (Katz et a1. 1981). In that study, aerosol particulate from a small reactor was trapped in liquid oxygen-cooled cold traps, which were warmed to room temperature prior to water contact. The variation in the data is likely due to variations in treatment, particularly to change in time of water contact, resulting in great overlap of species distributions versus humidity. Brazell et al. (1984) introduced flow ingestion analysis to the speciation procedure, reducing analysis time to 40 minutes, at the expense of the $>13 \mathrm{P}$ species. The more controlled combustion and sampling methods in the Brazell study resulted in measurable correlation of aerosol age and humidity on distribution of condensed phosphates.

The complexity of phosphorus chemical interactions, as influenced by the conditions present at combustion and sampling of the resultant aerosol, is evident from previous studies as discussed above. In this study we have built on these earlier findings by using the wind tunnel to more closely approach field conditions in a controlled manner.

The physical and chemical properties of the aerosols must be characterized before making interpretive evaluations. Plant and soil exposures occurred under steady-state aerosol conditions in the recirculating wind tunnel, which meant that the aerosol was a mixture of fresh and aging particles, resulting in "average" concentrations of polyphosphate species present versus experimental conditions of humidity and wind speed. While freshly generated RP/BR aerosol was not part of the exposure runs, study of such aerosol was necessary to provide experimental data that could directly show the effect of aerosol age.

\subsubsection{Particle Composition}

The composition of the phosphorus obscurant aerosols in the wind tunnel was measured during each exposure test, and during several other tests, to characterize changes in particle composition as affected by relative humidity. A limited amount of data were also generated that measured the change in particle composition with aging. The majority of these results involve the speciation of the phosphorus anions in solution in the particles and the percent of the phosphorus present in the particles as phosphate. These data are presented in the aerosol characterization section of this report. The obscurant aerosols were also characterized for free water and total phosphorus content. 
Measurements of actual, desiccated, and phosphorus mass on the filter samples of the wind tunnel obscurant aerosols were compared to determine ratios of desiccated/actual and phosphorus/actual particulate mass. The actual aerosol mass concentration was multiplied by these ratios to determine the desiccated and phosphorus aerosol mass concentrations for most exposure tests (see Tables 3.1 through 3.4 ). The ratios used for each exposure test are presented in Table 3.7. The amount of free water present on the particles was seen to increase with increasing relative humidity, with the nonevaporatable fraction of the particles decreasing from approximately $90 \%$ at low relative humidities to probably less than $50 \%$ at high humidities. The percentage of the particles made up of phosphorus, by mass, was observed to decrease with increasing relative humidity, from approximately $25 \%$ at low relative humidities to less than $15 \%$ for relative humidities near $90 \%$. The ratio of phosphorus mass to dried mass for all aerosols was apparentiy constant at $29.6 \% \pm 1.3 \%$ (standard deviation of 12 pairs of measurements). This ratio is $94 \%$ of the stoichmetric percentage $(31.6 \%)$ for dry phosphoric acid. Measurements made during the test performed under simulated rain conditions (RP/BR test-D8) revealed a larger phosphorus mass to dried mass ratio. At $45 \%$, this ratio suggests the addition of free water to the suspended particles as they passed through the simulated rain.

The percent of phosphorus, by mass, of the obscurant aerosols was plotted versus relative humidity and compared to results of several other investigators (Figure 3.8). The solid-line curve on the figure represents the equilibrium concentration of an aqueous solution of phosphoric acid; this function was reported to be relatively independent of temperature over a range of $10^{\circ} \mathrm{C}$ to $60^{\circ} \mathrm{C}$ (Tarnove 1980). Data from other investigators was typically calculated from tables listed in their reports or publications (Holmberg and Moneyhun 1982, Brazell et al. 1984, Tarnove 1980, and Burton et al. 1982). The scatter in these data may result from widely varying generation techniques, differing aerosol age at time of sampling, or from alternative methods of sample storage prior to actual analysis. To allow comparison with the phosphoric acid model, the data were plotted versus relative humidity; however, the scatter in the data was generally reduced when data were plotted versus water vapor content. The phosphoric acid equilibrium curve was not applicable in the latter case. Air temperatures which are 1 isted in Figure 3.8 ranged between $19^{\circ} \mathrm{C}$ and $30^{\circ} \mathrm{C}$. The trend seen in Figure 3.8 indicates that the phosphorus content of these aerosols was slightly greater than that of an aqueous phosphoric acid solution at equilibrium. This trend may result from fresh weight loss from aerosol samples during sample collection or to some other measurement error common to most of the data. However, considering the results of phosphorus speciation within the suspended particles, a more probable conclusion may be that a simple phosphoric acid model is insufficient for predicting the complicated chemical composition and evolution occurring within the particles of phosphorus obscurant aerosols. 
TABLE 3.7. RATIO OF DRIED/ACTUAL AND PHOSPHORUS/ACTUAL PARTICULATE MASS

Filter mass comparisons

Relative

$(\%)$

\begin{tabular}{rclc}
\hline $\begin{array}{l}\text { RP/BR RFT-A } \\
\text { (5 exposures) }\end{array}$ & $15-30^{(a)}$ & $\begin{array}{l}0.822 \pm .037(6) \\
(\mathrm{RFT}-\mathrm{A} 1 \& \text { A2) }\end{array}$ & $\begin{array}{c}0.271 \pm .001(3) \\
(\mathrm{RFT}-\mathrm{A} 1)\end{array}$ \\
$\begin{array}{l}\text { RP/BR RFT-B } \\
\text { (9 exposures) }\end{array}$ & $(20-25)$ & - & - \\
RP/BR test D1 & 53 & $0.813 \pm 0.012(2)$ & $0.252 \pm 0.013(8)$ \\
2 & 60 & $0.736-(1)$ & $0.234 \pm 0.007(5)$ \\
3 & 27 & $0.833-(1)$ & $0.251 \pm 0.007(4)$ \\
4 & 89 & $0.499 \pm 0.021(5)$ & $0.141 \pm 0.006(3)$ \\
5 & 64 & $0.937 \pm 0.021(3)$ & $0.224 \pm 0.006(7)$ \\
6.1 & 25 & $0.667 \pm 0.049(3)$ & $0.195 \pm 0.008(3)$ \\
6.2 & 56 & $0.340 \pm 0.044(4)$ & $0.096 \pm 0.002(3)$ \\
7 & 84 & $0.623 \pm 0.031(4)$ & 0.279 \\
$8.1(c)$ & 56 & $0.461 \pm 0.011(3)$ & $0.209 \pm 0.010(3)$ \\
8.2 & 67 & &
\end{tabular}

$\begin{array}{llr}\text { WP test E } & 1 & 57 \\ & 2 & 63 \\ & 3 & 235 \\ & 4 & 90 \pm 5\end{array}$

$0.717 \pm 0.050(6)$
$0.696 \pm 0.009(3)$
$0.819 \pm 0.002(3)$
$0.249 \pm 0.026(5)$

$0.212 \pm 0.011(5)$

$0.208 \pm 0.007(4)$

$0.250 \pm 0.003(3)$

$0.072 \pm 0.008(3)$

\footnotetext{
(a) Average relative humidity (of three wind speed tests) reported for RP/BR Test D5 and WP Test E2.

(b) \pm refers to standard deviation of data set. ( $n$ ) indicates a data set of $n$ separate filter measurements.

(c) Rainout portion of RP/BR Test D8.
}

It may be of interest to pursue this method of characterizing phosphorus aerosols when determining the actual aerosol mass concentration in the field. Actual, or fresh aerosol mass concentration is required during field exposures since it is the aerosol characteristic that is directly related to obscuration. This requirement was detemined in our laboratory as transmission of a He-Ne laser and was not well correlated to phosphorus or dried aerosol mass concentration when a wide range of humidities were considered. Measuring samples of aerosol material for phosphorus content and then converting the measurement to actual aerosol mass concentration, by estimating aerosol age and measuring relative humidi.ty, would el iminate errors resulting from evaporation of the free, or 


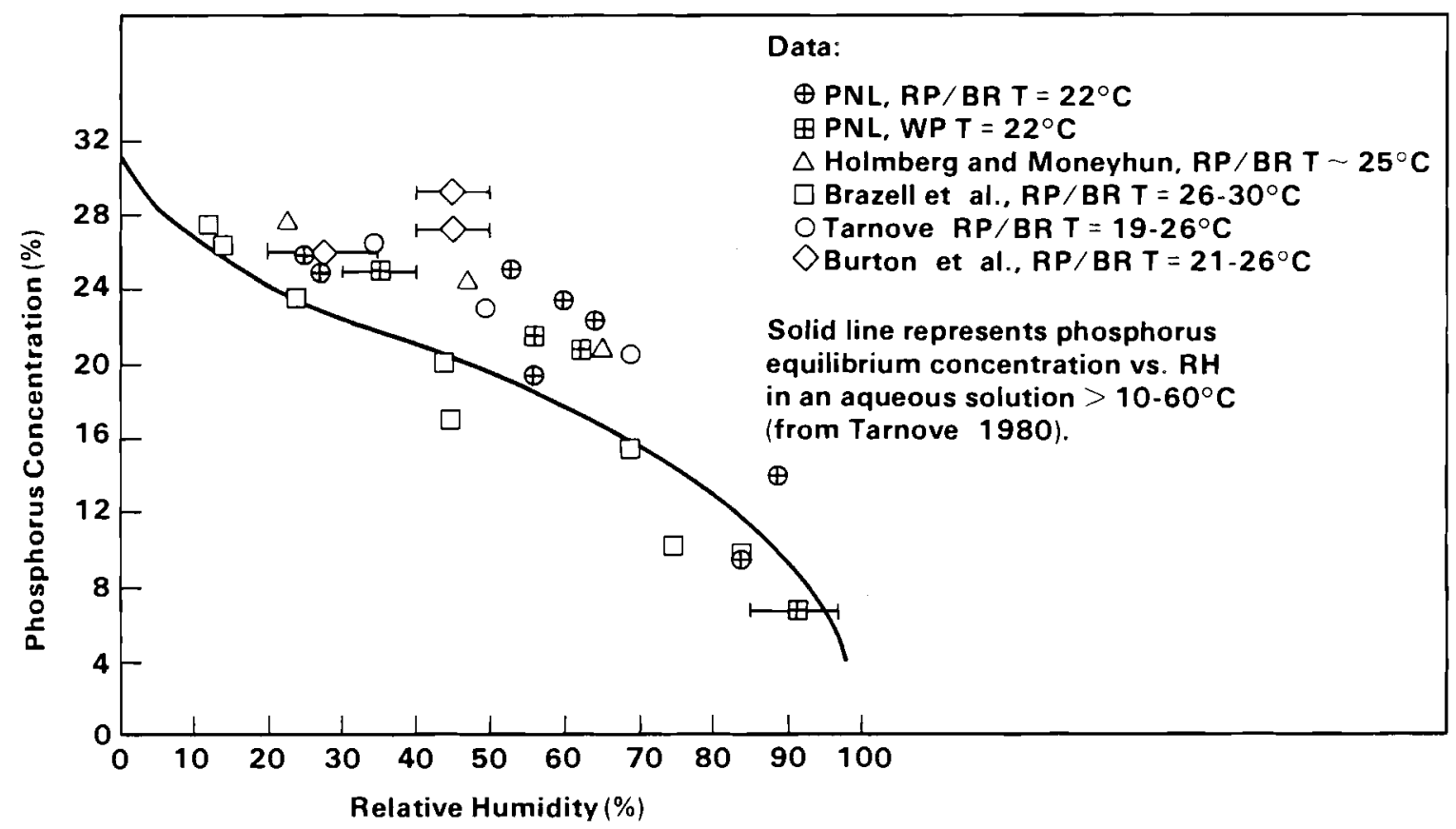

FIGURE 3.8. CHEMICAL COMPOSITION OF AIRBORNE PARTICLES: PERCENT PHOSPHORUS BY MASS IN VARIOUS AEROSOLS GENERATED FROM BOTH RP/BR AND WP

unbound, water in the particles. A similar relationship exists between actual and dried aerosol mass concentration; thus samples could be desiccated and weighed, and the actual aerosol mass concentration calculated.

\subsubsection{Deposition Velocities}

Deposition velocities for phosphorus aerosols onto wet and dry plates were calculated by using average aerosol mass concentration calculations (as $\mathrm{mg} \mathrm{P} / \mathrm{m}^{3}$ taken from Tables 3.1, 3.2, and 3.3). Although there is considerable spread in the data, average values for RP/BR (Tables 3.8 and 3.9) and WP (Table 3.10) are quite similar. Not included in Table 3.9 is the rainout (second hour) of test D8, where the estimated deposition velocity was $.090 \mathrm{~cm} / \mathrm{sec}$. Deposition velocities on several filter types (Table 3.8) averaged .0059 \pm .0008 ( \pm SD) when the GSWP filters were excluded. The latter filters showed an apparent charge attraction effect which was further enhanced by contact to the polystyrene support, causing abnormally high deposition. Increasing deposition rate with increasing humidity and the resulting increase in particle size is suggested, but the range is no greater than the variation between runs. The increased deposition onto a wet versus dry surface is consistently reproducible. The 
TABLE 3.8. DEPOSITION VELOCITIES OF RP/BR SMOKE PARTICLES UNDER VARYING EXPERIMENTAL CONDITIONS

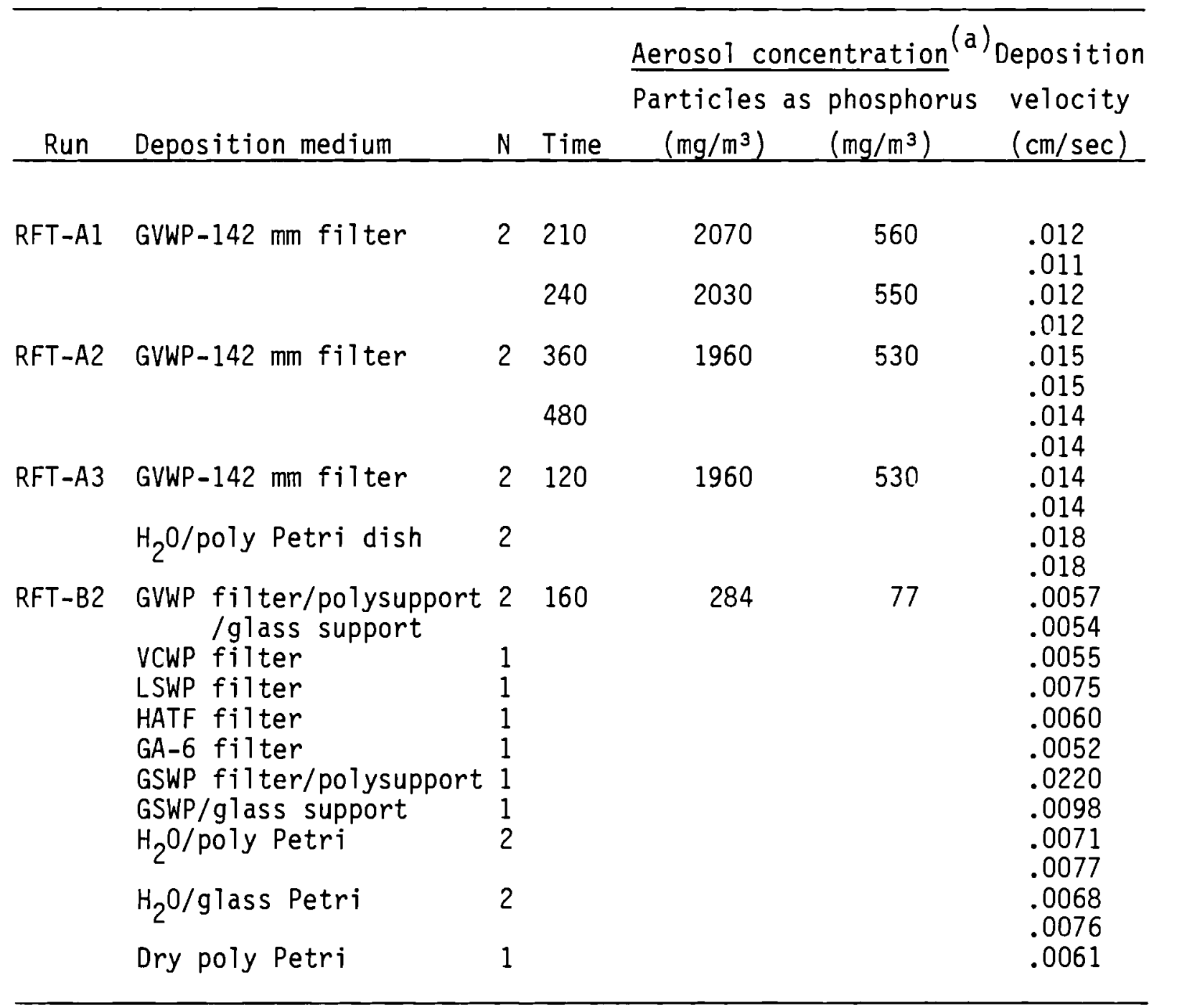

(a) Taken from Tables 3.1 and 3.2 .

(b) Taken from Tables 3.1 and 3.2 . $P$ in aerosol.

data shows reasonable independence of deposition velocity from aerosol concentration when only minor aerosol fluctuations are involved, but not over wide concentration ranges. A small study of deposition onto filter wedges assembled to resemble a simplistic leaf canopy produced an expected deposition pattern favoring tops and windward sides of the simulated leaves. The model was not pursued. 
TABLE 3.9. DEPOSITION VELOCITIES OF RP/BR SMOKE PARTICLES ON WET AND DRY SURFACES(a)

\begin{tabular}{|c|c|c|c|c|c|c|}
\hline est(b) & $\begin{array}{l}\text { Relative } \\
\text { humidity } \\
(\%)\end{array}$ & $\begin{array}{l}\text { Exposure } \\
\text { time } \\
\text { (minutes) }\end{array}$ & $\begin{array}{l}\text { Average aeroso } \\
\text { concentration } \\
\left(\mathrm{mg} \mathrm{P} / \mathrm{m}^{3}\right)\end{array}$ & $\begin{array}{l}\text { Depo } \\
\text { Wet } \\
\text { surface } \\
\text { (cm/sec) }\end{array}$ & $\begin{array}{c}\text { ition ve } \\
\text { Dry } \\
\text { surface } \\
\text { (cm/sec }\end{array}$ & $\begin{array}{l}\text { city } \\
\text { Ratio } \\
\text { (wet/ } \\
\text { dry) } \\
\end{array}$ \\
\hline \multirow[t]{2}{*}{$\begin{array}{l}\text { A3 } \\
\text { D1 } \\
\text { D2 } \\
\text { D3 } \\
\text { D4 } \\
\text { D5.1 } \\
\text { D5.2 } \\
\text { D5.3 } \\
\text { D6.1 } \\
\text { D6.2 } \\
\text { D7 } \\
\text { D8,1st hr }\end{array}$} & \multirow[t]{2}{*}{$\begin{array}{l}25 \\
53 \\
60 \\
27 \\
89 \\
67 \\
64 \\
62 \\
25 \\
56 \\
84 \\
56\end{array}$} & \multirow[t]{2}{*}{$\begin{array}{c}120 \\
240 \\
240(+32)(d) \\
240 \\
240 \\
60 \\
61 \\
61 \\
56 \\
58 \\
118 \\
60\end{array}$} & $\begin{array}{c}530 \\
673 \\
676(639)(d) \\
612 \\
441 \\
591 \\
591 \\
591 \\
630 \\
597 \\
425(\mathrm{e}) \\
\sim 726\end{array}$ & $\begin{array}{l}.018 \\
.022 \\
(.026) \\
.026 \\
.035 \\
.028 \\
.031 \\
.020 \\
.041 \\
.057 \\
.043 \\
.024\end{array}$ & $\begin{array}{l}.014 \\
.016 \\
(.022) \\
.020 \\
.029 \\
.024 \\
.022 \\
.017 \\
.031 \\
.043 \\
.034 \\
.018\end{array}$ & $\begin{array}{l}1.29 \\
1.38 \\
1.18 \\
1.30 \\
1.21 \\
1.17 \\
1.41 \\
1.18 \\
1.32 \\
1.33 \\
1.26 \\
1.33\end{array}$ \\
\hline & & & & \pm .011 & \pm .009 & \\
\hline
\end{tabular}

TABLE 3.10. DEPOSITION VELOCITIES OF WP SMOKE PARTICLES ON WET AND DRY SURFACES(a)

\begin{tabular}{|c|c|c|c|c|c|c|}
\hline \multirow[t]{2}{*}{ Test(f) } & \multirow{2}{*}{$\begin{array}{l}\text { Relative } \\
\text { humidity } \\
\qquad(\%)\end{array}$} & \multirow{2}{*}{$\begin{array}{l}\text { Exposure } \\
\text { time } \\
\text { (minutes) }\end{array}$} & \multirow{2}{*}{$\begin{array}{c}\text { Average aerosol( } \\
\text { concentration } \\
\left(\mathrm{mg} \mathrm{P} / \mathrm{m}^{3}\right)\end{array}$} & \multirow[b]{2}{*}{$\begin{array}{l}\text { Depo } \\
\text { Wet } \\
\text { surface } \\
(\mathrm{cm} / \mathrm{sec})\end{array}$} & \multirow[b]{2}{*}{$\begin{array}{l}\text { ition vel } \\
\text { Dry } \\
\text { surface } \\
(\mathrm{cm} / \mathrm{sec})\end{array}$} & \multirow[b]{2}{*}{$\begin{array}{l}\text { ocity } \\
\text { Ratio } \\
\text { (wet/ } \\
\text { dry) } \\
\end{array}$} \\
\hline & & & & & & \\
\hline $\begin{array}{l}\text { WPE } 1 \\
\text { WPE } 2.1 \\
\text { WPE } 2.2 \\
\text { WPE } 2.3 \\
\text { WPE } 3 \\
\text { WPE } 4 \\
\end{array}$ & $\begin{array}{r}57 \\
66 \\
61 \\
61 \\
35 \\
90 \pm 5\end{array}$ & $\begin{array}{r}240 \\
60 \\
60 \\
60 \\
240 \\
240\end{array}$ & $\begin{array}{l}625 \\
410 \\
440 \\
490 \\
515 \\
405\end{array}$ & $\begin{array}{l}.026 \\
.030 \\
.034 \\
.033 \\
.024 \\
.038 \\
\end{array}$ & $\begin{array}{l}.018 \\
.024 \\
.026 \\
.029 \\
.017 \\
.028\end{array}$ & $\begin{array}{l}1.43 \\
1.22 \\
1.31 \\
1.13 \\
1.39 \\
1.33\end{array}$ \\
\hline Averages & & & & $.031 \pm .005$ & $.024 \pm .05$ & $1.30 \pm .11$ \\
\hline
\end{tabular}
(a)
Wet surface $=$ water in polystyrene Petri dish bottom;
(b) dry surface $=$ polystyrene Petri dish cover.
(c) See exposure conditions, Tables 2.2 and 2.3 .
(d) Taken from Tables $3.1,3.2$ and 3.3 .
$639 \mathrm{mg} \mathrm{P} / \mathrm{m}^{3}=$ Average aerosol concentration when including the 32 minutes of decreasing smoke to which the static deposition plates
(f) Estimated value.
Taken from Table 3.4.
(e) were exposed.
g) See exposure conditions Table 2.4 . 


\subsubsection{Phosphate-Phosphorus}

3.1.2.3.1 Decomposition of polyphosphates in the "dry" state. Aging of aerosol deposited on dry polystyrene plates or collected on glass fiber filters showed the expected rapid breakdown to phosphate. A rough estimate of this conversion is shown in Table 3.11. This estimate is based on comparison of phosphate and total phosphorus concentrations for steady-state aerosols, and is compiled from several tests performed at a room temperature of $22{ }^{\circ} \mathrm{C}$ and relative humidity of $20 \%$ to $30 \%$. The 1 ist presented in Table 3.11 suggests a more rapid breakdown rate than that reported by Spanggord et al. (1985) for WP/F and RP/BR burn residues, where a residue half-life of 49 hours was reported for conversion to phosphoric acid. The variation in breakdown rate is not surprising since such factors as humidity and smoke particulate concentration (and the resultant $\mathrm{pH}$ ) would have a marked effect on the actual hydrolys is rate. Rapid water contact was necessary to slow the breakdown of polyphosphates.

\subsubsection{Particle Size Distribution Effects}

The general trend in percent phosphorus as phosphate versus particle size for RP/BR burns (Table 3.12) is for a decrease in phosphate with decreasing particle size, though some exceptions are noted. Usually, for the WP runs (Table 3.13). Phosphate values, again, were single determinations on each impactor stage. The time between sampling and water contact is critical, as discussed in the previous paragraph. Foil-collected impactor stages tended to require slightly more time prior to water contact; efficiency also improved with practice.

TABLE 3.11. HYDROLYSIS VERSUS AGE PRIOR TO WATER LEACH

\begin{tabular}{|c|c|c|c|c|}
\hline & $\begin{array}{c}\text { Time to } \\
\mathrm{H}_{2} \mathrm{O} \text { contact }(\mathrm{hr})\end{array}$ & $\mathrm{N}$ & $\% \mathrm{PO}_{4}^{3}$ & $\begin{array}{l}\text { - P/total phosphorus } \\
\pm \text { Standard deviation }\end{array}$ \\
\hline & $\begin{aligned} & 0^{(a)} \\
&<0.1(b) \\
& 0.3-0.8(c) \\
& 2(c) \\
&>24(b)\end{aligned}$ & $\begin{array}{r}33 \\
15 \\
16 \\
3 \\
2\end{array}$ & $\begin{array}{r}25.2 \\
26.0 \\
51.8 \\
61.9 \\
100\end{array}$ & $\begin{array}{l}2.8 \\
2.1 \\
1.8 \\
7.0 \\
2\end{array}$ \\
\hline $\begin{array}{l}(a) \\
(b) \\
(c)\end{array}$ & $\begin{array}{l}\text { Bubbler sampler, ra } \\
\text { Aerosol filter samp } \\
\text { Static deposition c } \\
\text { after end of test. }\end{array}$ & & $\begin{array}{l}\text { samplin } \\
\text { time s1 }\end{array}$ & $\begin{array}{l}\text { of aerosol. } \\
\text { ted is time to } \mathrm{H}_{2} \mathrm{O} \text { c }\end{array}$ \\
\hline
\end{tabular}


TABLE 3.12. PHOSPHATE CONTRIBUTION VERSUS PARTICLE SIZE FOR RP/BR AEROSOLS AT THREE HUMIDITIES AND WIND SPEEDS

\begin{tabular}{|c|c|c|c|c|c|c|c|c|c|c|}
\hline \multicolumn{2}{|c|}{$\begin{array}{l}\text { Relative } \\
\text { humidity (\%) }\end{array}$} & 27 & 53 & 56 & 56 & 89 & 84 & 84 & 64 & 60 \\
\hline \multicolumn{2}{|c|}{$\begin{array}{l}\text { Wind speed } \\
(\mathrm{m} / \mathrm{s})\end{array}$} & 0.9 & 0.9 & 0.9 & 0.9 & 0.9 & 0.9 & 0.9 & 2.0 & 4.5 \\
\hline Test run & ID \# & $D 3^{(a)}$ & D1 & D6.2 & $\mathrm{D} 6.2$ & D4 & D7 & D7 & D5.2 & D2 \\
\hline $\begin{array}{l}\text { Sampling } \\
\text { method }\end{array}$ & & Foil & Foil & Foil & Pan & Foil & Foil & Pan & Foil & Foil \\
\hline \multicolumn{11}{|c|}{$\begin{array}{lc}\text { Cascade } & \text { Approximate } \\
\text { impactor } & \text { particle } \\
\text { stage } & \text { size } \\
& (\mu \mathrm{m})\end{array}$} \\
\hline $\begin{array}{l}0 \\
1 \\
2 \\
3 \\
4 \\
5 \\
6 \\
7\end{array}$ & $\begin{array}{l}>9 \\
7.5 \\
4.8 \\
3.2 \\
2.1 \\
1.2 \\
0.65 \\
0.42\end{array}$ & $\begin{array}{r}\text { ND(b) } \\
41.5 \\
45.2 \\
47.7 \\
44.7 \\
40.9 \\
36.1 \\
33.5\end{array}$ & $\begin{array}{l}33.4 \\
33.5 \\
35.9 \\
32.6 \\
28.5 \\
26.5 \\
26.5 \\
27.8\end{array}$ & $\begin{array}{l}34.4 \\
38.5 \\
33.7 \\
35.4 \\
34.7 \\
29.9 \\
33.0 \\
26.7\end{array}$ & $\begin{array}{l}24.7 \\
30.4 \\
30.9 \\
28.2 \\
30.9 \\
28.4 \\
26.1 \\
23.3\end{array}$ & $\begin{array}{l}23.2 \\
25.4 \\
21.4 \\
16.9 \\
16.0 \\
14.0 \\
13.3 \\
20.6\end{array}$ & $\begin{array}{l}27.0 \\
28.7 \\
28.3 \\
20.5 \\
19.2 \\
18.1 \\
23.9 \\
25.6\end{array}$ & $\begin{array}{l}26.2 \\
30.1 \\
28.5 \\
21.8 \\
19.1 \\
17.0 \\
16.5 \\
24.1\end{array}$ & $\begin{array}{l}23.5 \\
31.2 \\
31.9 \\
31.4 \\
29.2 \\
23.0 \\
19.3 \\
22.5\end{array}$ & $\begin{array}{l}32.9 \\
27.9 \\
28.0 \\
27.4 \\
24.7 \\
21.0 \\
16.8 \\
19.4\end{array}$ \\
\hline Filter & $<.33$ & 16.2 & 26.8 & 13.1 & 22.2 & 48.1 & 17.5 & 15.0 & ND. ${ }^{2}$ & 15.5 \\
\hline
\end{tabular}

(a) Analysis of $D 3$ done on 6-day old unpreserved samples, which should show some increase in $\mathrm{PO}_{4}{ }^{3^{-}}$with

(b) ${ }_{\mathrm{ND}}^{\text {age }}=$ not determined. 
TABLE 3.13. PHOSPHATE CONTRIBUTION VERSUS PARTICLE SIZE FOR WP AEROSOLS AT THREE HUMIDITIES AND WIND SPEEDS $(\mathrm{N}=1)$

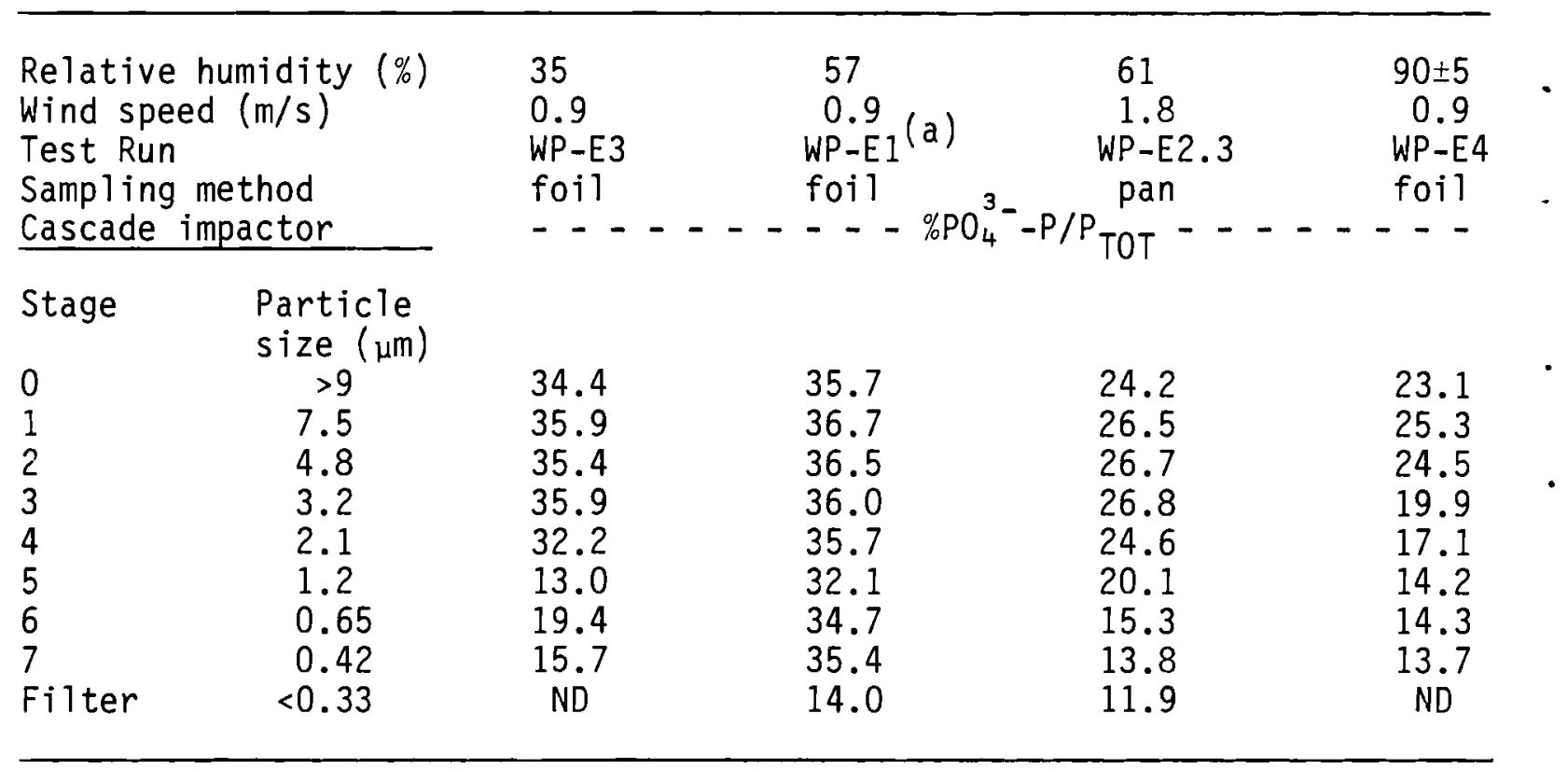

Water contact was delayed up to 30 minutes for this sample set, likely resulting in an increase in conversion to phosphate. All other contacts were done within 1 minute of weighing the foil or disassembling the pan-only impactor.

2 Phosphate contribution peaks in stages 1 to 2 , falls, and then increases slightly in stage 7. The peak stage of phosphate was not so well defined.

\subsubsection{Polyphosphate Distributions}

3.1.2.5.1 Aerosol age effects. The actual speciation of phosphorus in the aerosol that deposits on soils or vegetation depends on the humidity of the air, the temperature, and probably the composition of the air during ignition and subsequent aging in the wind tunnel or in a natural environment. The aerosol was sampled after it reached steady-state concentrations in the recirculating wind tunnel, with fresh smoke being continually added. The aerosol was thus a mixture of fresh and aging particles. Several small-scale ignitions of RP/BR were done, with the burn plume first sampled directly into bubbler traps and sampled again a short time later in the exposure section (Table 3.14). Actual water mass measurements corresponded to $20 \%$ relative humidity in the plume and $26 \%$ relative humidity in the test chamber and wind tunnel. The large amount of species not recovered at the short sampling periods apparently corresponded to very large polyphosphates, which break down as the aerosol ages. The 30-minute sampling point would correspond to the earliest sampling time during routine exposures of plants and soils. Only single analysis runs were done on each sample, due to the length of time required per analysis. 
TABLE 3.14. AGING OF RP/BR AEROSOL AT CONSTANT HUMIDITY $(\mathrm{N}=1)$

\begin{tabular}{|c|c|c|c|c|}
\hline \multicolumn{5}{|c|}{ PNL Data } \\
\hline $\begin{array}{l}\text { Sampling } \\
\text { time (min }\end{array}$ & ) & 5 & $\frac{1 c a}{5}$ & \\
\hline Location & $\begin{array}{l}\text { Plume } \\
\text { chamber }\end{array}$ & Burn & Tunne 1 & Tunne 1 \\
\hline \multicolumn{2}{|l|}{ Species $^{(a)}$} & \multicolumn{2}{|c|}{${ }^{-} / \mathrm{P}_{\mathrm{TOT}}$} & \\
\hline $\begin{array}{l}1 P \\
2 P \\
3-4 P \\
5-13 P \\
14-20 P \\
>20 P\end{array}$ & $\begin{array}{r}2.6 \\
1.9 \\
5.2 \\
34.0 \\
9.5 \\
46.9\end{array}$ & $\begin{array}{r}5.0 \\
2.5 \\
7.7 \\
47.2 \\
12.2 \\
25.4\end{array}$ & $\begin{array}{r}9.9 \\
4.1 \\
8.8 \\
44.9 \\
8.1 \\
24.3\end{array}$ & $\begin{array}{c}24.5 \\
10.2 \\
14.0 \\
44.0 \\
7.4 \\
0\end{array}$ \\
\hline
\end{tabular}

3.1.2.5.2 Sample matrix and time to analysis. Once sampled into an aqueous solution, hydrolysis of the aerosol to polyphosphates will slow somewhat but partial hydrolysis steps will continue. Brazell et al. (1984) showed the loss of $>13 \mathrm{P}$ and peaking of 5-13 $\mathrm{P}$ levels in an aqueous solution in two days, with significant increase in trimetaphosphate levels. Katz et a1. (1981) showed a 70\% drop in concentration of 5-8 $\mathrm{P}$ species in three days. We found a doubling of trimetaphosphate levels in less than two days in smoke-dosed de-ionized water (see Figure 3.9; shown in Table 3.33 ), followed by an additional $77 \%$ increase by day 9 , on a single determination. Since all of our speciation measurements were conducted using de-ionized water alone or with EDTA amendments, it must be stressed that the actual hydrolysis of phosphorus aerosols under environmental conditions would be directly dependent on the resulting matrix. This was demonstrated by Poston et al. (1985), where water hardness, ionic makeup, and neutralization caused marked changes in species distribution with time.

3.1.2.5.3 Humidity effects. When sampling with in RP/BR burn plumes at increasing humidities (Table 3.15), minor changes were seen in the phosphate ratios, while a marked reduction of higher polyphosphate species occurred. Again, low initial phosphate values were observed in all fresh smokes. Under steady-state conditions, deposition of RP/BR or WP aerosols onto static water coupons (Tables 3.16 and 3.17) showed species distributions very similar to those given by bubbler samples (Table 3.18 and Figure 3.10; and Table 3.19 and Figure 3.11). Concentrations of phosphate decreased while those of 2 to $4 \mathrm{P}$ increased with increasing humidity for both RP/BR and WP aerosols, as summarized in Table 3.20. Although the Brazell et al. (1984) study reported a decrease in phosphate with increasing humidity, that study reported a marked increase in $>13 \mathrm{P}$ 


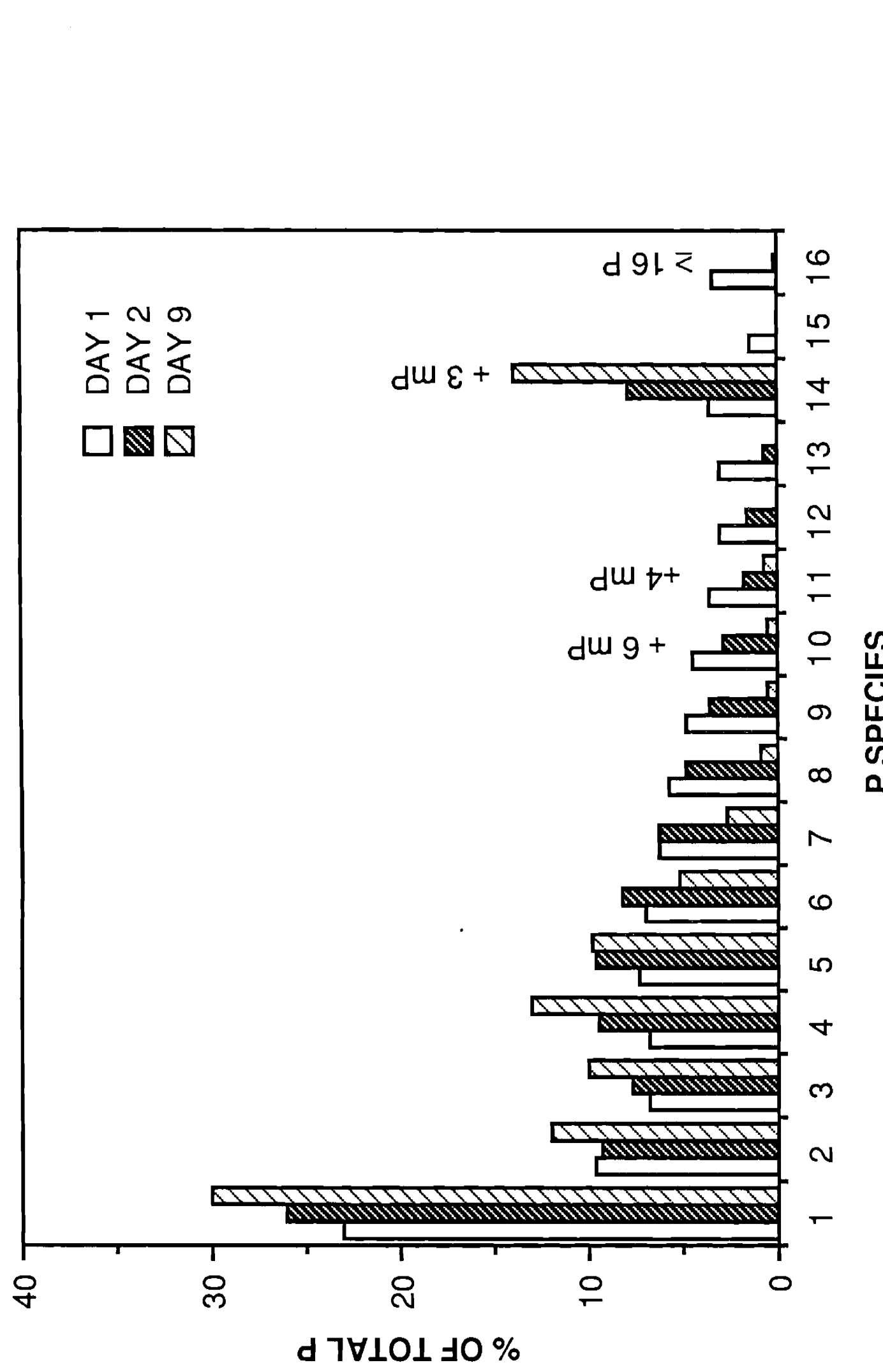

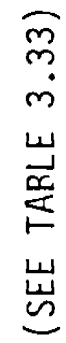

崖

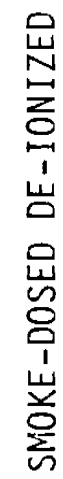

욤

는

क 只

号

옹
옹
홍
옴

岩

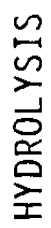

$\dot{m}$

峁 
TABLE 3.15. SPECIATION VERSUS HUMIDITY IN FRESH RP/BR AEROSOL (AQUEOUS IMPINGER COLLECTIONS; $N=1$ )

\begin{tabular}{|c|c|c|c|}
\hline \multirow[b]{2}{*}{ Species } & \multicolumn{3}{|c|}{ Relative humidity } \\
\hline & $\begin{array}{l}5 \% \\
---\end{array}$ & $\stackrel{2}{20 \%}_{\text {TOT }}$ & $\begin{array}{c}95 \% \\
---\end{array}$ \\
\hline $\begin{array}{l}1 P \\
2 P \\
3-4 P \\
5-13 P\end{array}$ & $\begin{array}{r}2.7 \\
0.7 \\
2.0 \\
23.5\end{array}$ & $\begin{array}{r}2.6 \\
1.9 \\
5.2 \\
34.0\end{array}$ & $\begin{array}{r}3.0 \\
2.0 \\
6.6 \\
39.1\end{array}$ \\
\hline $\begin{array}{c}14-20 \mathrm{P} \\
>20 \mathrm{P} \\
\mathrm{HPO}_{3}^{2}-\mathrm{P}\end{array}$ & $\begin{aligned} & N D^{(a)} \\
& 72.5 \\
< & 0.2\end{aligned}$ & $\begin{array}{r}9.5 \\
46.9 \\
\leq \quad 0.1\end{array}$ & $\begin{array}{r}12.2 \\
37.2 \\
0.1\end{array}$ \\
\hline
\end{tabular}

(a) Not quantified; concentration low

species with increasing humidity, a phenomena that we did not see with either fresh or steady-state aerosol. However, when the Brazell team ignited RP/BR and WP/F under free-burn conditions more closely resembling our steady-state conditions (Brazell et a1. 1984), no meta species or species $>11 \mathrm{P}$ were observed, and values of the lower $\mathrm{P}$ species resembled those determined here. 
TABLE 3.16. PHOSPHORUS SPECIATION OF RP/BR AEROSOLS VERSUS HUMIDITY AT 0.9 $M / S(2 \mathrm{mph})$ WIND SPEED AND $22^{\circ} \mathrm{C}$ : STATIC DEPOSITION ONTO WATER ( $N=1)$

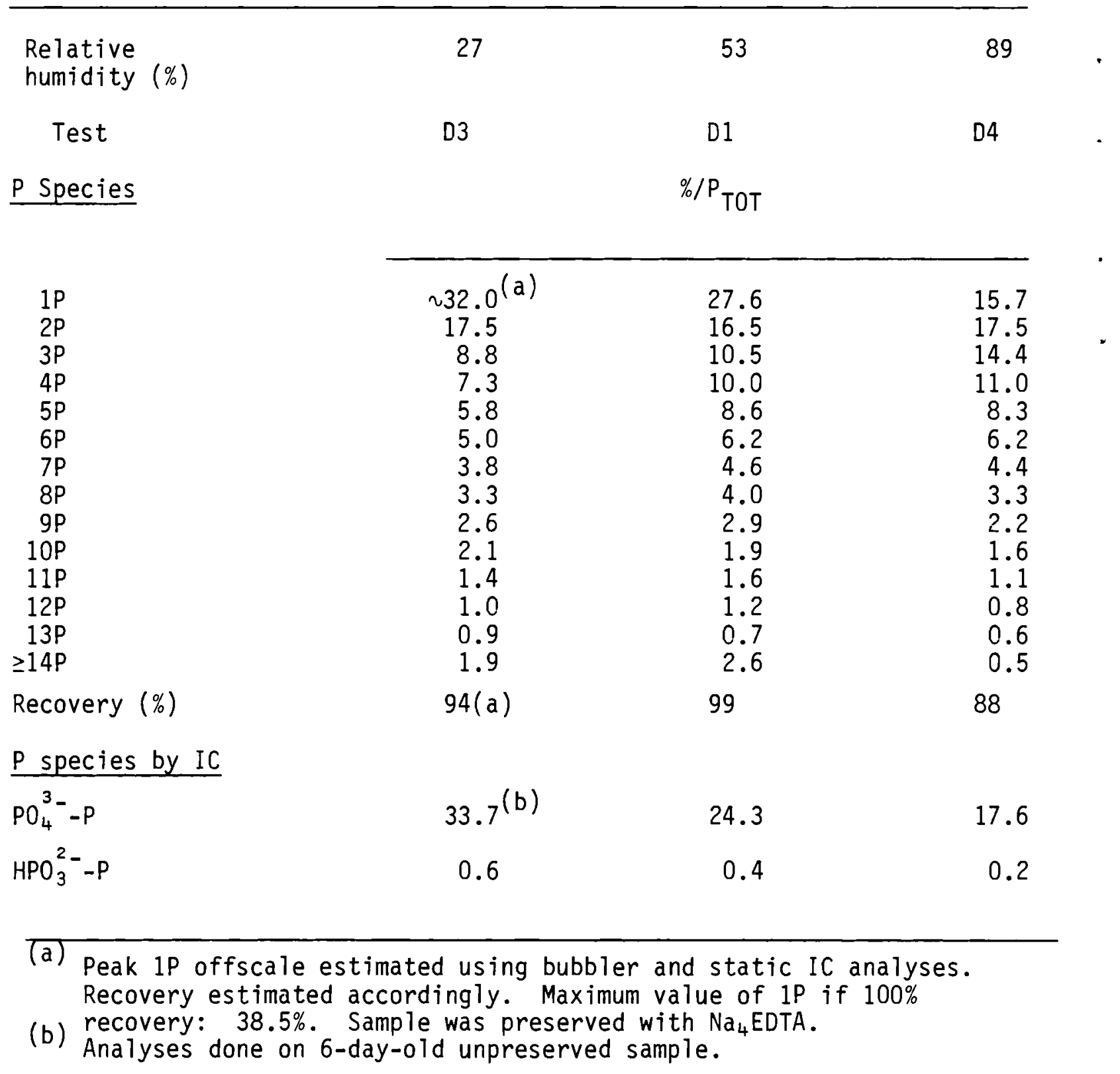


TABLE 3.17. PHOSPHORUS SPECIATION OF WP AEROSOL VERSUS HUMIDITY AT AT 0.9 M/SEC WIND SPEED (2 mph) AND $22^{\circ} \mathrm{C}$ : STATIC DEPOSITION ONTO WATER $(N=1)$

\begin{tabular}{|c|c|c|c|}
\hline $\begin{array}{l}\text { Relative } \\
\text { humidity (\%) }\end{array}$ & 35 & 57 & $90 \pm 5^{(a)}$ \\
\hline Test & WP-E3 & WP-E1 & WP-E4 \\
\hline P species & \multicolumn{3}{|c|}{$\% / P_{\text {TOT }}$} \\
\hline $\begin{array}{r}1 P \\
2 P \\
3 P \\
4 P \\
5 P \\
6 P \\
7 P \\
8 P \\
9 P \\
10 P \\
11 P \\
12 P \\
13 P \\
\geq 14 P\end{array}$ & $\begin{array}{r}30.3 \\
15.6 \\
8.1 \\
7.3 \\
6.1 \\
5.4 \\
4.4 \\
3.9 \\
3.2 \\
2.7 \\
1.8 \\
1.6 \\
1.2 \\
4.4\end{array}$ & $\begin{array}{r}21.3 \\
10.9 \\
6.8 \\
6.5 \\
6.4 \\
5.5 \\
5.0 \\
4.8 \\
4.1 \\
3.8 \\
2.9 \\
2.4 \\
1.6 \\
8.9\end{array}$ & $\begin{array}{r}18.1 \\
16.1 \\
13.4 \\
11.6 \\
9.1 \\
7.1 \\
5.5 \\
4.6 \\
3.3 \\
2.7 \\
1.8 \\
1.5 \\
1.0 \\
2.9\end{array}$ \\
\hline Recovery $(\%)$ & 96 & 91 & 99 \\
\hline \multicolumn{4}{|c|}{ P species by IC } \\
\hline $\mathrm{PO}_{4}^{3-}-\mathrm{P}$ & 31.3 & 21.4 & 17.4 \\
\hline $\mathrm{HPO}_{3}^{2-}-\mathrm{P}$ & 0.21 & 0.26 & 0.06 \\
\hline
\end{tabular}
(a) Added steam generation caused a jump in humidity during run
from $-85 \%$ to $\sim 95 \%$. 
TABLE 3.18. PHOSPHORUS SPECIATION OF RP/BR AEROSOL VERSUS HUMIDITY AT 0.9 $\mathrm{M} / \mathrm{S}$ (2 mph) WIND SPEED AND $22^{\circ} \mathrm{C}$ : AQUEOUS IMPINGER SAMPLES $(\mathrm{N}=1)$

\begin{tabular}{|c|c|c|c|c|c|c|}
\hline $\begin{array}{l}\text { Relative } \\
\text { humidity }(\%)\end{array}$ & 27 & 25 & 53 & 56 & 84 & \\
\hline Test & $D 3^{(a)}$ & D6. 1 & D1 & $D 6.2^{(\mathrm{c})}$ & D7 & D7 \\
\hline$P_{\text {species }}^{(b)}$ & \multicolumn{6}{|c|}{$\% / P_{\text {TOT }}$} \\
\hline $\begin{array}{l}1 P \\
2 P \\
3 P \\
4 P \\
5 P \\
6 P \\
7 P \\
8 P \\
9 P \\
10 P \\
11 P \\
12 P \\
13 P \\
\geqq 14 P(+3 m P)\end{array}$ & $\begin{array}{r}26.0 \\
15.4 \\
8.9 \\
7.3 \\
6.5 \\
5.5 \\
4.7 \\
3.7 \\
3.3 \\
2.9 \\
1.7 \\
1.4 \\
1.1 \\
2.4\end{array}$ & $\begin{array}{r}23.4 \\
12.4 \\
7.4 \\
6.6 \\
6.7 \\
5.9 \\
5.7 \\
4.6 \\
3.0 \\
2.6 \\
2.4 \\
1.9 \\
0.9 \\
3.7\end{array}$ & $\begin{array}{r}24.1 \\
16.0 \\
11.7 \\
10.1 \\
8.2 \\
6.7 \\
5.2 \\
4.1 \\
2.8 \\
2.8 \\
1.8 \\
1.4 \\
1.0 \\
2.8\end{array}$ & $\begin{array}{r}21.9 \\
19.5 \\
13.5 \\
12.5 \\
9.7 \\
7.1 \\
4.4 \\
2.8 \\
2.1 \\
1.4 \\
0.7 \\
0.6 \\
0.3 \\
3.4\end{array}$ & $\begin{array}{r}16.9 \\
18.5 \\
14.9 \\
12.4 \\
8.7 \\
6.7 \\
4.7 \\
3.1 \\
2.2 \\
1.8 \\
0.9 \\
0.8 \\
0.5 \\
1.5\end{array}$ & $\begin{array}{r}18.6 \\
19.3 \\
14.0 \\
11.0 \\
8.9 \\
7.2 \\
5.4 \\
3.6 \\
2.6 \\
2.0 \\
1.5 \\
0.9 \\
0.7 \\
1.5\end{array}$ \\
\hline Recovery (\%) & 92 & 88 & 100 & 100 & 94 & 97 \\
\hline \multicolumn{7}{|c|}{ P species by IC } \\
\hline $\mathrm{PO}_{4}^{3}-\mathrm{P}$ & 27.8 & 26.2 & 22.6 & 21.0 & 15.5 & 16.8 \\
\hline $\mathrm{HPO}_{3}^{2}-\mathrm{P}$ & 0.6 & 0.8 & 0.4 & 0.3 & 0.2 & 0.2 \\
\hline
\end{tabular}

\footnotetext{
(a) HPLC analysis done on a 6-day-old sample, preserved with added EDTA and adjusted to $\mathrm{pH} 7.1$. IC data on this run done on unpreserved

(b) ${ }_{n P}=\left(P_{n} 0_{3 n+1}\right)^{(n+2)-}$ chain polyphosphates. $n m P=\left(P_{n} 0_{3 n}\right)^{n-}$ cyclic metaphosphates.

(c) Analysis done on a 2-day-old unpreserved sample. Level of $\mathrm{PO}_{4}^{3-}-\mathrm{P}$ by IC on fresh sample was $19.1 \%$.
} 


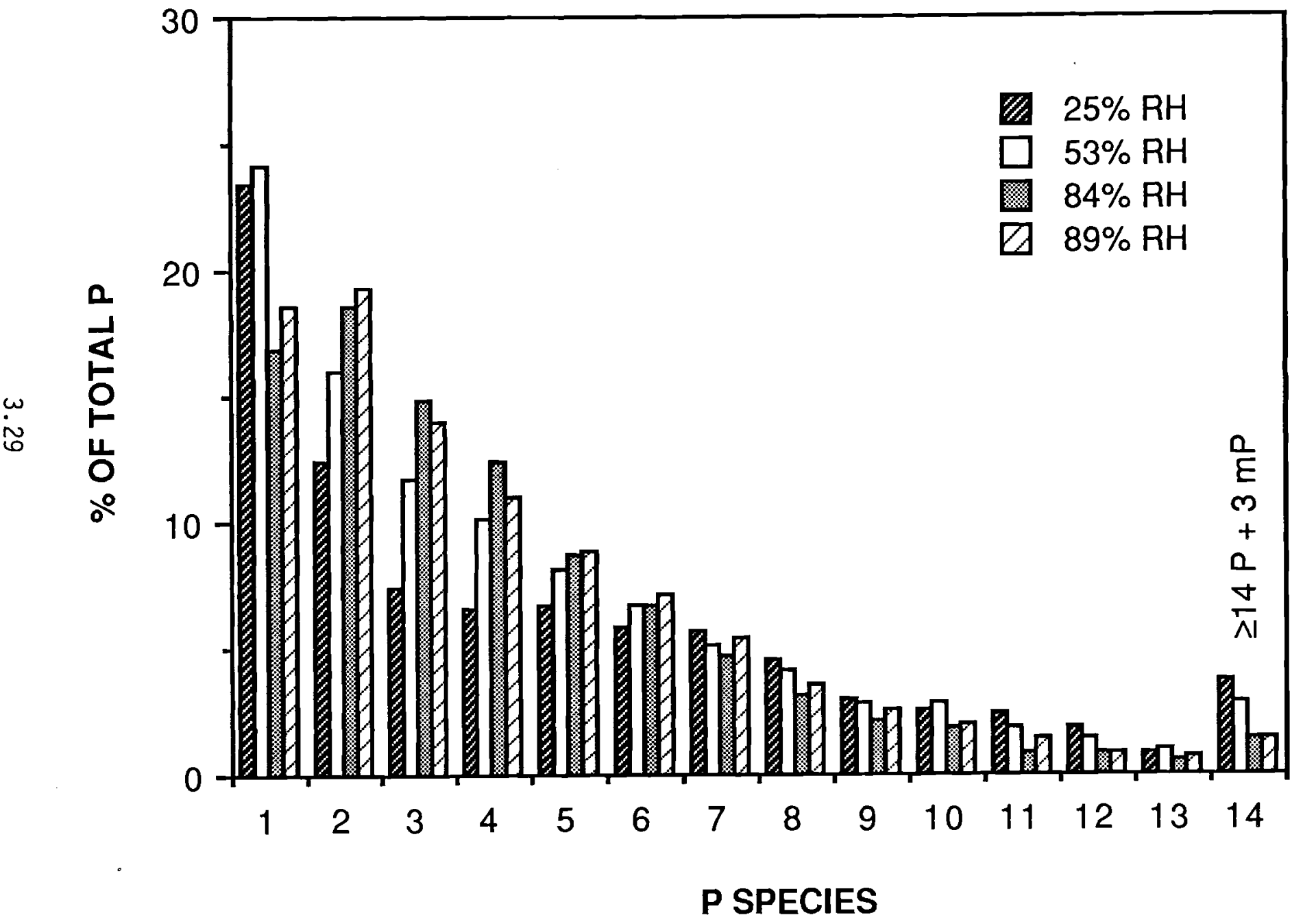

FIGURE 3.10. PHOSPHORUS SPECIATION OF RP/BR AEROSOL VERSUS HUMIDITY AT 0.9 M/S (2 mph) WIND SPEED AND $22^{\circ} \mathrm{C}$ : AQUEOUS IMPINGER SAMPLES $(N=1)$ 
TABLE 3.19. PHOSPHORUS SPECIATION OF WP AEROSOLS VERSUS HUMIDITY AT 0.9 $M / S$ WIND SPEED AND $22^{\circ} \mathrm{C}$ : AQUEOUS IMPINGER SAMPLES $(N=1)$

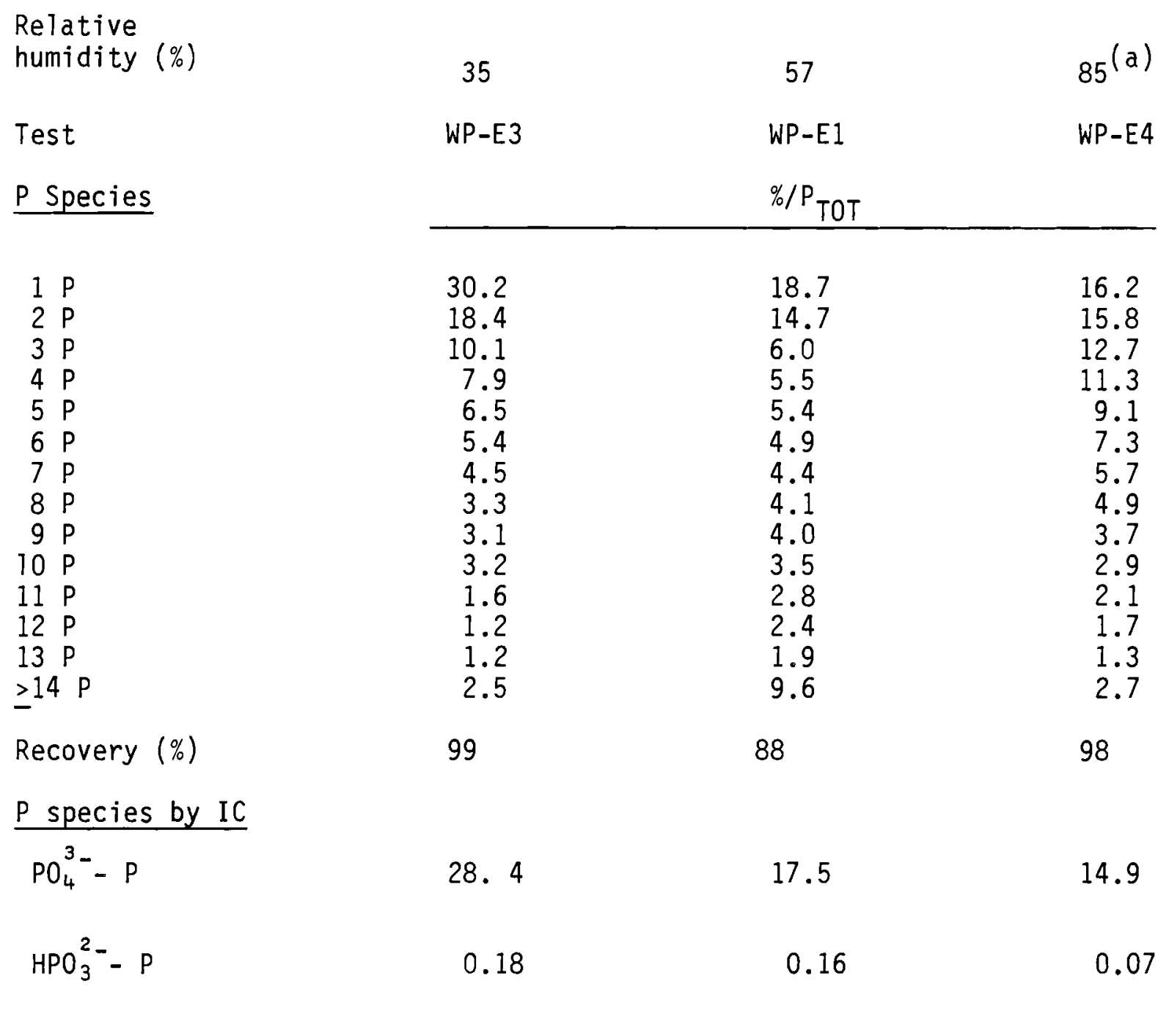

(a) Bubbler sample taken prior to jump in humidity from $\sim 85 \%$ to $\sim 95 \%$. 


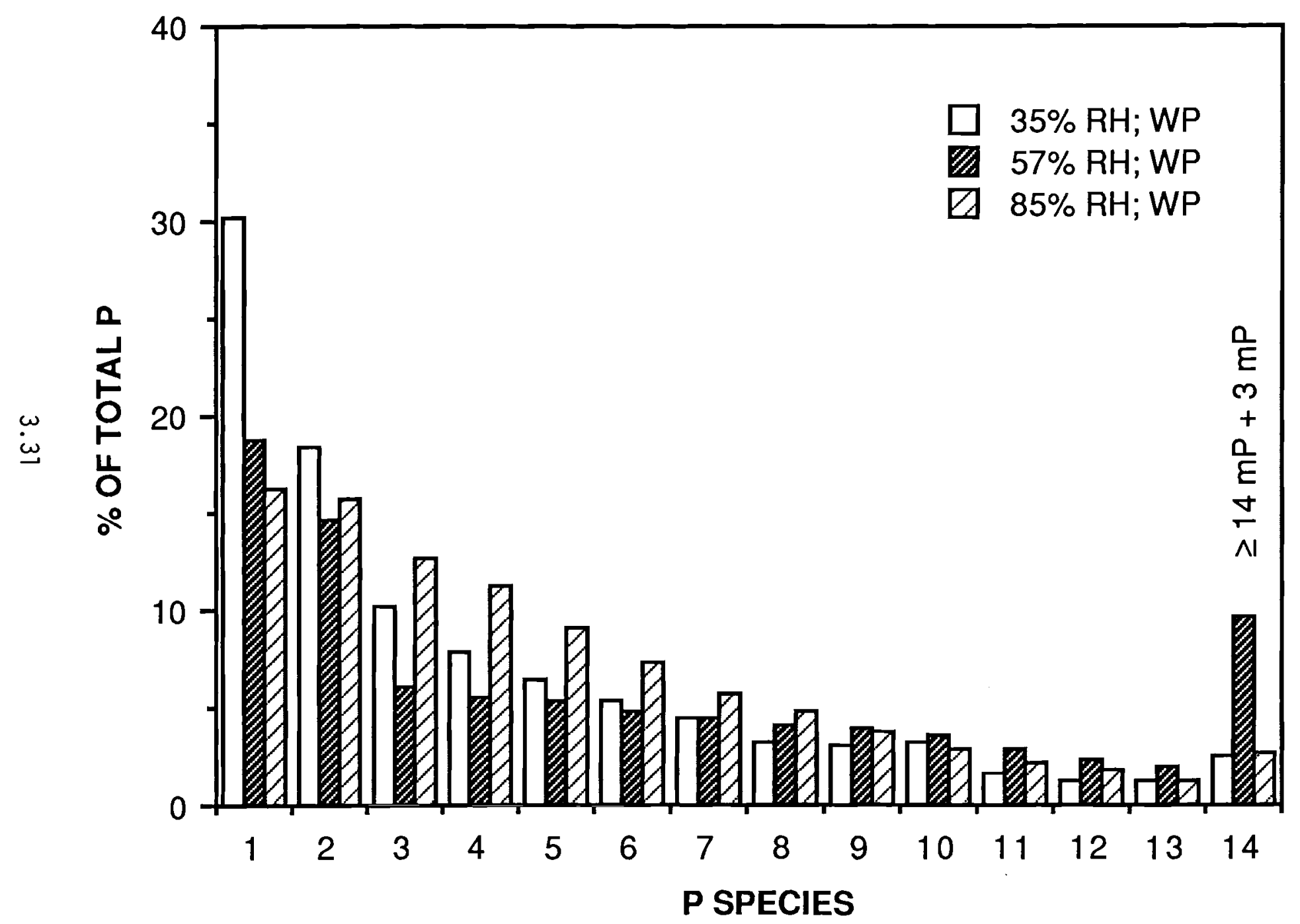

FIGURE 3.11. PHOSPHORUS SPECIATION OF WP AEROSOLS VERSUIS HUMIDITY AT $0.9 \mathrm{M} / \mathrm{S}$ WIND SPEED AND $22^{\circ} \mathrm{C}$ : AQUEOUS IMPINGER SAMPLES ( $\left.N=1\right)$ 
TABLE 3.20. PHOSPHORUS SPECIATION VERSUS HUMIDITY IN STEADY-STATE

AEROSOLS, AS SUMMARIZED FROM TABLES 3.18 and 3.19

\begin{tabular}{|c|c|c|c|c|c|c|}
\hline \multirow[b]{2}{*}{$\begin{array}{l}\text { Relative } \\
\text { humidity }(\%)\end{array}$} & \multicolumn{3}{|c|}{$\mathrm{RP} / \mathrm{BR}$} & \multicolumn{3}{|c|}{ WP } \\
\hline & $\overline{27}$ & 53 & 89 & $\overline{35}$ & 57 & 85 \\
\hline Species & & & & & & \\
\hline $\begin{array}{l}1 P \\
2 P \\
3-4 P \\
5-13 P \\
14-2 O P \\
>2 Q P \\
\mathrm{HPO}_{3}-P\end{array}$ & $\begin{array}{r}26.0 \\
15.4 \\
16.3 \\
30.8 \\
2.4 \\
7.6 \\
0.6\end{array}$ & $\begin{array}{l}24.1 \\
16.0 \\
21.8 \\
34.0 \\
2.8 \\
w 0 \\
0.4\end{array}$ & $\begin{array}{r}18.6 \\
19.3 \\
25.0 \\
32.8 \\
1.5 \\
2.7 \\
0.2\end{array}$ & $\begin{array}{r}30.2 \\
18.4 \\
18.0 \\
30.0 \\
2.5 \\
0.9 \\
0.2\end{array}$ & $\begin{array}{r}18.7 \\
14.7 \\
11.5 \\
33.4 \\
9.6 \\
12.1 \\
0.2\end{array}$ & $\begin{array}{r}16.2 \\
15.8 \\
24.0 \\
38.7 \\
2.7 \\
1.8 \\
0.1\end{array}$ \\
\hline
\end{tabular}

3.1.2.5.4 Wind speed effects. In tests using wind speeds of 0.2 to $4.4 \mathrm{~m} / \mathrm{s}$, we saw no significant shift in speciation in steady-state aerosols. While this is in agreement with a small-scale test done by Katz et al. (1981) under entirely different burn conditions, it differs from Braze1l et a1. (1984). The Brazell study showed a marked decrease in the $>13 \mathrm{P}$ species fraction and an increase in the 5 to $13 \mathrm{P}$ species fraction as wind speed rose from 2.0 to $8.2 \mathrm{~m} / \mathrm{s}$. We can offer no explanation for such an effect, unless the increased rate of RP/BR combustion with the higher wind speeds resulted in a concentration bias on the results. Even if wind speed does not have a significant effect on species distribution, increased speed does affect foliar deposition, particularly as mass loading changes from deposition to an impaction phenomenon.

3.1.2.5.5 Particle size effects. Differences in phosphorus speciation as a function of particle size were routinely monitored in terms of change in phosphate concentrations. The drop in phosphate and corresponding increase in higher polyphosphates was confirmed in a speciation check of two particle size levels taken from a cascade impactor during test D4 (Table 3.21). A bubbler sample representing an integrated aerosol sample from the same run is included for comparison. Since the particle size increases with age, the smaller particles would be expected to represent the fresher aerosol component of the continuous phosphorus combustion.

3.1.2.5.6 Environmental Mitigation. Polyphosphates in the presence of a sandy loam soil showed accelerated hydrolysis and lack of trimetaphosphate concentrations, compared to de-ionized water dosed at the same time (see Table 3.33 ). With simulated rainfall on RP/BR-exposed pine 
TABLE 3.21. PHOSPHORUS SPECIATION OF RP/BR AEROSOL (TEST D4) VERSUS

PARTICLE SIZE AT $9.0 \mathrm{M} / \mathrm{S}$ WIND SPEED AND $22^{\circ} \mathrm{C}$, AND $87 \%$ RELATIVE HUMIDITY $(\mathrm{N}=1)$

\begin{tabular}{|c|c|c|c|}
\hline $\begin{array}{l}\text { Cascade impactor } \\
\text { stage no. } \\
\text { Approximate particle } \\
\text { size }(\mu \mathrm{m}) \\
\text { P species }\end{array}$ & $\begin{array}{l}2 \\
4.8\end{array}$ & $\begin{array}{l}6 \\
0.65\end{array}$ & $\begin{array}{l}\text { Aqueous impinger } \\
\text { for comparison }\end{array}$ \\
\hline $\begin{array}{r}1 P \\
2 P \\
3 P \\
4 P \\
5 P \\
6 P \\
7 P \\
8 P \\
9 P \\
10 P \\
11 P \\
12 P \\
13 P \\
\geqq 14 P\end{array}$ & $\begin{array}{r}22.6 \\
18.9 \\
14.5 \\
10.9 \\
8.2 \\
6.3 \\
4.7 \\
3.1 \\
2.4 \\
1.8 \\
1.4 \\
1.0 \\
0.6 \\
1.0\end{array}$ & $\begin{array}{r}14.5 \\
20.0 \\
15.6 \\
13.0 \\
10.0 \\
8.1 \\
5.4 \\
4.2 \\
2.9 \\
2.1 \\
1.3 \\
1.2 \\
0.7 \\
0.9\end{array}$ & $\begin{array}{r}18.6 \\
19.3 \\
14.0 \\
11.0 \\
8.9 \\
7.2 \\
5.4 \\
3.6 \\
2.6 \\
2.0 \\
1.5 \\
0.9 \\
0.7 \\
1.5\end{array}$ \\
\hline $\begin{array}{l}\text { Recovery }(\%) \\
P \text { species by IC }\end{array}$ & 97 & 100 & 97 \\
\hline $\begin{array}{l}\mathrm{PO}_{4}^{3}-\mathrm{P} \\
\mathrm{HPO}_{3}^{2}-\mathrm{P}\end{array}$ & $\begin{array}{r}21.4 \\
0.3\end{array}$ & $\begin{array}{r}13.3 \\
0.2\end{array}$ & $\begin{array}{r}16.8 \\
0.2\end{array}$ \\
\hline
\end{tabular}

and sagebrush, the resultant solutions showed marked conversion ( $50 \%-60 \%)$ of total solubilized phosphorus to phosphate, compared to a $29 \%$ conversion in a water bubbler sample. Most of the higher polyphosphates were absent (accounting for $<10 \%$ of $\mathrm{P}_{\mathrm{T}}$, compared to $25 \%$ in the water bubbler sample), and only minor traces of trimetaphosphate were found.

\subsubsection{Phosphine and WP Determinations}

Analyses for phosphine $\left(\mathrm{PH}_{3}\right)$ in wind tunnel aerosols generated during the WP-E test series generally showed most values approaching the detection 
limit. The limit varied somewhat depending on baseline stability but was no worse than $43 \mu \mathrm{g} / \mathrm{m}^{3}$ (Table 3.22). The maximum phosphine concentration observed during the WP burns was $70 \mu \mathrm{g} / \mathrm{m}^{3}$, which represented $0.02 \%$ of the total phosphorus in the aerosol; minimum estimates represented $<0.002 \%$ of total phosphorus. The higher values were most prevalent at higher humidities. Katz et al. (1981) reported phosphine levels at less than $0.0001 \%$ of total phosphorus, while Brazell et al. (draft) detected no phosphine at a detection limit of $0.1 \mathrm{ppm}$. Spanggord et al. (1985) generated extremely high (500 ppm) levels of phosphine in a sealed reactor at $100 \%$ relative humidity over a 12 -day period, following WP/F oxidation in air and adjustment to $1 \mathrm{~atm}$. with air. However, such contained conditions hold little resemblance to actual field conditions. The Spanggord study reported no detectible phosphine generated with RP/BR in a similar reactor when initially oxidized in oxygen and then adjusted to $1 \mathrm{~atm}$ with air. The lower oxygen levels in the WP/F study probably encouraged the formation of lower phosphorus oxides (such as $\mathrm{P}_{4} \mathrm{O}_{6}$ ), which readily yielded $\mathrm{PH}_{3}$ upon disproportionation.

Phosphorus components other than phosphine were observed in some gas samples. Standard addition and re-analys is using the procedure described above plus a 4' Porapak-Q glass column followed by flame photometric detection confirmed that the multiple peaks were due to species other than phosphine.

Phosphine release from aqueous solutions containing $0.2 \mathrm{ppm} \mathrm{P}_{4}$ have been reported to range from $6 \%$ to $9 \%$ on initial $P_{4}$ (Lai and Rosenb $4 a t t$ 1977b). While this release rate may be significant for waters in contact with high levels of entrained $P_{A}$ (as is found in munition production schemes), such a phosphine release source would present little added danger to the exposed civilian population and troops under training and normal deployment conditions.

Levels of elemental WP $\left(P_{4}\right)$ in aerosols sampled via benzene impingers ranged from $0.007 \%$ to $0.015 \%$ of total phosphorus in the WP-E test series (Table 3.23). Upon deposition to de-ionized water surfaces (Table 3.24), the $\mathrm{P}_{4}$ levels ranged from a maximum of $.0009 \%$ of total phosphorus in one-hour tests to a maximum of $.0002 \%$ in the four-hour tests, as determined by extraction into benzine. The marked drop in $P_{4}$ upon water contact suggests that aerosol deposition may make a short-lived contribution of this toxic species to water bodies directly. However, the limit of combustion efficiency for WP/F munitions is estimated to be $92 \%$, so significant amounts of unreacted $P_{4}$ could remain on the ground under field conditions (Spanggord et a 1. 1985).

Run time, relative humidity, and wind speed all varied in this test series (see Table 2.4), making correlations questionable. A simple linear comparison of percent relative humidity to percent of WP/P TOT showed 1 itte correlation $\left(R^{2}=0.27\right)$. 
TABLE 3.22. PHOSPHINE $\left(\mathrm{PH}_{3}\right)$ CONCENTRATIONS IN WP AEROSOLS DURING WP-E TEST SERIES

\begin{tabular}{|c|c|c|c|c|}
\hline Test & Sample & $\begin{array}{l}\mathrm{PH}_{3} \\
\left(\mu \mathrm{g} / \mathrm{m}^{3}\right)\end{array}$ & $\begin{array}{l}\text { Estimated } \\
\text { aerosol } \\
\text { concentration } \\
\left(\mathrm{mg} \mathrm{P} / \mathrm{m}^{3}\right)(\mathrm{a})\end{array}$ & $\% \mathrm{PH}_{3} / \mathrm{P}_{\mathrm{TOT}}$ \\
\hline WP-E1 & $\begin{array}{l}\text { 1-Tunnel before burn } \\
\text { 2-Fresh aerosol } \\
\text { 3-Start of exposure } \\
\text { 4-Mid-exposure } \\
\text { 5-Prior to shutdown }\end{array}$ & $\begin{array}{l}<13 \\
<13 \\
<13 \\
<13 \\
<19\end{array}$ & $\begin{array}{l}<\mathrm{ND}(\mathrm{b}) \\
\sim 550(\mathrm{c}) \\
\sim 550 \\
650 \\
640\end{array}$ & $\begin{array}{l}<.002 \\
<.002 \\
<.002 \\
<.002\end{array}$ \\
\hline WP-E2.1 & $\begin{array}{l}\text { 1-Mid-exposure } \\
\text { 2-Room air blank }\end{array}$ & $\begin{array}{l}10 \\
<3\end{array}$ & $\begin{array}{l}335 \\
\text { ND }\end{array}$ & .003 \\
\hline$W P-E 2.2$ & 3-Mid-exposure & 24 & 385 & .006 \\
\hline WP-E2.3 & 4-Mid-exposure & 18 & 495 & .004 \\
\hline$W P-E 3$ & 2-Mid-exposure & $<43$ & 615 & $<.006$ \\
\hline WP-E4 & $\begin{array}{l}\text { 1-Mid-exposure } \\
\text { 2-Mid-exposure } \\
\text { 3-Room air blank }\end{array}$ & $\begin{array}{r}68 \\
70 \\
<38\end{array}$ & $\begin{array}{l}\sim 300(d) \\
\sim 400(d) \\
N D\end{array}$ & $\begin{array}{l}.023 \\
.018\end{array}$ \\
\hline
\end{tabular}

(a) Estimate of concentration at time of sampling, not average

(b) concentration over entire run.

(c) Not determined.

C) Estimated as being approximately equivalent to start of (d) exposure, though not actually measured.
$\pm 10 \%$. 
TABLE 3.23. CONCENTRATION OF $P_{4}$ IN AEROSOL BUBBLER SAMPLES: WP-E TEST SERIES $(N=1)$

\begin{tabular}{|c|c|c|c|c|}
\hline Test $^{(a)}$ & $\begin{array}{c}\text { Relative } \\
\text { Humidity } \\
(\%) \\
\end{array}$ & $\mu \mathrm{g} W P / \mathrm{m}^{3}$ & $\mathrm{mg}_{\mathrm{TOT}} / \mathrm{m}^{3}$ & $\% \mathrm{WP} / \mathrm{P}_{\mathrm{TOT}}$ \\
\hline WP-E1 trap 1 & 57 & 49 & 595 & .008 \\
\hline WP-E1 trap 2 & 57 & 83 & 655 & .013 \\
\hline $\begin{array}{r}W P-E 2.1 \\
2.2 \\
2.3\end{array}$ & $\begin{array}{l}66 \\
61 \\
61\end{array}$ & 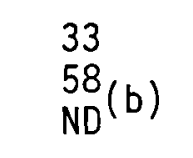 & $\begin{array}{r}420 \\
495 \\
\text { ND }\end{array}$ & $\begin{array}{l}.008 \\
.012 \\
\text { ND }\end{array}$ \\
\hline WP-E3 & 35 & 34 & 490 & .007 \\
\hline WP-E4 & $90 \pm 5$ & 63 & 425 & .015 \\
\hline \multicolumn{4}{|c|}{ Overall Average } & $.010 \pm .003$ \\
\hline
\end{tabular}

(a) See Table 2.4 for details.

(b) Pump failure caused loss of aerosol sample.

TABLE 3.24. CONCENTRATION OF $P_{4}$ FOLLOWING STATIC DEPOSITION WATER SURFACES: WP-E TEST SERIES $(N=1)$

\begin{tabular}{|c|c|c|c|c|}
\hline Test $^{(a)}$ & $\mathrm{ng} \mathrm{WP} / \mathrm{cm}^{2}$ & $\begin{array}{c}\mu \mathrm{g} W P \\
(\operatorname{tota} 1)\end{array}$ & $\mu \mathrm{g} \mathrm{P}_{\mathrm{TOT}} / \mathrm{cm}^{2}$ & $\% W P / P_{T O T}$ \\
\hline WP-E1 & .39 & .060 & 240 & .00016 \\
\hline $\begin{array}{r}\mathrm{WP}-\mathrm{E} 2 . \\
2 . \\
2.3 \\
\mathrm{WP}-\mathrm{E} 2\end{array}$ & $\begin{array}{r}.19 \\
.49 \\
.39 \\
\text { age }\end{array}$ & $\begin{array}{l}.030 \\
.075 \\
.060\end{array}$ & $\begin{array}{l}43.7^{(\mathrm{b})} \\
54.4^{(\mathrm{b})} \\
58.0^{(\mathrm{b})}\end{array}$ & $\begin{array}{c}.00043 \\
.00090 \\
.00067 \\
.00067 \pm .00024\end{array}$ \\
\hline WP-E3 & $<.10$ & $\leq .015$ & 179 & $\leq .00005$ \\
\hline WP-E4 & .19 & .030 & 218 & .00009 \\
\hline
\end{tabular}

(a) See Table 2.4.

(b) Determined from unextracted replicate deposition plates. 


\subsection{Transport, Fate, and Effects of Phosphorus Smoke Deposition on Soils}

\subsubsection{Soil-Phosphorus Background}

Soil phosphorus may be divided into two categories, inorganic and organic. While the major fraction may be organic, the inorganic forms are more reactive. Mechanisms for phosphorus retention by soils include precipitation, adsorption, microbial immobilization, plant uptake, and occlusion. Normally, soil phosphorus is considered sparingly soluble. At the $\mathrm{pH}$ range of most soils $(4.0-8.5), \mathrm{H}_{2} \mathrm{PO}_{4}{ }^{-}$and its soluble metallic complexes are the major phosphoric acid species. Sorption of phosphate generally involves an initial rapid stage followed by a second, slower stage that may continue for weeks to months. Phosphate sorption has been statistically correlated to $\mathrm{pH}, \mathrm{CaCO}_{3}$ content, particle size distribution, extractible (active) ifon and aluminum, and organic carbon. Organically complexed $\mathrm{Fe}^{+}$and $\mathrm{A}{ }^{+}$are considered the most likely sites for adsorption on organic matter surfaces. In acid and neutral solutions, the oxides of aluminum and iron carry a net positive charge, with positive and neutral sites on their surfaces. Depending on the ligand exchanged with phosphate, sorption could either decrease the surface positive charge, leaving the solution unchanged, or increase the solution hydroxyl concentration, leaving the surface charge unchanged (Berkheiser et al. 1980).

Inorganic soil phosphorus can be further classified into functional phosphorus fractions: nonoccluded, occluded, and calcium-precipitated mineral species. Nonoccluded phosphorus is associated with aluminum and iron oxide surfaces and is readily available to plants; occluded phosphorus is associated with the aluminum and iron oxide lattices and is not readily available to plants unless released by an outside mechanism; calcium-bound phosphates are not easily available to plants. In one test series, the phosphorus inventory in the root zone (B Horizon) changed little in organically bound and calcium-bound phosphorus, while the nonoccluded phosphorus generally decreased with soil age. Organic phosphorus content was highest at the surface, with distribution correlated with organic matter distributions and phosphorus recycling by plants (Meixner and Singer 1985).

When phosphorus is added to a soil, the equilibrium between aluminum oxides and silicate ion is disrupted. Under acidic conditions, such as those resulting from the addition of phosphorus smoke-screen particulates, the phosphates should be preferred to silica by the surface. If the acid conditions prevail for some time, a continuous decrease in silicon to aluminum ratio of the soil clay minerals should result. Phosphate enhances the dissolution of silica from the surface even when the solution concentration is only $10^{-3}$ to $10^{-5} \mathrm{M}$ phosphate. Phosphate is sorbed more strongly when the sample is subjectéd to severe leaching (Kafkafi 1972). While the apatite structure $\left(\mathrm{Ca}_{5}\left(\mathrm{PO}_{4}\right)_{3}(\mathrm{OH}, \mathrm{F})\right.$ is a primary form of phosphorus minerals, other structures are also common. In the plumbogummite group $\left(\mathrm{PbAl}_{3}\left(\mathrm{PO}_{4}\right)_{2}(\mathrm{OH})_{5} \mathrm{H}_{2} \mathrm{O}\right)$, lead's position may be replaced by calcium, strontium, barium, fron and others. Secondary hydroxyapatite, 
fluorapatite, octocalcium phosphate $\left(\mathrm{Ca}_{8} \mathrm{H}_{2}\left(\mathrm{PO}_{4}\right)_{6}\left(\mathrm{H}_{2} \mathrm{O}\right)_{5}\right)$, and struvite $\left(\left(\mathrm{H}, \mathrm{NH}_{4}, \mathrm{~K}\right) \mathrm{Mg}\left(\mathrm{PO}_{4}\right)\left(\mathrm{H}_{2} \mathrm{O}\right)_{3}\right)$ minerals may form as fert\}lizer reaction products or be part of a fertilizer itself. A major initial reaction product of phosphate fertilizers in soils is brushite $\left(\mathrm{CaH}\left(\mathrm{PO}_{4}\right)\left(\mathrm{H}_{2} \mathrm{O}\right)_{2}\right)$, which leads rapidly to monocalcium phosphate $\left(\mathrm{CaH}_{4}\left(\mathrm{PO}_{4}\right){ }_{2} \mathrm{H}_{2} \mathrm{O}\right)$. ${ }^{4}$ Other fertilizer reaction products reported have the structure types of $\mathrm{KFe}_{2}\left(\mathrm{PO}_{4}\right)_{2} \mathrm{OH}\left(\mathrm{H}_{2} \mathrm{O}\right)_{2}$ and $\left(\left(\mathrm{NH}_{4}\right)_{3}, \mathrm{~K}_{3}\right) \mathrm{H}_{6} \mathrm{Al}_{5}\left(\mathrm{PO}_{4}\right)_{8}\left(\mathrm{H}_{2} \mathrm{O}\right)_{18}$ (Dixon and Weed 1977).

The accumulation of organic phosphorus in soils and the importance of organic phosphorus mineralization in providing plant-available phosphorus are we 11-accepted facts. Methods for fractionation of inorganic, organic, and microbial phosphorus have been reported (Hedley et al. 1982, Kafkafi 1972), but much of soil phosphorus remains unidentified. Residual organic phosphorus is probably large molecular weight complexes corresponding to the humic acid and humin fractions. Disruption of the soil by cultivation and cropping can result in an increase in microbial activity, causing a redistribution of organic phosphorus in soils. However, phosphorus content of fungi and bacteria varies with phosphorus supply, as apparently does the mineralization of organic phosphorus (Hedley et al. 1982). The enzyme inorganic pyrophosphatase (pyrophosphate phosphohydrolase) is required for hydrolys is of pyrophosphate to orthophosphate. This widely distributed enzyme requires divalent metal ions for its activity, with $\mathrm{Mg}^{2 f}$ being a primary activator. It has been demonstrated that inhibition of pyrophosphatase activity occurred with other trace elements, particularly molybdenum (as $\mathrm{MoO}_{4}$ ) and tungsten (as $\mathrm{WO}^{-}$). Other effective inhibitors included $\mathrm{Hg}$ (II), $\mathrm{Cu}(\mathrm{II}), \mathrm{Fe}$ (II), Cd(II), B(III), V(IV), and $\mathrm{As}(\mathrm{V})$. Inhibition by $A I$ (III) and $F e$ (III) was small, and no inhibition was seen for $\mathrm{Co}$ (II), $\mathrm{Ba}($ II $), \mathrm{K}^{+}, \mathrm{Na}^{+}, \mathrm{Cl}^{-}, \mathrm{NO}^{2-}, \mathrm{NO}^{-}$, or $\mathrm{SO}_{4}$ (Stott et al. 1985).

Interaction of trace metals with phosphorus species can contribute to leachability and subsequent migration of those metals. In one study, addition of polyphosphates promoted dissolution of calcium, manganese, and zinc without forming stable complexes, while dissolution of magnesium and iron resulted in formation of extremely stable complexes which could then be leached into deeper soil horizons. Polyphosphates also caused a marked increase in soluble organic carbon, compared to non-phosphorus-amended and phosphate-phosphorus-amended soils. When not counteracted by sorption onto carbonate particles, addition of polyphosphates markedly increased mobile phosphorus levels, with condensed mineral phosphates comprising the predominent mobile forms. The picture is further complicated by evidence suggesting microbial production of polyphosphates in the field (Kudeyarova and Kvaralskheliya 1984).

Addition of phosphorus as the oxides formed during the production of smoke screens would differ from fertilizer addition because the amendment acts as the acid form of the oxides, rather than as the salts. The buffering capacity of most soils would counteract small or diluted acid additions. However, the chemical environment very near the smoke deposition particles would differ greatly from the apparent environment over a larger soil reservoir. Since our primary concern in this portion of 
the study was to elucidate any effects from smoke deposition, we looked first at worst-case conditions, specifically, high-deposition-to-soil-mass ratios.

Only surface soils were considered in this study since deposition of smoke particulate would be a surface-loading phenomenon. Erosion by wind and water runoff could conceivably concentrate the surface-deposited particulate (and the resulting solubilized species) to levels not seen by the bulk of the soil column. Therefore, thin layers of soils were exposed in an effort to reveal effects that might occur on the surface but would be mitigated by the effects of dilution or the soil-buffering capacity.

\subsubsection{Calibration Tests}

Premoistened soils exposed in a 4-hour RP/BR smoke test (June 26, 1984) produced dramatic effects of smoke deposition on soluble aluminum and irog when compared to control soil aliquots (Table 3.25). For these soils, $\mathrm{PO}_{4}-\mathrm{P}$ represented $77 \%, 84 \%$, and $87 \%$, respectively, of $\mathrm{P}_{\mathrm{T}}$ in the 24 -hour extractions. To magnify the effect of smoke deposition on soil in order to estimate the potential effects of surface runoff, additional tests were conducted using thin lenses of exposed air-dried soil. In conjunction with microbial testing, aliquots of soil were also amended with $\mathrm{NH}_{4}$ (as $\left.\left(\mathrm{NH}_{4}\right)_{2} \mathrm{SO}_{4}\right)$ corresponding to 2.8 and $28 \mathrm{meq} . / 100 \mathrm{~g}$ soil. These levels approach and saturate the sites on the sandy loam soil (CEC=5.5 meq./100 g soil). Prepared soils were exposed to RP/BR smoke (7/10/84). Again, solubility of aluminum increased dramatically, followed by expected decreases with time. The effect on iron is similar, though not as striking (Table 3.26). Neither aluminum nor iron is affected by $\mathrm{NH}_{4}{ }^{+}$levels in the dosed soils, though the solubility of both elements decreases with increasing $\mathrm{NH}_{4}^{+}$in the controls. Other species were also solubilized, but such changes could be reproduced by acid amendment. For all soil

TABLE 3.25. INTERACTION OF RP/BR SMOKE WITH SOIL: $0.5-C M$ DEPTHS (PREMOISTENED) $(\mathrm{N}=1)$

\begin{tabular}{|c|c|c|c|c|c|c|c|c|}
\hline & \multicolumn{4}{|c|}{ 24-hour incubation } & \multicolumn{4}{|c|}{ 120-hour incubation } \\
\hline & $\mathrm{pH}$ & Al & $\underline{\mathrm{Fe}}$ & $\underline{\mathrm{Ca}}$ & $\mathrm{pH}$ & $\underline{A 1}$ & $\underline{\mathrm{Fe}}$ & $\underline{\mathrm{Ca}}$ \\
\hline $\begin{array}{l}\text { Sandy loam }+4 \mathrm{hr} \\
\text { Deposition control }\end{array}$ & $\begin{array}{l}7.38 \\
7.55\end{array}$ & $\begin{array}{l}3.0 \\
0.65\end{array}$ & $\begin{array}{l}3.6 \\
0.94\end{array}$ & $\begin{array}{l}29 \\
23\end{array}$ & $\begin{array}{l}7.75 \\
7.77\end{array}$ & $\begin{array}{l}0.57 \\
0.96\end{array}$ & $\begin{array}{l}0.78 \\
1.15\end{array}$ & $\begin{array}{l}68 \\
47\end{array}$ \\
\hline $\begin{array}{l}\text { Silt loam }+4 \mathrm{hr} \\
\text { Deposition control }\end{array}$ & $\begin{array}{l}7.08 \\
7.06\end{array}$ & $\begin{array}{l}0.30 \\
0.79\end{array}$ & $\begin{array}{l}0.40 \\
1.2\end{array}$ & $\begin{array}{l}18 \\
13\end{array}$ & $\begin{array}{l}7.24 \\
7.22\end{array}$ & $\begin{array}{l}0.18 \\
1.3\end{array}$ & $\begin{array}{l}0.18 \\
1.8\end{array}$ & $\begin{array}{l}28 \\
17\end{array}$ \\
\hline $\begin{array}{l}\text { High organic }+4 \mathrm{hr} \\
\text { Deposition control }\end{array}$ & $\begin{array}{l}6.17 \\
6.82\end{array}$ & $\begin{array}{l}14 \\
2.8\end{array}$ & $\begin{array}{l}6.9 \\
3.6\end{array}$ & $\begin{array}{l}470 \\
290\end{array}$ & $\begin{array}{l}6.57 \\
7.06\end{array}$ & $\begin{array}{l}6.0 \\
2.7\end{array}$ & $\begin{array}{l}6.6 \\
5.8\end{array}$ & $\begin{array}{l}540 \\
350\end{array}$ \\
\hline
\end{tabular}


TABLE 3.26. MEAN SOLUBLE METAL CONCENTRATIONS OVER TIME FROM SANDY LOAM SOIL AFTER RP/BR SMOKE DEPOSITION FOLLOWED BY WATER EXTRACTION $(N=2)$

\begin{tabular}{|c|c|c|c|c|c|c|c|c|}
\hline Element & & & & & & $\mathrm{Mg}$ & & $\mathrm{Ca}$ \\
\hline Contact & $\overline{\text { Dosed }}$ & control & Dosed & control & Dosed & control & $\overline{\text { Dosed }}$ & con \\
\hline Part 1 & no am & ndments & & & & & & \\
\hline $\begin{array}{l}1 \text { day } \\
2 \text { days } \\
6 \text { days } \\
14 \text { days }\end{array}$ & $\begin{array}{l}20 \\
17 \\
12 \\
3.5\end{array}$ & $\begin{array}{l}2.1 \\
2.1 \\
2.4 \\
1.8\end{array}$ & $\begin{array}{l}4.3 \\
3.8 \\
3.4 \\
2.3\end{array}$ & $\begin{array}{l}2.5 \\
2.5 \\
2.8 \\
2.2\end{array}$ & $\begin{array}{l}24 \\
26 \\
29 \\
32\end{array}$ & $\begin{array}{l}6.1 \\
9.4 \\
14 \\
17\end{array}$ & $\begin{array}{l}116 \\
120 \\
118 \\
142\end{array}$ & $\begin{array}{l}28 \\
47 \\
66 \\
86\end{array}$ \\
\hline
\end{tabular}

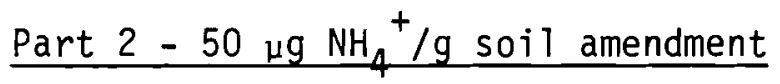

$\begin{array}{lllllllll}1 \text { day } & 21 & 1.9 & 4.5 & 2.2 & 28 & 9 & 137 & 42 \\ 2 \text { days } & 18 & 1.8 & 3.8 & 1.9 & 29 & 12 & 139 & 58 \\ 6 \text { days } & 12 & 1.5 & 3.1 & 2.0 & 33 & 17 & 138 & 83 \\ 14 \text { days } & 2.4 & 0.8 & 1.4 & 1.1 & 36 & 22 & 158 & 111\end{array}$

Part $3-500 \mu \mathrm{g} \mathrm{NH}_{4}^{+} / \mathrm{g}$ soil amendment

$\begin{array}{lllllllll}1 \text { days } & 22 & 0.9 & 3.6 & 1.1 & 47 & 30 & 232 & 152 \\ 2 \text { days } & 20 & 1.0 & 2.9 & 1.2 & 48 & 32 & 238 & 170 \\ 6 \text { days } & 12 & 0.8 & 2.3 & 1.2 & 51 & 34 & 238 & 179 \\ 14 \text { days } & 3.2 & 0.5 & 1.3 & 0.6 & 55 & 40 & 257 & 209\end{array}$

extractions, evaporation was not factored into results since controls were treated identically to samples. Evaporation rate was estimated at $0.58 \pm 0.04 \mathrm{~g} /$ day $(\mathrm{N}=9)$, or about $0.15 \%$ per day for the $40 \mathrm{~g}$ soil extraction tests.

\subsubsection{Changes in soluble components}

Tables 3.27 and 3.28 compare soluble components for dosed and control soils in RP/BR and WP exposures, respectively. The 0.8-day period was chosen to minimize secondary changes resulting from microbial activity and precipitation, while still allowing time for the soil to restabilize following water contact. Although initially acidic, Quillayute and Shawano soils have sufficient buffering capacity to minimize pH drop following deposition. Burbank soil reveals the least buffering capacity. The two Burbank aliquots represent different lots, with lot 1 being used for planting of native species for exposure and lot 2 for exposures to date. 
TABLE 3.27. COMPARISON OF SOLUBLE COMPONENTS RELEASED FROM SOILS

AFFECTED BY RP/BR SMOKE DEPOSITION AFTER 0.8-DAY

INCUBATION WITH WATER

\begin{tabular}{|c|c|c|c|c|}
\hline \multicolumn{5}{|c|}{ Ratio of exposed concentration/control soils $(a, b)$} \\
\hline & Burbank & Quillayute & Shawano & Yamac \\
\hline $\begin{array}{l}\mathrm{pH} \\
\mathrm{DOC}(\mathrm{c}) \\
\mathrm{Ca} \\
\mathrm{K} \\
\mathrm{A} 1 \\
\mathrm{Fe} \\
\mathrm{Na} \\
\mathrm{Mg} \\
\mathrm{Mn} \\
\mathrm{Si}^{-} \\
\mathrm{NO}_{3}^{-}\end{array}$ & $\begin{array}{l}4.95 / 8.20 \\
92 / 33 \\
275 / 20 \\
220 / 110 \\
71 / 1.5 \\
19 / 1.5 \\
(0.7) \\
56 / 4.6 \\
1.8 / .03 \\
84 / 33 \\
(0.95)\end{array}$ & $\begin{array}{l}4.76 / 5.25 \\
(1330) \\
64 / 30 \\
(32) \\
64 / 16 \\
4.4 / 3.2 \\
(2.2) \\
26 / 18 \\
8.5 / 4.2 \\
23 / 14 \\
8.6 / 5.3\end{array}$ & $\begin{array}{l}4.58 / 5.20 \\
(1880) \\
330 / 170 \\
(59) \\
92 / 20 \\
19 / 5.2 \\
(5.3) \\
79 / 44 \\
110 / 47 \\
(17) \\
42 / 27\end{array}$ & $\begin{array}{l}8.15 / 9.48 \\
(26) \\
110 / 14 \\
(<3) \\
(.1) \\
1.4 / 0.8 \\
(100) \\
46 / 2.7 \\
(.06) \\
(5.0) \\
(10)\end{array}$ \\
\hline $\mathrm{SO}_{4}=$ & $12 / 3.0$ & $3.0 / 1.7$ & $(67)$ & $(150)$ \\
\hline
\end{tabular}

Dissolved organic carbon (DOC) increases by more than $50 \%$ only for Burbank and Maxey Flats soils (Tables 3.27 and 3.28).

The solubilities of major cations $\left(\mathrm{Ca}^{2}, \mathrm{~K}^{+}, \mathrm{Na}^{+}, \mathrm{Mg}^{+}\right)$increase after smoke deposition, though the relative amounts vary greatly. Major anions $\left(\mathrm{Cl}^{-}, \mathrm{NO}_{3}, \mathrm{SO}_{4}{ }^{-}\right.$) show both positive and negative variations; $\mathrm{Cl}^{-}$is not included in the tables because of suspected interference by organic acid anions in IC analysis. All of the significant changes in the release of soluble trace or macro ions from the soils tested can be produced by the addition of phosphoric acid (except to aluminum and, in some cases, iron). Table 3.29 compares acid leaching to smoke deposition for the soils used in the WP exposures. 
TABLE 3.28. COMPARISON OF SOLUBLE COMPONENTS RELEASED FROM SOILS AFFECTED BY WP SMOKE DEPOSITION AFTER 0.8-DAY

INCUBATION WITH WATER

Ratio of exposed concentration/control soils

\begin{tabular}{|c|c|c|c|}
\hline & Burbank-1 & Burbank-2 & Maxey Flats \\
\hline $\mathrm{pH}$ & $3.4 / 7.7$ & $3.5 / 7.7$ & $3.1 / 5.0$ \\
\hline$D O C$ & $150 / 43$ & $128 / 30$ & $595 / 109$ \\
\hline $\mathrm{Ca}$ & $521 / 21$ & $540 / 20$ & $158 / 24$ \\
\hline K & $239 / 48$ & $285 / 66$ & $18 /<3$ \\
\hline A1 & $199 /<.3$ & $186 /<.3$ & $272 / 2.3$ \\
\hline $\mathrm{Fe}$ & $80 / 0.3$ & $76 / 0.2$ & $28 / 0.5$ \\
\hline $\mathrm{Na}$ & $7.4 / 1.3$ & $6.2 / 1.2$ & $2.6 / 1.6$ \\
\hline $\mathrm{Mg}$ & $107 / 3.3$ & $106 / 3.7$ & $25 / 4.6$ \\
\hline$M n$ & $10.8 / .04$ & $10.1 / \leqq .02$ & $76 / 9.2$ \\
\hline $\mathrm{Si}$ & $162 / 26$ & $148 / 24$ & $29 / 6.6$ \\
\hline $\mathrm{NO}_{3}^{-}$ & 7.3 & (8.1) & $(157)$ \\
\hline $\mathrm{SO}_{4}=$ & 7.8 & $6.2 / 2.9$ & $50 / 41$ \\
\hline
\end{tabular}

(a) Only results that differ by more than $50 \%$ from the unexposed controls are shown; otherwise only the control value is shown in ( ).

(b) Results are in $\mu \mathrm{g} / \mathrm{gm}$ soil released except for $\mathrm{pH}$, which is actual value of $10: 1$ solution to soil ratio. 
TABLE 3.29. SOLUBLE COMPONENTS RELEASED FROM SOILS BY WP SMOKE DEPOSITION VERSUS $\mathrm{H}_{3} \mathrm{PO}_{4}$ LEACHING AT 0.8 DAY

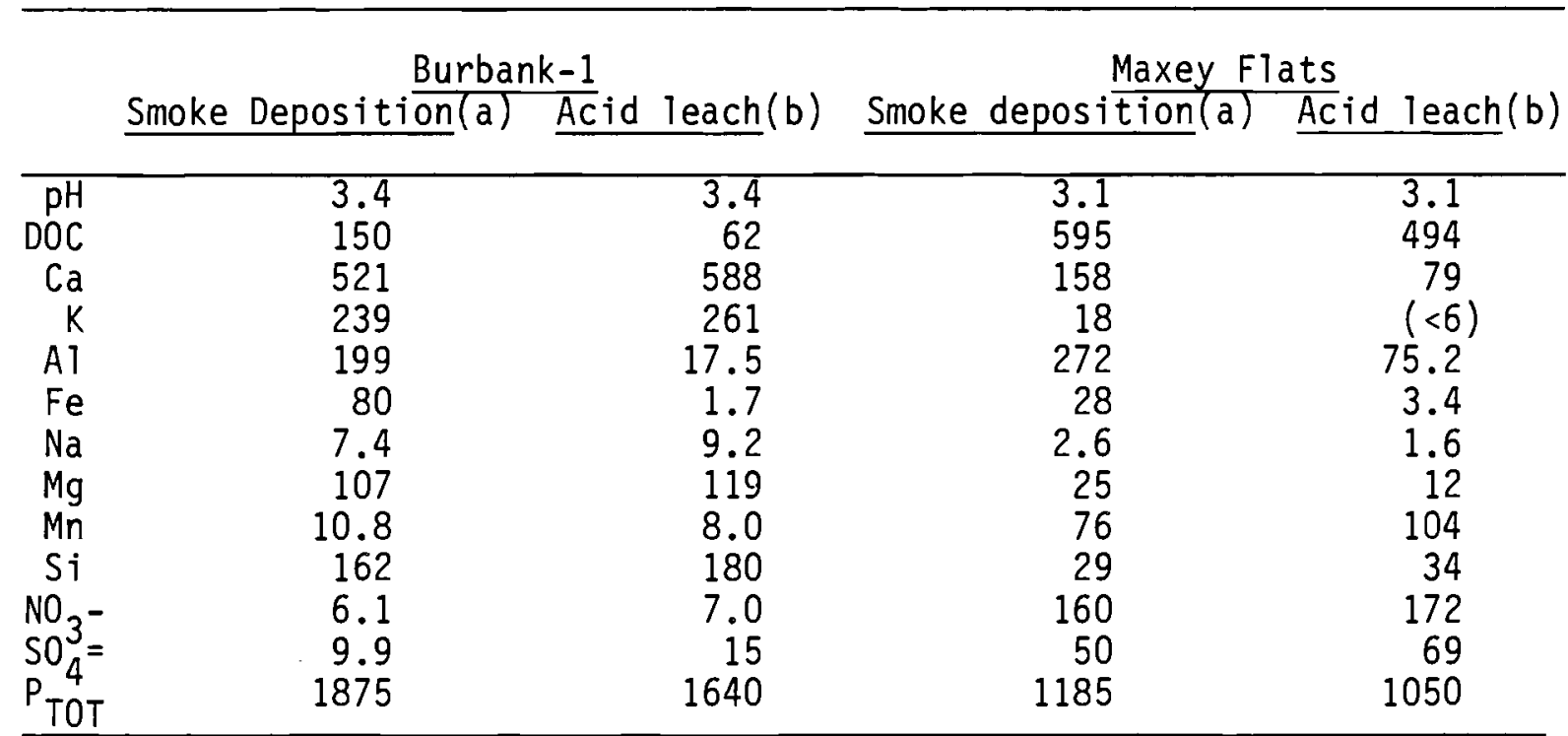

(a) $\mathrm{N}=2$

(b) $N=1$

The behavior of soluble aluminum with leaching time and with time to water contact for the four surface soils exposed to RP/BR smoke is shown in Figures $3.12,3.13,3.14$, and 3.15. Duplicate soil al iquots were contacted with deionized water immediately after smoke deposition, while 1 aliquot per soil was held for each holding period of 2 and 8 days prior to water contact. Controls consisted of unexposed soils at the same water ratio incubated with the first set of exposed soils. After termination of the main experiment ( 26 days) these controls were then spiked with $\mathrm{H}_{3} \mathrm{PO}_{4}$ (1400 mg P/g soil), approximating the total $P$ level deposited on aerosol exposed soils, and any changes in soluble species noted. In the case of Burbank soil, results could also be compared to the direct acid leach test described in Table 3.29. All the soils show variations of exponential decrease in solubility from a soil solution with time. Exponential curve fits for soluble Al concentration from Burbank soil (Figure 3.12) are as follows:

$\begin{array}{lll}\text { (1) no delay time: } & Y=72.98 * 10(-.0213) x, & R^{2}=0.90 \\ \text { (2) delay time } 2 \text { days: } & Y=57.41 * 10(-.0368) x, & R^{2}=1.0 \\ \text { (3) delay time } 8 \text { days: } & Y=62.35 * 10(-.0441) x, & R^{2}=0.98\end{array}$

The other three soils respond better to logarithmic curve fitting. For soluble Al from Quillayute (Figure 3.10) the resulting equations are as follows: 


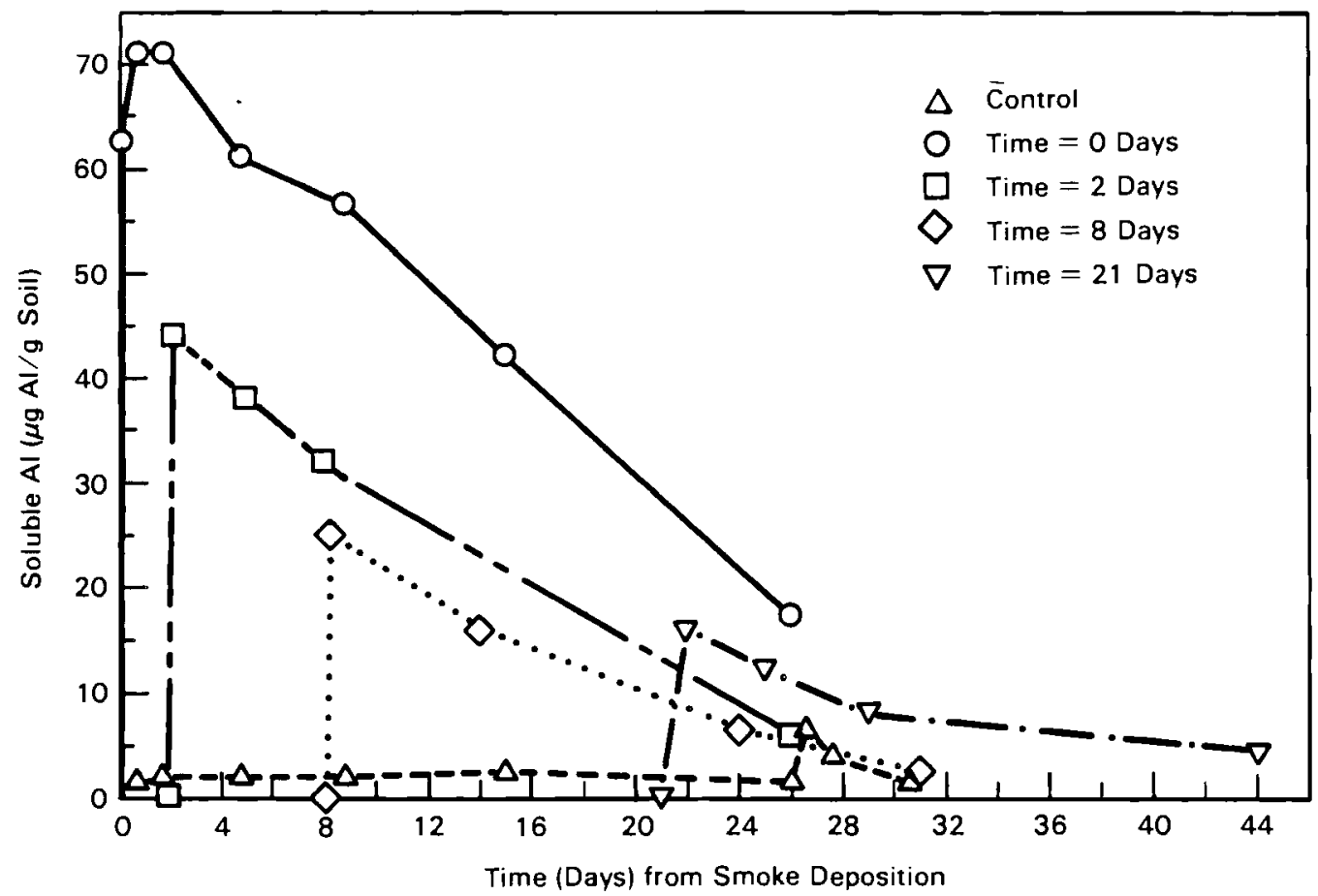

FIGURE 3.12. BEHAVIOR OF SOLUBLE AL FROM BURBANK SOIL AFTER RP/BR EXPOSURE

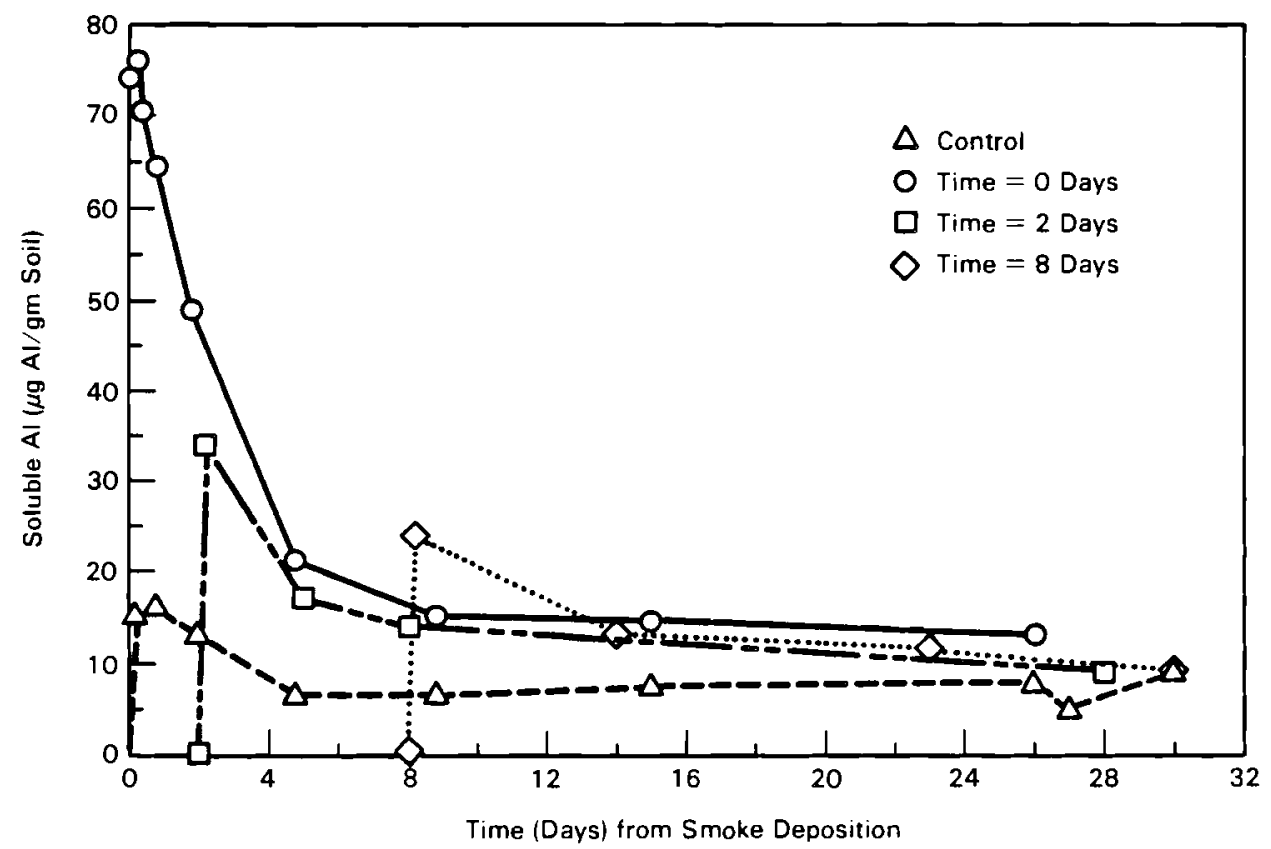

FIGURE 3.13. BEHAVIOR OF SOLUBLE AL FROM QUILLAYUTE SOIL AFTER $\mathrm{RP} / \mathrm{BR}$ EXPOSURE 


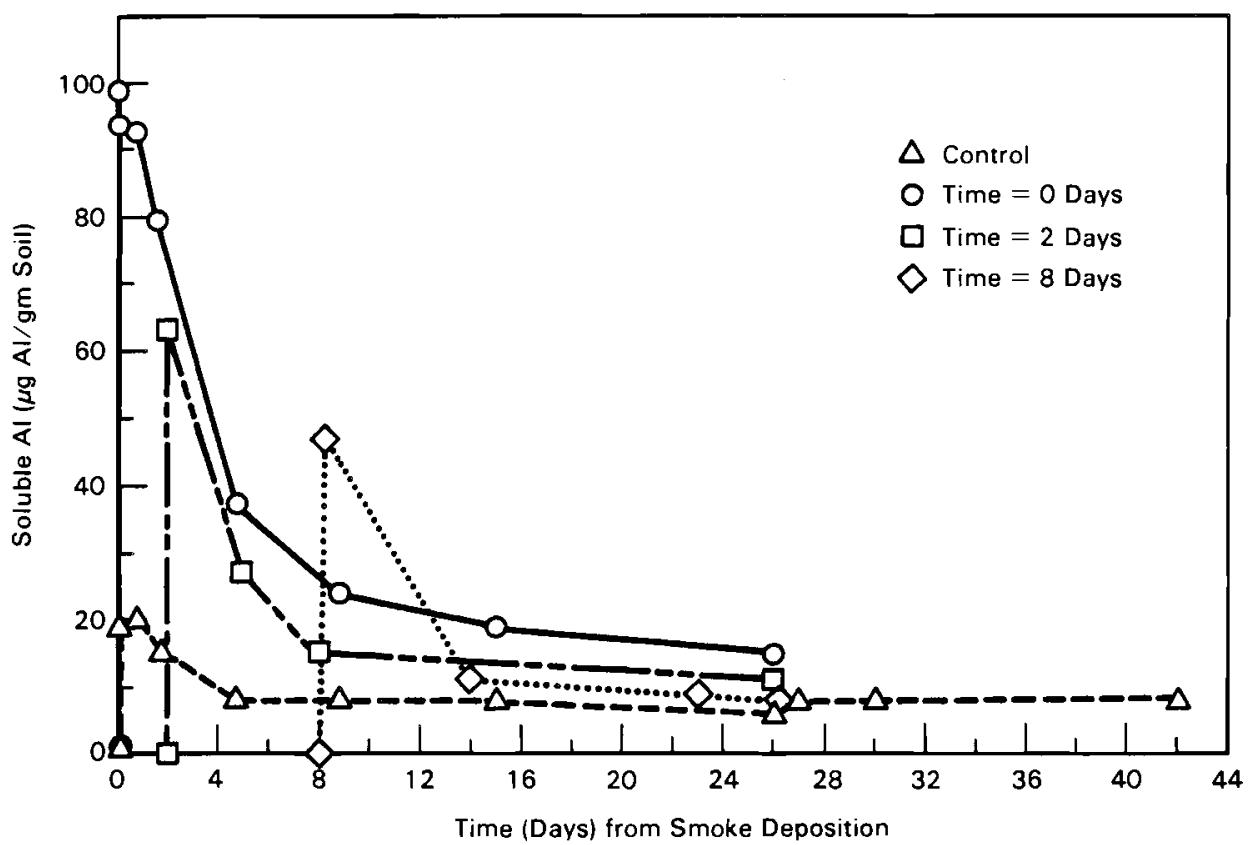

FIGURE 3.14. BEHAVIOR OF SOLUBLE AL FROM SHAWANO SOIL AFTER RP/BR EXPOSURE

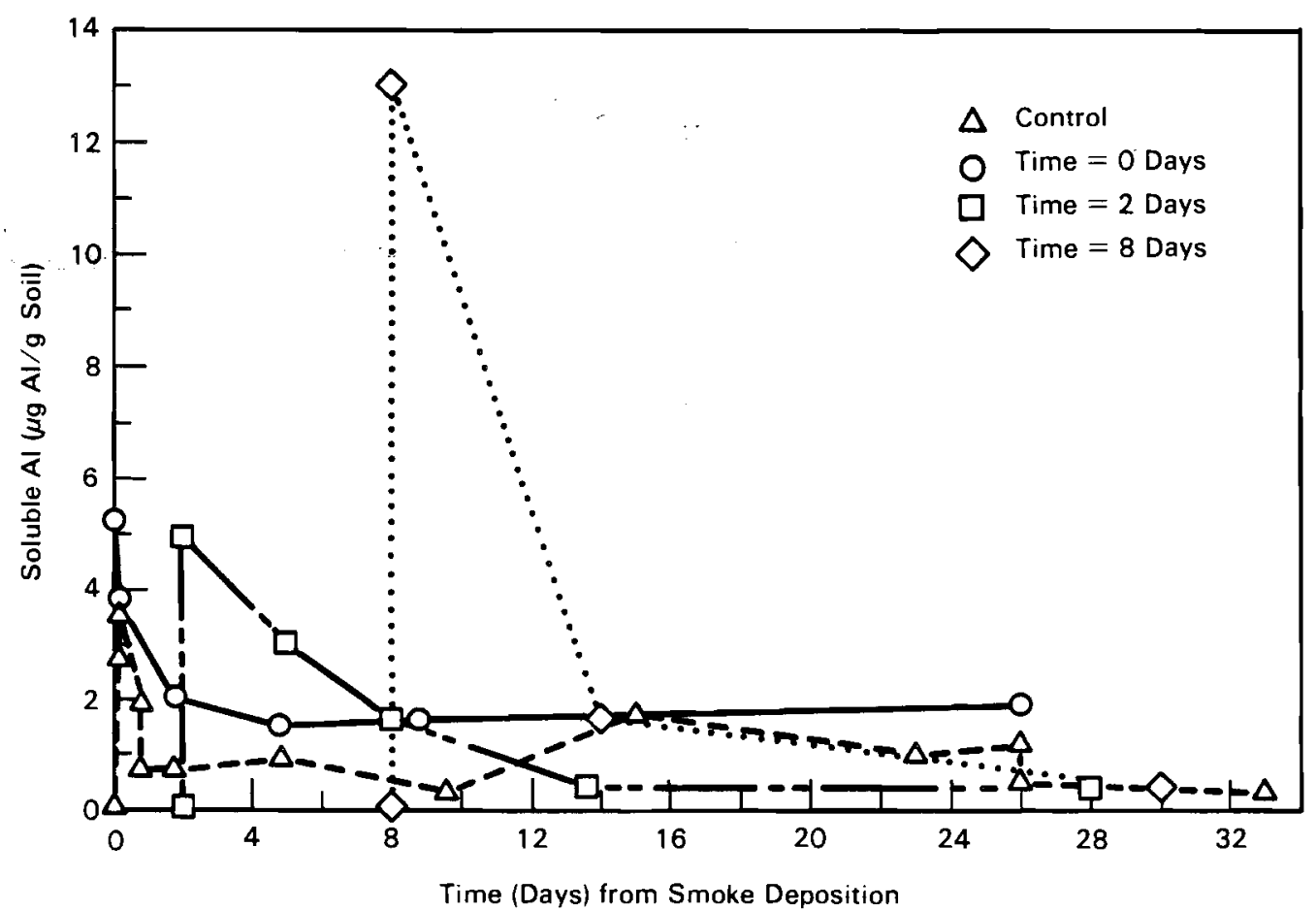

FIGURE 3.15. BEHAVIOR OF SOLUBLE AL FROM YAMAC SOIL AFTER RP/BR EXPOSURE 
(1) no delay time: $\quad Y=41.88 * 10(-.364) x, R^{2}=0.90$

(2) delay time 2 days: $Y=44.76 * 10(-.517) X, \quad R^{2}=0.94$

(3) delay time 8 days: $Y=111.4 * 10^{(-.762) \times}, R^{2}=0.92$

In similar fashion, soluble Al from exposed Shawano soil (Figure 3.11) fit to logarithmic equations yielding $R^{2}$ values ranging from 0.86 to 0.90 . Yamac (Figure 3.15) exhibits poorer agreement $\left(R^{2}=.79\right)$ for the no time-delay curve, chiefly due to the elevated 15-day Al value. Delayed contacts resulted in $\mathrm{log}$ fits having $\mathrm{R}^{2}$ values of 0.96 and 0.90 for the 2-day and 8-day delay periods, respectively. Only Yamac soil shows an increase in initial solubility of aluminum with increase in elapsed time prior to water contact of an exposed soil. Burbank soil displayed the slowest rate of aluminum solubility loss. Addition of phosphoric acid to the controls on day 26 did not cause any significant increase in aluminum solubility in any soils. Burbank and Maxey Flats soils (see Table 3.29) appear to release iron in a soluble form as a result of smoke deposition; an equivalent or greater release of iron is seen with the other three soils as a result of phosphoric acid addition.

When soil aliquots of depths varying over a 35-fold range were exposed to RP/BR smoke (range-finding test B9.2), followed by water leaching as previously discussed, the affected soluble species changed in proportion to the effective dilution ratio when adjusted for the control concentrations. Data for Burbank soil is presented in Table 3.30. Logarithmic curve fit $(Y=A \star X \wedge B)$ parameters are given for the species listed. For clarity, selected curve fits are displayed graphically in Figures 3.16 through 3.19. Total P (Figure 3.16) shows essentially a simple dilution effect with increased exposed soil depth ratio. The fit soluble Fe concentration with increased exposed soil depth ratio is not as good, most likely due to interactive effects of resultant solution $\mathrm{pH}$ on solubilization. Increase in percent of total soluble $P$ as phosphate (Figure 3.19) with increased exposed soil depth ratio suggests that the effects of aerosol deposition will be primarily that of acidic phosphate deposition, once allowed to be diluted in the environment. All soils showed that any effect of the smoke addition is essentially mitigated at the greater soil depth ratios, with the possible exception of soluble calcium from Burbank soil. Even poorly buffered soils such as Burbank soil appear to be able to neutralize smoke effects, provided enough soil is present. The interaction between dispersion, percolation through soil, and runoff pooling will most likely govern the soluble composition and hydrolysis rates of phosphorus species under actual field conditions. 
TABLE 3.30. EFFECT OF RP/BR-EXPOSED SOIL DEPTH ON SOLUBLE SPECIES AFTER 5-DAY INCUBATION

\section{Burbank soil}

Depth $\mathrm{P}_{\text {TOT }} \% \mathrm{PO}_{4}{ }^{3^{-}-\mathrm{P}}$

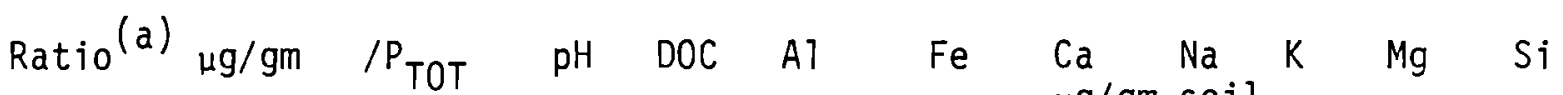
- - - - - -

\begin{tabular}{|c|c|c|c|c|c|c|c|c|c|c|c|}
\hline $\begin{array}{c}1 \\
2 \\
4.5 \\
8.9 \\
35 \\
\text { Control } \\
\text { previous } \\
\text { run a } \\
\text { depth 1 }\end{array}$ & $\begin{array}{r}689 \\
333 \\
144 \\
74 \\
20 \\
5\end{array}$ & $\begin{array}{r}60 \\
67 \\
80 \\
90 \\
100 \\
100\end{array}$ & $\begin{array}{l}5.5 \\
6.5 \\
7.2 \\
7.6 \\
7.9 \\
8.0\end{array}$ & $\begin{array}{l}79 \\
64 \\
56 \\
44 \\
37 \\
35\end{array}$ & $\begin{array}{l}49 \\
17 \\
2.7 \\
1.4 \\
0.9 \\
1.1\end{array}$ & $\begin{array}{r}10.6 \\
3.9 \\
1.8 \\
1.5 \\
1.4 \\
1.3\end{array}$ & $\begin{array}{r}256 \\
130 \\
68 \\
54 \\
43 \\
34\end{array}$ & $\begin{array}{l}6.5 \\
5.2 \\
5.4 \\
5.2 \\
3.7 \\
4.7\end{array}$ & $\begin{array}{l}214 \\
177 \\
156 \\
153 \\
131 \\
129\end{array}$ & $\begin{array}{l}57 \\
33 \\
19 \\
17 \\
10 \\
10\end{array}$ & $\begin{array}{r}177 \\
119 \\
87 \\
70 \\
58 \\
60\end{array}$ \\
\hline \multicolumn{12}{|c|}{ Curve Parameters(b) } \\
\hline $\begin{array}{l}A \\
B \\
R^{2}\end{array}$ & $\begin{array}{r}666.5 \\
-.995 \\
1.00\end{array}$ & $\begin{array}{r}61.6 \\
.149 \\
.96\end{array}$ & $\begin{array}{l}5.9 \\
-.09 \\
.85\end{array}$ & $\begin{array}{r}76 \\
-.2 \\
.98\end{array}$ & $\begin{array}{r}31.2 \\
-1.16 \\
.88\end{array}$ & $\begin{array}{c}6.5 \\
-.5 \\
.76\end{array}$ & $\begin{array}{r}192 \\
-.49 \\
.85\end{array}$ & $\begin{array}{c}6.3 \\
-.13- \\
.86\end{array}$ & $\begin{array}{r}201 \\
-.12 \\
.92\end{array}$ & $\begin{array}{r}48 \\
-.47 \\
.94\end{array}$ & $\begin{array}{r}154 \\
-.30 \\
.92\end{array}$ \\
\hline
\end{tabular}

(a) Approximate deepest depth: $14.5 \mathrm{~mm}$. Estimated depth ratio of 1 would be equivalent to depth of approximately $0.4 \mathrm{~mm}$.

(b) Fit via equation $Y=A X^{B}$, where $Y=$ concentration of species of interest and $X=$ depth ratio. 


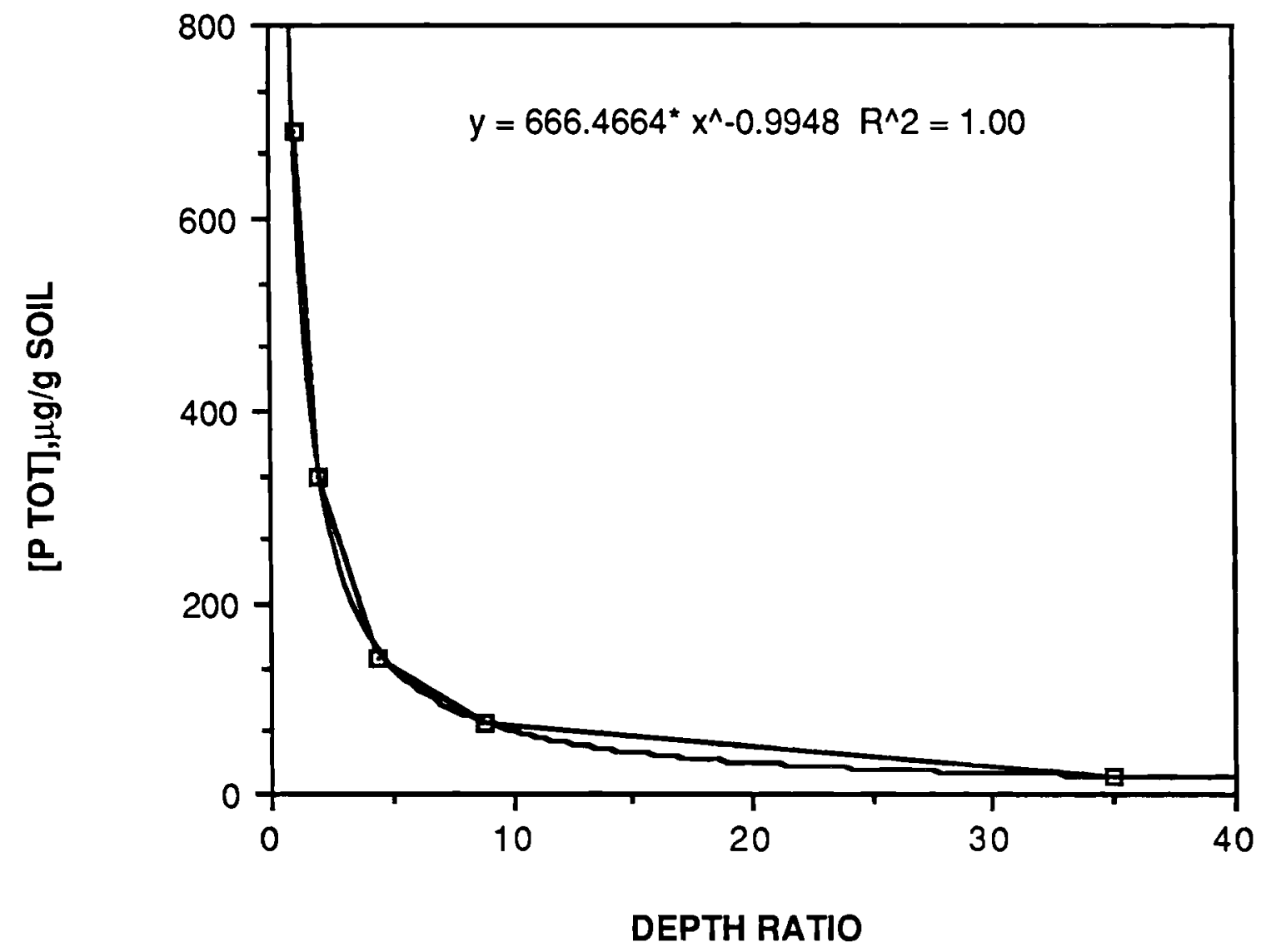

FIGURE 3.16. CONCENTRATION OF SOLUBLE P VERSUS EXPOSED SOIL DEPTH RATIO (SEE TABLE 3.30) 


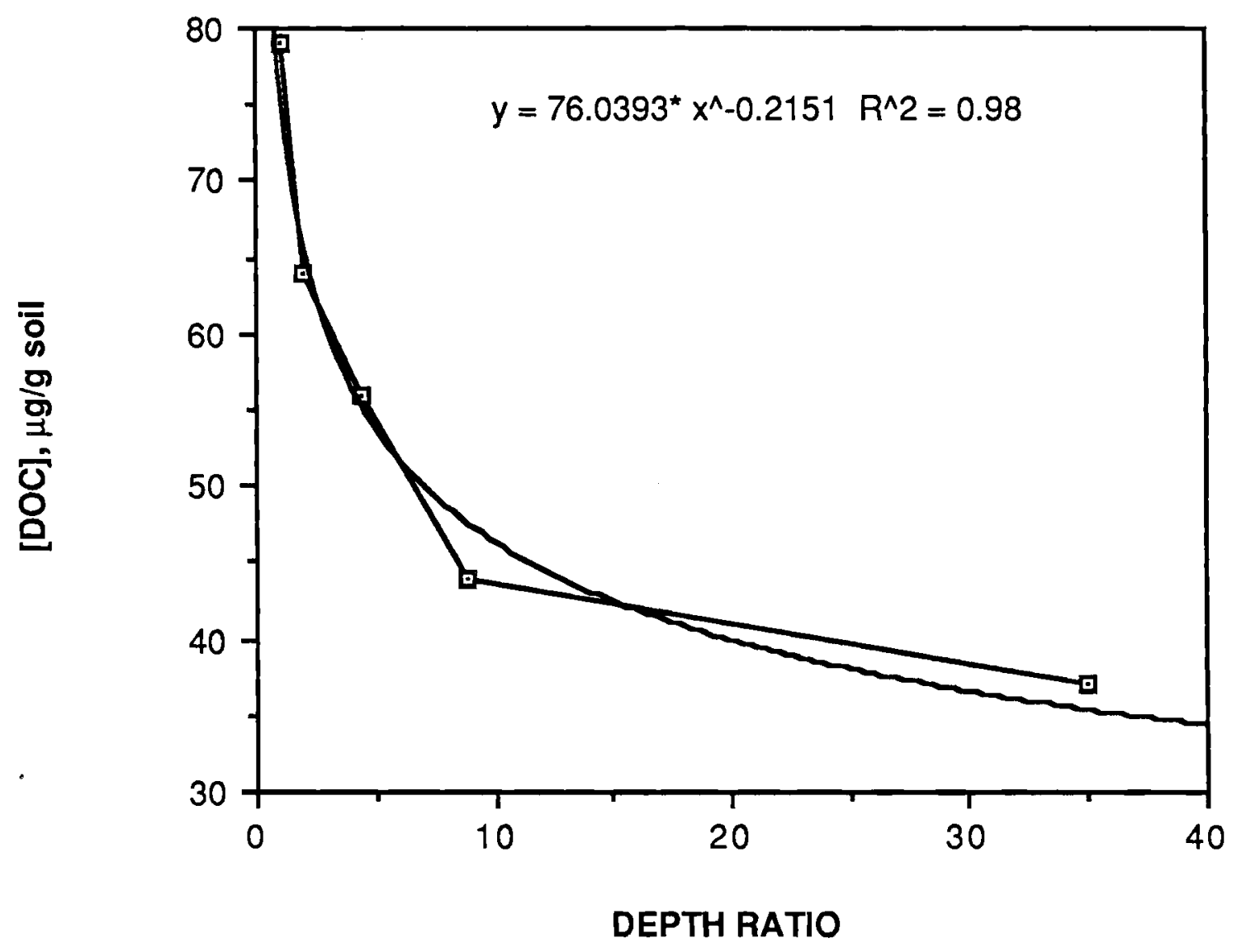

FIGURE 3.17. CONCENTRATION OF DISSOLVED ORGANIC $C$ VERSUS EXPOSED SOIL DEPTH RATIO (SEE TABLE 3.30) 


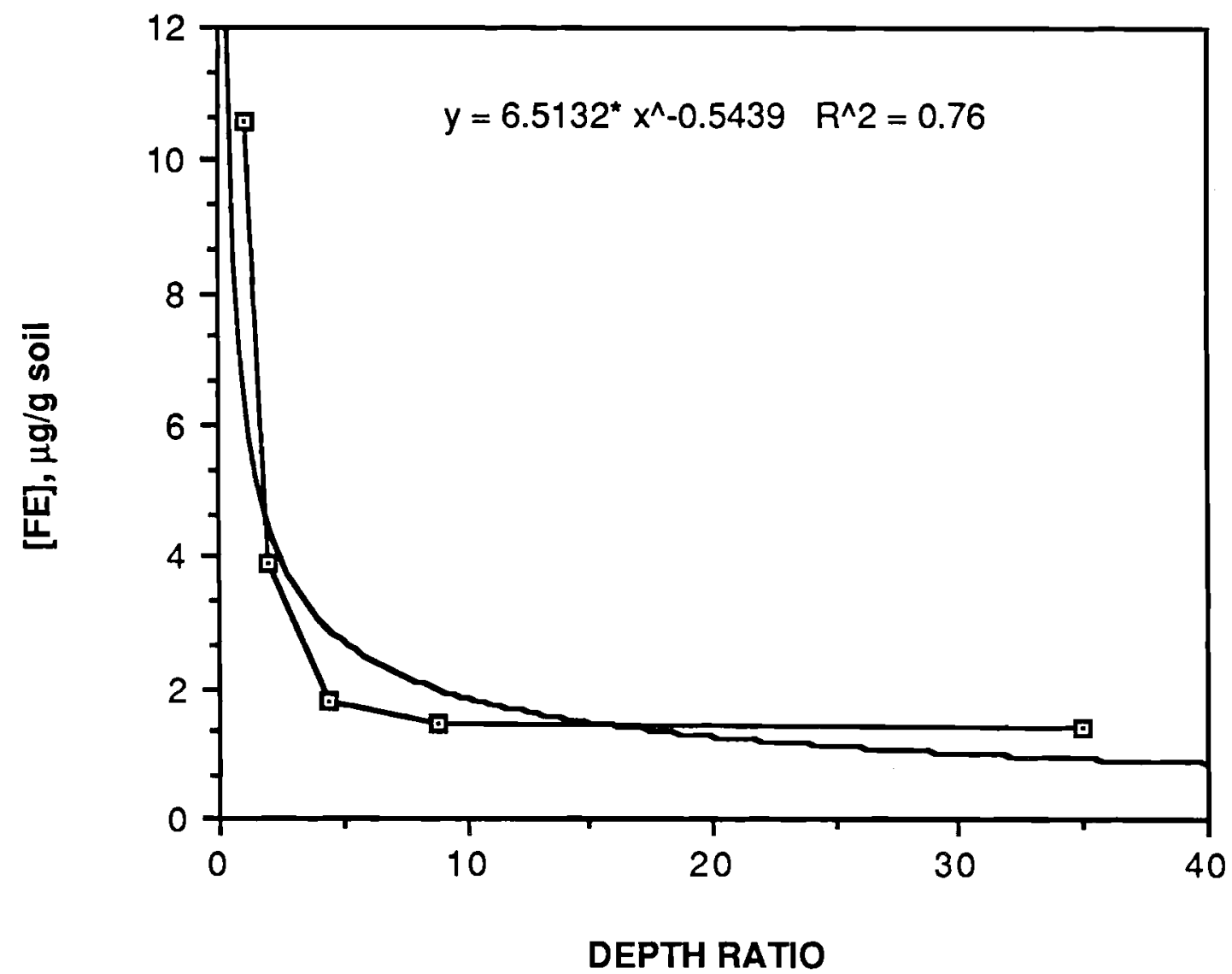

FIGURE 3.18. CONCENTRATION OF SOLUBLE IRON VERSUS EXPOSED SOIL DEPTH RATIO (SEE TABLE 3.30) 


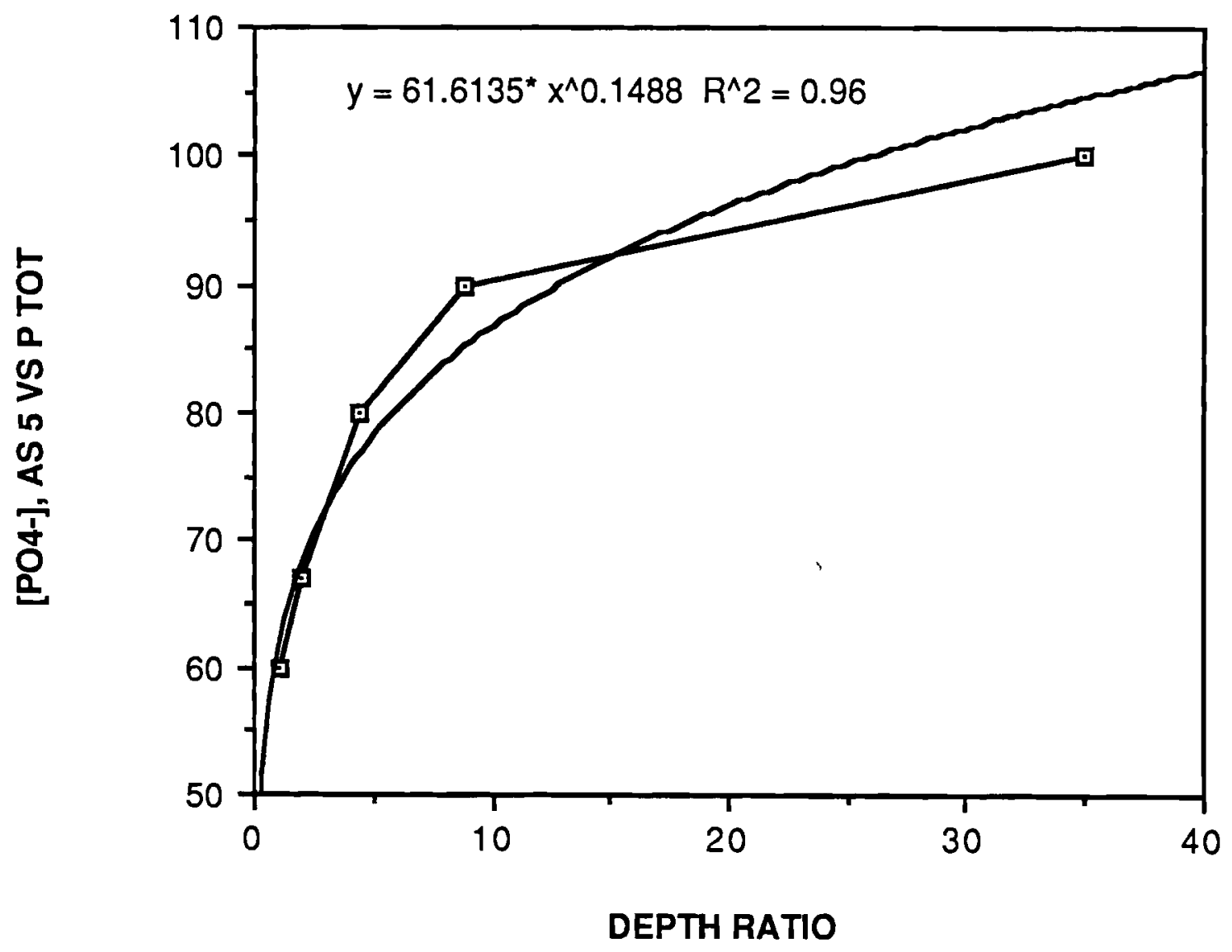

FIGURE 3.19. PERCENT OF TOTAL SOLUBLE PHOSPHORUS AS PHOSPHATE VERSUS EXPOSED SOIL DEPTH RATIO (SEE TABLE 3.30) 


\subsubsection{Total and Phosphate -P Distribution}

Four well-characterized surface soils representing a range in soil properties were exposed in replicate to a 2-hour RP/BR aerosol (range-finding test $A 3$ ). After termination of the 26-day leaching study, the control flasks were amended with phosphoric acid (140 ppm phosporus) at a level approximating the levels deposited to the soils, based on deposition velocities to surfaces. As an added control, a fresh aliquot of Burbank soil was also contacted with dilute phosphoric acid (118 ppm phosphorus). Burbank and Maxey Flats (silt loam) soils were exposed in a 4-hour WP test (WP-E3), but acidification following the 24-day leaching study was not done since there was no indication of change in soil response with phosphorus type. Two analyses using Burbank soil were used in the WP test since the batch used for planting native species was from a different lot than that used in the RP/BR exposures.

A striking difference in soil response between the RP/BR and WP exposures is seen in the amount of soluble phosphorus and $\mathrm{PO}_{4}-\mathrm{P}$ with time (Tables 3.31 and 3.32). Values for exposed soils are averages of replicate results. Control values at 0.8 and 9-10 days are included. Since all soils within a set were exposed simultaneously to the corresponding aerosol, variation in soluble $P_{\text {TOT }}$ must result from precipitation/adsorption effects. The similar loss of soluble phosphorus following phosphoric acid spiking of the control flasks supports this theory. The phosphorus mass loading on soils exposed to WP smoke was over twice that of the RP/BR test, mainly because of the length of the exposure. Although Maxey Flats soils showed a marked loss of soluble phosphorus with time, the percent of that soluble portion which was as phosphate was not radically different from that of the Burbank soil. Both soils show a lower percent as phosphate at 24 days than was seen with RP/BR ( $72 \%$ versus $87 \%$ ), which could be due in part to the increased phosphorus loading and subsequent lower $\mathrm{pH}$ on the soils with WP exposure.

When RP/BR-exposed soils were held in covered (but not airtight) Petri dishes for periods of time prior to initial water contact, loss of soluble

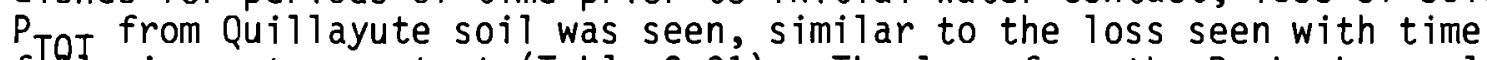
following water contact (Table 3.31). The loss from the Burbank sample was unexpected; however, the percent as phosphate rose expectedly in all cases except for Yamac soil, where it remained relatively constant. Since Yamac was the only soil to display increased aluminum solubility with time delay to water contact, the breakdown of the higher order polyphosphates is likely passing through, or being rate determined by, a smaller poly- or metaphosphate with no particular affinity for aluminum. Further work in this area should include the study of effects on solubilities in soils upon amendment with known compounds, such as tripoly-and trimetaphosphate. When varying depths of Burbank soil were exposed to RP/BR (range-finding test B9.2), the percent of total phosphorus present in the subsequent leachings increased to essentially $100 \%$ as the depth ratio rose to 35 at the 5 -day sampling period. 
TABLE 3.31. EFFECT OF SOIL TYPE AND LEACHING TIME OF P0 ${ }_{4}^{3}-{ }_{-P}$ AND TOTAL SOLUBLE PHOSPHORUS FOLLOWING RP/BR AEROSOL EXPOSURE

$$
\text { Soluble } \mathrm{P}_{\mathrm{TOT}}(\mu \mathrm{g} / \mathrm{g} \text { soil }) \quad \% \mathrm{PO}_{4}{ }^{3-}-\mathrm{P} / \mathrm{P}_{\mathrm{TOT}} \text { Soluble }
$$

Time

(days) Burbank Quillayute Shawano Yamac Burbank Quillayute Shawano Yamac

$\begin{array}{lllllllll}0.1 & 770 & 130 & 660 & 570 & 41 & 5.8 & 52 & 38\end{array}$

$\begin{array}{lllllllll}0.2 & 740 & 120 & 620 & 540 & 44 & 5.8 & 56 & 40\end{array}$

$\begin{array}{lllllllll}0.8 & 820 & 100 & 630 & 580 & 40 & 2.9 & 55 & 40\end{array}$

$\begin{array}{lllllllll}2 & 780 & 68 & 600 & 580 & 46 & 2.1 & 57 & 42\end{array}$

$\begin{array}{lllllllll}5 & 810 & 22 & 460 & 560 & 56 & 9.5 & 76 & 60\end{array}$

$\begin{array}{lllllllll}9 & 800 & 11 & 380 & 540 & 64 & 216 & 83 & 72\end{array}$

$\begin{array}{lllllllll}15 & 760 & 8 & 320 & 540 & 74 & \sim 18 & 90 & 87\end{array}$

$\begin{array}{lllllllll}26 & 730 & 5 & 300 & 600 & 87 & \text { 232 } & 93 & 96\end{array}$

Control

\begin{tabular}{lllllllll}
0.8 & 6 & 2 & 42 & 12 & 77 & 54 & 53 & 53 \\
9 & 6 & 4 & 16 & 13 & 83 & $<5$ & 55 & 61 \\
\hline
\end{tabular}




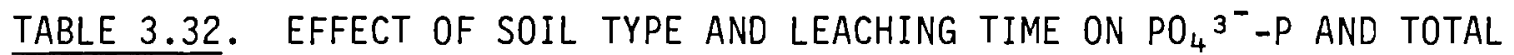
SOLUBLE PHOSPHORUS FOLLOWING WP AEROSOL EXPOSURE

\begin{tabular}{|c|c|c|c|c|c|c|}
\hline \multirow[b]{2}{*}{$\begin{array}{l}\begin{array}{l}\text { Time } \\
\text { (days) }\end{array} \\
0.2 \\
0.8 \\
3 \\
5 \\
10 \\
15 \\
25\end{array}$} & \multicolumn{2}{|c|}{ Soluble $\mathrm{P}_{\mathrm{TOT}}(\mathrm{mg} / \mathrm{g}$ soil) } & \multirow[b]{2}{*}{$\begin{array}{r}\text { Maxey } \\
\text { Flats } \\
1270 \\
1185 \\
1105 \\
1030 \\
940 \\
866 \\
838\end{array}$} & \multicolumn{3}{|c|}{$\% \mathrm{PO}_{4}{ }^{3}-\mathrm{P} / \mathrm{P}_{\mathrm{TOT}}$ soluble } \\
\hline & $\begin{array}{c}\text { Burbank-1 }(a) \\
1825 \\
1875 \\
1835 \\
1815 \\
1735 \\
1655 \\
1650\end{array}$ & $\begin{array}{c}\text { Burbank-2(b) } \\
1875 \\
1865 \\
1830 \\
1810 \\
1735 \\
1635 \\
1645\end{array}$ & & $\begin{array}{c}\text { Burbank-1 } \\
44 \\
46 \\
47 \\
51 \\
59 \\
68 \\
73\end{array}$ & $\begin{array}{c}\text { Burbank-2 } \\
42 \\
45 \\
46 \\
52 \\
59 \\
67 \\
71\end{array}$ & $\begin{array}{c}\text { Maxey } \\
\text { Flats } \\
53 \\
56 \\
54 \\
56 \\
62 \\
69 \\
73\end{array}$ \\
\hline 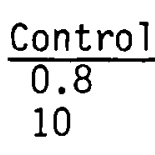 & $\begin{array}{l}6.4 \\
6.4\end{array}$ & $\begin{array}{l}6.2 \\
4.8\end{array}$ & $\begin{array}{r}2.8 \\
0.45\end{array}$ & $\begin{array}{l}66 \\
89\end{array}$ & $\begin{array}{l}49 \\
90\end{array}$ & $\begin{array}{r}13 \\
\sim 44\end{array}$ \\
\hline$\frac{\text { Acid Te }}{1}$ & $\begin{array}{r}\text { ch, day } 1 \\
1640 \\
1600\end{array}$ & $\begin{array}{l}\text { ND } \\
\text { ND }\end{array}$ & $\begin{array}{r}1050 \\
818\end{array}$ & $\begin{array}{l}99 \\
96\end{array}$ & $\begin{array}{l}\text { ND } \\
\text { ND }\end{array}$ & $\begin{array}{r}104 \\
96\end{array}$ \\
\hline
\end{tabular}




\subsubsection{Phorphorus speciation with soil contact}

To compare the effect of soil and its inherent microbial population on the stability of phosphorus species resulting from phosphorus smoke deposition, water extracts of exposed unamended sandy loam (Burbank) soil (6/26/84 exposure) were compared to de-ionized water depositions. Changes in phosphorus speciation with time following water contact of the soil are given in Table 3.33 (see Figure 3.9). Since metaphosphate elution is superimposed on the polyphosphate series, some peaks are not sufficiently separated for positive identification in the early samples. The increase in trimetaphosphate with time results from the breakup of long-chain polyphosphates. Much smaller amounts of tetra- and hexametaphosphates have been seen with time in other smoke solutions held for weeks to months (Poston et al. 1985). In contrast, soil contact greatly accelerated the breakdown of the polyphosphates to phosphate, and also either prevented formation of trimetaphosphate or accelerated its breakdown. After only 14 days, phosphate accounted for $94 \%$ of the soluble $\mathrm{P}_{\text {TOT }}$, as determined by IC.

\subsection{INTERACTIONS AND EFFECTS OF PHOSPHORUS SMOKES ON VEGETATION}

\subsubsection{Deposition Velocities for Phosphorus Smokes to Vegetative Surfaces}

The deposition velocity for an airborne contaminant to a receptor surface is influenced by atmospheric parameters and the characteristics of the receptor surface. The atmospheric parameters include particle size distribution, relative humidity, turbulence, and wind speed. These parameters affect the rate of transfer from the air column to the receptor. At low wind speed and turbulence, the deposition of small particles $(<0.5 \mu \mathrm{m})$ is controlled primarily by diffusional processes. As the particle size increases, sedimentation and gravitational forces become more important; with increased wind speed and turbulence, the rate of impaction and deposition to surfaces is accelerated. Relative humidity particularly affects the latter processes by increasing the effective aerodynamic size of hygroscopic particles. Likewise, the characteristics of the receptor surface can influence deposition velocity. These characteristics include surface roughness, thermal and water gradients in the case of diffusional processes, and canopy configuration or structure in the case of gravitational and sedimentation processes.

In each of the plant and/or soil exposures conducted using RP and WP smokes, deposition velocities were calculated to determine if they could be used to predict long-term impact to training sites. In practice, deposition velocity would be used to establish the relationship between frequency of obscurant smoke used in the field under a range of environmental and dosing conditions, and adverse terrestrial effects estimated from laboratory studies. 
TABLE 3.33. CHANGE IN PHOSPHORUS SPECIATION WITH TIME AFTER RP/BR DEPOSITION ON WATER AND ON THIN LAYER OF SANDY LOAM SOIL FOLLOWED BY WATER EXTRACTION

\begin{tabular}{|c|c|c|c|c|c|c|}
\hline \multirow{2}{*}{$\begin{array}{l}\text { Time of } \mathrm{H}_{2} \mathrm{O} \text { contact } \\
\text { Media }\end{array}$} & \multicolumn{2}{|c|}{ Day } & \multicolumn{2}{|c|}{ Day 2} & \multicolumn{2}{|c|}{ Day 9} \\
\hline & $\overline{\mathrm{H}_{2} \mathrm{O}}$ & Soi1 & $\overline{\mathrm{H}_{2} \mathrm{O}}$ & Soi1 & $\overline{\mathrm{H}_{2} \mathrm{O}}$ & Soi1 \\
\hline $\begin{array}{l}P \text { Species } \\
1 P \\
2 P \\
3 P \\
4 P \\
5 P \\
6 P \\
7 P \\
8 P \\
9 P \\
10 P+6 m p \\
11 P+4 m P \\
12 P \\
13 P \\
14 P+3 m P \\
15 P \\
16 P \\
17 P \\
18 P \\
19 P \\
20 P \\
21 P \\
22 P \\
23 P\end{array}$ & $\begin{array}{r}23 \\
9.6 \\
6.8 \\
6.8 \\
7.3 \\
6.9 \\
6.2 \\
5.7 \\
4.8 \\
4.5 \\
3.5 \\
3.0 \\
3.1 \\
\sim 3.6 \\
1.4 \\
0.9 \\
1.1 \\
0.5 \\
0.4 \\
0.3 \\
0.2 \\
\sim 0.2 \\
\sim 0.2\end{array}$ & $\begin{array}{l}42 \\
4.1 \\
6.9 \\
7.6 \\
7.1 \\
5.3 \\
3.1 \\
3.5 \\
2.8 \\
3.1 \\
1.6 \\
1.7 \\
1.3 \\
8.4 \\
0.6 \\
0.6 \\
0.6\end{array}$ & $\begin{array}{l}26 \\
9.2 \\
7.6 \\
9.5 \\
9.6 \\
8.2 \\
6.3 \\
4.9 \\
3.6 \\
2.9 \\
1.8 \\
1.6 \\
0.8 \\
7.9\end{array}$ & $\begin{array}{r}42 \\
3.3 \\
8.4 \\
8.0 \\
7.4 \\
5.7 \\
2.6 \\
2.9 \\
2.5 \\
2.4 \\
1.8 \\
21.2 \\
1.0 \\
10.3\end{array}$ & $\begin{array}{r}30 \\
12 \\
10 \\
13 \\
9.8 \\
5.1 \\
2.6 \\
0.9 \\
0.5 \\
0.5 \\
0.7\end{array}$ & \begin{tabular}{r}
\multicolumn{1}{c}{8} \\
3.7 \\
7.3 \\
1.5 \\
0.8 \\
0.4 \\
0.2 \\
$<0.2$ \\
$<0.2$ \\
1.7 \\
1.3
\end{tabular} \\
\hline
\end{tabular}




\subsubsection{Influence of Exposure Duration}

In Table 3.34, deposition velocities are shown for the initial range-finding test for RP smoke exposure. Five plant species with a range of canopy structure and geographic distributions were exposed for 2 to 8 hours to smokes containing $524 \mathrm{mg} \mathrm{P} / \mathrm{m}^{3}\left(\sim 2 \mathrm{~g}\right.$ smoke $\left./ \mathrm{m}^{3}\right)$, at constant temperature and humidity and at a wind speed of $2 \mathrm{mph}$.

In the case of the native plants (ponderosa pine, short-needle pine, sagebrush, and blando brome), deposition velocities averaged $13 \times 10^{3}$ $\mathrm{cm} / \mathrm{sec}$. These velocities were relatively constant with the durations of exposure, as would be expected. The similarity in deposition velocity between these species is primarily due to their common canopy characteristics (open canopy structure, with little shadowing of adjacent foliage). Deposition values for bushbean are approximately half of that determined for the native species, in the 2- to 6-hour exposures, and are comparable at 8 hours. It is assumed these differences are real, based on the overall data for bushbean, and result because bushbean has a more closed canopy structure, with large leaves that droop to shadow lower foliage. Therefore, deposition velocities to cultivated, densely packed, agricultural species may be lower than those observed for the native species. Because of the chemical similarities between RP/BR and WP smokes, range-finding tests were not performed for WP.

\subsubsection{Influence of Relative Humidity}

Relative humidity can affect the deposition of particles. The hydration of airborne particles can increase their MMAD and rate of sedimentation to plant surfaces and/or soils. In addition, changes in relative humidity can alter the thermal and water gradients of receptor surfaces. Such changes are more common with particles of $<0.1 \mu \mathrm{m}$ MMAD, which are deposited by diffusional processes. In Table 3.35, deposition velocities of RP smokes to vegetative canopies are reported for relative humidities of $27 \%$ to $89 \%$. If deposition velocity is assumed to represent an interception efficiency, then blando brome is most efficient, followed by the pines and sagebrush, with bushbean the least efficient in particle collection.

This efficiency is consistent for each of the three humidity treatments presented in Table 3.35 and Figure 3.20. With each plant species, there appears to be an effect of relative humidity on deposition velocity. The lowest deposition velocity values occur at $53 \%$ relative humidity with all five plant species. The values increase slightly at $27 \%$ relative humidity and are statistically significant and apparently result from the increase in MMAD of airborne particles from 1.60 to $1.73 \mu \mathrm{m}$. The particle size increase apparently results from conditions of the burn, and cannot be assigned to the water content of the air stream. At $89 \%$ relative humidity, however, the deposition velocity values almost double for each plant species. The values correspond to a sharp rise in MMAD to $1.95 \mu \mathrm{m}$, and most probably result from hydration and phosphorus particle growth. 
TABLE 3.34. DEPOSITION VELOCITIES FOR PLANT SPECIES EXPOSED TO A CONSTANT AIR CONCENTRATION OF RP SMOKE

\begin{tabular}{|c|c|c|c|c|}
\hline Plant species & \multicolumn{4}{|c|}{ Exposure duration (hr) } \\
\hline & \multicolumn{4}{|c|}{$v_{d}\left(\mathrm{~cm} / \mathrm{sec} \times 10^{3}\right)^{(b)}$} \\
\hline $\begin{array}{l}\text { Ponderosa pine } \\
\text { Short-needle pine } \\
\text { Sagebrush } \\
\text { Blando brome } \\
\text { Bushbean }\end{array}$ & $\begin{array}{r}17 \pm 12 \\
12 \pm 1 \\
13 \pm 4 \\
13 \pm 3 \\
4 \pm 1\end{array}$ & $\begin{array}{r}14 \pm 4 \\
12 \pm 1 \\
11 \pm 2 \\
10 \pm 2 \\
7 \pm 2\end{array}$ & $\begin{array}{r}11 \pm 1 \\
13 \pm 1 \\
18 \pm 2 \\
12 \pm 1 \\
7 \pm 2\end{array}$ & \\
\hline
\end{tabular}

(a) Exposures conducted at $21^{\circ} \mathrm{C}$ and $-20 \%$ relative humidity; aerosols had a

(b) MMAD of $0.75 \mathrm{mu}$ and a GSD of 1.60 ; experiment code A-1 and A-2.

(b) Deposition velocity $\left(V_{d}\right)$ expressed in $\mathrm{cm} / \mathrm{sec}$ and is based on $2 X$ projected area; values are means \pm SD for four replicates.

TABLE 3.35. INFLUENCE OF RELATIVE HUMIDITY ON DEPOSITION VELOCITIES FOR RP/BR DEPOSITION TO VEGETATIVE SURFACES. ${ }^{(a)}$

\begin{tabular}{|c|c|c|c|c|c|c|}
\hline \multicolumn{2}{|c|}{ Experimentai } & Ponderosa & $\begin{array}{l}\text { Short- } \\
\text { needle } \\
\text { pine }\end{array}$ & Sagebrush & Bushbean & \multirow[t]{2}{*}{$\begin{array}{l}\text { Bl ando } \\
\text { brome }\end{array}$} \\
\hline Condition & code & & & $\mathrm{cm} / \mathrm{sec} \times 10^{3}$ & & \\
\hline $2 \mathrm{mph} / 27 \% \mathrm{RH}$ & $D-3$ & $8.4 \pm 0.33$ & $8.3 \pm 0.10$ & $10.4 \pm 0.8$ & $6.1 \pm 0.9$ & $14.4 \pm 2.0$ \\
\hline $2 \mathrm{mph} / 53 \% \mathrm{RH}$ & $D-1$ & $7.0 \pm 0.5$ & $7.5 \pm 0.2$ & $6.4 \pm 2.4$ & $4.1 \pm 0.6$ & $9.3 \pm 0.1$ \\
\hline $2 \mathrm{mph} / 898 \mathrm{RH}$ & $D-4$ & $12.9 \pm 2.4$ & $13.2 \pm 1.6$ & $10.4 \pm 1.7$ & $7.7 \pm 1.6$ & $16.6 \pm 1.7$ \\
\hline
\end{tabular}

(a) Air concentrations for exposures $D-3, D-1$ and $D-4$ were 612,673 and $441 \mathrm{mgP} / \mathrm{m}^{3}$; MMAD (CSD) for exposures $D-3, D-1$, and $D-4$ were $1.73 \mu \mathrm{m}(1.57), 1.60 \mu \mathrm{m}(1.57)$, and $1.95 \mu \mathrm{m}(1.57)$, respectively. Exposure duration was 4 hours. $A v g \pm S D, n=3$. 

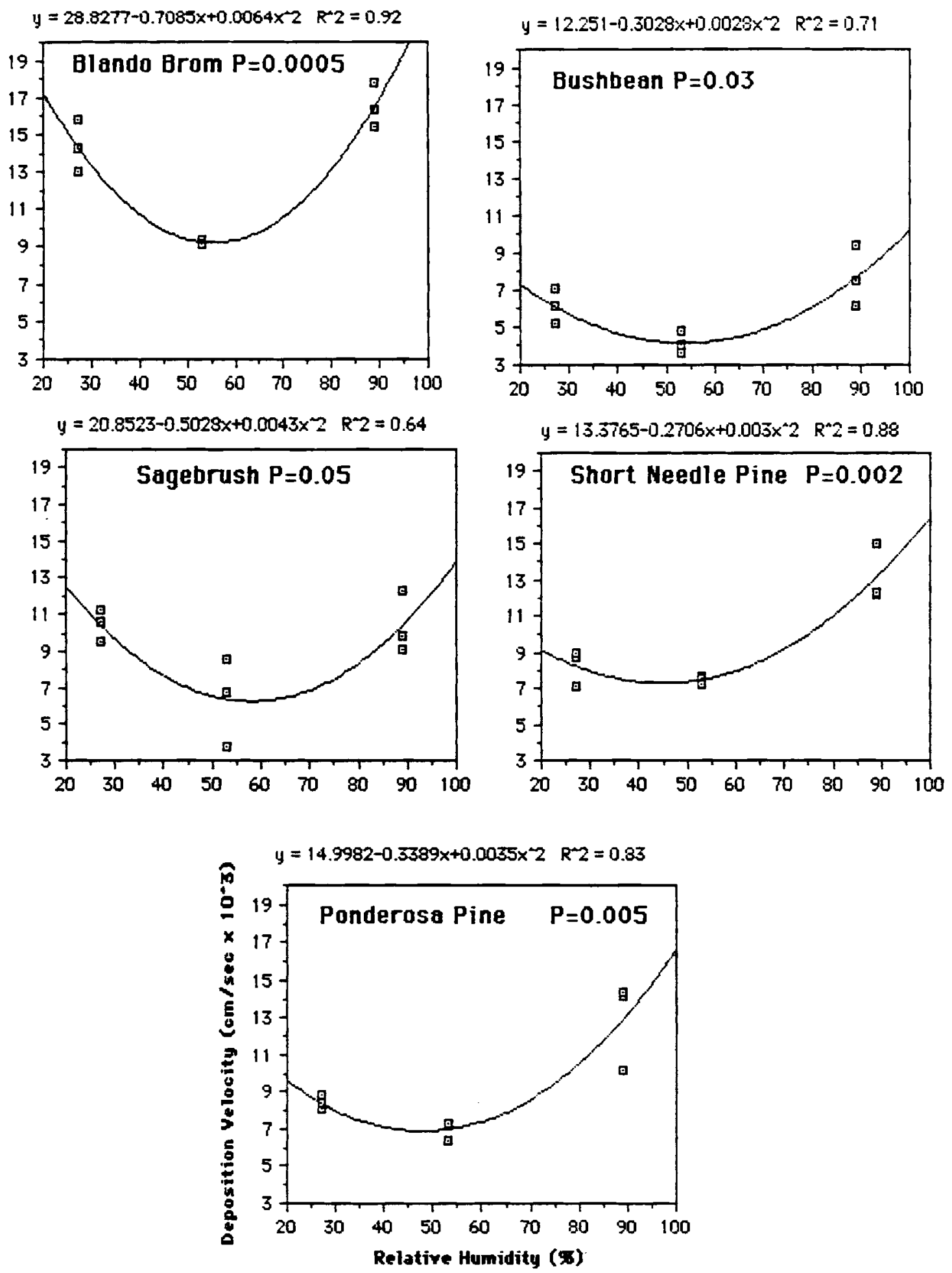

FIGURE 3.20. INFLUENCE OF RELATIVE HUMIDITY ON DEPOSITION VELOCITIES FOR FOLIAR SURFACES FOLLOWING EXP.OSURE TO RP/BR SMOKES. SEE TABLE 3.35 FOR PARTICLE SIZE DATA. 
However, effects of relative humidity on canopy characteristics affecting deposition cannot be ruled out.

In the WP smoke studies, the burn chamber was reconfigured to allow the addition of fresh, conditioned air, rather than totally tunnel-recycled air as in the RP tests. The new configuration gave a much more consistent particle size distribution over the individual 4-hour exposures. As noted in Table 3.36 and Figure 3.21, MMAD for the WP smokes increased relatively linearly from 1.50 to 1.62 to $1.75 \mu \mathrm{m}$ as the relative humidity was increased from $35 \%$ to $57 \%$ to $90 \%$. This indicates that as relative humidity increases, the particle size increases proportionally because of the hydration of phosphorus particles. The deposition velocity results for WP are generally consistent with those for RP/BR, if the MMAD are used as a basis for evaluating velocity. Deposition velocities for ponderosa pine, short-needle pine and bushbean are relatively constant at 4 to $9 \times 10$ $\mathrm{cm} / \mathrm{sec}$ at both $35 \%$ and $57 \%$ relative humidity. At $90 \%$ relative humidity, the deposition velocity for each of these plant species increases by a factor of two. Based on the MMAD for these three relative humidity treatments, it would appear that particle growth cannot totally explain the increase in deposition velocity, with at least a portion of the deposition efficiency being affected by changes in canopy characteristics at both the high and low relative humidity. The elevated deposition velocity is also seen with sagebrush and blando brome, and is consistent with the RP results. In the case of sagebrush and blando brome, deposition velocity values are somewhat elevated at 35\% relative humidity compared to the $57 \%$ relative humidity treatments. Regression analyses of the deposition velocity/relative humidity (Figure 3.17), shows deposition efficiency for WP to be generally comparable to that of RP/BR (Figure 3.18). In the case of WP, particle sizes increased from $1.5 \mu \mathrm{m}$ to $1.75 \mu \mathrm{m}$ with increasing relative humidity; thus the deposition velocity depressions noted at $\sim 50 \%$ relative humidity appear to be a function of canopy/particle interaction.

\subsubsection{Influence of Wind Speed}

Wind speed can significantly effect deposition velocity values by disrupting boundary conditions at the receptor surface and increasing the relative contribution of particle impaction, compared to diffusional and gravitational processes. In Table 3.37, deposition velocity values are shown for ponderosa pine and blando brome exposed to RP/BR smokes at $60 \%$ relative humidity for 1 hour at wind speeds from 0.5 to $10 \mathrm{mph}$. Particle size distributions for the four wind speed treatments were relatively consistent, considering three separate burns were conducted. Deposition velocities are comparable at 0.5 and $2 \mathrm{mph}$ for both plant species, and are consistent with previous deposition velocity values. As wind speed is increased to 5 and $10 \mathrm{mph}$, deposition velocity values for RP/BR increase sharply. For the ponderosa pine the effective rate of deposition is increased by a factor of 120 for 10 versus $2 \mathrm{mph}$, while the rate of deposition is higher by a factor of 70 for the grass species. The increases undoubtedly result from an increase in the impaction component of the deposition processes. 
TABLE 3.36. DEPOSITION VELOCITIES FOR WP TO FOLIAR SURFACES AS A FUNCTION OF RELATIVE HUMIDITY AND PLANT SPECIES(a)

\begin{tabular}{lccc}
\hline $\begin{array}{c}\text { Plant } \\
\text { species }\end{array}$ & $\begin{array}{c}\text { Exposure } \\
\text { code }\end{array}$ & $\begin{array}{l}\text { Relative } \\
\text { humidity }\end{array}$ & $\begin{array}{c}\text { Deposition } \\
\text { velocity } \\
\left.\text { (cm/sec } \times 10^{3}\right)\end{array}$ \\
\hline $\begin{array}{l}\text { Ponderosa } \\
\text { Pine }\end{array}$ & E3 & $35 \%$ & $7.9 \pm 0.8$ \\
& E1 & $57 \%$ & $6.8 \pm 1.1$ \\
Short & E4 & $90 \%$ & $12.9 \pm 1.5$ \\
Needle & E3 & $35 \%$ & $8.6 \pm 1.0$ \\
Pine & E1 & $57 \%$ & $9.4 \pm 1.1$ \\
Sagebrush & E4 & $90 \%$ & $12.4 \pm 1.1$ \\
& E3 & $35 \%$ & $13.5 \pm 2.5$ \\
& E1 & $57 \%$ & $8.5 \pm 1.4$ \\
Bushbean & E4 & $90 \%$ & $12.0 \pm 1.2$ \\
& E3 & $35 \%$ & $5.1 \pm 0.6$ \\
& E1 & $57 \%$ & $4.3 \pm 0.2$ \\
B1ando brome & E4 & $90 \%$ & $12.2 \pm 6.3$ \\
& E3 & $35 \%$ & $10.9 \pm 1.8$ \\
& E1 & $57 \%$ & $7.7 \pm 0.2$ \\
& E4 & $90 \%$ & $14.5 \pm 0.8$ \\
\hline
\end{tabular}

(a) Air concentrations for exposures E-3, E-1 and E-4 were 515, 625 and 405 $\mathrm{mg} P / \mathrm{m}^{3}$, respectively. MMAD (GSD) for exposures $\mathrm{E}-3, \mathrm{E}-1$, and $\mathrm{E}-4$ were $1.50 \mu \mathrm{m}(1.59), 1.62 \mu \mathrm{m}(1.65)$, and $1.75 \mu \mathrm{m}(1.60)$, respectively. Exposure duration was 4 hours; wind speed was $2 \mathrm{mph}$. Avg $\pm S D, n=3$. 

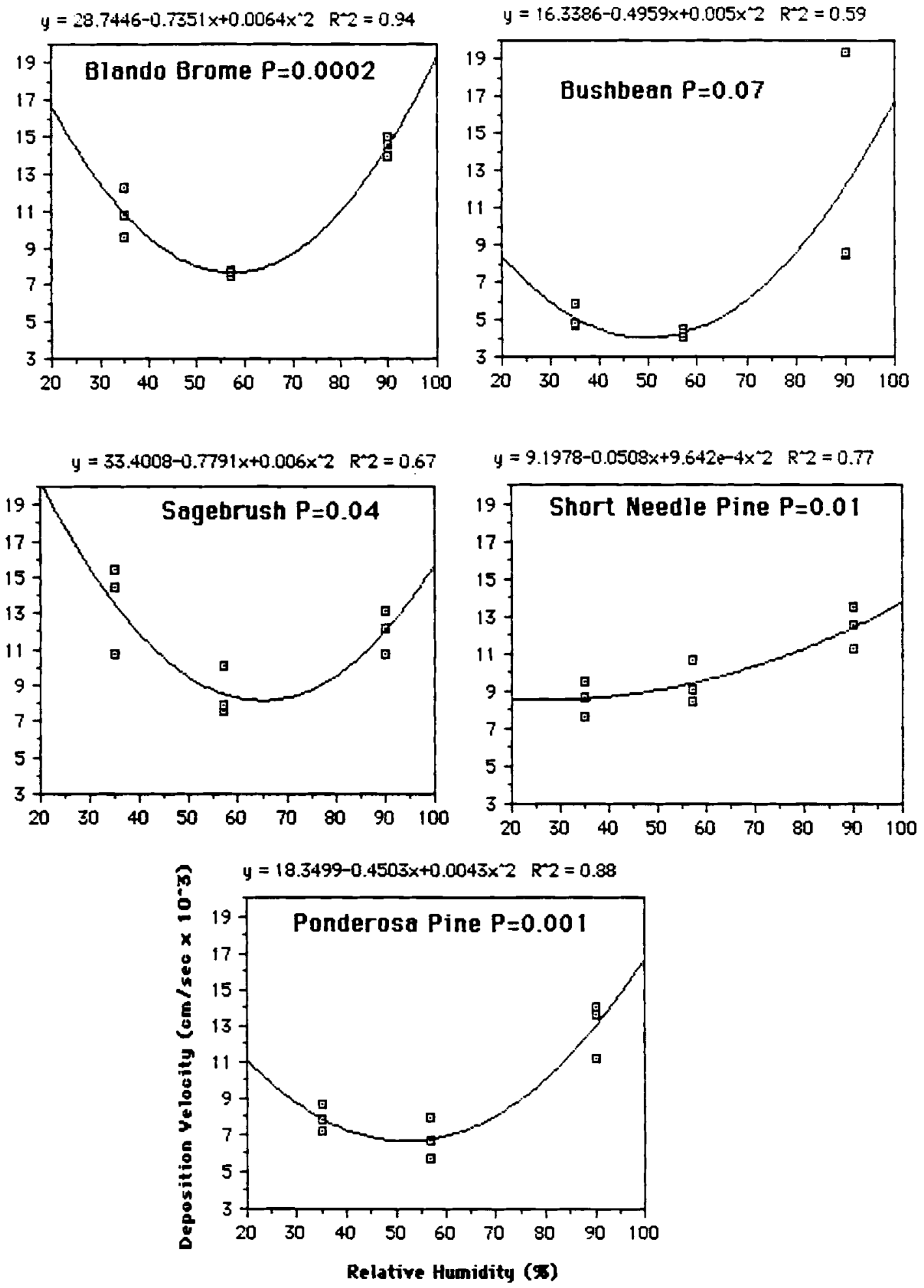

FIGURE 3.21. INFLUENCE OF RELATIVE HUMIDITY ON DEPOSITION VELOCITIES FOR FOLIAR SURFACES FOLLOWING EXPOSURE TO WP SMOKES. SEE TABLE. 3.36 FOR PARTICLE SIZE DATA. 
TABLE 3.37. INFLUENCE OF WIND SPEED ON DEPOSITION VELOCITY OF RP/BR SMOKES TO FOLIAGE OF PONDEROSA PINE AND BLANDO BROME(a)

\begin{tabular}{lccc}
\hline Plant species & Exposure code & $\begin{array}{c}\text { Wind speed } \\
(\mathrm{mph})\end{array}$ & $\begin{array}{c}\text { Deposition velocity } \\
\left(\mathrm{cm} / \mathrm{sec} \times 10^{3}\right)\end{array}$ \\
\hline \multirow{3}{*}{ Ponderosa Pine } & & & \\
& $D-5.3$ & 0.5 & $6.7 \pm 0.8$ \\
& $D-1$ & 2.0 & $7.0 \pm 0.5$ \\
& D-5.2 & 4.9 & $28.7 \pm 1.4$ \\
& D-2 & 10.0 & $835 . \pm 89$ \\
Blando Brome & D-5.3 & 0.5 & $8.7 \pm .10$ \\
& D-1 & 2.0 & $9.3 \pm 0.1$ \\
& D-5.2 & 4.9 & $160 . \pm 20$ \\
& $D-2$ & 10.0 & $657 . \pm 30$ \\
\hline
\end{tabular}

(a) Air concentrations for exposures $D-5.3, D-1, D-5.2$ and $D-2$ were 428 , 673,547 and $676 \mathrm{mg} \mathrm{P} / \mathrm{m}^{3}$, respectively; MMAD (GSD) for exposures $\mathrm{D}-5.3, \mathrm{D}-1, \mathrm{D}-5.2$, and $\mathrm{D} .2$ were $1.68 \mu \mathrm{m}(1.6), 1.60 \mu \mathrm{m}(1.57), 1.68 \mu \mathrm{m}$ (1.6), and $1.55 \mu \mathrm{m}(1.59)$, respectively. Exposure duration was 1 hour, at $53 \%$ to $64 \%$ relative humidity. Avg $\pm S D, n=3$.

Similar wind speed studies were conducted with WP smokes (Table 3.38). Wind speeds were varied from 2 to $10 \mathrm{mph}$, rather than from 0.5 to $10 \mathrm{mph}$ as for the RP smokes, in order to bracket the $5 \mathrm{mph}$ treatment that showed a rapid increase in deposition velocity. The results obtained for WP smokes are generally consistent with those obtained for RP smokes. In the case of ponderosa pine, deposition velocity values increase from $7 \times 10^{-3} \mathrm{~cm} / \mathrm{sec}$ at $2 \mathrm{mph}$, to $1200 \times 10^{-3} \mathrm{~cm} / \mathrm{sec}$ at wind speeds of $10 \mathrm{mph}$. Results for blando brome are comparable, and range from 8 to $920 \times 10^{-3} \mathrm{~cm} / \mathrm{sec}$. Based on the results for both RP/BR and WP, the deposition velocity to vegetative surfaces begins to increase at some point between 2 and $4 \mathrm{mph}$. It is important to note that deposition velocity is a deposition constant that is directly related to the extent of mass loading to leaves and soil, and therefore would indicate an increased impact at higher wind speeds. The magnitude of the change in mass loading for 2 versus $10 \mathrm{mph}$, based on deposition velocity values, would be a factor of 150 . 
TABLE 3.38. INFLUENCE OF WIND \$PEED ON DEPOSITION VELOCITY OF WP SMOKES TO FOLIAR SURFACES $\$$ (a)

\begin{tabular}{llcc}
\hline $\begin{array}{c}\text { Plant } \\
\text { species }\end{array}$ & $\begin{array}{l}\text { Exposure } \\
\text { code }\end{array}$ & $\begin{array}{l}\text { Wind } \\
\text { speed } \\
(\mathrm{mph})\end{array}$ & $\begin{array}{c}\text { Deposition } \\
\text { velocity } \\
\left(\mathrm{cm} / \mathrm{sec} \times 10^{3}\right)\end{array}$ \\
\hline Ponderosa Pine & E1 & 2 & $6.8 \pm 1.1$ \\
& E2.3 & 4 & $36.0 \pm 14.0$ \\
& E2.2 & 6 & $140 . \pm 30$. \\
E2.1 & 10 & $1180 . \pm 560$. \\
& E1 & 2 & $7.7 \pm 0.2$ \\
& E2.3 & 4 & $74 . \pm 16$ \\
& E2.2 & 6 & $147 . \pm 57$ \\
& E2.1 & 10 & $920 . \pm 170$
\end{tabular}

(a) Air concentrations for exposures E-1, E-2.3, E-2.2 and E-2.1 were 625, 490,440 and $410 \mathrm{mgP} / \mathrm{m}^{3}$, respectively; MMAD (GSD) for exposures E1, $\mathrm{E} 2.3, \mathrm{E} 2.2$, and E2.1 were $1.62 \mu \mathrm{m}(1.65), 1.59 \mu \mathrm{m}(1.62), 1.58 \mu \mathrm{m}$ $(1.6)$, and $1.52 \mu \mathrm{m}(1.53)$, respectively. Exposure duration was 1 hour at $57 \%$ to $66 \%$ relative humidity. $A v g \pm S D, n=3$.

The results of regression analyses of the wind speed tests for RP/BR and WP are shown in Figure 3.22. These figures clearly show a common relationship between wind speed and deposition velocity, with the latter being proportional to the magnitude of the mass loading or foliar dose. (For RP/BR the equation describing that exponential relationship is $Y=6.3457 * 10(0.2138 x)$, with an $R$ value of 0.96 . For WP the relationship is described by the $Y=4.303^{*} 10^{(0.2438 x}$, , with an $R$ value of 0.97$)$. The important point to note is that at wind speeds in excess of $6 \mathrm{mph}$, deposition velocity and therefore mass loading increase in a disproportionate manner. Thus the plant impacts reported in the $2 \mathrm{mph}$ experiment would be substantially more intense had the wind speed been higher. Thus, once deposition velocity has been determined for a set of conditions it can be used to compute mass loading of a smoke to vegetative and soil surfaces under field conditions, and can therefore be used to predict potential impact to the environment. 

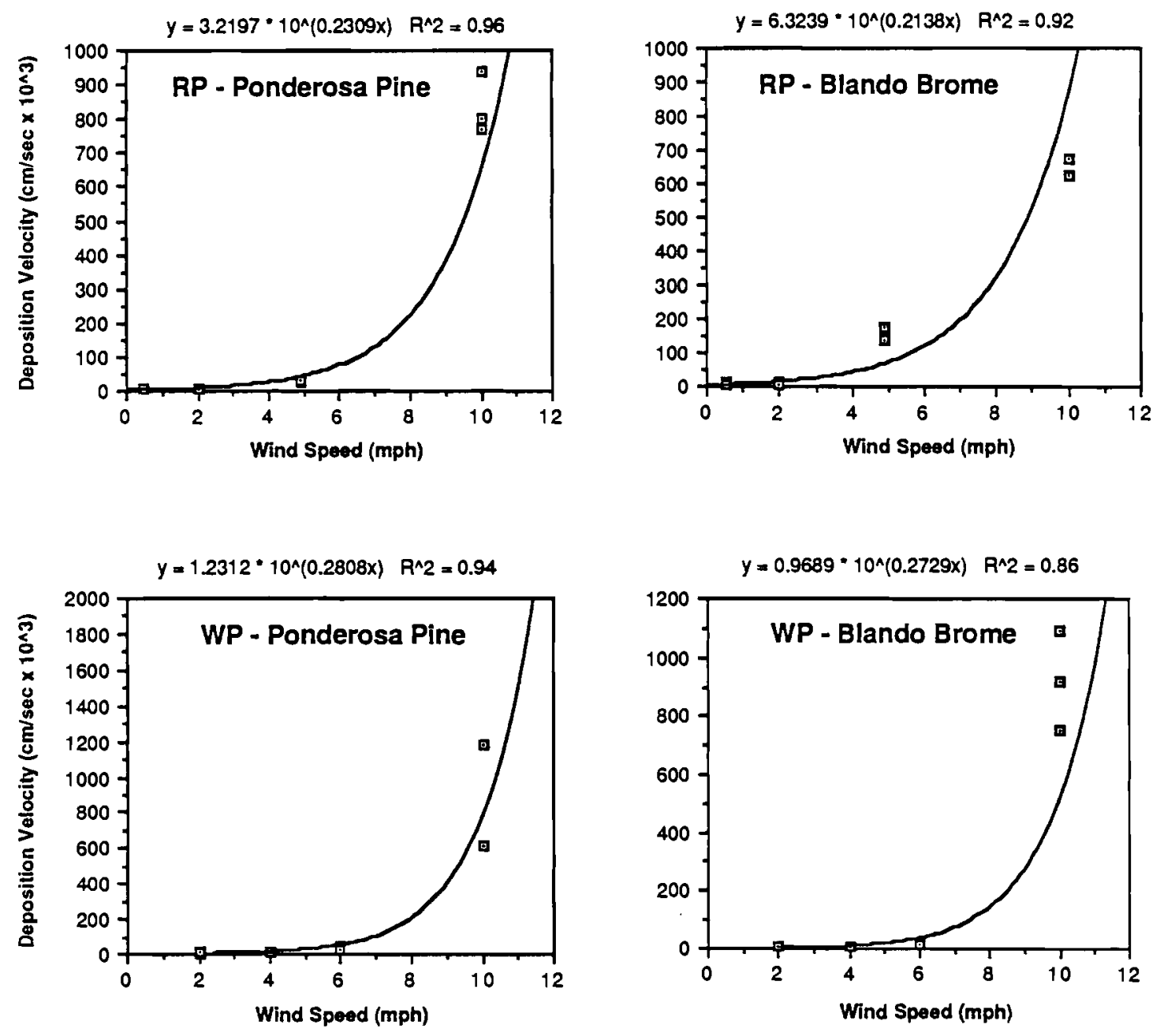

FIGURE 3.22. RELATIONSHIP BETWEEN WIND SPEED AND DEPOSITION VELOCITIES FOR PONDEROSA PINE AND BLANDO BROME FOLIAGE EXPOSED TO RP/BR AND WP SMOKES. SEE TABLES 3.37 and 3.38 FOR PARTICLE SIZE DATA. 


\subsubsection{Mass Loading to Vegetative Surfaces and Influence of Post-Exposure Simulated RainfaT1}

\subsubsection{Influence of Exposure Duration on Mass Loading}

The purpose of the range-finding test for RP/BR was to establish a dose/exposure regime that would produce detectable toxicity in the test plant species. Only limited statistical evaluations were performed with the mass loading data presented in this section. This is based on the fact that changes in the mass loading values with treatment are best considered in terms of deposition velocity which normalizes the data based on air concentration, since the latter varies slightly from run to run. As noted previously, our point of reference for the actual mass loading of phosphorus (or other measurable, representative components of a particular smoke) is the primary means for accessing both damage, in the case of different smokes, and treatment variables, such as relative humidity and wind speed, on vegetative surfaces. Table 3.39 shows the mass loading of phosphorus to foliage to increase proportionally with increases in the duration of exposure. Mass loading ranged from approximately 50 to $200 \mu \mathrm{g}$ $\mathrm{P} / \mathrm{cm}^{2}$ for each of the five plant species studied. Regression analysis of the mass loading results (Figure 3.23 ) for the five plant species show loading to be linearly related to exposure duration, although substantial data scatter is seen for ponderosa pine and bushbean in these early studies. Interception and retention of smoke aerosols was relatively consistent for the four native plants, and slightly lower for bushbean at the shorter exposure periods. As noted previously, the closed canopy structure in the bushbean may contribute to the time required for aerosols to equilibrate within the canopy.

As part of the phytotoxicity studies, a subset of each treatment was subjected to a post-exposure simulated rainfall equivalent to $0.5 \mathrm{~cm}$ of precipitation. This exposure permitted an evaluation of the ameliorating influence of rainfall on reducing mass loading levels on foliage and therefore any potential phytotoxicity. It is also possible, depending on the solubility and/or toxicity of the foliar-deposited contaminants, that the added surface moisture accentuates the effects of smoke materiais by increasing the extent of foliar absorption and subsequent toxicity. In the RP/BR range-finding test, application of a post-exposure simulated rainfall reduced mass loading in all species tested (Table 3.39). Mass loading on foliage was reduced from $50 \%$ to $95 \%$. The pines, with their open canopies, exhibited the greatest removal of foliar contaminants (85\%-95\%); mass loadings for sagebrush and bushbean, with relatively closed canopies, were reduced by $50 \%$ to $75 \%$. These results indicate that phosphorus smokes deposited onto foliar surfaces are not tightly bound or sorbed and can be readily removed during rainfall, and post-exposure rainfall may be an ameliorating process in environs with frequent rainfall events as compared to desert environs. 
TABLE 3.39. MASS LOADING OF RP/BR SMOKES TO PLANT FOLIAGE AS A FUNCTION OF EXPOSURE DURATION (RANGE-FINDING TEST), AND INFLUENCE OF POST-EXPOSURE SIMULATED RAINFALL ON RETENTION OF PHOSPHORUS (a)

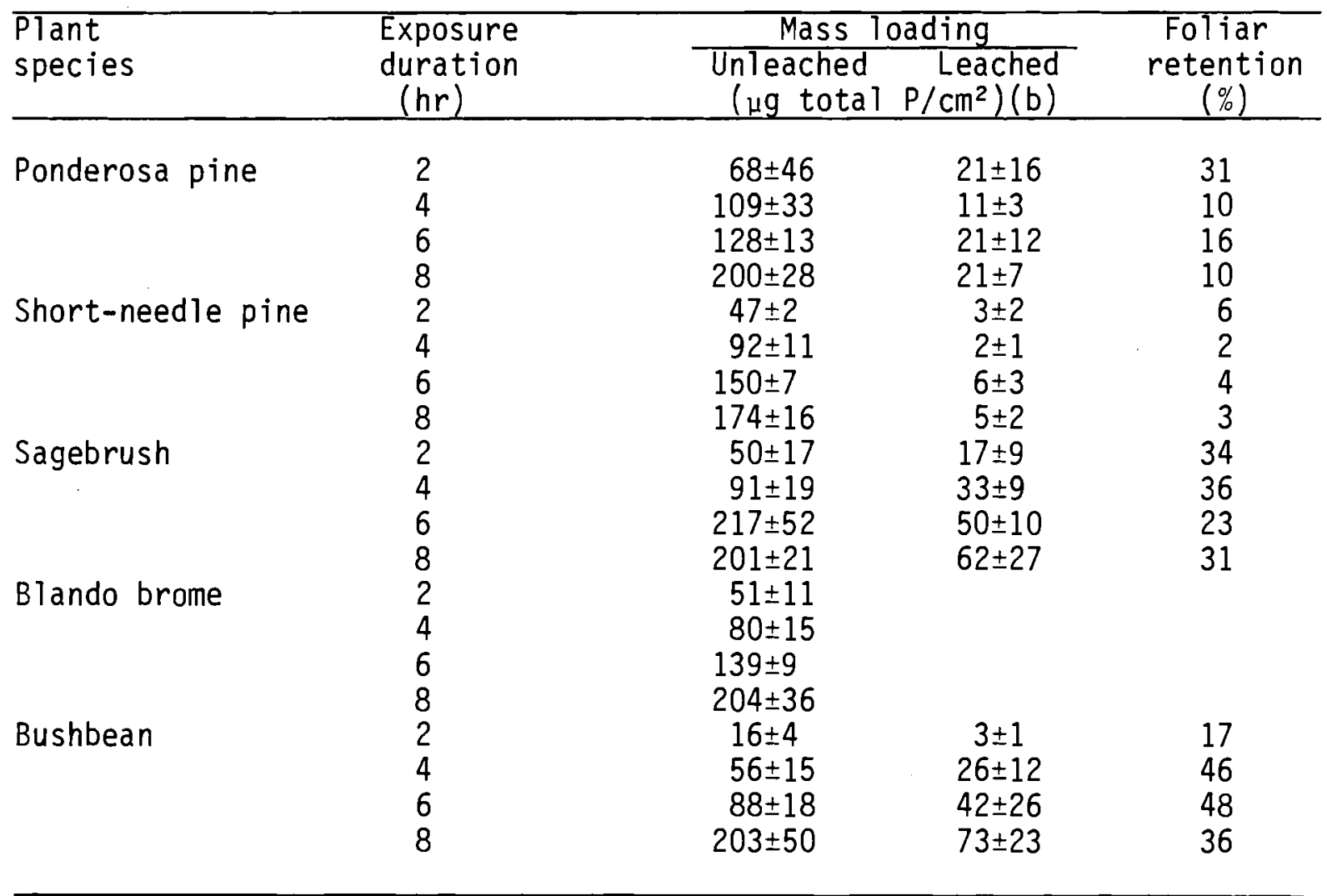

(a) See Table 3.33 for data on Expt $A-1$ and A-2. Post-exposure leaching/simulated rainfall was conducted within 2 hours of contamination, and consisted of $350 \mathrm{ml}$ of synthetic rainwater passed through the canopy over a 15-minute period, and is equivalent to a 0.5 . $\mathrm{cm}$ rainfall. Mall loading based on the projected area of foliar

(b) samples.

Projected leaf area. Avg $\pm S D, n=4$. 

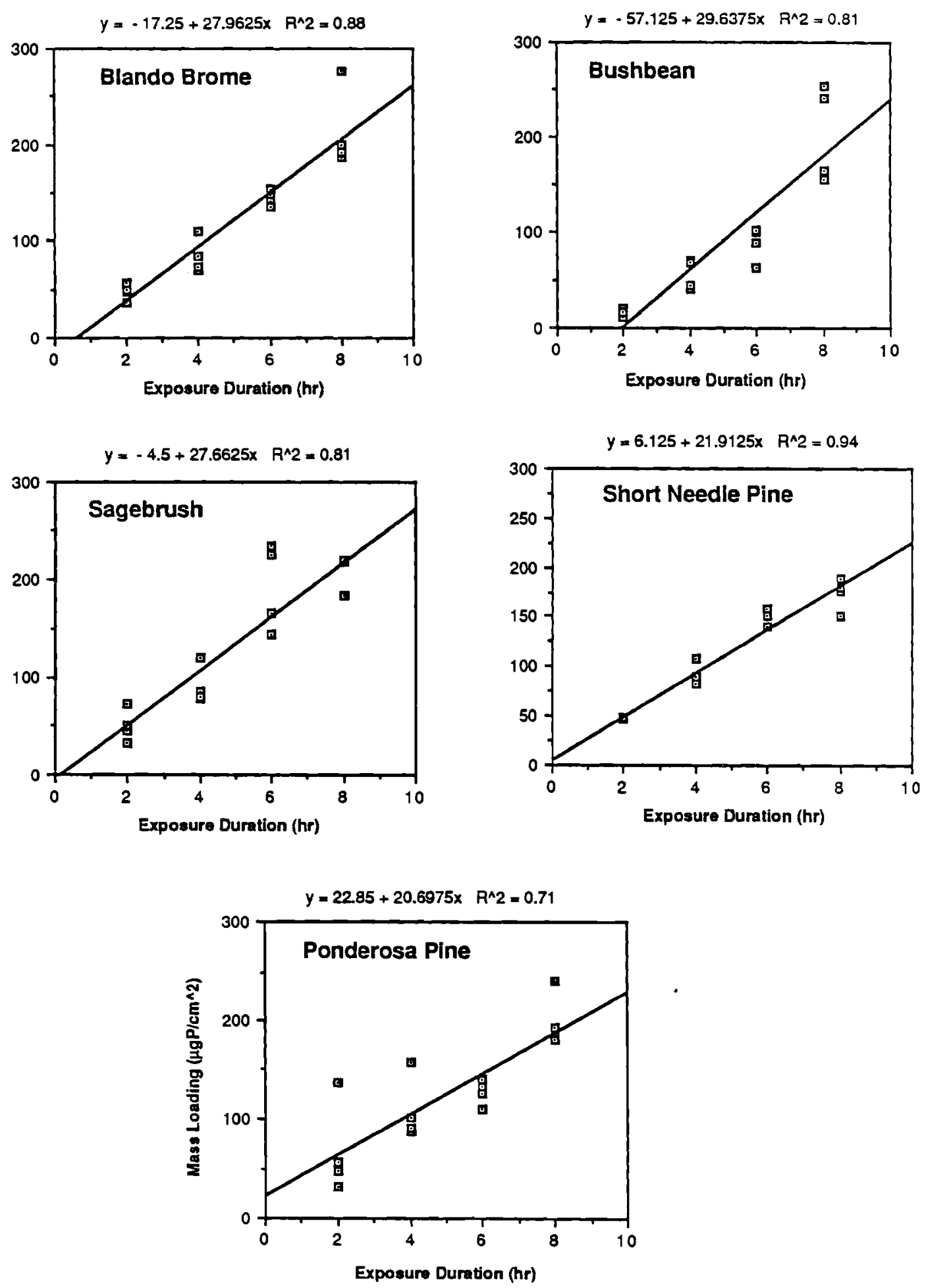

FIGURE 3.23. INFLUENCE OF EXPOSURE DURATION ON MASS LOADING RP/BR SMOKES TO PLANT FOLIAGE. SEE TABLE 3.34 FOR PARTICLE SIZE DATA. 


\subsubsection{Influence of Relative Humidity and Simulated Rainfall on Mass Loading}

Relative humidity appears to influence mass loading of RP/BR smokes to the foliage of each plant species (see $V_{d}$, Figure 3.20). This is particularly evident at the lower and high relative humidity treatments (Table 3.40 ), and readily seen in the mass loading data for sagebrush and blando brome. Overall, mass loading was relatively comparable for ponderosa pine, short-needle pine, and sagebrush for each of the relative humidity treatments $\left(125\right.$ to $\left.185 \mu \mathrm{g} P / \mathrm{cm}^{2}\right)$. Bushbean had slightly lower mass loading values ( 80 to $110 \mu \mathrm{g} P / \mathrm{cm}^{2}$ ), while the grass species, blando brome, had higher mass loadings ranging from 180 to $255 \mu \mathrm{g} \mathrm{P} / \mathrm{cm}^{2}$.

As noted for the deposition velocity results for these exposures, the increased deposition of RP/BR with increasing relative humidity may simply result form the slightly higher MMAD of particles for the $27 \%$ and $89 \%$ relative humidity treatments (see Table 3.36 ). If so, then relative humidity has little effect on the mass loading of RP/BR smoke components to vegetative surfaces. However, plant species, or canopy configuration, does appear to affect mass loading.

In the relative humidity tests for RP/BR smokes, the effect of rainout during smoke exposure was also evaluated. This test involved exposure of plants to RP/BR smokes for 1 hour ( $2 \mathrm{mph}, 89 \%$ relative humidity), followed by a simulated rainout during the following hour of exposure. Mass loading levels following this treatment ranged from 22 to $35 \mu \mathrm{g} \mathrm{P} / \mathrm{cm}^{2}$. These values are of the same magnitude as those seen with the 2-hour RP/BR exposure followed by post-exposure leaching in Table 3.39. The rainout and post-exposure simulated rainfall studies show that natural precipitation events can reduce foliar mass loading levels and may reduce adverse effects of phosphorus smokes.

The relationship between relative humidity and mass loading of WP smokes is shown in Table 3.41. Mass loading levels for the pine species, sagebrush and bushbean are comparable to those seen with RP/BR smokes (see Table 3.40). Values for blando brome are somewhat lower for WP smokes than RP/BR smokes. With the exception of sagebrush values, the slightly lower mass loading values for WP can be explained by the reduced particle size distributions for the WP exposures (see Tables 3.35 and 3.36 ).

As with the RP/BR exposures, no clear or consistent effect of relative humidity is noted on mass loading levels. Although mass loading increases with relative humidity in ponderosa pine and blando brome, the increase is believed to be a random trend, based on the total data sets for RP/BR and WP.

Foliar retention of WP smokes following a simulated post-exposure rainfall is higher than that observed for RP/BR smokes in the range-finding test (see Table 3.39), and generally comparable to those in the relative humidity tests (see Table 3.40). Based on the similarity of RP/BR and WP 
TABLE 3.40. INFLUENCE OF RELATIVE HUMIDITY AND SIMULATED RAINOUT ON FOLIAR MASS LOADING OF RP/BR SMOKES ON PLANT FOLIAGE

\begin{tabular}{|c|c|c|c|c|c|c|}
\hline Condition $(a)$ & $\begin{array}{l}\text { Experiment } \\
\text { code }\end{array}$ & $\begin{array}{l}\text { Ponderosa } \\
\text { pine }\end{array}$ & $\begin{array}{l}\text { Short-Needle } \\
\text { pine } \\
\mu g \text { total } \mathrm{P} / \mathrm{cm}^{2}\end{array}$ & $\begin{array}{l}\text { Sagebrush } \\
\text { (b) }\end{array}$ & Bushbean & $\begin{array}{l}\text { Bl ando } \\
\text { brome }\end{array}$ \\
\hline $2 \mathrm{mph} / 278 \mathrm{RH}$ & $D-3$ & $148 \pm 6(30)$ & $145 \pm 18(3)$ & $183 \pm 15(14)$ & $108 \pm 17(33)$ & $254 \pm 34$ \\
\hline $2 \mathrm{mph} / 53 \% \mathrm{RH}$ & $D-1$ & $135 \pm 10(52)$ & $145 \pm 6(12)$ & $124 \pm 47(16)$ & $80 \pm 12(57)$ & $180 \pm 2$ \\
\hline $2 \mathrm{mph} / 89 \% \mathrm{RH}$ & $D-4$ & $164 \pm 30(10)$ & $167 \pm 20(8)$ & $132 \pm 21(26)$ & $97 \pm 21(36)$ & $210 \pm 2$ \\
\hline $2 \mathrm{mph} / \mathrm{rainout}(\mathrm{c})$ & $D-4$ & $28 \pm 12$ & $22 \pm 1$ & $35 \pm 5$ & $30 \pm 4$ & $35 \pm 14$ \\
\hline
\end{tabular}

(a) Exposure duration was 4 hours. Avg $\pm S D, n=6$ for RH treatments; $n=2$ for rainout. See

(b) Figure 3.13 for statistical evaluation.

Value in () represents foliar retention following post-exposure leaching. Mass loading based on projected leaf area.

(c) Two plants were exposed for 1 hour, followed by 1 hour of simulated rainout during smoke generation; rain intensity was approximately $2 \mathrm{~cm} /$ hour.

smokes, it is difficult to rationalize these differences based on chemical behavior. It is therefore assumed that these differences are the result of inconsistencies in simulated rainfall delivery. 
TABLE 3.41. MASS LOADING LEVELS OF WP TO FOLIAR SURFACES AS A FUNCTION OF RELATIVE HUMIDITY AND PLANT SPECIES, AND THE INFLUENCE OF POST-EXPOSURE SIMULATED RAINFALL ON FOLIAR RETENTION OF PHOSPHORUS (a)

\begin{tabular}{|c|c|c|c|c|}
\hline $\begin{array}{l}\text { Plant } \\
\text { species }\end{array}$ & $\begin{array}{l}\text { Exposure } \\
\text { code }\end{array}$ & $\begin{array}{l}\text { Relative } \\
\text { humidity }\end{array}$ & $\begin{array}{c}\text { Mass } \\
\text { loading } \\
\text { (ug total } \mathrm{P} / \mathrm{cm}^{2}\end{array}$ & $\begin{array}{c}\text { Foliar } \\
\text { (b) retention }\end{array}$ \\
\hline Ponderosa pine & $\begin{array}{l}\text { E3 } \\
\text { E1 } \\
\text { E4 }\end{array}$ & $\begin{array}{l}35 \% \\
57 \% \\
90 \%\end{array}$ & $\begin{array}{l}117 . \pm 11 \\
122 . \pm 20 \\
151 . \pm 18\end{array}$ & $\begin{array}{l}23 \% \\
30 \% \\
12 \%\end{array}$ \\
\hline Short needle pine & $\begin{array}{l}\text { E3 } \\
\text { E4 }\end{array}$ & $\begin{array}{l}35 \% \\
57 \% \\
90 \%\end{array}$ & $\begin{array}{l}127 . \pm 14 \\
170 . \pm 20 \\
145 . \pm 13\end{array}$ & $\begin{array}{l}12 \% \\
16 \% \\
12 \%\end{array}$ \\
\hline Sagebrush & $\begin{array}{l}\text { E3 } \\
\text { E1 }\end{array}$ & $\begin{array}{l}35 \% \\
57 \% \\
90 \%\end{array}$ & $\begin{array}{l}200 . \pm 37 \\
154 . \pm 24 \\
140 . \pm 14\end{array}$ & $\begin{array}{l}25 \% \\
26 \% \\
54 \%\end{array}$ \\
\hline Bushbean & $\begin{array}{l}\text { E3 } \\
\text { E1 }\end{array}$ & $\begin{array}{l}35 \% \\
57 \% \\
90 \%\end{array}$ & $\begin{array}{c}75 . \pm 9 \\
77 . \pm 4 \\
142 . \pm 73\end{array}$ & $\begin{array}{r}6 \% \\
53 \% \\
30 \%\end{array}$ \\
\hline Blando brome & $\begin{array}{l}\text { E3 } \\
\text { E1 }\end{array}$ & $\begin{array}{l}35 \% \\
57 \% \\
90 \%\end{array}$ & $\begin{array}{l}81 . \pm 28 \\
138 . \pm 4 \\
168 . \pm 8\end{array}$ & $\begin{array}{l}- \\
- \\
-\end{array}$ \\
\hline
\end{tabular}

(a) Exposures conducted at $2 \mathrm{mph}$; 4-hour exposure duration.

(b) Projected leaf area. Avg $\pm S D, n=3$. See Figure 3.21 for statistical evaluation.

\subsubsection{Influence of Wind Speed on Mass Loading}

Computed deposition velocity values for deposition of RP/BR and WP smokes to foliage increased in proportion to wind speed in Tables 3.37 and 3.38 . If it is assumed that the toxicity of phosphorus smokes is directly related to mass loading to vegetative surfaces, then wind speed can be an important variable. The effect of wind speed on foliar mass loading of RP/BR and WP is shown in Tables 3.42 and 3.43 , respectively. Plants exposed to RP/BR smokes at 0.5 to $10 \mathrm{mph}$ exhibit a 100 - to 170 -fold increase in mass loading over this wind speed range. Both ponderosa pine and blando brome show only minimal increases in mass loading below $4.5 \mathrm{mph}$; between 4.5 and $10 \mathrm{mph}$, 
TABLE 3.42. INFLUENCE OF WIND SPEED ON MASS LOADING OF RP/BR SMOKES TO FOLIAGE OF PONDEROSA PINE AND BLANDO BROME(a)

\begin{tabular}{llcc} 
Plant species & $\begin{array}{c}\text { Exposure } \\
\text { code }\end{array}$ & $\begin{array}{c}\text { Wind } \\
\text { speed } \\
(\mathrm{mph})\end{array}$ & $\begin{array}{c}\text { Mass } \\
\text { loading } \\
\left(\mu \mathrm{g} P / \mathrm{cm}^{2}\right)\end{array}$ \\
\hline Ponderosa pine & $\mathrm{D}-5.3$ & 0.5 & $21 . \pm 3$ \\
& $\mathrm{D}-1$ & 2.0 & $34 . \pm 3$ \\
& $\mathrm{D}-5.2$ & 4.5 & $115 . \pm 5$ \\
& $\mathrm{D}-2$ & 10.0 & $3555 . \pm 379$ \\
Blando brome & $\mathrm{D}-5.3$ & 0.5 & $27 . \pm 3$ \\
& $\mathrm{D}-1$ & 2.0 & $45 . \pm 1$ \\
& $\mathrm{D}-5.2$ & 4.5 & $640 . \pm 79$ \\
& $\mathrm{D}-2$ & 10.0 & $2796 . \pm 126$
\end{tabular}

(a) Exposures conducted for 1 hour at $60 \%$ relative humidity.

(b) Projected leaf area. Avg $\pm S D, n=3$. See Figure 3.22 for statistical evaluation.

TABLE 3.43. INFLUENCE OF WIND SPEED ON MASS LOADING OF WP SMOKES TO FOLIAR SURFACES(a)

\begin{tabular}{lccc}
\hline $\begin{array}{l}\text { Plant } \\
\text { species }\end{array}$ & $\begin{array}{c}\text { Wxposure } \\
\text { code }\end{array}$ & $\begin{array}{c}\text { Wind } \\
\text { speed } \\
(\mathrm{mph})\end{array}$ & $\begin{array}{c}\text { Mass } \\
\text { loading }(\mathrm{b})\end{array}$ \\
\hline
\end{tabular}

Ponderosa pine

E1

E2.3

$\mathrm{E} 2.2$

E2.1

E1

E2.3

$\mathrm{E} 2.2$

E2.1
2

6

10

2
4
6
10
$40 . \pm 7$

$128 . \pm 49$

$440 . \pm 81$

$3480 . \pm 1675$

$$
\begin{gathered}
34 . \pm 1 \\
259 . \pm 57 \\
585 . \pm 212 \\
2719 . \pm 497
\end{gathered}
$$

(a) Exposures conducted for 1 hour at $60 \%$ relative humidity.

(b) Projected leaf area. Avg $\pm S D, n=3$. See Figure 3.22 for statistical evaluation. 
there is a rapid increase in deposition to foliage. A similar behavior is noted for WP smokes. In the latter exposures, the 0.5 and $4.5 \mathrm{mph}$ treatments were omitted and replaced by 4 and 6 mph treatments to better define the wind speed conditions impacting deposition. From the data in Table 3.42, it is clear that deposition begins to increase disproportionately at some wind speed between 2 and $4 \mathrm{mph}$, while increasing with a $\log$ function at wind speeds in excess of $4 \mathrm{mph}$.

These results, in addition to demonstrating the influence of wind speed on the mass loading of phosphorus smokes to vegetation, clearly show the effect of various physical deposition processes on particle interception. For example, the MMAD of particles generated during the phosphorus exposures approximated $1.7 \mu \mathrm{m}$. Based on the mass loading results, it would appear that two distinct processes dominate. At wind speeds below approximately $4 \mathrm{mph}$, deposition is low due to limitations in diffusional and gravitational fluxes between the air column and receptor surfaces. Above $4 \mathrm{mph}$, boundary layers at the receptor surface are reduced and physical impaction of particles on foliar surfaces begins to dominate, compared to diffusional and gravitational fluxes. These processes, driven by wind speed, become extremely important with respect to phytotoxicity of phosphorus smokes.

\subsubsection{Direct Phytotoxicity of Phosphorus Smokes}

The previous studies were performed to establish the relative importance of several environmental and exposure conditions on the deposition of phosphorus smokes to foliar surfaces, including relative humidity, wind speed, exposure duration, rainout, and post-exposure simulated rainfall. Each of these parameters, with the possible exception of relative humidity, influence the mass loading of phosphorus smokes to vegetative surfaces. In the following studies we have attempted to establish the relationship between foliar mass loading and phytotoxicity resulting from direct contact with foliage. In each study the soil container was bagged to prevent soil contamination, thus allowing only foliar contact toxicity to be evaluated. The indirect effects of phosphorus smokes on plants, via soil contamination, is addressed in a later section.

Dealing with foliar contact toxicity presents several problems. In this study all but one of the plant species (Bushbean) are natural genetic stock, and each individual can represent a slightly different genotype. Such differences allow for some physiological variability and possible toxicity response differences within each test species. Also, under both field conditions and in the wind tunnel exposure system, where air movement occurs along a given vector (i.e., wind direction), deposition to canopies can occur irregularly depending on canopy structure, density, and the presence of back eddies. The air movements and currents account for a substantial fraction of the foliar deposition in both instances, and are representative of real conditions. This approach is substantially more suited to toxicity testing than stirred or unstirred static-exposure 
systems. Another problem is how to quantify damage to vegetation in a consistent and cost effective manner. After preliminary results with RP/BR smokes were obtained, it was decided that the best approach to evaluating contact toxicity was to use a nonparametric grading system, namely, a modification of the Daubenmire rating scale (1959), as a damage index.

The modified Daubenmire rating scale (MDRS) and descriptors for toxicity symptoms are given in Table 3.44, and are used to describe the toxicity responses in each of the following studies. The MDRS is used to describe the extent of visual damage caused by phosphorus smokes delivered under different experimental conditions. The damage can be any one or more of the listed symptoms; however, for the phosphorus smokes the major effects appeared to be tip burn, chlorosis, and leaf dieback and drop. In the case of the pines, grass, and in some instances sagebrush, the intensity of foliar damage was further quantified by determining the physical length of needle or leaf damage. The data generated for foliar contact toxicity are nonparametric, and represent an overall estimate of foliar damage to individual plants.

\subsubsection{Effect of Exposure Duration and Post-Exposure Simulated Rainfall on Phytotoxicity}

The purpose of the range-finding test with RP/BR smoke was to determine if the extent of plant damage is proportional to mass loading onto vegetative surfaces (i.e., exposure to a single concentration for $2,4,6$, or 8 hours), if a post-exposure simulated rainfall would intensify or ameliorate any observed effects, and to establish a working exposure level for subsequent RP/BR and WP studies. The extent of phytotoxicity or visual symptoms were rated for each plant within each exposure treatment using the MDRS. This basically involves a periodic, post-exposure examination of plant foliage to estimate the fraction of the canopy that is adversely affected; scale ratings are given in Table 3.44. In addition, a quantitative estimate of the extent of damage per needle, blade, or leaf is determined where feasible, and any obvious symptoms are noted.

Table 3.44 shows the tabulated results for the observed symptoms. In general, the five plant species used exhibited a wide range in response to the RP/BR smokes. The grass appeared to be the least sensitive, followed by the sagebrush and pines, with bushbean being the most sensitive. In all cases, with the exception of bushbean, a post-exposure simulated rainfall substantially ameliorated toxic effects. Effects were progressive with both time post-exposure and duration of exposure (i.e., mass loading to foliage, see Table 3.39). Based on the time and mass loading dependence, it would appear that phosphorus species are being transported from the foliar surfaces to the interior cells, inducing a disruption of either osmotic and/or metabolic processes, and resulting in the observed tip or edge burn and leaf dieback. Specific observations are presented in Table 3.45. Toxicity rating values shown in all tables represent the median values for the three replicates. In the case of the ponderosa and short-needle pines, $100 \%$ of the needles exhibited tip burn and dieback 
TABLE 3.44. CODING FOR THE MODIFIED DAUBENMIRE RATING SCALE AND ASSOCIATED PHYTOTOXICITY SYMPTOMS

Symptom/intensity

Description

Modified Daubenmire rating scale:

0

1

2

3

4

5

6

Phenotypic responses:

$O G A$

NGA

O\&NGA

$T B$

LBD

NS

LD

$\mathrm{Ch} 1$

$\mathrm{BD}$

LC

W

GD

$D$

$\mathrm{F} / \mathrm{SA}$

(value) no obvious effects over controls

$<5 \%$ of plant foliage affected

between $5 \%-25 \%$ of foliage affected

between $25 \%-50 \%$ of foliage affected

between $50 \%-75 \%$ of foliage affected

between $75 \%-95 \%$ of foliage affected

between $95 \%-100 \%$ of foliage affected

old growth affected

new growth affected

old and new growth affected

tip or leaf edge burn

leaf burn and leaf drop

necrotic spotting

leaf abscission or needle drop

chTorosis

blade dieback

leaf curl

wilting

growing tip dieback

plant dead

floral or seed/fruit abortion

indicates the length in $\mathrm{cm}$ that

needles or leaves exhibit dieback

or tip burn 
TABLE 3.45. PHYTOTOXIC RESPONSES OBSERVED FOR PLANTS EXPOSED TO RP/BR SMOKES FOR 2, 4, 6, AND 8 HOURS. COMPARISON OF PLANTS EXPOSED WITHOUT POST-EXPOSURE TREATMENT AND PLANTS SUBJECTED TO A POSTEXPOSURE SIMULATED RAINFALL.

\begin{tabular}{|c|c|c|c|c|c|c|}
\hline \multirow[b]{2}{*}{ Plant species } & \multirow{2}{*}{$\begin{array}{c}\text { Time } \\
\text { (post- } \\
\text { exposure) }\end{array}$} & \multicolumn{5}{|c|}{ Exposure duration(hour)(a) } \\
\hline & & & 2 & 4 & 6 & 8 \\
\hline & \multicolumn{3}{|l|}{ (day) } & \multicolumn{2}{|c|}{ Degree of phytotoxic response } & \\
\hline \multirow[t]{3}{*}{ Ponderosa pine } & 2 & & 0 & TB $1(0-0.5)$ & TB $1(0-1.0)$ & TB $6(1-2)$ \\
\hline & 6 & TB & $1(0-2)$ & TB $3(0.5-6.5)$ & TB $6(3.5-10)$ & TB $6(1.5-4)$ \\
\hline & 12 & TB & $4(2.5-9)$ & TB $6(3.5-6.5)$ & TB $6(4.5-11)$ & TB $6(3.5-7)$ \\
\hline Ponderosa pine & 2 & & 0 & 0 & 0 & 0 \\
\hline \multirow[t]{2}{*}{ (leached) } & 6 & & 0 & 0 & TB $2(0-1)$ & TB $2(0-1)$ \\
\hline & 12 & & 0 & TB $3(0-1.5)$ & TB $2(2-2.5)$ & TB $3(4-7)$ \\
\hline \multirow[t]{3}{*}{ Short-needle pine } & 2 & & 0 & TB $1(0-0.5)$ & TB $6(0-1)$ & TB $6(1-3)$ \\
\hline & 8 & TB & $2(0-1.5)$ & TB $3(1-5)$ & TB $6(8-9.5)$ & TB $6(6-9)$ \\
\hline & 12 & TB & $2(0-2)$ & TB $3(2-6)$ & TB $6(10-11)$ & TB $6(6-11){ }^{(b)}$ \\
\hline \multirow{3}{*}{$\begin{array}{l}\text { Short-needle pine } \\
\text { (1eached) }\end{array}$} & 2 & & 0 & 0 & 0 & TB $1(0-0.5)$ \\
\hline & 8 & & 0 & 0 & 0 & TB $2(0-1)$ \\
\hline & 12 & & 0 & 0 & TB $2(1-3)$ & TB $2(0-2)$ \\
\hline \multirow[t]{3}{*}{ Sagebrush } & 2 & & 0 & 0 & $\operatorname{LBD}(5,2)$ & $\operatorname{LBD}(6,3)$ \\
\hline & 10 & & 0 & $\operatorname{LBD}(4,2)$ & $\operatorname{LBD}(6,3)$ & $\operatorname{LBD}(6,3)$ \\
\hline & 16 & & 0 & $\operatorname{LBD}(6,2)$ & $\operatorname{LBD}(6,3)$ & $\operatorname{LBD}(6,3)$ \\
\hline \multirow{3}{*}{$\begin{array}{l}\text { Sagebrush } \\
\text { (1 eached) }\end{array}$} & 2 & & 0 & 0 & 0 & $\operatorname{LBD}(6,1)$ \\
\hline & 10 & & 0 & 0 & $\operatorname{LBD}(2,1)$ & $\operatorname{LBD}(6,1)$ \\
\hline & 16 & & 0 & 0 & $\operatorname{LBD}(3,1)$ & $\operatorname{LBD}(6,1)$ \\
\hline \multirow[t]{3}{*}{$\mathrm{Bl}$ ando brome } & 2 & & 0 & 0 & TB $2(0-0.5)$ & TB $3(2-6)$ \\
\hline & 10 & & 0 & 0 & TB $2(0-1)$ & TB $5(2-8)$ \\
\hline & 15 & $\mathrm{~TB}$ & $2(0-0.5)$ & TB $2(0.5-1)$ & TB $3(0.5-3)$ & TB $6(4-10) \quad 0 C A$ \\
\hline \multirow[t]{3}{*}{ Bushbean } & 1 & & 0 & TB 5 & D & $\mathrm{D}$ \\
\hline & 3 & TB & 3 & TB 6 & D & $\mathrm{D}$ \\
\hline & 10 & $\mathrm{~TB}$ & 4 & D & $\mathrm{D}$ & $D$ \\
\hline \multirow{3}{*}{$\begin{array}{l}\text { Bushbean } \\
\text { (1 eached) }\end{array}$} & 1 & & 0 & D & D & $\mathrm{D}$ \\
\hline & 3 & TB & 4 & D & $\mathrm{D}$ & $D$ \\
\hline & 10 & TB & 4 & $D$ & $D$ & $D$ \\
\hline
\end{tabular}

(a) See Tables 3.34 and 3.39 for experimental conditions.
(b) New and old growth 
following 6 and 8 hours of exposure. The burn and dieback occurred within 1 to 3 days following exposure. For each treatment, the extent of tissue affected (percentage of plant foliage affected) and the intensity of effects (length in $\mathrm{cm}$ ) of individual needles exhibiting dieback) increases with time following exposure. In general it appears that the older vegetative tissues are preferentially affected; this was most prevalent in the short-needle pine that initiated bud break prior to exposure and had newly expanding needles. This new growth showed tip burn and dieback only in the 8-hour exposure and after 12 days post-treatment. Application of a post-exposure simulated rainfall, which on average results in removal of $40 \%$ to $80 \%$ of the foliar mass loading depending on canopy structure (a11 other factors constant), substantially reduces the extent and intensity of the effects. This may be of consequence in alleviating potential adverse site effects, particularly in the southeast and mountainous western sites where periodic rainfall is prevalent.

Sagebrush exhibited no adverse effects for 16 days following 2 hours of exposure. However, the 4-, 6-, and 8-hour treatments showed a rapid onset of leaf edge burn and dieback, similar in extent to that noted for the pines. In addition, the relatively short leaves of sagebrush were prone to abscission and leaf drop once dieback affected $50 \%$ to $75 \%$ of the individual leaves. Application of a post-exposure simulated rainfall markedly reduced leaf burn and dieback in the 4- and 6-hour treatments, and the extent of leaf drop in the 4-, 6-, and 8-hour treatments.

Blando brome was most resistant to phosphorus effects based on the extent of foliar tissue affected and the intensity of the effects. As noted for the short-needle pine, damage is primarily associated with the older leaves. Compared with the other plant species tested, blando brome exhibited minimal adverse response. Severe effects were noted for the 8-hour treatment, only after 15 days post-treatment; the effects were mainly associated with the oldest whorls of leaves.

The effects of RP/BR smokes were most severe with bushbean. However, bushbean was included in these studies primarily as an indicator species because of its potential susceptibility to foliar insults. The plants died as a result of the 4-, 6-, and 8-hour treatments, while the 2-hour exposure caused rapid and severe symptoms ranging from leaf burn, dieback and abscission of primary leaves, to edge burn and necrosis of trifoliates, to dieback of the growing tips. Contrary to results of the other plant species, post-exposure leaching appeared to amplify the toxic effects of the RP/BR smokes, and resulted in plant stunting and chlorosis. While the extent and intensity of these effects were unexpectedly severe, bushbean will continue to be used to indicate effects from airborne contaminants.

Since the objective of these studies was to evaluate close-in effects of obscurant smokes, the initial range-finding tests were performed using airborne smoke concentrations of $1900 \mathrm{mg} / \mathrm{m}^{3}$, or approximately $525 \mathrm{mg} \mathrm{P} / \mathrm{m}^{3}$, and individual test durations of $2,4,6$, and $8 \mathrm{hrs}$. In addition, because the tunnel was run in a partial recycle mode, both the range-finding tests 
and cumulative dosing tests (CDT) were conducted at low relative humidity to minimize the extent of phosphorus hydrolysis to phosphate and maximize close-in effects resulting from partial oxidation and hydrolys is products. The objectives appear to have been met since leachates of vegetation samples taken within 1 hour of exposure contain $25 \%-40 \%$ phosphate, $<1 \%$ phosphite, and the balance in linear and cyclic polyphosphates. Based on these exposure conditions and the chemical composition of the smokes, plant and soil effects should be maximized, particularly if one assumes that plant effects must be preceded by transport from foliar surfaces to the interior of the leaves, as indicated by the data.

The severity of the plant effects compared to those obtained in static exposure systems (Battelle Columbus Laboratories Monthly Report No. 8, USAMBRDL Contract No. DAMD17-84-C-4001) was initially thought to be based on the differences in combustion products produced by the two burning methods. However, the products deposited to vegetative surfaces in our studies were rapidly converted to phosphate, and should have only a transient effect, if any. In addition, the maximum exposure level attained in the studies at $B C L$ were on the average only approximately $900 \mathrm{mg}$ of $\mathrm{RP} / \mathrm{BR}$ smoke/ $\mathrm{m}^{3}$ for 2 hours, with peak exposure levels (and therefore deposition) occurring over a 15-minute period. This would suggest that, at best, our lowest exposure treatment was 2 to 3 times higher in magnitude than that of BCL. Also, the modes of foliar contamination will undoubtedly influence deposition velocities to vegetative surfaces (i.e., stirred chamber versus a wind tunnel with a replenished moving air column). Therefore, the lack of significant plant effects in the BCL studies are nearly comparable to the minimal effects observed in our studies for the 2-hour treatment.

Foliar contact toxicity results for RP/BR are summarized in Figure 3.24. This five part Figure shows the relative toxicity for the five plant species to a range of foliar mass loadings, and the general ameliorating influence of a post-exposure simualted rainfall. A number of conclusions can be drawn from these data and the detailed data provided in Table 3.45 . First, phytotoxicity in the range-finding test is proportional to the duration of exposure (i.e., mass loading to foliage). Second, based on the symptoms observed, foliar contaminants associated with RP/BR smokes are readily transported to the interior cells of the leaves. The edge burn and dieback observed is consistent with either salt damage or acidity effects, which result in irreversible osmotic damage. However, the rapid onset of damage would indicate the possible interaction of specific $P$ species with metabolic processes, since we would not expect salt damage to occur so rapidly. This conclusion is somewhat supported by the presence of moderately severe damage observed even when some plants are subjected to simulated rainfall within 2 hours of exposure at low humidity. Third, post-exposure leaching does partially ameliorate RP/BR smoke effects, which indicates that training sites in areas with moderate to high rainfall may be impacted less than training sites in arid regions. Fourth, preliminary deposition velocity and mass loading data show a preferential loading of leading and side surfaces of the canopy, with a $20 \%$ to $70 \%$ reduction in 

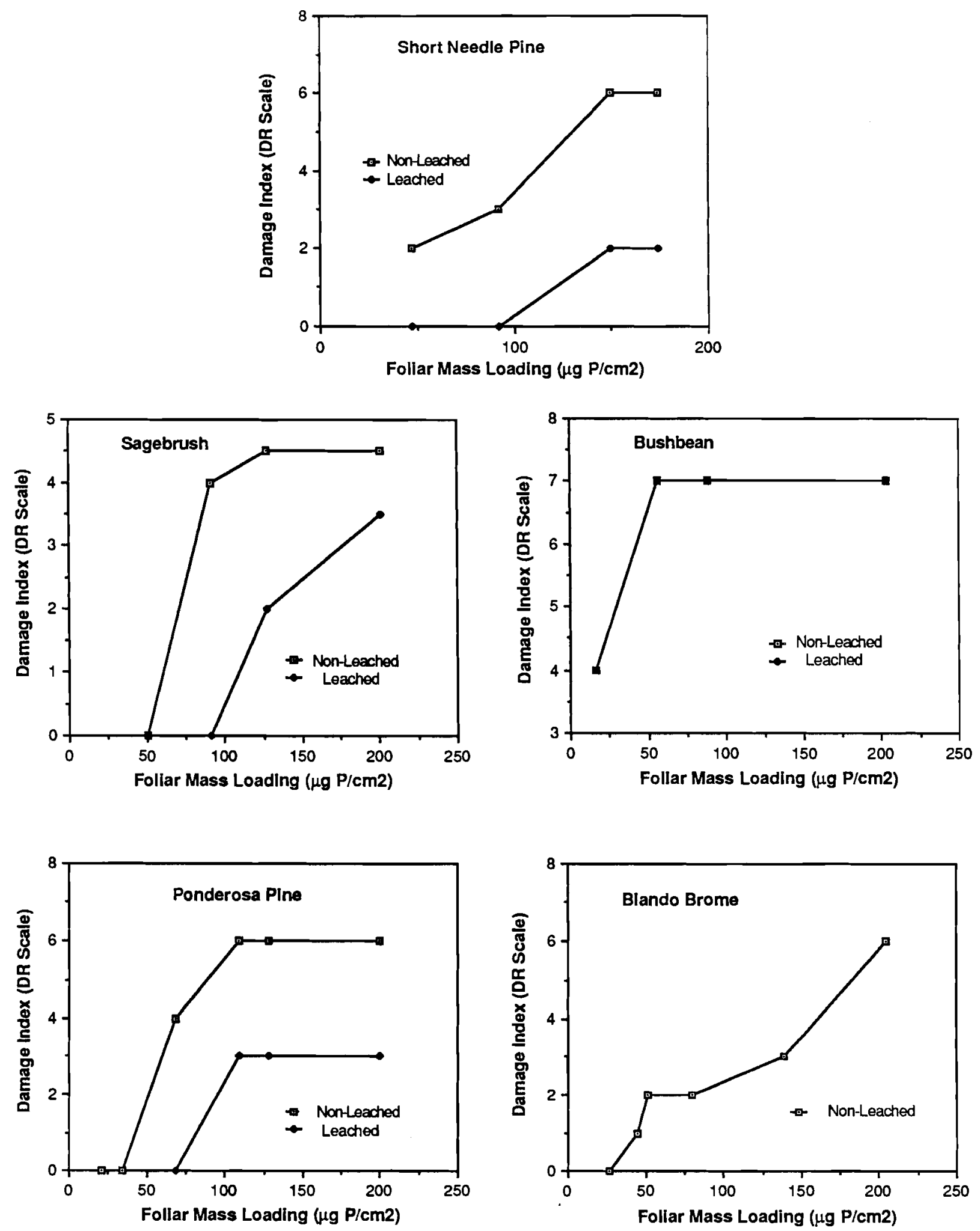

FIGURE 3.24. INFLUENCE OF FOLIAR MASS LOADING AND POST-EXPOSURE LEACHING ON CONTACT TOXICITY OF RP/BR SMOKES TO (a) SHORT NEEDLE PINE, (b) SAGEBRUSH, (c) BUSHBEAN, (d) BLANDO BROME, AND (e) PONDEROSA PINE 
loading rates for the trailing surfaces. Fifth, damage from RP/BR smokes appears to preferentially occur to older tissues. This effect was primarily observed in the short-needle pine that had newly emerging needles in addition to the present year's growth, and in the blando brome that had whorls of blades of decreasing age. In addition, several of the grasses exposed were in late boot stage and some indication of floral abortion was noted. Finally, while the toxic effects appear to be severe, the damage observed to date for the native plant species should be transient. Even the plants exposed at $2 \mathrm{gm} / \mathrm{m}^{3}$ for 8 hours will survive. However, the near-long term effect of repeated exposure at these high levels would undoubtedly reduce their vigor and ability to compete in the environment.

\subsubsection{Effect of Cumulative Dosing on Phytotoxicity}

Briefly, the purpose of the CDP was to determine if a series of repetitive low-dose exposures to RP/BR smokes would elicit the same extent and intensity of effects observed in the range-finding test using a single air concentration delivered to foliage for from 2 to 8 hours. The basic question being addressed is whether or not plants can metabolically compensate, given time between contamination events, to a given foliar mass loading.

While plant toxicity to phosphorus smokes will undoubtedly be related to mass loading, it may be more convenient under field conditions to use a value based on air concentration and exposure duration. Such a value would be appropriate assuming that deposition velocity is relatively constant. In the range-finding test, for example, where plants were exposed for 2,4 , 6 , or 8 hours to RP/BR smokes at concentrations of $524 \mathrm{mg}$ total $P / \mathrm{m}^{3}$ (Table 3.39), an exposure dose can be calculated based on the air concentration of phosphorus and the exposure duration. This time-weighted exposure level (TWEL) would calculate to $1048,2096,3144$, and $8384 \mathrm{mg} P \times$ hour for the 2-, 4-, 6-, and 8-hour treatments, respectively. Mass loading rates for each of the foliar types investigated are relatively proportional to these TWEL values. Air concentrations employed in the CDT series were selected to establish mass loading rates that equal and exceed those that elicited an effect for a given plant species in the range-finding test. For example, in the case of ponderosa pine (Table 3.45 ), if the 6-hour exposure treatment were selected as a reference point based on the intensity of response (MDRS of 6 ) the corresponding point of reference in the CDT would be the TWEL of $3144 \mathrm{mg} \mathrm{P} \times \mathrm{hr}$ (or its corresponding mass loading rate for that tissue type), if there were no plant compensation for a sequential exposure series. If there were a time dependent compensation, then a substantially higher TWEL value would be required to induce the same level of toxicity. To bracket the dose/effect results from the range-finding test, two air concentrations were employed in the CDT; [i.e., 60 and $314 \mathrm{mg}$ total $\mathrm{P} / \mathrm{m}^{3}$ (divided by 0.276 to obtain total smoke concentrations]. Table 3.46 shows the corresponding cumulative air concentrations and TWELs for the CDT. The air concentrations and TWELs in effect expand the lower exposure regime, and exceed the highest TWEL (60 to $11,300 \mathrm{mg} P \times \mathrm{hr}$ ) employed in the range-finding test (1048 to $8384 \mathrm{mg} \mathrm{P} \times \mathrm{hr}$ ), as noted 
TABLE 3.46. EXPOSURE FREQUENCIES AND TIME-WEIGHTED EXPOSURE LEVELS FOR RP/BR SMOKES IN THE CUMULATIVE DOSE TEST

\begin{tabular}{|c|c|c|c|c|c|}
\hline \multirow{2}{*}{$\begin{array}{l}\text { Exposure } \\
\text { date }\end{array}$} & \multirow{2}{*}{$\begin{array}{l}\text { Exposure } \\
\text { number }\end{array}$} & \multicolumn{2}{|c|}{ Low dose exposure(a) } & \multicolumn{2}{|c|}{ High dose exposure } \\
\hline & & $\begin{array}{c}\mathrm{CAC} \\
\left(\mathrm{mgP} / \mathrm{m}^{3} / 4 \mathrm{hr}\right)\end{array}$ & $\begin{array}{c}\text { TWEL } \\
\text { (mgPxhr) }\end{array}$ & $\begin{array}{c}\mathrm{CAC} \\
\left(\mathrm{mgP} / \mathrm{m}^{3} / 4 \mathrm{hr}\right)\end{array}$ & $\begin{array}{l}\text { TWEL } \\
(\mathrm{mgPxhr})\end{array}$ \\
\hline $10 / 15$ & 1 & 59 & 240 & 242 & 968 \\
\hline $10 / 17$ & 2 & 112 & 448 & 526 & 2105 \\
\hline $10 / 19$ & 3 & 185 & 741 & 841 & 3362 \\
\hline $10 / 22$ & 4 & 244 & 976 & 1164 & 4656 \\
\hline $10 / 24$ & 5 & 304 & 1214 & 1467 & 5870 \\
\hline $10 / 26$ & 6 & 370 & 1479 & 1812 & 7248 \\
\hline $10 / 28$ & 7 & 431 & 1723 & 2146 & 8584 \\
\hline $10 / 31$ & 8 & 485 & 1940 & 2458 & 9831 \\
\hline $11 / 02$ & 9 & 545 & 2179 & 2825 & 11,300 \\
\hline
\end{tabular}
(a) CAC; (cumulative air concentration) based on either 60 or $314 \mathrm{mg}$ total $\mathrm{P} / \mathrm{m}^{3}$ as the target level for low and high dose exposures, respectively; TWEL based on air concentration and 4-hour exposure durations.

above. Plants were exposed to these levels for 4-hour periods, 9 consecutive times, and at 2- to 3-day intervals over 21 days. Mass loading rates were measured at the end of the study (exposure No. 9) and estimated for exposures 1 through 8 . Results are shown in Table 3.47; note that for the cumulative dose test series dose/mass loading was measured at the end of the series, and dose for exposures 1 through 8 were calculated. As can be seen, the low dose mass loadings following exposure No. 9 approximate the mass loadings obtained for the leached plants in the range-finding test (Table 3.39), while the high dose loadings approximate and exceed those from the unleached 6- and 8-hour treatments. In theory, if no plant compensation to mass loading occurs then effects observed for the range-finding test and the CDT should be comparable at a given mass loading.

If the delay between repetitive exposures in the CDT permits time for plant compensation, then effects should be reduced for plants at a specific mass loading in the CDT. The tabulated toxicity responses from the CDT exposures to RP/BR are shown in Table 3.48. These responses are compared to toxicity data from the range-finding test found in Table 3.45. In addition, comparisons of mass loading rates for the range-finding test 
TABLE 3.47. ESTIMATED AND MEASURED MASS LOADING RATES TO FOLIAGE FOR THE CUMULATIVE DOSE TEST

\begin{tabular}{lcc}
\hline $\begin{array}{c}\text { Treatment/ } \\
\text { exposure } \\
\text { number }\end{array}$ & $\begin{array}{c}\text { Ponderosa } \\
\text { pine }\end{array}$ & $\begin{array}{c}\text { Short-needle } \begin{array}{c}\text { Mass loading rate by species }(\mathrm{a}) \\
\text { pine }\end{array} \\
\text { Low dose exposure }\end{array}$ \\
\hline
\end{tabular}

$\begin{array}{rrrrrr}1 & 7 & 8 & 5 & 4 & 1 \\ 2 & 14 & 15 & 10 & 7 & 2 \\ 3 & 21 & 23 & 15 & 11 & 3 \\ 4 & 28 & 31 & 20 & 15 & 4 \\ 5 & 35 & 38 & 25 & 18 & 5 \\ 6 & 42 & 46 & 31 & 22 & 6 \\ 7 & 49 & 53 & 36 & 26 & 7 \\ 8 & 56 & 61 & 41 & 29 & 8 \\ 9 & 63 \pm 2 & 69 \pm 4 & 46 \pm 4 & 33 \pm 2 & 9 \pm 1\end{array}$

High dose exposure

\begin{tabular}{|c|c|c|c|c|c|}
\hline $\begin{array}{l}1 \\
3 \\
4 \\
5 \\
5 \\
7 \\
3 \\
9\end{array}$ & $\begin{array}{r}33 \\
65 \\
98 \\
131 \\
163 \\
196 \\
229 \\
261 \\
294 \pm 22\end{array}$ & $\begin{array}{r}39 \\
78 \\
117 \\
155 \\
194 \\
233 \\
272 \\
311 \\
350 \pm 8\end{array}$ & $\begin{array}{r}43 \\
86 \\
129 \\
172 \\
215 \\
259 \\
302 \\
345 \\
388 \pm 19\end{array}$ & $\begin{array}{c}53 \\
107 \\
160 \\
214 \\
267 \\
320 \\
373 \\
427 \\
480 \pm 100\end{array}$ & $\begin{array}{r}10 \\
21 \\
32 \pm 1 \\
\star\end{array}$ \\
\hline
\end{tabular}

(Table 3.39) and the CDT (Tables 3.46 and 3.47) should be noted. The phytotoxicity results from the CDT are quite surprising, considering that the mass loadings and TWELs resulting from the high dose treatment were substantially above the values for the range-finding test. Results are given in Table 3.48, for each plant species. Exposure numbers are listed for each of the low and high dose exposures, and the mass loading (TWEL) values are provided for plants after the ninth and final exposure in the sequence. The last column contains the toxicity response data for these plants as they first appeared and one week after the final exposure. To compare the effects from single versus multiple exposures, the mass loading 
TABLE 3.48. TABULATED PHYTOTOXICITY DATA FOR THE REPETITIVE LOW AND HIGH EXPOSURE DOSE TREATMENTS FROM THE CUMULATIVE DOSE TEST (THESE DATA ARE COMPARED WITH PLANT EFFECTS, FOLIAR MASS LOADING, AND TIME-WEIGHTED EXPOSURE LEVELS FOR THE RP/BR SMOKE RANGE-FINDING TEST)

\begin{tabular}{|c|c|c|c|c|c|}
\hline \multirow{2}{*}{$\begin{array}{c}\text { Plant } \\
\text { species }\end{array}$} & \multirow{2}{*}{$\begin{array}{c}\text { Exposure } \\
\text { number }\end{array}$} & \multirow{2}{*}{$\begin{array}{l}\text { Dose } \\
\text { leve } 1\end{array}$} & \multicolumn{2}{|c|}{$M L(T W E L)(a)$} & CDT \\
\hline & & & CDT & RFT & Toxicity response \\
\hline \multirow[t]{5}{*}{ Ponderosa pine } & $1-8$ & $L$ & & & 0 \\
\hline & 9. & $L$ & $63(2179)$ & $<68(1048)$ & TB $1(0-0.5)$ \\
\hline & $1-4$ & $H$ & & & $\begin{array}{c}0 \\
0\end{array}$ \\
\hline & 5 & $H$ & & & TB 2 (0-1) \\
\hline & & $\begin{array}{l}H \\
H\end{array}$ & $204(11300)$ & $68(1048)$ & $\left.\begin{array}{llll}\text { TB } & 3 & (0-2) \\
T B & 4 & (0-2 & 5\end{array}\right)$ \\
\hline \multirow[t]{4}{*}{ Short-needle pine } & $1-8$ & L & & & 0 \\
\hline & 9 & $L$ & $69(2179)$ & $<47(1048)$ & TB $1(0-1)$ \\
\hline & $\begin{array}{l}1-5 \\
6\end{array}$ & $\begin{array}{l}H \\
H\end{array}$ & & & TB $1 \stackrel{0}{(0-0.5)}$ \\
\hline & 9 & $H$ & $350(11,300)$ & $<92(2096)$ & TB $3(0-2) \quad N G A$ \\
\hline \multirow[t]{4}{*}{ Sagebrush } & $\begin{array}{l}1-7 \\
8\end{array}$ & $\begin{array}{l}L \\
L\end{array}$ & & & $\begin{array}{c}0 \\
\mathrm{LBD}(1.0) \mathrm{ch} 1\end{array}$ \\
\hline & 9 & $L$ & $46(2179)$ & $<91(2096)$ & $\operatorname{LBD}(1,0) \mathrm{Ch}$ \\
\hline & $\begin{array}{l}1-5 \\
6\end{array}$ & $\begin{array}{l}\mathrm{H} \\
\mathrm{H}\end{array}$ & & & $\begin{array}{c}0 \\
\operatorname{LBD}(1,0)\end{array}$ \\
\hline & 9 & $H$ & $388(11,300)$ & $<91(2096)$ & $\operatorname{LBD}(5,1)$ \\
\hline \multirow[t]{5}{*}{ Blando brome } & $\begin{array}{l}1-5 \\
6\end{array}$ & $\begin{array}{l}L \\
L\end{array}$ & & & TB $1 \frac{0}{(0-0.5)}$ \\
\hline & 9 & $L$ & $33(2179)$ & $<51(1048)$ & TB $3(0-1) W$ \\
\hline & & $\begin{array}{l}\mathrm{H} \\
\mathrm{H}\end{array}$ & & & TB $1 \stackrel{0}{(0-0.5)}$ \\
\hline & $3-6$ & $H$ & & & TB $6(2-7) W, F A$ \\
\hline & 9 & $H$ & $480(11,300)$ & 201(8384) & $\begin{array}{l}\text { TB } 6(3-10) \\
N G A, W, F / S A\end{array}$ \\
\hline \multirow[t]{5}{*}{ Bushbean } & $1-4$ & $L$ & & & 0 \\
\hline & 5 & $L$ & & & TB 4 W,LD \\
\hline & 9 & $\underset{H}{\mathrm{~L}}$ & $9(2179)$ & $56(2096)$ & $\begin{array}{lll}\text { TB } & 6 \text { LC, LD,FA } \\
T B & 6\end{array}$ \\
\hline & 2 & $\mathrm{H}$ & $32(2105)$ & $56(2096)$ & TB 6 W,LD,LC,GD \\
\hline & 3 & $H$ & & & D \\
\hline
\end{tabular}

(a) ML (mass loading) and TWEL (time-weighted exposure level) obtained from Tables $3.39,3.46$, and 3.47 . 
(TWEL) values are given for the single exposure range-finding test; the latter represent the dose inducing a level of plant toxicity equivalent to that obtained from cumulative dosing.

From the results shown in Table 3.48 , it can be seen that the extent and intensity of toxicity for ponderosa pine, short-needle pine, sagebrush, and blando brome in the CDT are much reduced over those resulting from a single 8-hour exposure in the range-finding test (see Table 3.45). If the extent and intensity of effects for the two exposure tests are compared, and these effects are related to a dose level using either mass loading or TWEL values, it is possible to determine if there is a plant compensation to repetitive dose events compared with a single dose giving the same mass loading. These values are compared under the heading ML(TWEL) in the table. From the comparison of mass loading (TWEL) values for the range-finding test and the CDT, it is clear that the foliar loading resulting from repetitive exposures is substantially less toxic than single high dose exposures, as is particularly evident in the high dose level treatments. For example, with ponderosa pine a single 2-hour exposure with a TWEL of $1048 \mathrm{mg} P x$ hour (mass loading of $68 \mu \mathrm{g} P / \mathrm{cm}^{2}$ ) results in approximately the same damage as the repetitive dosing equivalent to a TWEL of $11,300 \mathrm{mg} P \times$ hour and cumulative mass loading of $294 \mu \mathrm{g} \mathrm{P} / \mathrm{cm}^{2}$. A similar trend is obtained for each of these four plant species at both the low and high dose levels. The data for bushbean is not so clear. Severe and rapid onset of damage occurred even at mass loading and TWEL values below those employed in the range-finding test.

The results of the cumulative dose test clearly show that repetitive exposure of plants to subtoxic levels of RP/BR smokes are not particularly additive. This may result from the ability of the plant to neutralize, given time, a fraction of either the salt load or acidity entering the leaf interior. One additional point concerning RP/BR effects should be noted. As suggested in the range-finding test, floral abortion and dieback of reproductive structures for both blando brome and bushbean were observed in the CDT. Although this observation is not surprising, based on the overall toxicity response, changes in species diversity for training sites may result by reducing the ability of a specific species to propagate. Also in the CDT, new growth present on both short-needle pine and blando brome was not noticeably affected by exposures to RP/BR; this observation is again consistent with either salt or acidity damage, and the general resistance of younger tissues to this type of injury.

\subsubsection{Effect of Relative Humidity on Phytotoxicity}

In the following discussion of direct phytotoxic effects of phosphorus smokes, care should be used when comparing treatment effects within this data set with previous RP-effects tests. First, mass loading rates, which represent our only point of reference for effects, are exposure specific and should be compared. Secondly, the pines and sagebrush broke dormancy in November and in effect have a full complement of foliage from the previous year (old), and a full flush of current-year foliage (new). 
Finally, the grasses and bushbean plants are older than those originally used to enable the evaluation of effects of RP/BR smokes on floral abortion and seed development. Foliage age presents some special problems in assessing the extent of foliar damage since the tissue age effect noted in previous tests is accentuated.

In Table 3.49, an oversimplified comparison of treatments versus extent of damage (14 days post-exposure) has been made for each of the plant species in order to place overall damage into perspective. The five treatments employed separate RP/BR burns and have somewhat different air mass concentrations (440 to $725 \mathrm{mg} \mathrm{P} / \mathrm{m}^{3}$ ) and particle size distributions (Table 3.35 and 3.40), and are therefore different mass loading rates. With wind speed held constant at $2 \mathrm{mph}$ and relative humidity increased from $25 \%$ to $90 \%$, ponderosa pine shows an increased level of damage while damage to short-needle pine remains relatively constant. In sagebrush, moderate damage occurs at $27 \%$ and $89 \%$ relative humidity, but is minimal at $53 \%$. In both bushbean and blando brome, damage is relatively severe at all three relative humidities. At $2 \mathrm{mph}$, where a rainout was simulated during exposure, effects on ponderosa pine and short-needle pine were somewhat ameliorated. While in sagebrush, bushbean and blando brome effects were not reduced over those observed at $90 \%$ relative humidity.

As a general observation, deposition to vegetation at low relative humidities appears to be as discreet particles which fail to coalesce and therefore fail to uniformly distribute on foliar surfaces. However, at high relative humidities $(>60 \%)$, the larger and more hydrated aerosol particles appear to wet the foliar surfaces, and even result in runoff of liquid. This effect may in fact represent an added variable that must be considered in resolving phosphorus effects.

TABLE 3.49. COMPARISON OF GROSS PHYTOTOXICITY OBSERVED 14 DAYS POST-EXPOSURE FOR EACH PLANT SPECIES BASED ON TREATMENTS EMPLOYED IN THE RELATIVE HUMIDITY TEST SERIES

\begin{tabular}{|c|c|c|c|c|c|c|}
\hline Treatment & & $\begin{array}{l}\text { onderosa } \\
\text { pine }\end{array}$ & $\begin{array}{l}\text { Short-needle } \\
\text { pine }\end{array}$ & Sagebrush & Bushbean & $\begin{array}{l}\text { Blan } \\
\text { brom }\end{array}$ \\
\hline WS (mph) & $\mathrm{RH}(\%)$ & & \multicolumn{4}{|c|}{ Response rating (a) } \\
\hline $\begin{array}{l}2 \\
2 \\
2 \\
2\end{array}$ & $\begin{array}{l}27 \\
53 \\
89 \\
\text { RO(b) }\end{array}$ & $\begin{array}{l}1 \\
2 \\
6 \\
2\end{array}$ & $\begin{array}{l}4 \\
3 \\
3 \\
1\end{array}$ & $\begin{array}{l}2 \\
1 \\
4 \\
3\end{array}$ & $\begin{array}{l}6 \\
6 \\
6 \\
6\end{array}$ & \\
\hline
\end{tabular}

(a) Modified Daubenmire rating scale.

(b) Simulated rainout during generation and exposure. 
The detailed toxicity responses observed for each of the plant species for the various treatments associated with the relative humidity test series was evaluated. Results for ponderosa pine show a progression in both the extent and intensity of effects with time post-exposure. For the $27 \%$ and $53 \%$ relative humidity treatments, minimal toxicity was noted and post-exposure leaching had little ameliorating effect on toxicity (Table 3.50). For comparison, the values in ( ) indicate the length $(\mathrm{cm})$ of tip burn and dieback. At $89 \%$ relative humidity, effects were much more pronounced for both old and new tissues, and both the extent and intensity of the effects were dramatically reduced by post-exposure leaching. During the course of the $89 \%$ relative humidity exposure, a rapid coalescence of deposited particles was noted, with subsequent runoff from leaves. The runoff may have accounted for the severe toxicity (i.e., solubilization and foliar uptake of phosphorus components). When a rainfali/rainout was simulated during the course of the entire exposure period, toxicity was comparable to the unleached treatments. This comparison was unexpected since the mass loadings for this treatment were only $20 \%$ to $30 \%$ of the unleached plants, which supports the assumption that moisture on the foliar surface (i.e., dew, brief rainfall event) may result in solubilization and absorption of surface contaminants and thereby increase toxicity. An increase in toxicity would not be in conflict with the theory that post-exposure simulated rainfall events may ameliorate smoke effects; in the latter instance moisture, rather than solubilizing contaminants, actually washes particulates from the surface.

Results obtained for short-needle pine (Table 3.51) were comparable to ponderosa pine, except that effects were somewhat more severe. In general, new growth was less affected than old growth at the lower relative humidities and in the rainout study. At relative humidities above $50 \%$, old and new growth was affected. Rainout, in the case of short-needle pine, did partially ameliorate toxicity.

Studies with sagebrush (Table 3.52) show relatively little effect following contamination with RP/BR at $27 \%$ and $53 \%$ relative humidity, while a post-exposure leaching ameliorated much of the effect. The latter effects were confined to leaf or tip burn, with a small amount of leaf drop evident after 14 days in the $27 \%$ relative humidity treatment. At $89 \%$ relative humidity, effects are much more pronounced, and we begin to see the onset of relatively severe leaf burn and increased leaf drop. In the unleached treatments, both new and old growth are affected. Post-exposure leaching reduces the effects of the smoke because only old growth is impacted and leaf drop is eliminated. The rainout treatment resulted in both leaf burn and leaf drop, but primarily affected only older leaves.

Bushbean, as usual, provides a great variety of effects (Table 3.53). Toxicity responses were generally severe for all treatments, with post-exposure leaching generally accentuating the effects. However, new growth formed post-exposure is viable, even though deformed (curling and puckering of leaves). Flowers generalily are not aborting even though 
TABLE 3.50. COMPARISON OF THE INFLUENCE OF RELATIVE HUMIDITY, POST-EXPOSURE SIMULATED RAINFALL, AND RAINOUT ON PHYTOTOXIC RESPONSES OF PONDEROSA PINE TO RP/BR SMOKES

\begin{tabular}{|c|c|c|c|c|c|}
\hline $\begin{array}{l}\text { Treat } \\
\text { wind } \\
\text { speed }\end{array}$ & $\begin{array}{l}\frac{\mathrm{ent}}{\mathrm{RH}} \\
(\%) \\
\end{array}$ & $\begin{array}{l}\text { Post- } \\
\text { exposure } \\
\text { test(a) }\end{array}$ & $\begin{array}{l}\text { Days } \\
\text { post- } \\
\text { exposure } \\
\end{array}$ & $\begin{array}{l}\text { Toxicity(b) } \\
\text { rating }\end{array}$ & $\begin{array}{l}\text { Observed } \\
\text { responses }\end{array}$ \\
\hline 2 & 27 & unleached & $\begin{array}{r}1 \\
4 \\
14 \\
1 \\
4 \\
14\end{array}$ & $\begin{array}{l}0 \\
\\
0 \\
\text { TB }(0-1) 1 \\
0 \\
0 \\
\text { TB }(0-4) 4\end{array}$ & \\
\hline \multirow[t]{2}{*}{2} & 53 & un leached & $\begin{array}{r}1 \\
4 \\
14\end{array}$ & $\begin{array}{ll} & 0 \\
\text { TB } & (0-1) 1 \\
\text { TB } & (0-1) 2\end{array}$ & \\
\hline & & leached & $\begin{array}{r}1 \\
4 \\
14\end{array}$ & $\begin{array}{l}\text { TB }(0-1) 1 \\
\text { TB }(0-1) 2 \\
\text { TB }(0-2) 3\end{array}$ & NS \\
\hline 2 & 89 & Teached & $\begin{array}{r}1 \\
6 \\
14 \\
1 \\
6 \\
14\end{array}$ & $\begin{array}{ll} & 0 \\
\text { TB } & (0-2) 6 \\
\text { TB } & (0-3) 6 \\
& 0 \\
& 0 \\
\text { TB } & (0-1.5) 1\end{array}$ & $\begin{array}{l}\text { O\&NGA, NS } \\
\text { O\&NGA, NS }\end{array}$ \\
\hline 2 & RO & & $\begin{array}{r}3 \\
14\end{array}$ & $\begin{array}{l}\text { TB }(0-2) 1 \\
\text { TB }(0-4) 2\end{array}$ & \\
\hline
\end{tabular}

(a) Post-exposure simulated rainfal1; RO is a rainout during exposure. MDRS (see Table 3.44). 
TABLE 3.51. COMPARISON OF THE INFLUENCE OF RELATIVE HUMIDITY, POST-EXPOSURE SIMULATED RAINFALL AND RAINOUT ON PHYTOTOXIC RESPONSES OF SHORT-NEEDLE PINE TO RP/BR SMOKES

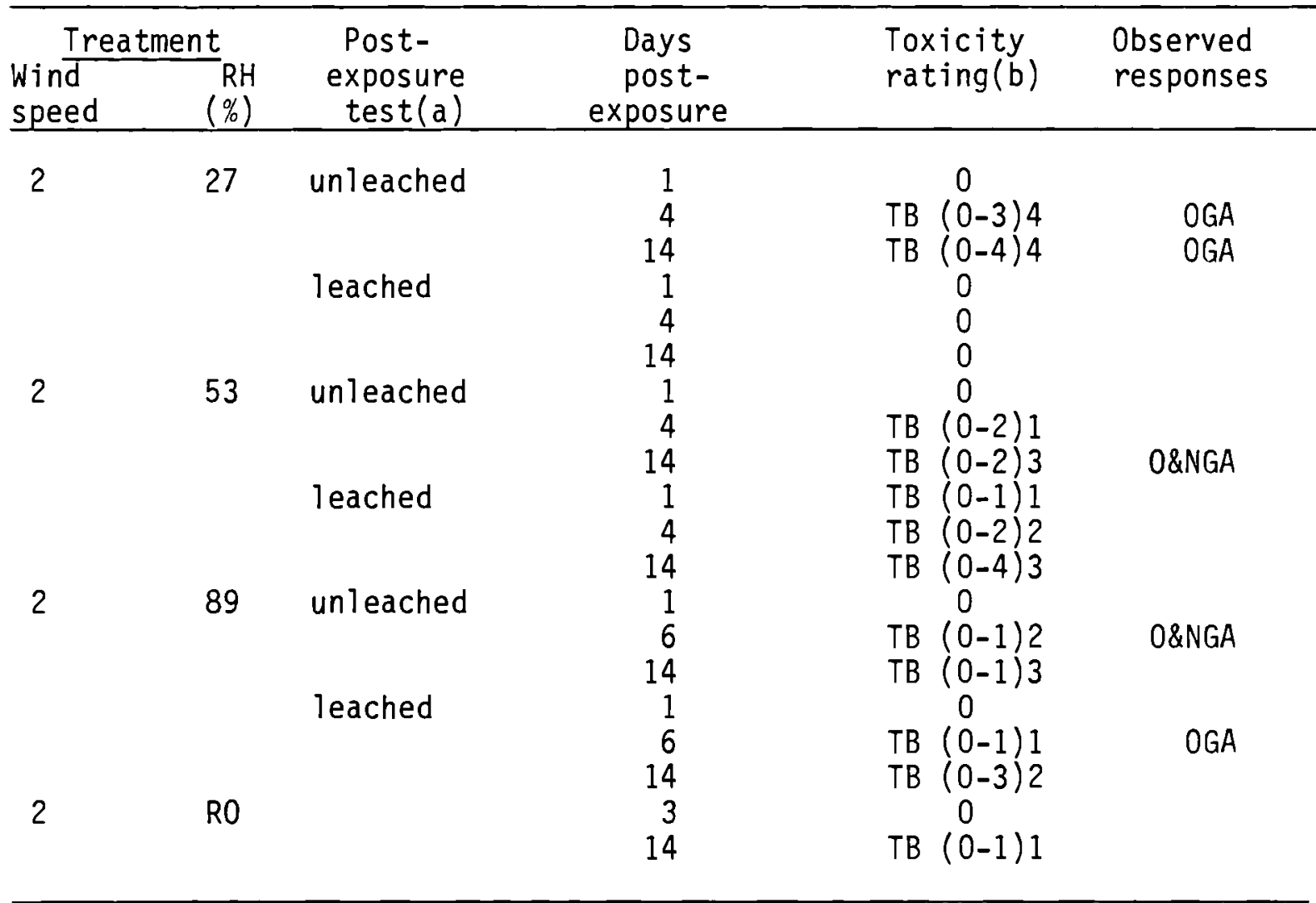

(b) Post-exposure simulated rainfall; RO is a rainout during exposure. MDRS (see Table 3.44).

exposed to RP/BR smokes. Fruit formed either pre- or post-exposure continues to develop and fill, although the surface is deformed (puckered). Only in the rainout study was flower and fruit abortion observed.

The severity of results obtained for blando brome (Table 3.54) were somewhat surprising based on its resistance to RP/BR smokes in the range-finding test and the CDT series. The results may be attributable to age, in that somewhat older plants were used in this test to allow evaluation of seed set and seed development. Effects observed with the unleached treatments were rated as severe for all relative humidity tested. The rainout study resulted in no amelioration of effects. In general only the older growth was affected, and plants showed a rapid onset of wilting and leaf drop at $27 \%$ and $89 \%$ relative humidity. The least severe effects were noted in the rainout study, where new growth and the developing seed head appeared to be reasonably resistant to RP/BR smokes. 
TABLE 3.52. COMPARISON OF THE INFLUENCE OF RELATIVE HUMIDITY, POST-EXPOSURE SIMULATED RAINFALL AND RAINOUT ON PHYTOTOXIC RESPONSES OF SAGEBRUSH TO RP/BR SMOKES

\begin{tabular}{|c|c|c|c|c|c|}
\hline $\begin{array}{l}\text { Trea } \\
\text { Wind } \\
\text { speed }\end{array}$ & $\underset{(\%)}{\mathrm{nt}}$ & $\begin{array}{l}\text { Post- } \\
\text { exposure } \\
\text { test }(a)\end{array}$ & $\begin{array}{l}\text { Days } \\
\text { post- } \\
\text { exposure }\end{array}$ & $\begin{array}{l}\text { Toxicity }(b) \\
\text { rating }\end{array}$ & $\begin{array}{l}\text { Observed } \\
\text { responses }\end{array}$ \\
\hline \multirow[t]{2}{*}{2} & 27 & unleached & $\begin{array}{r}1 \\
4 \\
14\end{array}$ & $\begin{array}{c}0 \\
0 \\
\operatorname{LBD}(2,1)\end{array}$ & \\
\hline & & leached & $\begin{array}{r}1 \\
4 \\
14\end{array}$ & $\begin{array}{r}0 \\
0 \\
\operatorname{LB}(1)\end{array}$ & \\
\hline \multirow[t]{2}{*}{2} & 53 & unleached & $\begin{array}{r}1 \\
4 \\
14\end{array}$ & $\begin{array}{l} \\
\operatorname{LB}(1) \\
\operatorname{LB}(1)\end{array}$ & \\
\hline & & leached & $\begin{array}{r}1 \\
4 \\
14\end{array}$ & $\begin{array}{l}0 \\
0 \\
0\end{array}$ & \\
\hline \multirow[t]{2}{*}{2} & 89 & unleached & $\begin{array}{r}1 \\
6 \\
14\end{array}$ & $\begin{array}{l}\operatorname{LB}(1) \\
\operatorname{LBD}(3,1) \\
\operatorname{LBD}(4,2)\end{array}$ & O\&NGA \\
\hline & & leached & $\begin{array}{r}1 \\
6 \\
14\end{array}$ & $\begin{array}{l}0 \\
\operatorname{LB}(2) \\
\operatorname{LB}(2)\end{array}$ & OGA \\
\hline 2 & RO & & $\begin{array}{r}3 \\
14\end{array}$ & $\begin{array}{c}0 \\
\operatorname{LBD}(3,2)\end{array}$ & \\
\hline $\begin{array}{l}\text { (a) } \mathrm{F} \\
\text { (b) } \mathrm{N}\end{array}$ & $\sigma^{-}$ & S & & nout $d$ & sure. \\
\hline
\end{tabular}


TABLE 3.53. COMPARISON OF THE INFLUENCE OF RELATIVE HUMIDITY, POST-EXPOSURE SIMULATED RAINFALL AND RAINOUT ON PHYTOTOXIC RESPONSES OF BUSHBEAN TO RP/BR SMOKES(a)

\begin{tabular}{|c|c|c|c|c|c|}
\hline $\begin{array}{l}\text { Wind } \\
\text { speed }\end{array}$ & $\begin{array}{l}\mathrm{nt} \\
\mathrm{RH} \\
(\%)\end{array}$ & $\begin{array}{l}\text { Post- } \\
\text { exposure } \\
\text { tests }(a)\end{array}$ & $\begin{array}{l}\text { Days } \\
\text { post- } \\
\text { exposure }\end{array}$ & $\begin{array}{l}\text { Toxicity }(b) \\
\text { rating }\end{array}$ & $\begin{array}{l}\text { Observed } \\
\text { responses }\end{array}$ \\
\hline 2 & 27 & leached & $\begin{array}{r}1 \\
4 \\
14 \\
1 \\
4 \\
14\end{array}$ & $\begin{array}{l}\operatorname{LB}(4) \\
\operatorname{LB}(5) \\
\operatorname{LBD}(6,3) \\
\operatorname{LB}(4) \\
\operatorname{LBD}(5,2) \\
\operatorname{LBD}(6,3)\end{array}$ & $\begin{array}{l}\text { NS, Chl } \\
\text { NS, Chl }\end{array}$ \\
\hline 2 & 53 & $\begin{array}{l}\text { un leached } \\
\text { leached }\end{array}$ & $\begin{array}{r}1 \\
4 \\
14 \\
1 \\
4 \\
14\end{array}$ & $\begin{array}{l}\text { LB (1) } \\
\text { LB (3) } \\
\text { LB (4) } \\
\text { LB (2) } \\
\text { LB (6) } \\
\text { LB (6) }\end{array}$ & $\begin{array}{l}\text { NS } \\
\text { Ch1 } \\
\text { Ch1, FA }\end{array}$ \\
\hline 2 & 89 & leached & $\begin{array}{r}1 \\
6 \\
14 \\
1 \\
6 \\
14\end{array}$ & $\begin{array}{l}\operatorname{LB}(5) \\
\operatorname{LBD}(6,3) \\
\operatorname{LBD}(6,4) \\
\operatorname{LB}(6) \\
\operatorname{LBD}(6,2) \\
\operatorname{LBD}(6,4)\end{array}$ & $\begin{array}{l}N S, F A \\
N S, F A \\
F / S A\end{array}$ \\
\hline
\end{tabular}

(a) Post-exposure simulated rainfall; RO is a rainout during exposure. (b) MDRS (see Table 3.44).

Studies of the influence of relative humidity on the toxicity of WP smokes to the five standard plant test species were conducted using experimental conditions similar to those for RP/BR smokes. Plants were exposed to WP smokes for 4 hours, at a wind speed of $2 \mathrm{mph}$ and relative humidity of $35 \%, 57 \%$, and $90 \%$. Replicates of the exposed plants were either held without further treatment or subjected to a simulated post-exposure rainfall to evaluate their effectiveness in alleviating or accentuating exposure effects. All plants were held for 14 days post-exposure to evaluate overall damage and symptoms. Rainout during exposure was not conducted. The phytotoxicity of WP smokes to the individual plant species is discussed below.

The overall effects of WP smokes, delivered at various relative humidity levels, on ponderosa pine (Table 3.55 ) are comparable to results obtained for effects from RP/BR smokes (see Table 3.50). The primary toxicity response noted was tip burn in both the unleached and leached treatments. In the unleached treatments both old and new growth was 
TABLE 3.54. COMPARISON OF THE INFLUENCE OF RELATIVE HUMIDITY, POST-EXPOSURE SIMULATED RAINFALL AND RAINOUT ON PHYTOTOXIC RESPONSES OF BLANDO BROME TO RP/BR SMOKES(a)

\begin{tabular}{|c|c|c|c|c|c|}
\hline $\begin{array}{l}\text { Tre } \\
\text { Wind } \\
\text { speed }\end{array}$ & $\begin{array}{c}\text { nent } \\
\mathrm{RH} \\
(\%)\end{array}$ & $\begin{array}{l}\text { Post- } \\
\text { exposure } \\
\text { test }(a) \\
\end{array}$ & $\begin{array}{c}\text { Days } \\
\text { post- } \\
\text { exposure }\end{array}$ & $\begin{array}{l}\text { Toxicity }(b) \\
\text { rating }\end{array}$ & $\begin{array}{l}\text { Observed } \\
\text { responses }\end{array}$ \\
\hline 2 & 27 & unleached & $\begin{array}{r}1 \\
4 \\
14\end{array}$ & $\begin{array}{l}\text { TB }(0-0.5) 3 \\
\text { TB }(0-6) 4 \\
\text { TB }(0-10) 6\end{array}$ & $\begin{array}{l}W \\
F / S A\end{array}$ \\
\hline 2 & 53 & unleached & $\begin{array}{r}1 \\
4 \\
14\end{array}$ & $\begin{array}{l}\text { TB }(0-1) 1 \\
\text { TB }(0-2) 4 \\
\text { TB }(0-9) 6\end{array}$ & $W$ \\
\hline 2 & 89 & unleached & $\begin{array}{r}1 \\
6 \\
14\end{array}$ & $\begin{array}{l}\text { TB }(0-3) 2 \\
\text { TB }(0-5) 5 \\
\text { TB }(0-6) 5\end{array}$ & $W, L D$ \\
\hline 2 & RO & & $\begin{array}{r}3 \\
14\end{array}$ & $\begin{array}{l}\text { TB }(0-1) 1 \\
\text { TB }(0-5) \frac{1}{5}\end{array}$ & NS \\
\hline
\end{tabular}

(a) Post-exposure simulated rainfall; $\mathrm{RO}$ is a rainout during exposure. MDRS (see Table 3.44).

affected, with the extent of toxicity (MDRS) increasing from a value of 1 at $35 \%$ relative humidity to a value of 2 and 4 at $57 \%$ and $90 \%$ relative humidity, respectively. The intensity of toxicity (in this case the length of needle exhibiting dieback due to needle tip burn) is also greater at the high relative humidity. Mass loading rates for this study and the RP/BR study were comparable for the lower relative humidity treatments and only slightly higher at $90 \%$ relative humidity (see Tables 3.40 and 3.41 ). Plants subjected to a post-exposure simulated rainfall leach treatment showed little or no amelioration of effects. This is somewhat surprising, since mass loading rates were substantially reduced following leaching (see Table 3.41). Leaching appears to reduce WP smoke effects on newly formed needles, particularly at the lower relative humidity levels.

Results for short-needle pine (Table 3.56) are generally similar to those obtained with ponderosa pine. Unleached plants exhibit an increase in both the extent and intensity of toxicity at $90 \%$ relative humidity compared with $35 \%$ and $57 \%$; tip burn is the primary response, and both new and old growth is affected. The effects of WP smoke appear to be substantially less than those observed for RP/BR (see Table 3.51), even though mass loadings were comparable. Leaching generally reduces the 
TABLE 3.55. INFLUENCE OF RELATIVE HUMIDITY AND POST-EXPOSURE SIMULATED RAINFALL ON PHYTOTOXICITY OF WHITE PHOSPHORUS SMOKES TO PONDEROSA PINE. TOXICITY AS OF 2 WEEKS POST-EXPOSURE.

\begin{tabular}{clll}
\hline $\begin{array}{c}\text { Relative } \\
\text { humidity }\end{array}$ & $\begin{array}{c}\text { Post-exposure } \\
\text { treatment }\end{array}$ & $\begin{array}{c}\text { Toxicity (a) } \\
\text { rating }\end{array}$ & $\begin{array}{l}\text { Observed } \\
\text { responses }\end{array}$ \\
\hline $35 \%$ & $\begin{array}{l}\text { unleached } \\
\text { leached }\end{array}$ & $\begin{array}{l}\text { TB1 }(0.5-2) \\
\text { TB2 }(0-1)\end{array}$ & $\begin{array}{l}\text { O\&NGA; TB } \\
\text { OGA; TB }\end{array}$ \\
$57 \%$ & $\begin{array}{l}\text { unleached } \\
\text { leached }\end{array}$ & TB2 $(0-2)$ & O\&NGA; TB \\
& TB1 $(0.5-3)$ & OGA; TB \\
& $\begin{array}{l}\text { unleached } \\
\text { leached }\end{array}$ & TB4 $(1-7)$ & O\&NGA; TB \\
& TB3 $(2-5)$ & O\&NGA; TB \\
\hline
\end{tabular}

(a) MDRS (see Table 3.44)

intensity of effects, particularly in the $90 \%$ relative humidity treatment, even though foliar retention was siightiy greater for WP smokes than RP/BR smokes (see Tables 3.40 and 3.41 ).

Sagebrush exposed to WP smokes exhibited substantially more toxicity than the pines (Table 3.57). In the unleached treatment, no clear relative humidity effect was evident. Effects included leaf burn and in severe cases leaf drop, old growth was affected preferentially over newly formed leaves. Post-exposure leaching reduced the extent of leaf burn and leaf drop at the low relative humidity, but greatly increased effects at $90 \%$ relative humidity. In the latter instance both new and old growth were affected.

The grass species, blando brome, was severely impacted at all three relative humidity treatments (Table 3.58). The intensity of effects was, however, substantially less at $35 \%$ relative humidity. In addition to tip burn and dieback, necrotic spotting of leaves where smoke droplets impacted the surface and chlorosis were evident. No leaching was performed post-exposure.

The response of bushbean to WP smokes (Table 3.59) was just as severe as its response to RP/BR smokes (see Table 3.53). Toxicity generally involved widespread leaf burn and necrosis, followed by abscission and leaf drop. Post-exposure leaching partially ameliorated effects at $35 \%$ relative humidity, while accentuating effects at the higher relative humidity levels. Overal1, effects were comparable to those for RP/BR, except for the extent of leaf drop. It should be noted that even in the most severely impacted bushbean plants floral damage was not evident, and seeds and pods developed normaliy except for necrotic spotting. 
TABLE 3.56. INFLUENCE OF RELATIVE HUMIDITY AND POST-EXPOSURE SIMULATED RAINFALL ON PHYTOTOXICITY OF WHITE PHOSPHORUS SMOKES TO SHORT-NEEDLE PINE

\begin{tabular}{|c|c|c|c|}
\hline $\begin{array}{l}\text { Relative } \\
\text { humidity }\end{array}$ & $\begin{array}{l}\text { Post-exposure } \\
\text { treatment }\end{array}$ & $\begin{array}{c}\text { Toxicity(a) } \\
\text { rating }\end{array}$ & $\begin{array}{l}\text { Observed } \\
\text { responses }\end{array}$ \\
\hline $35 \%$ & $\begin{array}{l}\text { unleached } \\
\text { leached }\end{array}$ & $\begin{array}{l}1(0.5-2) \\
1(0-0.5)\end{array}$ & $\begin{array}{l}\text { O\&NGA; TB } \\
\text { NGA; TB }\end{array}$ \\
\hline $57 \%$ & $\begin{array}{l}\text { unleached } \\
\text { leached }\end{array}$ & $\begin{array}{ll}1 & (0.5-3) \\
1 & (0-0.5)\end{array}$ & $\begin{array}{l}\text { O\&NGA; TB } \\
\text { OGA; TB }\end{array}$ \\
\hline $90 \%$ & $\begin{array}{l}\text { unleached } \\
\text { leached }\end{array}$ & $\begin{array}{l}4(2-5) \\
3(0-0.5)\end{array}$ & $\begin{array}{l}\text { O\&NGA; TB } \\
\text { OGA; TB }\end{array}$ \\
\hline
\end{tabular}

(a) MDRS (see Table 3.44).

TABLE 3.57. INFLUENCE OF RELATIVE HUMIDITY AND POST-EXPOSURE SIMULATED RAINFALL ON PHYTOTOXICITY OF WHITE PHOSPHORUS SMOKES TO SAGEBRUSH

\begin{tabular}{|c|c|c|c|}
\hline $\begin{array}{l}\text { Relative } \\
\text { humidity }\end{array}$ & $\begin{array}{c}\text { Post-exposure } \\
\text { treatment }\end{array}$ & $\begin{array}{c}\text { Toxicity }(a) \\
\text { rating } \\
\end{array}$ & $\begin{array}{l}\text { Observed } \\
\text { responses }\end{array}$ \\
\hline $35 \%$ & $\begin{array}{l}\text { unleached } \\
\text { leached }\end{array}$ & $\begin{array}{l}\operatorname{LBD}(4,1) \\
\operatorname{LB} 1\end{array}$ & $\begin{array}{l}O G A ; L B, L D \\
O G A ; L B\end{array}$ \\
\hline $57 \%$ & $\begin{array}{l}\text { unleached } \\
\text { leached }\end{array}$ & $\begin{array}{l}\operatorname{LBD}(3,1) \\
\operatorname{LBD}(2,1)\end{array}$ & $\begin{array}{l}\text { O\&NGA; Ch1,LD } \\
\text { OGA; LB,LD }\end{array}$ \\
\hline $90 \%$ & $\begin{array}{l}\text { unleached } \\
\text { leached }\end{array}$ & $\begin{array}{l}\operatorname{LB} 3 \\
\operatorname{LBD}(6,4)\end{array}$ & $\begin{array}{l}\text { OGA; LB } \\
\text { O\&NGA; LB, LD }\end{array}$ \\
\hline
\end{tabular}

(a) MDRS (see Table 3.44). 
TABLE 3.58. INFLUENCE OF RELATIVE HUMIDITY ON PHYTOTOXICITY OF WHITE PHOSPHORUS SMOKES TO BLANDO BROME

\begin{tabular}{cccc}
\hline $\begin{array}{l}\text { Relative } \\
\text { humidity }\end{array}$ & $\begin{array}{c}\text { Post-exposure } \\
\text { treatment }\end{array}$ & $\begin{array}{c}\text { Toxicity(a) } \\
\text { rating }\end{array}$ & $\begin{array}{c}\text { Observed } \\
\text { responses }\end{array}$ \\
\hline $35 \%$ & unleached & $5(0.5-2)$ & OGA; TB, NS, Ch 1 \\
$57 \%$ & $\begin{array}{l}\text { unleached } \\
\text { unleached }\end{array}$ & $\begin{array}{l}5(1-9) \\
\text { (1-5) }\end{array}$ & $\begin{array}{l}\text { OGA; TB, NS } \\
\text { OGA; TB, Ch1, NS }\end{array}$ \\
\hline
\end{tabular}

(a)

MDRS (see Table 3.44).

TABLE 3.59. INFLUENCE OF RELATIVE HUMIDITY AND POST-EXPOSURE SIMULATED RAINFALL ON PHYTOTOXICITY OF WHITE PHOSPHORUS SMOKES TO BUSHBEAN

\begin{tabular}{|c|c|c|c|}
\hline $\begin{array}{l}\text { Relative } \\
\text { humidity }\end{array}$ & $\begin{array}{c}\text { Post-exposure } \\
\text { treatment }\end{array}$ & $\begin{array}{c}\text { Toxicity }(a) \\
\text { rating } \\
\end{array}$ & $\begin{array}{l}\text { Observed } \\
\text { responses }\end{array}$ \\
\hline $35 \%$ & $\begin{array}{l}\text { unleached } \\
\text { leached }\end{array}$ & $\begin{array}{l}\operatorname{LBD}(6,3) \\
\operatorname{LB} 4\end{array}$ & $\begin{array}{l}\text { OGA; LB,NS,LD } \\
\text { OGA; LB,NS }\end{array}$ \\
\hline $57 \%$ & $\begin{array}{l}\text { unleached } \\
\text { leached }\end{array}$ & $\begin{array}{l}\operatorname{LBD}(4,2) \\
\operatorname{LBD}(6,4)\end{array}$ & $\begin{array}{l}\text { OGA; LB,NS,LD } \\
\text { OGA; LB,NS, LD }\end{array}$ \\
\hline $90 \%$ & $\begin{array}{l}\text { unleached } \\
\text { leached }\end{array}$ & $\begin{array}{l}\operatorname{LBD}(5,3) \\
\operatorname{LBD}(6,4)\end{array}$ & $\begin{array}{l}\text { OGA; LB,NS,LD } \\
\text { OGA; LB,NS,LD }\end{array}$ \\
\hline
\end{tabular}

(a) MDRS (see Table 3.44).

In summary, the overall toxicity observed with RP/BR and WP smokes appears not to be consistently impacted by relative humidity (see Table 3.49). Results are summarized for both RP/BR and WP in Figure 3.25. Ponderosa pine was the only one of the five plant species to show an increasing extent of toxicity with increasing relative humidity. However it is doubtful, based on the behavior of the other four plant species, that there is an effect of relative humidity on the toxicity of phosphorus smokes. Post-exposure simulated rainfall had only a minimal, if any, ameliorating influence on toxicity. In many cases the presence of foliar surface moisture accentuated the effects of toxicity, even though the mass 

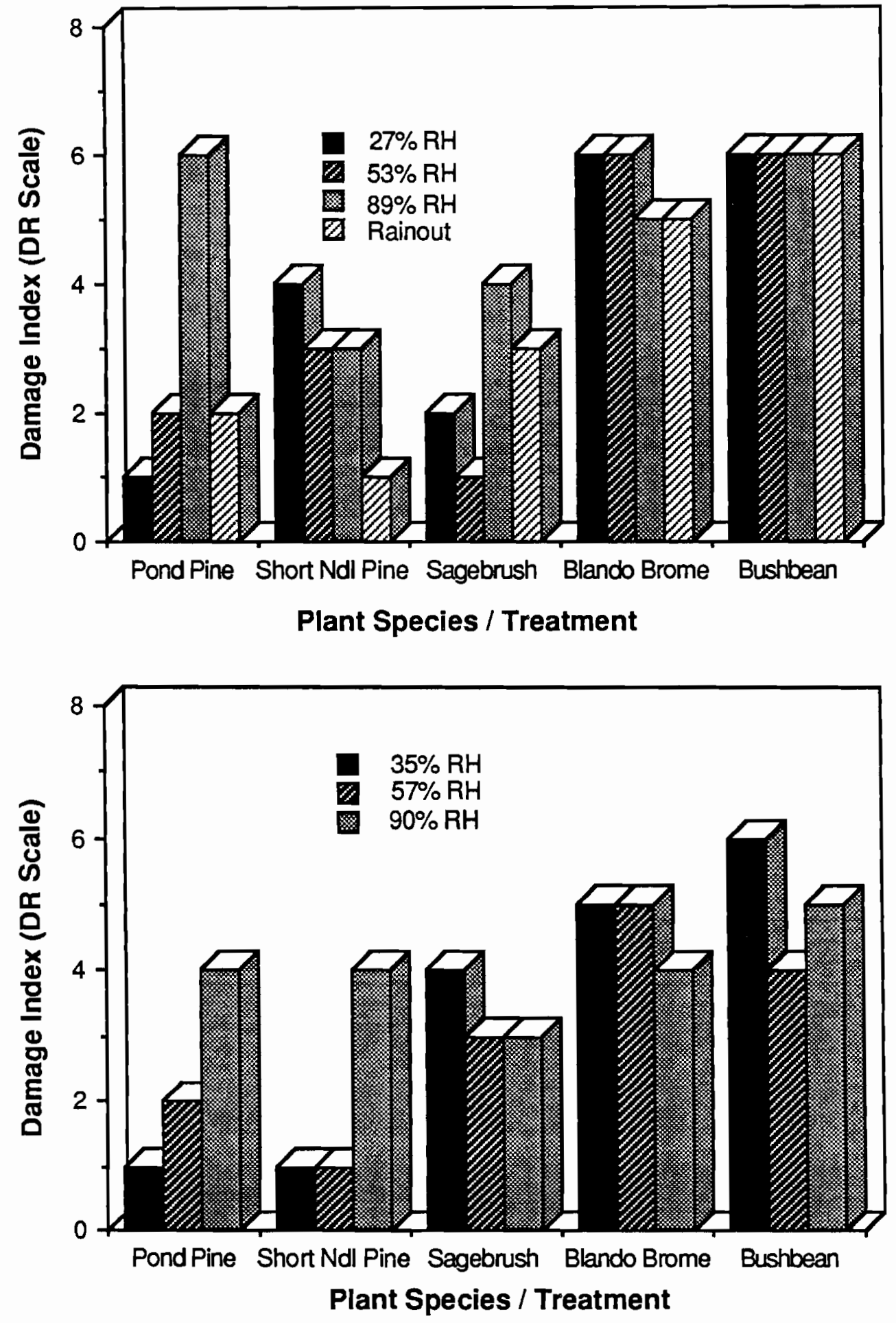

FIGURE 3.25. OVERALL IMPACT OF RELATIVE HUMIDITY AND RAINOUT ON THE PHYTOTOXICITY OF RP/BR (TOP) AND WP (BOTTOM) 
loading levels were dramatically reduced. These results appear to be inconsistent with the results obtained in the dose/response RFT for RP/BR smokes (Table 3.45), where amelioration of smoke effects was observed. However, if one compares the mass loading rates for the RP/BR RFT with the patterns of toxicity, and amelioration of effects following simulated rainfall, it appears that post-exposure leaching is only effective at mass loading levels of $100 \mu \mathrm{g}$ total $\mathrm{P} / \mathrm{cm}^{2}$ or less at the 2- and 4-hour exposures in the RFT. At 6 and 8 hours of exposure, where mass loadings exceed the $100 \mu \mathrm{g} \mathrm{P} / \mathrm{cm}^{2}$ level, post-exposure leaching has less and less of an

ameliorating effect. The latter dose level appears to represent a critical point in the dose/response relationship. This dose level also explains the discrepancy in results between the RFT and relative humidity tests. In the relative humidity tests, mass loading levels were generally substantially above $125 \mu \mathrm{g} \mathrm{P} / \mathrm{cm}^{2}$ (Tables 3.40 and 3.41). Under these conditions, toxicity is expected to be more severe, and the effects of post-exposure simulated rainfall to be less ameliorating.

\subsubsection{Influence of Wind Speed on Phytotoxicity}

In each of the previous toxicity tests wind speed was held to $2 \mathrm{mph}$, and from the resulting data it appears that the severity of observed effects are closely correlated with mass loading to vegetative surfaces. As noted above, the critical dose appears to be at or above mass loading levels of $-125 \mu \mathrm{gP} / \mathrm{cm}^{2}$. On the basis of the actual mass loading levels determined over a range of wind speeds (Tables 3.42 and 3.43 ), an elevated dose response would be predicted as wind speed increases above $4 \mathrm{mph}$. Preliminary wind speed studies indicated that 4-hour exposures were too long to obtain meaningful mass loading and toxicity data because of complete wetting and run off of condensed smokes from foliar surfaces. To compensate for this problem, exposures were limited to 1 hour. The results for both RP/BR smokes and WP smokes are shown in Table 3.60. As would be predicted, there is an increased toxicity of both smokes as wind speed is increased.

In the case of RP/BR smokes, as wind speed was increased from 0.5 to $10 \mathrm{mph}$, mass loading to foliar surfaces increased from 20 to $3000 \mu \mathrm{g} \mathrm{P} / \mathrm{cm}^{2}$ (see Table 3.42). Toxicity to both plant species was minimal at 0.5 and 2 $\mathrm{mph}$, as expected from mass loadings of less than $45 \mu \mathrm{g} \mathrm{P} / \mathrm{cm}^{2}$. At $4.5 \mathrm{mph}$, mass loading increases to $115 \mu \mathrm{g} P / \mathrm{cm}^{2}$ for ponderosa pine and $600 \mu \mathrm{g} \mathrm{P} / \mathrm{cm}^{2}$ for blando brome, and toxicity is more severe with MDRS values of 4 and 6 for ponderosa pine and blando brome, respectively. The severity of effects for the pine under these conditions are comparable to those obtained at 2 $\mathrm{mph}$ and a 4-hour exposure, which yielded the same approximate mass loading level (Tables 3.50). For the grass, the higher mass loading resulted in a greater intensity of damage than previously observed (Table 3.54). At 10 $\mathrm{mph}$, mass loading increases by a factor of 5 for the grass and a factor of 30 for the pine, compared with the 4.5-mph treatment. This increase resulted in a rapid onset of toxicity and relatively severe plant damage, including tip or blade burn and dieback in both species, necrotic spotting of foliage, and bud dieback in the pine. Damage was severe enough in the 
pine to make the plants appear dead at three weeks post-exposure. In the WP study wind speeds were adjusted to provide better resolution of deposition and toxicity response at midrange for the wind speed range. Based on the mass loading data in Table 3.43, and the toxicity results in Table 3.60 , it becomes clear that both loading and toxicity effects increase sharply between 2 and $4 \mathrm{mph}$, with a near logarithmic increase between 6 and $10 \mathrm{mph}$. Overall, toxicity results for WP smokes based on mass loading were comparable to RP/BR smokes. In both cases the blando brome was more severely impacted than the pine. At wind speeds of $4 \mathrm{mph}$ and above, foliar damage was most severe on the windward side and tops of the plants; the lee side appeared to be shadowed by the leading canopy edge, with backside turbulence and eddies apparently not dominating deposition. Both old and new growth was affected. When collected from foliar surfaces, the condensed smokes had a pH of approximately 1 , indicating that the primary mode of damage may in fact be $\mathrm{pH}$. In addition, the grass, which was in bloom at exposure, showed continued seed development post-exposure. Finally, the pines that were nearly defoliated 2 to 3 weeks post-exposure were placed into the greenhouse following the observation period. After 30 days, they underwent bud break and new growth and developed normally. These results again support the theory that much of the direct phytotoxicity observed with phosphorus smokes is transient, and can be tolerated by plants that are subjected to periodic exposure.

\subsubsection{Relationships of Foliar Characteristics to Mass Loading and Phytotoxicity}

The foliar interception of particulate contaminants or aerosols, such as those associated with obscurant smokes, is generally considered to be based on a series of physical process. These processes involve sedimentation and impaction, which are in turn dependent on wind speed, turbulence, and physical aerodynamic characteristics of the airborne particles. Within these physical limits, the rates and extent of particle transfer from air to surfaces, including individual foliar surfaces, can be predicted with some certainty. However, mathematical simulation of particle deposition to more complex plant canopies, even those of single plants, becomes a bit more tenuous. This results from unpredictable changes in boundary layer conditions surrounding the canopy; this uncertainty is imposed by thermal and water gradients, and the formation of complex eddy patterns as air passes over complex foliar structures.

In the present wind tunnel studies, the process uncertainties associated with the transfer of airborne contaminants from air to foliar surfaces are eliminated by establishing an overall value, under controlled/defined conditions, for the deposition velocity for a particular canopy type. This represents a reliable approach only if one knows the important variables affecting this value, namely wind speed, relative humidity (particularly if the smoke is hygroscopic), temperature and particle size distribution. This provides not only a measure for mass loading (dose) the laboratory studies, but also a means of extrapolating to field dose, based on air concentration and the above controlling variables. 
TABLE 3.60. INFLUENCE OF WIND SPEED ON THE PHYTOTOXICITY OF RP/BR AND WP SMOKES TO PONDEROSA PINE AND BLANDO BROME

\begin{tabular}{|c|c|c|c|c|c|}
\hline $\begin{array}{l}\text { Smoke } \\
\text { type }\end{array}$ & $\begin{array}{l}\text { Expt } \\
\text { code }\end{array}$ & $\begin{array}{l}\text { Wind } \\
\text { speed } \\
\text { (mph) } \\
\end{array}$ & $\begin{array}{c}\text { Time post- } \\
\text { exposure } \\
\text { (days) }\end{array}$ & $\begin{array}{l}\text { Toxicity } R \\
\text { Ponderosa } \\
\text { pine } \\
\end{array}$ & $\begin{array}{r}\text { Response }(a) \\
\text { Blando } \\
\text { brome } \\
\end{array}$ \\
\hline \multirow[t]{4}{*}{$\mathrm{RP} / \mathrm{BR}$} & $D-5.3$ & 0.5 & 14 & 0 & 0 \\
\hline & $D-1$ & 2.0 & 14 & 0 & TB1 \\
\hline & $D-5.2$ & 4.5 & $\begin{array}{r}0 \\
2 \\
14\end{array}$ & $\begin{array}{l}{ }^{1} 0 \\
\text { TB1 } \\
\text { TB4 }(2-6)\end{array}$ & $\begin{array}{l}\text { TB2 } \\
\text { TB5 }(2-6) \\
\text { TB6 }(6-12) \text { NS }\end{array}$ \\
\hline & $D-2$ & 10 & $\begin{array}{r}0 \\
2 \\
14\end{array}$ & $\begin{array}{c}0 \\
\text { TB4 }(4-9) N S \\
\text { TB6 }(10-16), \\
\text { NS , BD, D }\end{array}$ & $\begin{array}{l}\text { TB3 }(1-4) N S \\
\text { TB5 }(5-10) N S \\
\text { TB6 }(6-12) \text { NS }\end{array}$ \\
\hline \multirow[t]{4}{*}{ WP } & $E-1$ & 2.0 & 14 & TB1 $(0-1)$ & $\mathrm{TB} 1(0-0.5)$ \\
\hline & $E-2.3$ & 4.0 & $\begin{array}{r}0 \\
2 \\
14\end{array}$ & $\begin{array}{l}0 \\
\operatorname{TB} 1(0.5-2) \\
\operatorname{TB} 2(1-7)\end{array}$ & $\begin{array}{l}0 \\
\text { TB2 }(0.5-1.5) \mathrm{NS} \\
\operatorname{TB} 4(2-8) \mathrm{NS}\end{array}$ \\
\hline & $E-2.2$ & 6.0 & $\begin{array}{r}0 \\
2 \\
14\end{array}$ & $\begin{array}{l}{ }^{2} 0 \\
\text { TB1 } \\
\text { TB4 (2-9) }\end{array}$ & $\begin{array}{l}\text { TB2 } \\
\text { TB5 }(2-9) N S \\
\text { TB5 }(5-11) N S\end{array}$ \\
\hline & $E-2.1$ & 10 & $\begin{array}{r}0 \\
2 \\
14\end{array}$ & $\begin{array}{c}0 \\
\text { TB3 }(2-6) N S \\
\text { TB6 }(6-11) N S, \\
\text { BD }\end{array}$ & $\begin{array}{l}\text { TB3 } \\
\text { TB6 }(3-11) \text { NS } \\
\text { TB6 }(9-15) \text { NS }\end{array}$ \\
\hline
\end{tabular}

(a) See Tables 3.42 and 3.43 for mass loading values. 
However, the quantity of smoke residue deposited to foliar surfaces is not the sole measure of subsequent contact toxicity effects. The smoke residues must be retained and eventually absorbed into the leaf interior to elicit an effect. The results of the phosphorus smoke studies clearly show differences in toxicity response for individual plant species, with exposure condition, when mass loading is held relatively constant. Assuming that the metabolic systems of each of these plant species are similar, the observed differences in contact toxicity response must be due to the absorption characteristics of foliar surfaces. This can be indirectly inferred from the simulated rainfall and leaching studies where the extent of removal of smoke residues from foliar surfaces varies with plant species.

Scanning electron microscopy (SEM) was employed to place the role of surface structure in perspective with respect to foliar retention and pathways for absorption of smoke residues. Figures $3.26,3.27$, and 3.28 represent SEM's at magnifications of 100 times and 2000 times for the five plant species employed in these studies. SEM's for the two pine species are shown in Figure 3.26 at 100 times, two of the three surfaces of ponderosa pine needles are exposed. Aside from the stomatal aperatures and leaf margin spikes, the surface is relatively smooth with longitudinally oriented cuticular wax patterns. At 2000 times, surface structure is still relatively smooth, with loose wax deposits accumulating around the stomates and cuticular furrows. Surface structure of short-needle pine (Figure $3.26 \mathrm{c}$ and $d$ ) is generally similar to that of ponderosa pine with a few exceptions. These include the absence of leaf margin spikes and wax plate accumulations surrounding the stomates. In both species, the absence of visible epidermal cell outlines would indicate a relatively thick wax cuticle.

In the case of both blando brome grass blades and bushbean leaves (Figure 3.27a and c), epidermal cell outlines are visible and suggests the presence of relatively thin cuticular wax layers. The surface of the grass is furrowed (Figure 3.27a), and contains well-spaced leaf hairs. Stomates are vișible at the base of the furrows. At higher magnification (Figure $3.27 b$ ), the relatively smooth surface is seen to be covered by a rough layer of wax deposits. Low magnification of bushbean leaves show a relatively complex, yet regular surface relief (Figure $3.27 \mathrm{c}$ ). This consists of relatively deep furrowing associated with the epidermal cells, and pronounced relief produced by the leaf hairs and their associated basal cells. At higher magnification (Figure $3.27 \mathrm{~d}$ ), there is an absence of the rough cuticular waxes observed for ponderosa pine and blando brome, while the furrows are more pronounced.

The surface structure for sagebrush is markedly different from the other four plant species and is shown in Figures 3.28a and b. At both low and high mangification, it is clear that the leaf surface is covered by a dense mat of wax fibers. This wax is dense enough to completely obscure even the stomatal aperatures, and is characteristic of many drought tolerant species. 


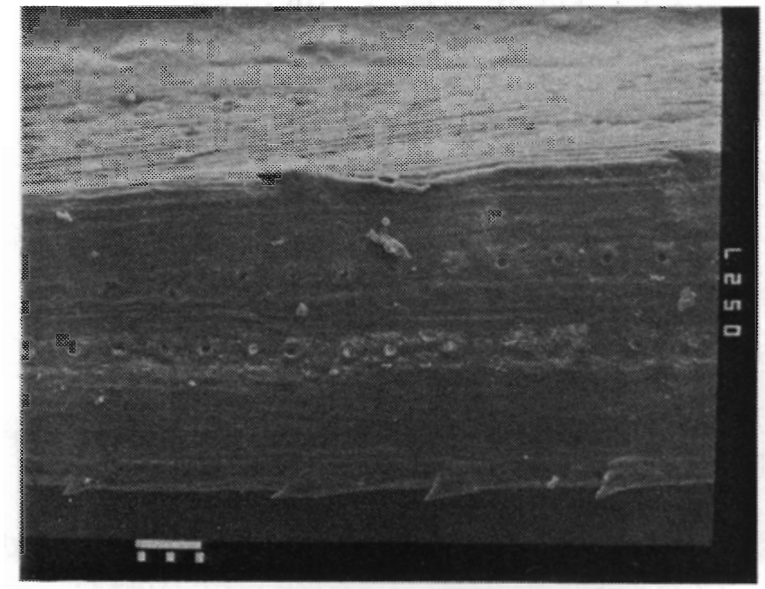

A

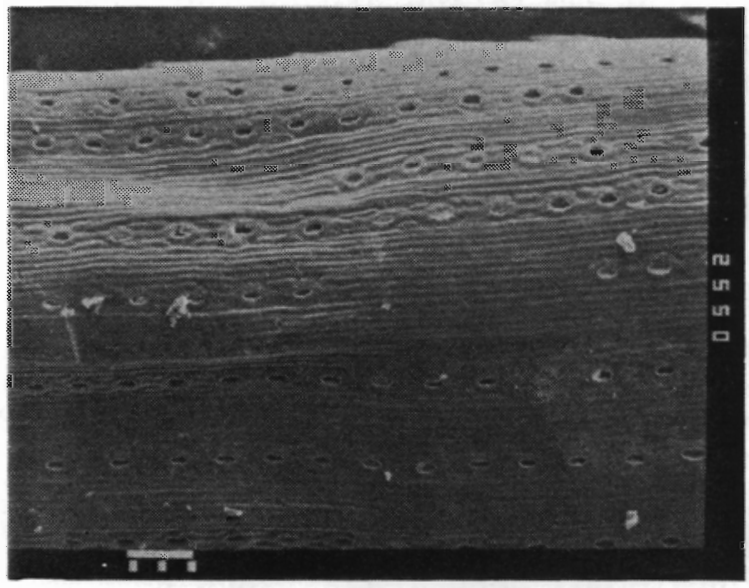

C

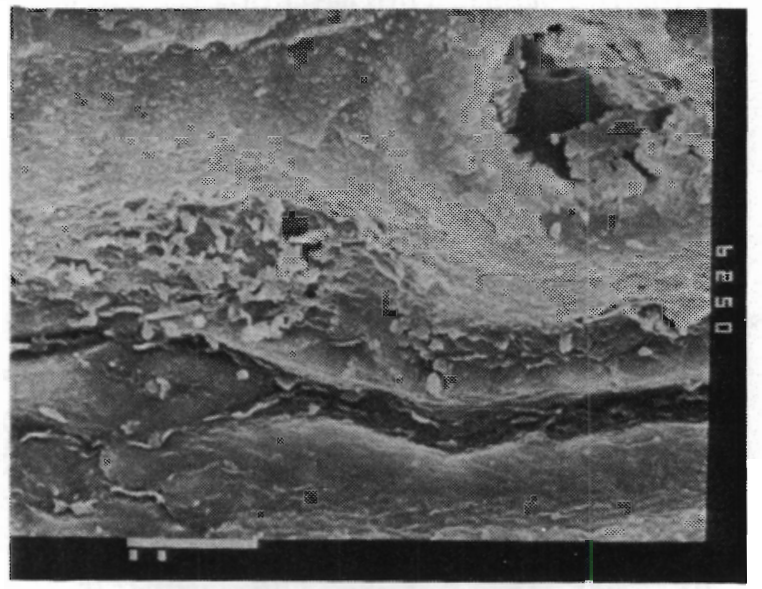

B

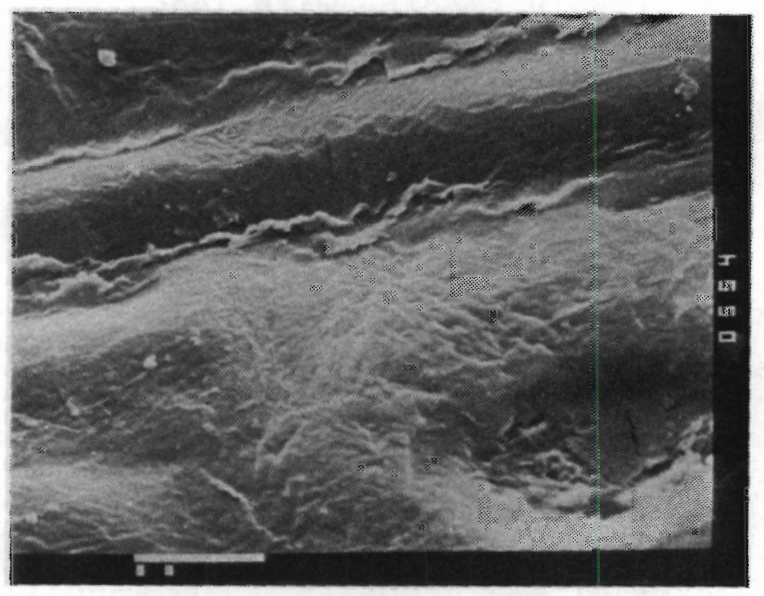

D

FIGURE 3.26. SCANNING ELECTRON MICROGRAPHS OF PONDEROSA PINE (A AND B) AND SHORT-NEEDLE PINE NEEDLES (C AND D). MAGNIFICATIONS ARE 100 TIMES AND 2000 TIMES, RESPECTIVELY 


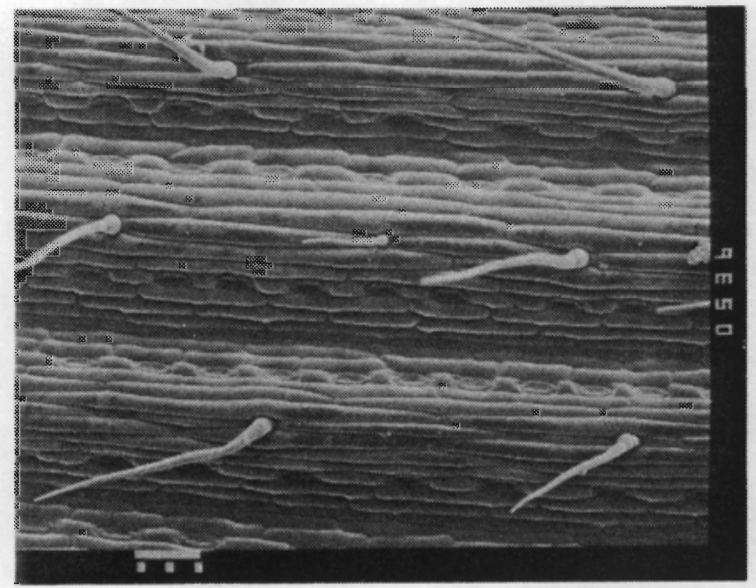

A

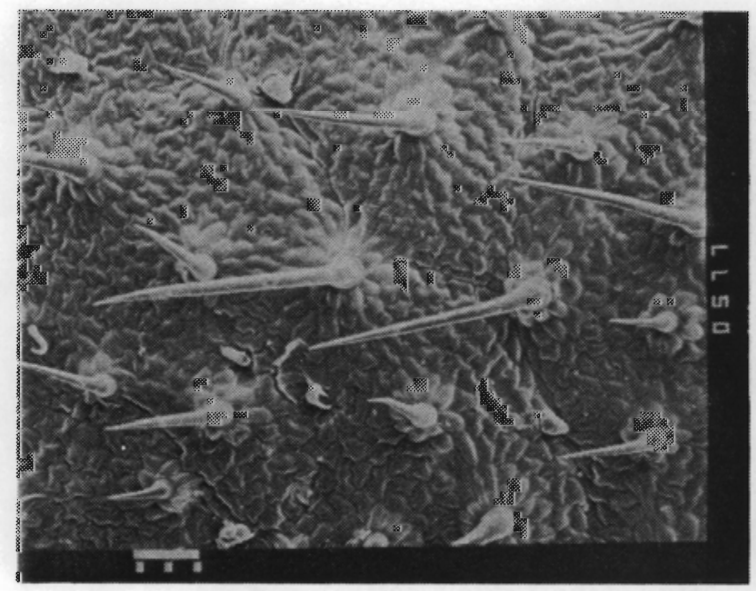

C

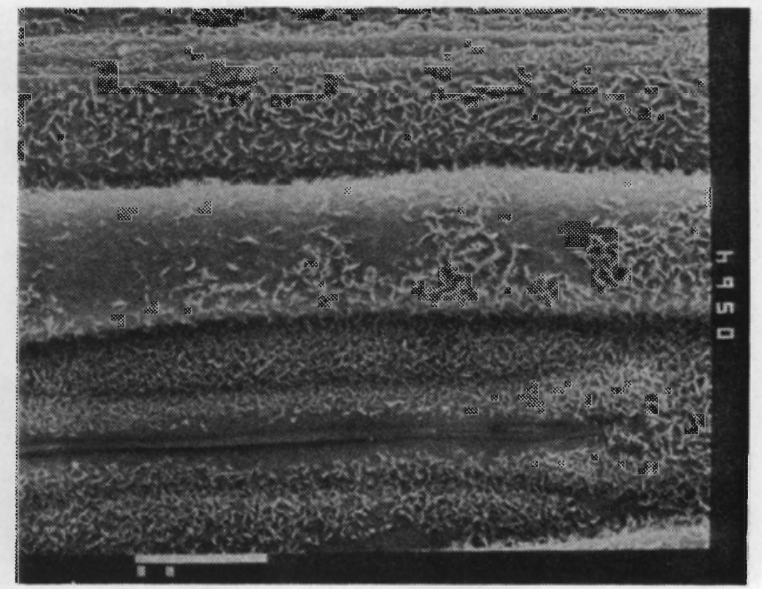

B

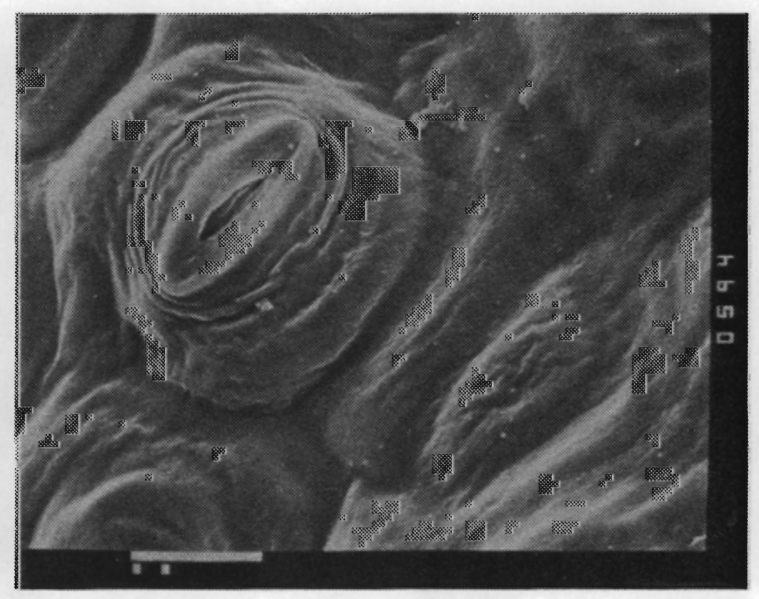

D

FIGURE 3.27 SCANNING ELECTRON MICROGRAPHS OF BLANDO BROME (A AND B) AND BUSHBEAN LEAVES (C AND D). MAGNIFICATIONS ARE 100 TIMES AND 2000 TIMES, RESPECTIVELY 

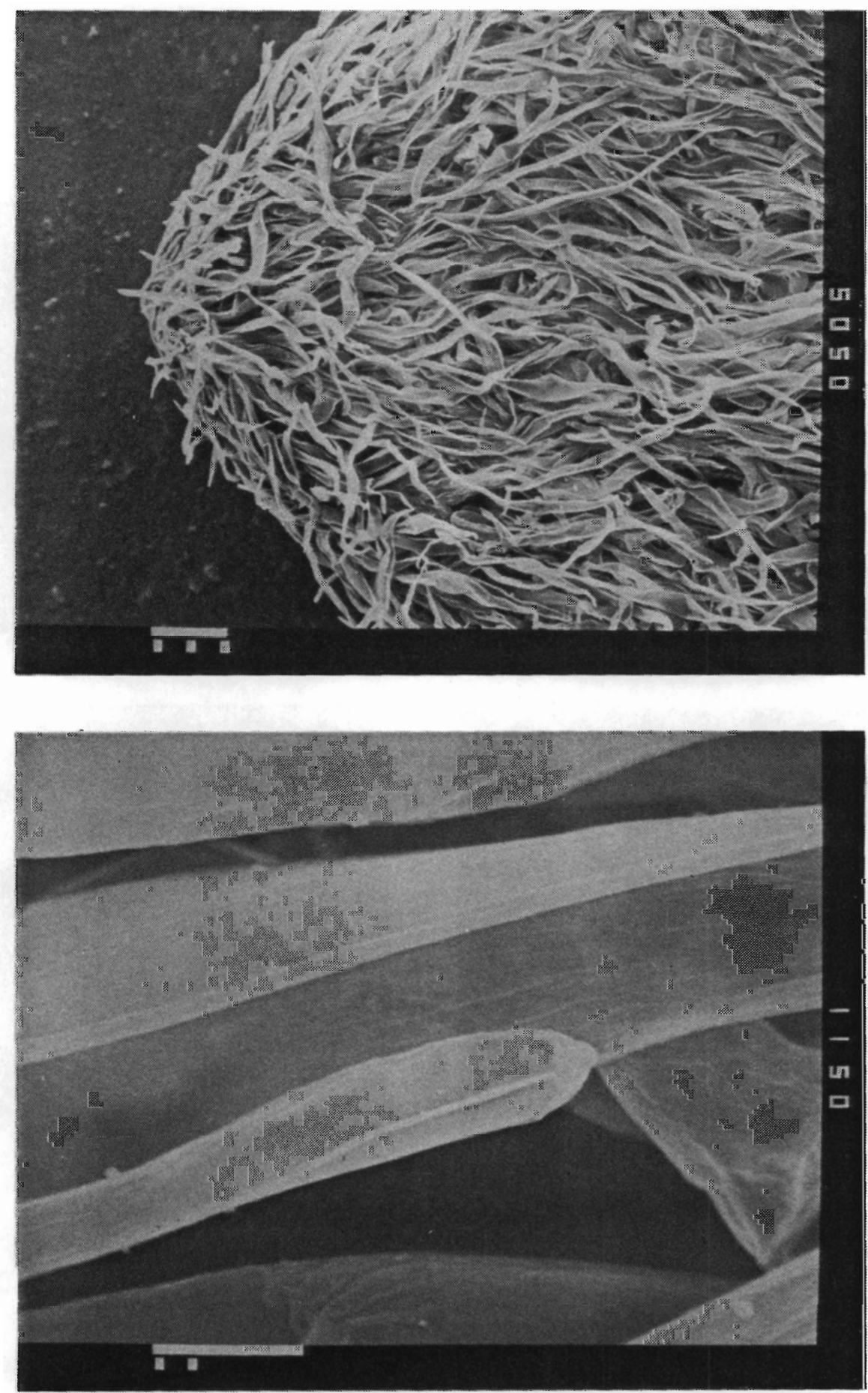

FIGURE 3.28. SCANNING ELECTRON MICROGRAPHS OF SAGEBRUSH LEAVES (A AND B). MAGNIFICATIONS ARE 100 TIMES AND 2000 TIMES, RESPECTIVELY 
The surface structure of these plants helps in explaining some of the observed foliar retention and effects data for the phosphorus smokes. In the case of pines, the higher retention of smoke residues by ponderosa pine compared with short-needle pine, may be due to the wax accumulations around the stomates. The retention by sagebrush obviously results from particle entrapment within the complex wax structures of the surface. In all of the above, the relatively thick cuticular structure of the foliage would limit transfer of foliar deposits to the leaf interior and therefore reduce overall effects. Similarly, the relativley thin cuticular wax deposits found in the grass and bushbean and greater potential for foliar absorption, may account for their generally higher sensitivity to phosphorus smokes, both by direct contact toxicity, and residual impact described in regrowth studies.

\subsubsection{Residual Effects of Phosphorus Smokes on Regrowth of Grasses}

While the above phytotoxicity data represent direct effects from foliar deposition of phosphorus smokes, it was observed during the RP/BR studies that when blando brome was harvested for biomass production, regrowth was noticeably inhibited in some treated plants. Because of the inhibited regrowth, the effects of phosphorus smokes on biomass production following harvest of the standing vegetation were evaluated. The evaluation elucidates the adverse residual effects of phosphorus smokes on regrowth of the perennial grass caused by foliar uptake of smoke components. It should be noted that this regrowth response was not observed with the relative humidity treatments, appeared to be related to mass loading, and therefore was studied only in those experiments where mass loading was high. Results for both RP/BR and WP smokes are shown in Table 3.61. Before comparing the relationship between foliar mass loading and residual regrowth effects, it should be noted that in the early RP/BR studies plants were grown for approximately 60 days prior to exposure, and had limited biomass. In later studies, it was necessary to determine if phosphorus smokes affected flowering and seed development. Substantially older plants were used to determine this effect (90 to 110 days). These changes in plant age are reflected in the first harvest standing biomass, with the values in () indicating the post-exposure observation period. The second harvest biomass values are for the stated regrowth period, and their magnitude again will reflect the size of the root mass able to support regrowth.

Data from the first harvest of the grass show no dramatic residual effect of mass loading on dry matter production in any of the three experiments. As noted, this would be expected based on the total growth period compared with the post-exposure period. The regrowth, or second harvest, data tabulated in Tabie 3.61 and graphically presented in Figure 3.29 , clearly show the presence of a residual effect of foliar contamination for both the RP/BR smoke and WP smoke exposures. In the cumulative dose test, where plants were exposed nine consecutive times to low and high air concentrations of smoke, there is a $90 \%$ reduction in biomass production at the higher mass loading rate. In the RP/BR wind speed 
TABLE 3.61. RESIDUAL EFFECTS OF FOLIAR-DEPOSITED PHOSPHORUS SMOKES ON REGROWTH OF BLANDO BROME

\begin{tabular}{|c|c|c|c|c|}
\hline \multirow[b]{2}{*}{ Smoke } & \multirow[b]{2}{*}{ Experiment } & \multirow{2}{*}{$\begin{array}{c}\text { Mass } \\
\text { loading } \\
\left(\mu \mathrm{g} P / \mathrm{cm}^{2}\right) \\
\end{array}$} & \multicolumn{2}{|c|}{$\begin{array}{c}\text { Shoot dry matter production(a) } \\
\text { (gm dry wt tissue) }\end{array}$} \\
\hline & & & First harvest(b) & Second harvest \\
\hline $\mathrm{RP} / \mathrm{BR}$ & $\begin{array}{l}\text { CDT } \\
\text { low } \\
\text { high }\end{array}$ & $\begin{array}{l}\text { Control } \\
33 \\
480\end{array}$ & $\begin{array}{l}1.72 \pm 0.29 \text { (21 days) } \\
1.83 \pm 0.35- \\
1.57 \pm 0.27-\end{array}$ & $\begin{array}{l}0.24 \pm 0.02 \text { (22 days) } \\
0.20 \pm 0.09 \quad- \\
0.02 \pm 0.01 \quad+++\end{array}$ \\
\hline & $\begin{array}{l}\text { WST } \\
0.5 \mathrm{mph} \\
4.5 \mathrm{mph} \\
10 \mathrm{mph}\end{array}$ & $\begin{array}{l}\text { Control } \\
27 \\
640 \\
2796\end{array}$ & $\begin{array}{ll}3.78 \pm 0.72 & (14 \text { days }) \\
3.42 \pm 0.69- \\
3.47 \pm 0.89- \\
3.28 \pm 0.55-\end{array}$ & $\begin{array}{ll}0.95 \pm 0.05 \text { (33 days) } \\
0.96 \pm 0.02 & - \\
0.50 \pm 0.02 & +++ \\
0.005 \pm 0.002 & +++\end{array}$ \\
\hline WP & $\begin{array}{l}\text { WST } \\
2 \mathrm{mph} \\
4 \mathrm{mph} \\
6 \mathrm{mph} \\
10 \mathrm{mph}\end{array}$ & $\begin{array}{l}\text { Control } \\
34 \\
259 \\
585 \\
2719\end{array}$ & $\begin{array}{l}10.23 \pm 0.43 \text { (14 days) } \\
10.40 \pm 1.34- \\
8.44 \pm 0.81- \\
8.53 \pm 0.92- \\
9.91 \pm 1.61-\end{array}$ & $\begin{array}{ll}4.91 \pm 0.42 \text { (28 days) } \\
5.02 \pm 0.38 \\
3.91 \pm 0.11 & + \\
3.34 \pm 0.12 & ++ \\
2.93 \pm 0.40 & +++\end{array}$ \\
\hline
\end{tabular}

(a) Value in parenthesis indicate either the post-exposure observation period, or the second harvest growth period. $A v g \pm S D, n=3$; levels of significance based on $t$-test are $P \leq 0.01(+++), P \leq 0.05(++), P \leq 0.1(+)$,

(b) and not significant $(-)$.

Pretreatment growth periods for the three experiments were 60,90 , and 110 days.

test (WST), where plants were older when exposed, effects are somewhat less at comparable mass loading levels. There is a $50 \%$ reduction in regrowth at mass loadings of $640 \mu \mathrm{g} \mathrm{P} / \mathrm{cm}^{2}$, and a $95 \%$ reduction at $2800 \mu \mathrm{g} \mathrm{P} / \mathrm{cm}^{2}$. Results for WP are qualitatively similar to RP/BR, but not quantitatively. Mass loading levels of 250,580 , and $2700 \mu \mathrm{g} \mathrm{P} / \mathrm{cm}^{2}$, result in biomass reductions of $20 \%, 32 \%$, and $40 \%$, respectively. This is substantially less than that seen with the RP/BR treatments. However, we have seen no evidence that the combustion products of RP/BR smokes differ from those of WP smokes, and can rule out smoke chemistry. It appears that the older the plant at exposure, the lower the intensity of the residual regrowth effects.

There are physiological mechanisms to explain this effect. Plants comprising these three studies were in either a rapidly growing vegetative state (RP/CDT), early boot stage where reproductive structures were just forming (RP/WST), or in mid to late seed-filling stage (WP/WST). In the vegetative stage metabolites, possibly including phosphorus smoke 

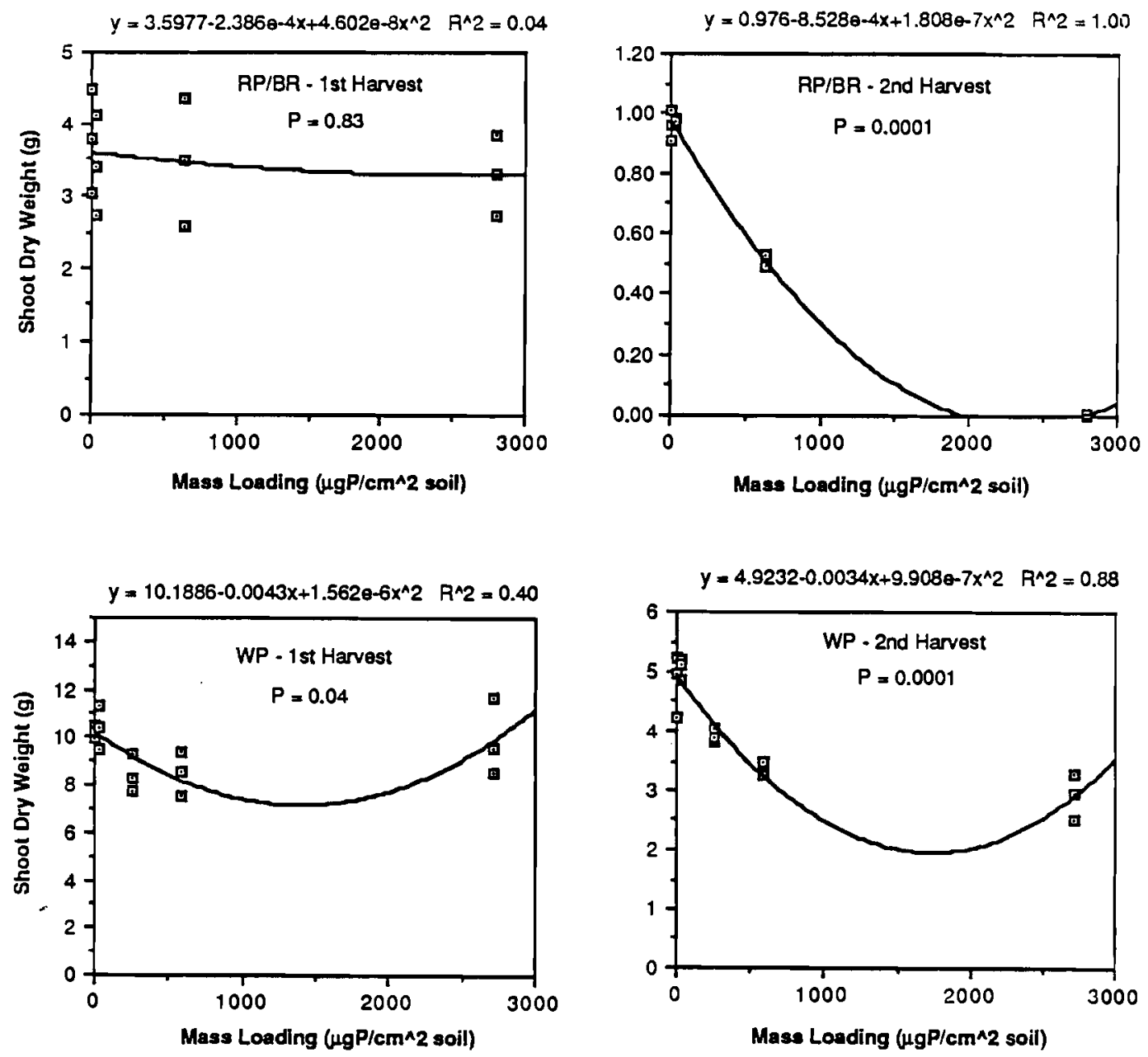

FIGURE 3.29. RESIDUAL EFFECTS OF FOLIAR CONTAMINATION WITH RP/BR and WP (SMOKES ON FIRST AND SECOND HARVEST BIOMASS PRODUCTION FOR BLANDO BROME). RESULTS FOR WIND SPEED TESTS, SEE TABLE 3.61

components, are being transported from foliage to roots to establish the roots for the next year's foliage growth. As the plant matures, less foliar material is transported to the root, and more is transferred from fol iage to the developing reproductive structures and/or seed. In the latter situation, less of the phosphorus components causing the observed effects would be transported to the root and regrowth effects would be expected to be less.

\subsubsection{Indirect Effects of Phosphorus Smokes on Grasses Grown in Contaminated Soil}

The short-term adverse effects of smokes resulting from direct contact with mature, above-ground plant structures have been evaluated. However, obscurant smokes used at training sites that have marginal soil fertility and/or hostile environmental conditions could result in long-term adverse 
effects. Specifically, what effect does the high acidity and/or high phosphorus loads to soil have on the survival and replacement of plants at field installations? The specific objectives to be addressed included: 1) evaluation of the effects of phosphorus smoke deposition to soil on seed germination, using blando brome as a test species; and 2) a determination of the influence of high acidity/high phosphorus loads to soils on the availability of soil elements to growing plants, again using blando brome. The assumption was that the mobilization of potentially toxic elements in soils could accelerate their absorption by plants and adversely affect either germination and/or subsequent growth, and therefore plant vigor.

Two soils were employed in these studies, a Burbank silt-sand and a Maxey Flats clay-loam. The Burbank soil is characteristic of the arid central Washington state region, including the Yakima Firing Range. It has a pH of 7 and is relatively fertile. The Maxey Flats soil was collected in Kentucky and is representative of humid eastern soils, has a pH of approximately 5.5 , and is a comparatively heavily leached soil with low fertility. Pots containing approximately $400 \mathrm{gm}$ dry wt soil, maintained at $2 / 3$ field capacity, were exposed during each of the tests (RFT, RHT, CDT, and WST). Mass loading levels were estimated based on wet and dry deposition coupons. Following exposure, each pot/treatment was seeded with 20 blando brome seeds, germination percentage was noted and allowed to grow for a set period of time. The tissues were harvested for total elemental analysis by ICP, and regrown if necessary for second harvest data.

\subsubsection{Germination}

Soils exposed to either RP/BR or WP smokes, under various conditions of exposure duration cumulative dose, relative humidity or wind speed, and untreated control pots were seeded with blando brome. Control soils had germination rates of $85 \%$ to $95 \%$. Based on these control rates, in no case did either RP/BR or WP smoke, under any condition, significantly affect germination. The lack of any adverse effect on germination would suggest that this step of the plant growth cycle is insensitive to any secondary effects of either $\mathrm{pH}$ or high phosphorus.

\subsubsection{Biomass Production}

In range finding test $A$, soils were exposed to RP/BR smokes for 2 to 8 hours, mass loading was estimated, and biomass production determined 55-days post-planting. Results for RFT and CDT series are tabulated in Table 3.62, and graphically presented for the RFT series in Figure 3.30 . In the case of Maxey Flats soil, the first harvest biomass increased significantly with increasing soil deposition levels, compared with controls. In this instance phosphorus loading of the soil actually increased plant growth on the low-fertility soil. After cropping and regrowth for an additional 34 days, biomass production again increased with phosphorus loading to soil. No evidence of retarded regrowth was evident, as seen with direct foliar contamination. Biomass results for the first and second harvest of plants grown in Burbank soil showed no significant effect on plant growth. 
TABLE 3.62. EFFECT OF SOIL-DEPOSITED RP/BR SMOKES ON THE GROWTH OF BLANDO BROME SEEDED POST-EXPOSURE. SOILS WERE EXPOSED EITHER FOR 2, 4,6, OR 8 HOURS IN RFT-A, OR TO CONSECUTIVE DOSES IN THE CDT

\begin{tabular}{|c|c|c|c|c|c|c|}
\hline \multirow[b]{2}{*}{ Soil } & \multirow[b]{2}{*}{$\begin{array}{c}\text { Experiment } \\
\text { code }\end{array}$} & \multirow{2}{*}{$\begin{array}{l}\text { Soil mass } \\
\text { loading } \\
\left(\mu \mathrm{gP} / \mathrm{cm}^{2}\right)\end{array}$} & \multicolumn{4}{|c|}{ Shoot dry wt $(g m)^{(a)}$} \\
\hline & & & $\begin{array}{l}\text { First } \\
\text { harvest }\end{array}$ & & $\begin{array}{l}\text { Second } \\
\text { harvest }\end{array}$ & \\
\hline Maxey Flats & RFT-A & $\begin{array}{l}\text { Control } \\
190 \\
390 \\
580 \\
780\end{array}$ & $\begin{array}{l}0.07 \pm 0.01 \\
0.26 \pm 0.08 \\
0.36 \pm 0.0 \\
0.53 \pm 0.07 \\
0.53 \pm 0.06\end{array}$ & $\begin{array}{l}++ \\
+++ \\
+++ \\
+++\end{array}$ & $\begin{array}{l}0.04 \pm 0.01 \\
0.48 \pm 0.06 \\
0.97 \pm 0.15 \\
1.12 \pm 0.10 \\
1.09 \pm 0.10\end{array}$ & $\begin{array}{l}+++ \\
+++ \\
+++ \\
+++\end{array}$ \\
\hline Burbank & RFT-A & $\begin{array}{l}\text { Control } \\
190 \\
390 \\
580 \\
780\end{array}$ & $\begin{array}{l}0.51 \pm 0.08 \\
0.51 \pm 0.12 \\
0.66 \pm 0.10 \\
0.61 \pm 0.01 \\
0.63 \pm 0.02\end{array}$ & $\begin{array}{l}- \\
- \\
-\end{array}$ & $\begin{array}{l}0.86 \pm 0.14 \\
0.98 \pm 0.08 \\
0.90 \pm 0.15 \\
0.85 \pm 0.08 \\
0.76 \pm 0.01\end{array}$ & $\begin{array}{l}- \\
- \\
- \\
-\end{array}$ \\
\hline Maxey Flats & $\begin{array}{l}\text { CDT } \\
\text { Low } \times 9 \\
\text { High } \times 9\end{array}$ & $\begin{array}{l}\text { Control } \\
160 \\
2080\end{array}$ & $\begin{array}{l}0.06 \pm 0.1 \\
0.31 \pm 0.13 \\
1.63 \pm 0.17\end{array}$ & $\begin{array}{l}++ \\
+++\end{array}$ & $\begin{array}{l}0.14 \pm 0.01 \\
0.37 \pm 0.05 \\
0.83 \pm 0.03\end{array}$ & $\begin{array}{l}+++ \\
+++\end{array}$ \\
\hline Burbank & $\begin{array}{l}\text { CDT } \\
\text { Low } \times 9 \\
\text { High } \times 9\end{array}$ & $\begin{array}{l}\text { Control } \\
160 \\
2080\end{array}$ & $\begin{array}{l}1.82 \pm 0.07 \\
2.02 \pm 0.01 \\
2.25 \pm 0.14\end{array}$ & $\begin{array}{l}+ \\
++\end{array}$ & $\begin{array}{l}0.54 \pm 0.06 \\
0.57 \pm 0.06 \\
0.64 \pm 0.07\end{array}$ & - \\
\hline
\end{tabular}

(a) $A v g \pm S D, n=3$; levels of significance based on t-test are $P \leq 0.01(+++)$,

(b) $P<0.0 .05(++), P \leq 0.1(+)$, and not significant $(-)$.

(c) $5 \overline{6}$ days

34 days 

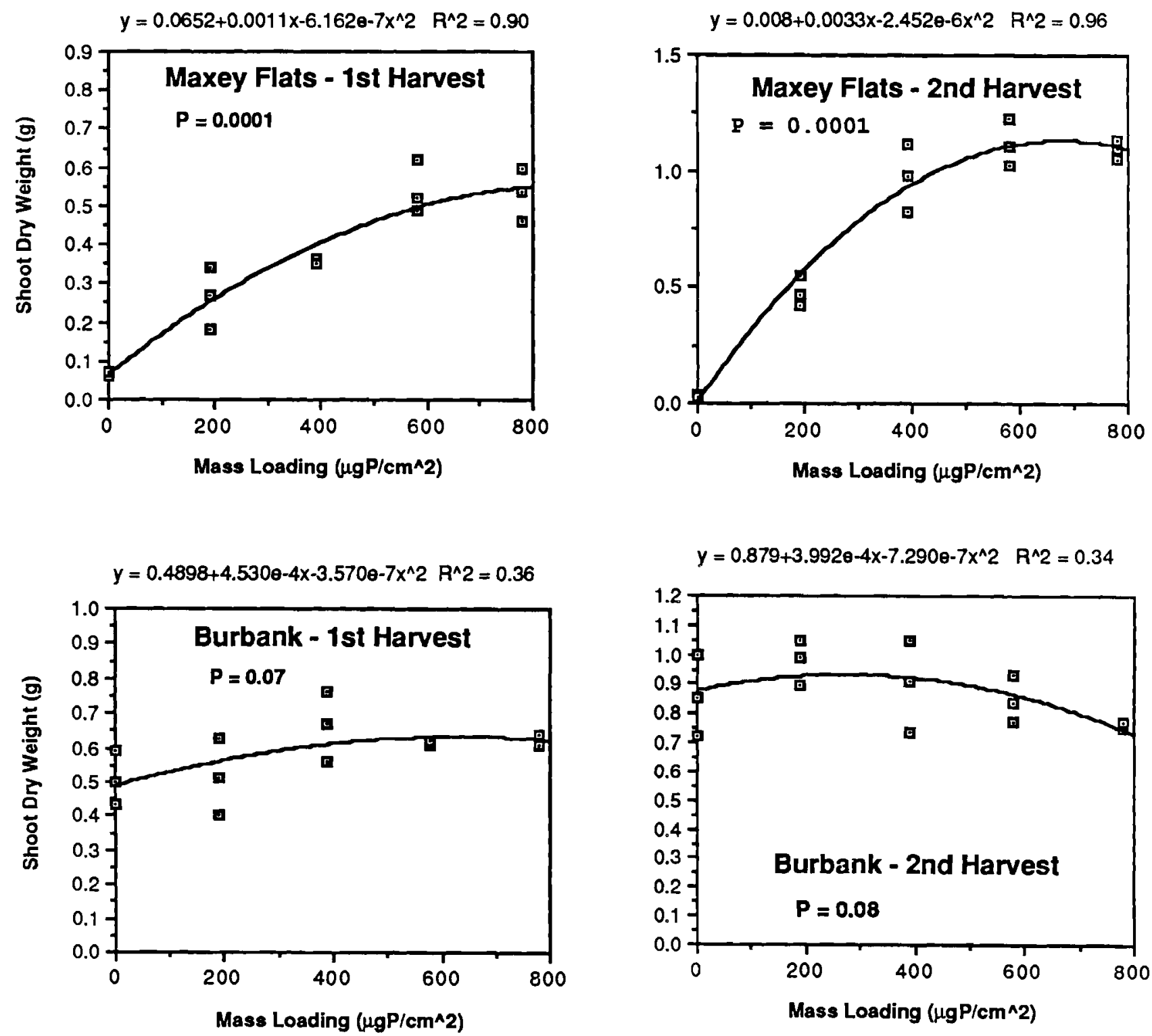

FIGURE 3.30. INDIRECT EFFECTS OF SOIL DEPOSITED RP/BR SMOKES ON GROWTH OF BLANDO BROME ON BURBANK SILT-SAND AND MAXEY FLATS 
In the CDT, at the first harvest (60 days) the low dose exposure resulted in soil mass loading levels comparable to the 2 -hour treatment in the RFT, while the high dose gave soil mass loadings a factor of 2 to 3 times higher than the 8 hour treatment, or $2000 \mu \mathrm{gP} / \mathrm{cm}^{2}$ soil surface. In Burbank soil contaminated in the cumulative dose test series, significant increases in biomass production is observed for the first harvest, but not in the second harvest. Similarly, the first harvest from Maxey Flats soil shows a significant increase in biomass production at both low and high dose levels. Since growth was minimal on Maxey Flat control soils, N-P-K fertilizer was applied to all three treatments (cumulative dose test) of this soil following the first harvest. Dry matter production for the second harvest ( 42 days), for each treatment, was higher than the controls. In fact, fertilization of the Maxey Flats soil did little to influence the phosphorus effects other than increase second harvest biomass results for the controls.

The indirect plant effects of RP/BR and WP smokes generated over a range of relative humidity treatments were similar, therefore only the data set for RP/BR is presented, particularly since the latter included a rainout treatment. In test series $D$, soils were exposed to RP/BR smokes under three relative humidity conditions and simulated rainout. For the relative humidity, treatments were approximately $180 \mu \mathrm{g} \mathrm{P} / \mathrm{cm}^{2}$ and increased by $15-$ fold to $3000 \mu \mathrm{g} \mathrm{P} / \mathrm{cm}^{2}$ under rainout conditions (Table 3.63 ). In the case of Burbank soils, the rainout treatment, with its much higher deposition to soil, increased biomass by $32 \%$ compared with the control. In comparison, the lower soil dose resulting from non-rainout conditions at $27 \%$, $53 \%$, and $89 \%$ relative humidity, reduced biomass production significantly. In fact, these results suggest that low relative humidities tend to contain smoke components inhibitory to growth, more so that at either of the higher relative humidity's or under rainout conditions. This response pattern is maintained through the second harvest on Burbank soils. Again, the lack of significant growth reduction at the high rainout levels and a residual toxicity with relative humidity, particularly at the lower relative humidity, are noted. This apparent residual toxicity is seen also in the canopy height data, where only the relative humidity treatments of the second harvest exhibit a reduced blade length of 22 versus 33 centimeters.

Results for Maxey Flats soil are not totally consistent with those of Burbank soil. As before (see Table 3.62), growth was promoted with all phosphorus additions, compared with the controls. However, the high phosphorus loadings resulting from rainout are inhibitory compared with the lower loadings in the relative humidity treatments $(P=0.003)$. This suggests the presence of some adverse interaction. In the first harvest, the effect of relative humidity is clearly seen although not and indicates a reduced rate of dry matter production as relative humidity during exposure is reduced. In the second harvest the rainout treatment continues to exhibit an inhibitory trend $(P=0.006)$, while the effects of relative humidity are no longer evident. 
TABLE 3.63. INFLUENCE OF RELATIVE HUMIDITY AND RAINOUT ON GROWTH OF BLANDO BROME GROWN ON SOILS CONTAMINATED WITH RP/BR SMOKES, EXPOSURE SERIES D

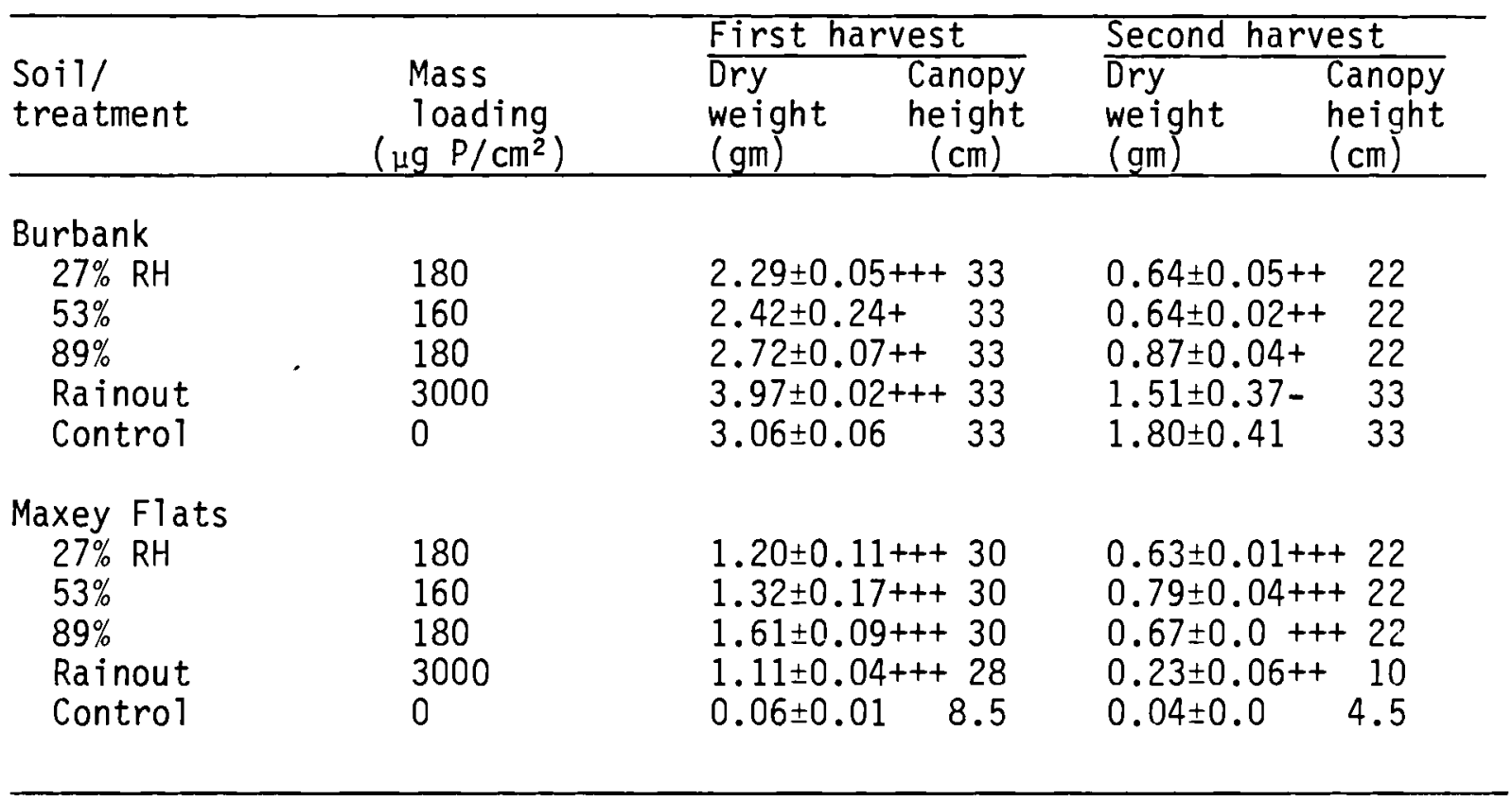

$A \vee g \pm S D, n=3$; levels of significance based on t-test are $P \leq 0.01(+++)$, $P \leq 0.05(++), P \leq 0.1(+)$, and not significant $(-)$.

It is presently unclear as to the cause of either the residual effects following foliar contamination or the indirect effects on plant growth following soil contamination. Two reasonable options are plausible. First, there is some component in phosphorus smokes that is readily absorbed and persists and affects subsequent plant growth. Secondly, the presence of available phosphorus in soils, resulting from either root excretion following foliar uptake or directly deposited to soil in the latter studies, may cause either an ion imbalance or result in solubilization of toxic materials in soil that are otherwise unavailable for plant uptake thereby inducing the observed effects. The first possibility is, in our opinion, much more plausible.

\subsubsection{Elemental Composition of Plant Tissues}

The deposition of phosphorus smokes to soils and the evaluation of subsequent plant availability of soil elements, was performed for soils exposed from 2 to 8 hours (RFT), for soils receiving nine repetitive exposures to low and high concentration smokes (CDT), and to soils exposed to smokes under a range of relative humidity and simulated rainout conditions (relative humidity test). The purpose of the evaluation was 
identify the immediate causes for yield reductions observed with post-exposure planted soils, and to identify any subtoxic mobilization of non-nutrient trace elements normally associated with soils.

In the RFT, where soils were exposed to RP/BR smokes for 2 to 8 hours, mass loading of phosphorus to soil surfaces ranged from 190 to $780 \mu \mathrm{g} \mathrm{P} / \mathrm{cm}^{2}$. Results for the concentrations of individual elements in shoot tissues for blando brome are shown in Table 3.64. It should be noted that in this and the subsequent three data sets, no evidence of $\mathrm{As}, \mathrm{Cd}, \mathrm{Co}, \mathrm{Cr}, \mathrm{Ni}$, or $\mathrm{Pb}$ mobilization was observed. In addition, the behavior of $\mathrm{Ba}, \mathrm{Na}, \mathrm{Li}$, and $\mathrm{Sr}$

TABLE 3.64. AVAILABILITY OF SOIL ELEMENTS FOR PLANT UPTAKE FOLLOWING CONTAMINATION OF SOILS WITH RP/BR SMOKES FOR 2 TO 8 HRS(a)

\begin{tabular}{|c|c|c|c|c|c|}
\hline \multirow{2}{*}{$\begin{array}{l}\text { Soil/Element (b) } \\
\text { Maxey Flats silt-loam }\end{array}$} & \multicolumn{5}{|c|}{ Tissue concentration ( $\mu \mathrm{g} / \mathrm{gm}$ dry wt) } \\
\hline & & & & & \\
\hline Exposure duration (hrs) & Control & 2 & 4 & 6 & 8 \\
\hline Mass Loading ( $\left.\mu \mathrm{g} P / \mathrm{cm}^{2}\right)$ & 0 & 190 & 390 & 580 & 780 \\
\hline AL & $441 \pm 56$ & $340 \pm 58$ & $212 \pm 86$ & $390 \pm 69$ & $1276 \pm 254$ \\
\hline B & $26 \pm 1$ & $14 \pm 1$ & $15 \pm 1$ & $17 \pm 1$ & $18 \pm 3$ \\
\hline $\mathrm{Ca}$ & $6158 \pm 442$ & $5040 \pm 40$ & $6820 \pm 200$ & $7070 \pm 350$ & $8090 \pm 730$ \\
\hline $\mathrm{Cu}$ & $11 \pm 1$ & $9 \pm 1$ & $9 \pm 1$ & $8 \pm 1$ & $14 \pm 7$ \\
\hline $\mathrm{Fe}$ & $311 \pm 23$ & $266 \pm 42$ & $222 \pm 23$ & $437 \pm 140$ & $829 \pm 77$ \\
\hline K & $38700 \pm 7000$ & $33000 \pm 1000$ & $28000 \pm 2,000$ & $24000 \pm 4000$ & $26700 \pm 4100$ \\
\hline Mg & $1627 \pm 261$ & $1890 \pm 94$ & $2790 \pm 30$ & $2980 \pm 60$ & $3730 \pm 630$ \\
\hline Mn & $464 \pm 33$ & $369 \pm 15$ & $513 \pm 1$ & $663 \pm 19$ & $975 \pm 33$ \\
\hline$P$ & $701 \pm 121$ & $1483 \pm 203$ & $3640 \pm 420$ & $3650 \pm 250$ & $5270 \pm 770$ \\
\hline $2 n$ & $32 \pm 6$ & $39 \pm 2$ & $50 \pm 1$ & $56 \pm 8$ & $75 \pm 25$ \\
\hline \multicolumn{6}{|l|}{ Burbank silt-sand } \\
\hline Mass loading ( $\left.\mu \mathrm{g} P / \mathrm{cm}^{2}\right)$ & 0 & 190 & 390 & 580 & 780 \\
\hline AL & $388 \pm 130$ & $356 \pm 150$ & $350 \pm 211$ & $362 \pm 176$ & $324 \pm 120$ \\
\hline B & $16 \pm 2$ & $14 \pm 1$ & $13 \pm 2$ & $13 \pm 1$ & $14 \pm 1$ \\
\hline $\mathrm{Ca}$ & $8788 \pm 32$ & $8440 \pm 615$ & $7590 \pm 610$ & $7210 \pm 10$ & $7600 \pm 240$ \\
\hline $\mathrm{Cu}$ & $16 \pm 1$ & $17 \pm 4$ & $16 \pm 1$ & $15 \pm 2$ & $16 \pm 2$ \\
\hline $\mathrm{Fe}$ & $696 \pm 328$ & $623 \pm 230$ & $658 \pm 380$ & $323 \pm 23$ & $532 \pm 250$ \\
\hline K & $54500 \pm 500$ & $53000 \pm 3,000$ & $49500 \pm 500$ & $51000 \pm 1,000$ & $51500 \pm 500$ \\
\hline $\mathrm{Mg}$ & $3250 \pm 70$ & $3380 \pm 320$ & $3030 \pm 170$ & $3030 \pm 30$ & $3160 \pm 100$ \\
\hline$M n$ & $28 \pm 8$ & $31 \pm 3$ & $30 \pm 7$ & $23 \pm 1$ & $30 \pm 3$ \\
\hline$P$ & $2730 \pm 170$ & $4090 \pm 190$ & $4810 \pm 70$ & $5700 \pm 420$ & $6030 \pm 30$ \\
\hline $\mathrm{Zn}$ & $21 \pm 15$ & $38 \pm 12$ & $45 \pm 15$ & $25 \pm 1$ & $27 \pm 1$ \\
\hline
\end{tabular}

(a) Pots $(11.5 \mathrm{~cm}$ dia $\times 10 \mathrm{~cm}$ deep) were exposed to aerosols containing and planted with

(b) Bl ando brome. MeantRange, $n=2$.

$\mathrm{As}, \mathrm{Cd}, \mathrm{Co}, \mathrm{Cr}, \mathrm{Ni}$ and $\mathrm{Pb}$ were at or below detection $\mathrm{limits}$. 
was comparable to their monovalent and divalent nutrient analogs, and are not reported. The following discussion is complicated by substantial differences in the interaction of phosphorus smokes with the two soils used.

Results for Maxey Flat soil show the tissue concentrations of the divalent cations $\mathrm{Ca}, \mathrm{Fe}, \mathrm{Mg}, \mathrm{Mn}$, and $\mathrm{Zn}$ to increase with increasing soil loading of RP/BR smoke, while the concentration of monovalent $K$ decreases, and there is no apparent effect on Cu (Figure 3.31). Compared to the control plants, tissue concentrations of phosphorus tend to increase with mass loading, as one might expect. The concentration of $A 1$ is relatively unchanged at 2 to 6 hours, but increases sharply at the highest smoke loading. Based on these data, the first harvest growth promotion (see Table 3.63) may in fact be due to limited phosphorus availability, while the inhibition noted in the second harvest at 8 hours could result from $A 1$ and Mn toxicity.

Results with the Burbank silt-loam soil, as noted, are somewhat different. No statistically significant patterns for plant availability are noted for $\mathrm{Al}, \mathrm{Cu}, \mathrm{Fe}, \mathrm{K}, \mathrm{Mg}, \mathrm{Mn}$, or $\mathrm{Zn}$. The availability of $\mathrm{Ca}$ shows a decreasing trend with mass loading; K shows a similar trend (Figure 3.32). Control tissues show substantially higher phosphorus levels, compared with Maxey Flat soil, with increased tissue concentration with mass loading level. Some decrease in tissue concentration for $B$ are also indicated.

In the cumulative dose test, the high dose treatment resulted in a 2 to 3-fold increase in mass loading compared to the range-finding test. For the first harvest from Maxey flats soil (Table 3.65), a comparison of the elemental concentrations in tissues from controls and high dose soils generally reinforce the previous results. At the high dose the concentrations of $\mathrm{Al}, \mathrm{B}, \mathrm{Cu}, \mathrm{Fe}, \mathrm{K}$, and $\mathrm{Zn}$ decrease, while $\mathrm{Mg}$ increases, and $\mathrm{Mn}$ and $\mathrm{Ca}$ remain constant. The Burbank soil, which showed no definitive trends (except for $\mathrm{B}, \mathrm{K}$, and $\mathrm{Ca}$ ) with mass loading up to $780 \mathrm{\mu g}$ $\mathrm{P} / \mathrm{cm}^{2}$ (see Table 3.64), does exhibit some changes with respect to plant availability at $2080 \mu \mathrm{gP} / \mathrm{cm} 2$. This is seen in the noted increases in $\mathrm{Al}$, $\mathrm{Fe}$, and $\mathrm{Mn}$ in tissues. Concentrations of $\mathrm{Ca}$ decrease, while those of $\mathrm{B}, \mathrm{Cu}$, $\mathrm{K}, \mathrm{Mg}$, and $\mathrm{Zn}$ remain unchanged. 


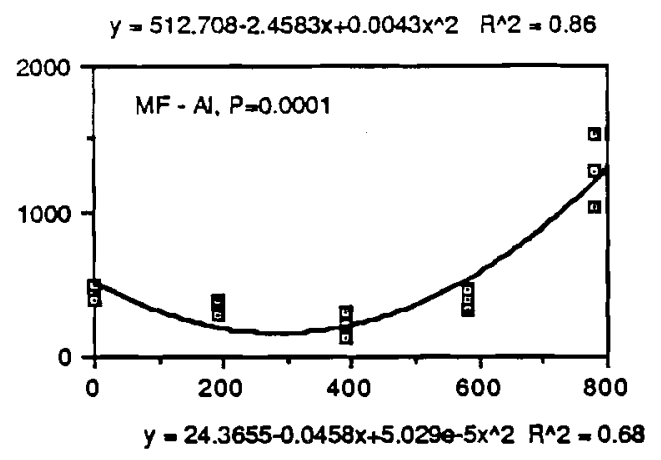

$y=3.9200+4-43.3481 x+0.034 x^{\wedge} 2 R^{\wedge} 2=0.68$
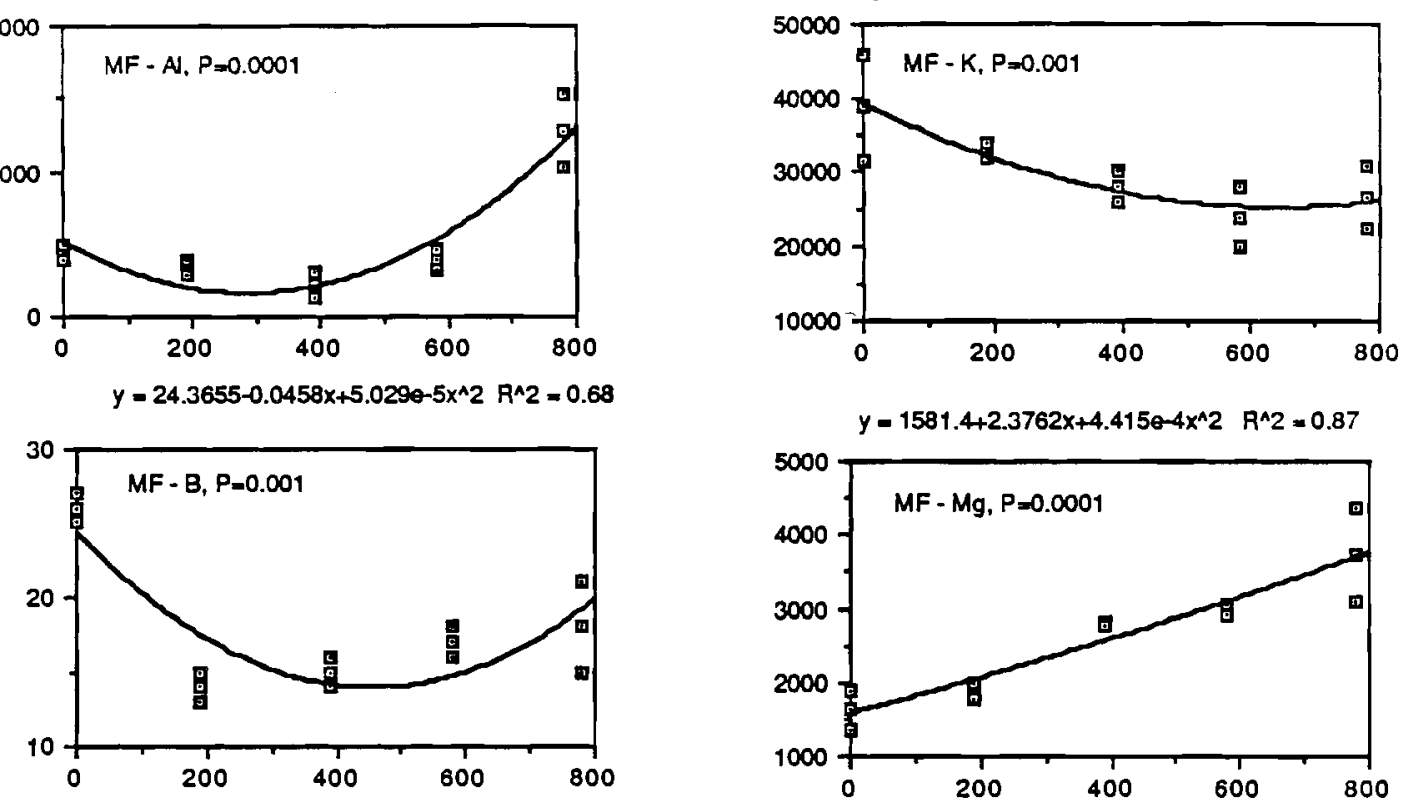

$y=5836.5977-0.871 x+0.005 x^{\wedge} 2 \quad R^{\wedge} 2=0.70$
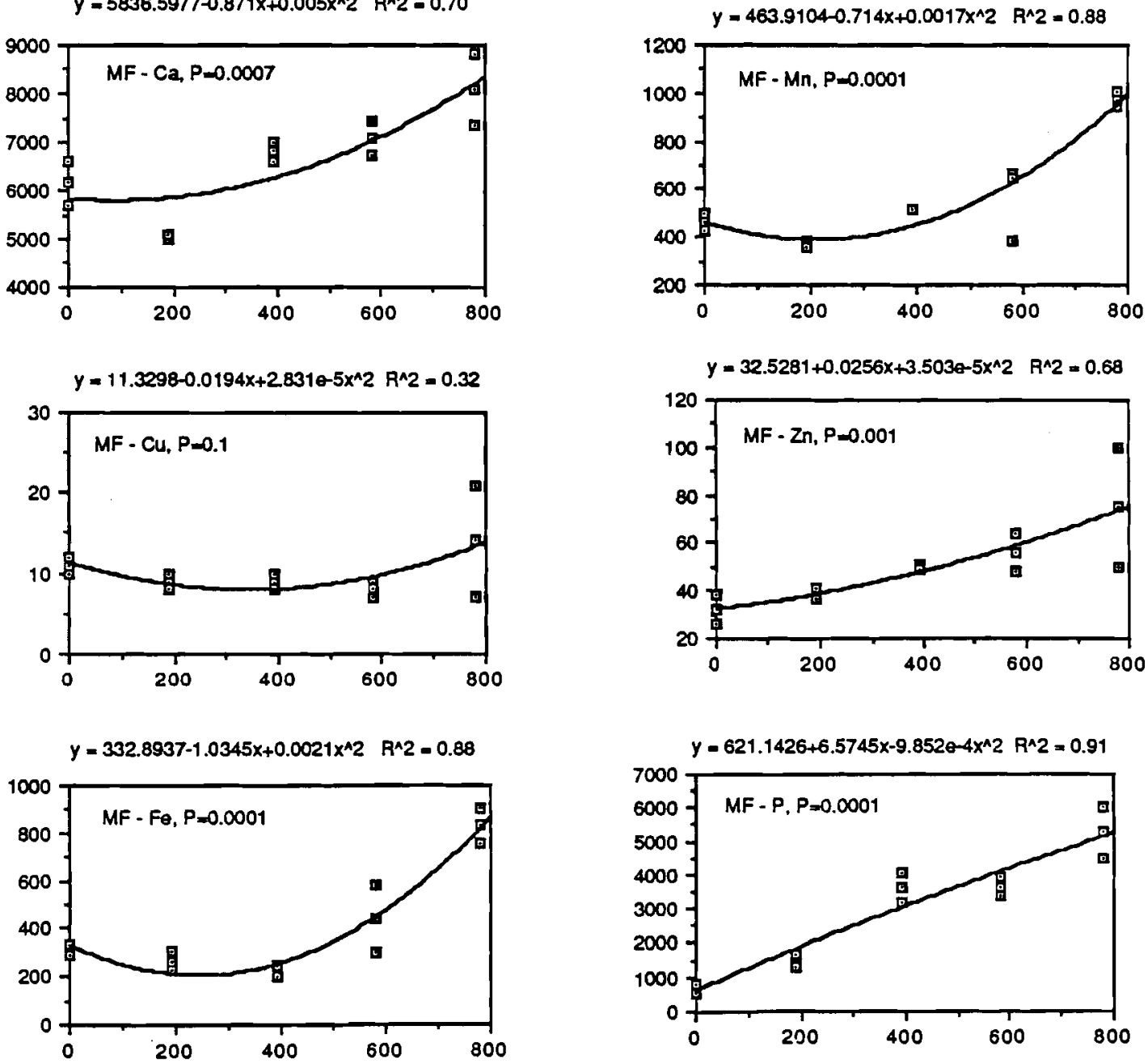

FIGURE 3.31. PLANT TISSUE CONCENTRATIONS OF DIVALENT CATIONS FOR PLANTS GROWN IN MAXEY FLAT SOIL AND EXPOSED TO RP/BR 
$y=15.9879-0.0128 x+1.319 \theta-5 x^{\wedge} 2 R^{\wedge} 2=0.45$
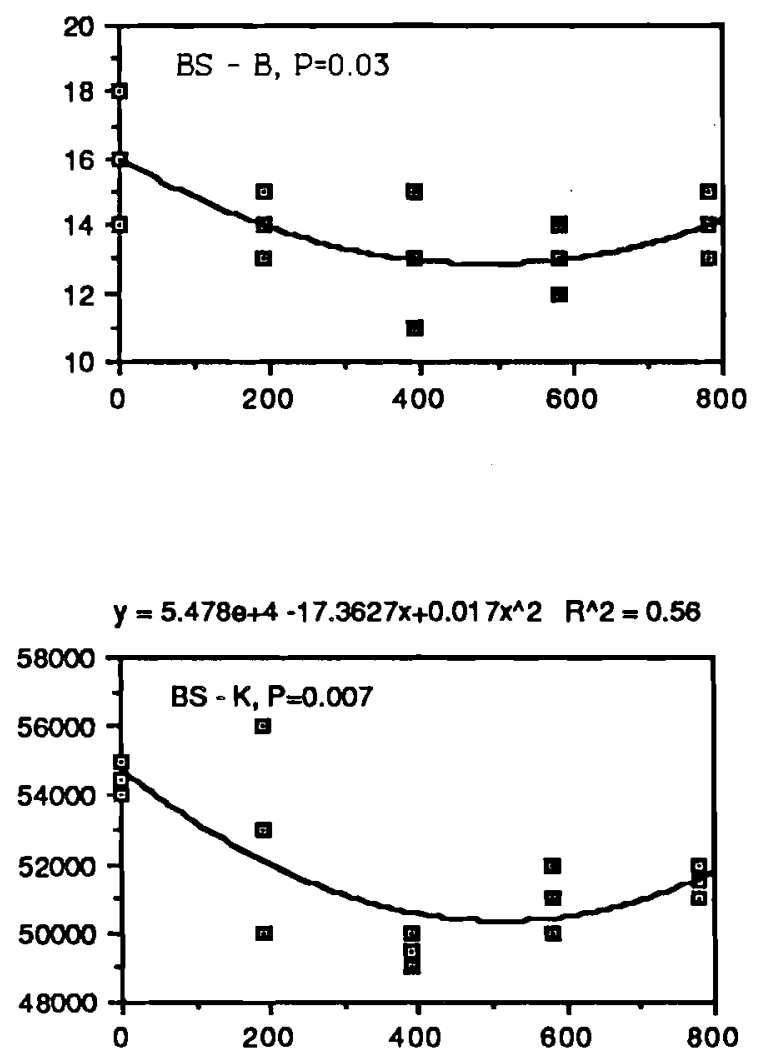
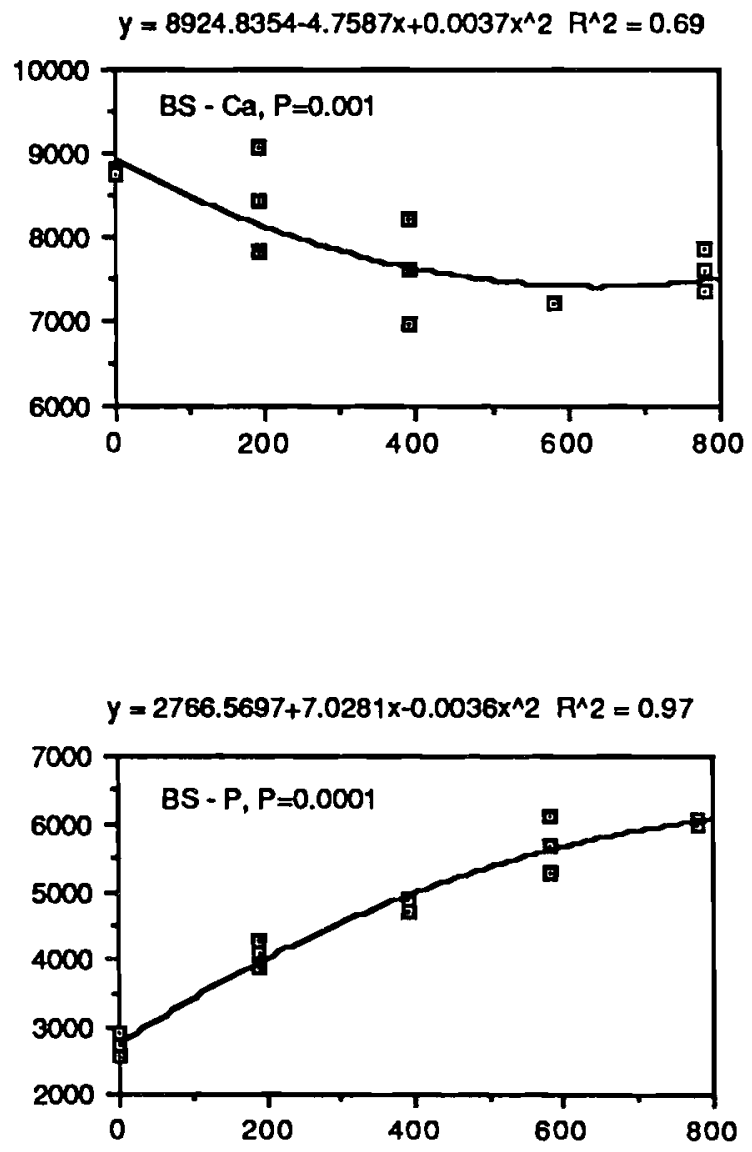

FIGURE 3.32. ELEMENTAL COMPOSITION OF PLANT TISSUE FOR PLANTS GROWN IN BURBANK SOIL 
TABLE 3.65. AVAILABILITY OF ELEMENTS FOLKOWING CUMULATIVE DOSING WITH RP/BR SMOKES (FIRST HARVEST)

\begin{tabular}{llll}
\hline Soil/Element & Tissue concentration ( $\mu \mathrm{g} / \mathrm{gm}$ dry wt) \\
\hline Maxey Flat silt-loam & & & \\
Mass loading $\left(\mu \mathrm{gP} / \mathrm{cm}^{2}\right)$ & 160 & 2080 & Control \\
\hline A & & & \\
B & $107 \pm 66$ & $82 \pm 30$ & $312 \pm 39$ \\
Ca & $21 \pm 2$ & $21 \pm 2$ & $29 \pm 2$ \\
Cu & $3886 \pm 1522$ & $7793 \pm 400$ & $6357 \pm 804$ \\
Fe & $13 \pm 2$ & $9 \pm 1$ & $21 \pm 6$ \\
K & $138 \pm 16$ & $117 \pm 14$ & $262 \pm 39$ \\
Mg & $27300 \pm 4100$ & $9800 \pm 1311$ & $24540 \pm 2280$ \\
Mn & $1148 \pm 577$ & $3086 \pm 155$ & $1856 \pm 60$ \\
P & $618 \pm 102$ & $749 \pm 7$ & $823 \pm 174$ \\
Zn & $1400 \pm 260$ & $3120 \pm 260$ & $841 \pm 20$ \\
Burbank silt-sand & $40 \pm 7$ & $35 \pm 4$ & $60 \pm 12$ \\
Mass loading & & & \\
AL & 160 & 2080 & Control \\
B & & & \\
Ca & $42 \pm 2$ & $133 \pm 83$ & $27 \pm 1$ \\
Cu & $18 \pm 2$ & $18 \pm 1$ & $20 \pm 1$ \\
Fe & $4306 \pm 329$ & $4206 \pm 233$ & $5090 \pm 50$ \\
K & $10 \pm 1$ & $11 \pm 1$ & $13 \pm 4$ \\
Mg & $128 \pm 5$ & $278 \pm 135$ & $114 \pm 11$ \\
Mn & $32300 \pm 300$ & $34000 \pm 2000$ & $32000 \pm 100$ \\
P & $1720 \pm 120$ & $1800 \pm 100$ & $1825 \pm 10$ \\
Zn & $28 \pm 5$ & $41 \pm 4$ & $22 \pm 2$ \\
& $1807 \pm 83$ & $4673 \pm 590$ & $1200 \pm 60$ \\
& $16 \pm 1$ & $16 \pm 1$ & $18 \pm 5$ \\
\hline
\end{tabular}

The results from the second harvest of tissue data from these treated soils are shown in Table 3.66. For the Maxey Flats soil, which was fertilized following the first harvest, the control tissues increased in $K$ and $P$. In the high dose treatment, the concentrations of $\mathrm{B}, \mathrm{Ca}, \mathrm{Cu}, \mathrm{K}, \mathrm{Mg}$, and $M n$ increased compared to control values. Zinc decreases, and $A 1$ and Fe remain unchanged. In the Burbank soil, all element concentrations in tissues remained constant, with the exception of $A 1$ and $M n$. Untike $A T$ in the first harvest, which increased, Al concentration decreased substantially in the second harvest. Mn exhibited a persistent increase in availability in both harvests. 
TABLE 3.66. AVAILABILITY OF ELEMENTS FOLLOWING CUMULATIVE DOSING WITH RP/BR SMOKES (SECOND HARVEST).

\begin{tabular}{|c|c|c|c|}
\hline \multirow{2}{*}{$\begin{array}{l}\text { Soil/Element } \\
\text { Maxey Flat silt-loam } \\
\text { Mass loading } \\
\end{array}$} & \multicolumn{3}{|c|}{ Tissue concentration ( $\mu \mathrm{g} / \mathrm{gm}$ dry wt) } \\
\hline & 160 & 2080 & Control \\
\hline $\begin{array}{l}\mathrm{AL} \\
\mathrm{B} \\
\mathrm{Ca} \\
\mathrm{Cu} \\
\mathrm{Fe} \\
\mathrm{K} \\
\mathrm{Mg} \\
\mathrm{Mn} \\
\mathrm{P} \\
\mathrm{Zn}\end{array}$ & $\begin{array}{l}105 \pm 22 \\
20 \pm 2 \\
6253 \pm 600 \\
15 \pm 1 \\
285 \pm 200 \\
32000 \pm 8700 \\
2006 \pm 394 \\
883 \pm 224 \\
1039 \pm 120 \\
48 \pm 14\end{array}$ & $\begin{array}{l}650 \pm 55 \\
35 \pm 2 \\
10200 \pm 415 \\
12 \pm 1 \\
386 \pm 17 \\
44700 \pm 4600 \\
3086 \pm 100 \\
1074 \pm 89 \\
3330 \pm 115 \\
28 \pm 1\end{array}$ & $\begin{array}{l}521 \pm 155 \\
23 \pm 1 \\
7150 \pm 250 \\
16 \pm 1 \\
365 \pm 69 \\
30000 \pm 100 \\
2580 \pm 40 \\
808 \pm 50 \\
1260 \pm 20 \\
52 \pm 1\end{array}$ \\
\hline $\begin{array}{l}\text { Burbank silt-sand } \\
\text { Mass loading }\end{array}$ & 160 & 2080 & Control \\
\hline $\begin{array}{l}\mathrm{AL} \\
\mathrm{B} \\
\mathrm{Ca} \\
\mathrm{Cu} \\
\mathrm{Fe} \\
\mathrm{K} \\
\mathrm{Mg} \\
\mathrm{Mn} \\
\mathrm{P} \\
\mathrm{Zn}\end{array}$ & $\begin{array}{l}87 \pm 11 \\
30 \pm 3 \\
6733 \pm 560 \\
11 \pm 2 \\
169 \pm 14 \\
21500 \pm 1000 \\
2426 \pm 200 \\
101 \pm 29 \\
2600 \pm 121 \\
17 \pm 2\end{array}$ & $\begin{array}{l}131 \pm 34 \\
38 \pm 6 \\
6150 \pm 630 \\
14 \pm 5 \\
267 \pm 37 \\
21800 \pm 1000 \\
2506 \pm 400 \\
160 \pm 8 \\
3800 \pm 209 \\
27 \pm 14\end{array}$ & $\begin{array}{l}284 \pm 102 \\
37 \pm 3 \\
7030 \pm 170 \\
11 \pm 1 \\
389 \pm 105 \\
22000 \pm 100 \\
2900 \pm 100 \\
79 \pm 22 \\
2290 \pm 50 \\
19 \pm 1\end{array}$ \\
\hline
\end{tabular}

For Burbank soil, the influence of relative humidity and rainout conditions on the plant availability of soil elements for the first and second harvests is shown in Table 3.67. First harvest data show Al $(P<0.05)$ to be elevated in only the $53 \%$ relative humidity treatment; while $B(P \leq 0.1) \mathrm{Ca}(P \leq 0.05), \mathrm{Mg}(P \leq 0.1), \mathrm{Mn}(P \leq 0.05)$ and $\mathrm{Zn}(P \leq 0.05)$ are reduced in concentration. Only $\mathrm{Ca}, \overline{\mathrm{F}} \mathrm{e}, \mathrm{Mn}, \mathrm{P}$ and $\mathrm{Zn}$ are significantly at all relative humidity treatments. Tissue concentrations for the second harvest are similar to controls except for $M n(P<0.05)$ and $P(P<0.1)$. These results would suggest that disruption of solubility controls in soils as a result of low contamination levels of RP/BR are not particularly persistent. However, in the rainout treatment where a simulated rainfall during generation accounts for the elevated soil deposition, amounting to approximately $3000 \mu \mathrm{g} \mathrm{P} / \mathrm{cm}^{2}$, some changes in tissue concentrations were observed. In the first harvest, the tissue levels of AI, Fe, and possibly Mn were elevated. The elevation is consistent with the first harvest 
TABLE 3.67. PLANT AVAILABILITY OF ELEMENTS FROM BURBANK SILT-SAND FOLLOWING CONTAMINATION WITH RP/BR SMOKES AT A RANGE (a) OF RELATIVE HUMIDITIES AND UNDER RAINOUT CONDITIONS

\begin{tabular}{|c|c|c|c|c|c|}
\hline \multicolumn{2}{|l|}{ Treatment/element } & \multicolumn{2}{|c|}{ Tissue concentration } & \multicolumn{2}{|c|}{$(\mu \mathrm{g} / \mathrm{gm}$ dry $w t)$} \\
\hline $\begin{array}{l}\text { Burbank first harvest } \\
\text { Treatment } \\
\text { Mass loading }\end{array}$ & $\begin{array}{l}53 \% \\
160 \\
\end{array}$ & $\begin{array}{l}27 \% \\
180 \\
\end{array}$ & $\begin{array}{l}89 \% \\
180 \\
\end{array}$ & $\begin{array}{l}\text { Ra inout } \\
3000\end{array}$ & Control \\
\hline $\begin{array}{l}\mathrm{AL} \\
\mathrm{B} \\
\mathrm{Ca} \\
\mathrm{Cu} \\
\mathrm{Fe} \\
\mathrm{K} \\
\mathrm{Mg} \\
\mathrm{Mn} \\
\mathrm{P} \\
\mathrm{Zn}\end{array}$ & $\begin{array}{l}61 \pm 13 \\
20 \pm 1 \\
3920 \pm 120 \\
11 \pm 2 \\
141 \pm 10 \\
3410 \pm 250 \\
1630 \pm 56 \\
32 \pm 2 \\
2880 \pm 240 \\
151\end{array}$ & $\begin{array}{l}35 \pm 8 \\
22 \pm 5 \\
4350 \pm 290 \\
9 \pm 1 \\
150 \pm 22 \\
3380 \pm 120 \\
1635 \pm 70 \\
28 \pm 2 \\
3150 \pm 50 \\
15 \pm 1\end{array}$ & $\begin{array}{l}21 \pm 1 \\
20 \pm 3 \\
4670 \pm 390 \\
8 \pm 1 \\
87 \pm 37 \\
3460 \pm 140 \\
1744 \pm 88 \\
29 \pm 1 \\
3310 \pm 10 \\
14 \pm 1\end{array}$ & $\begin{array}{l}54 \pm 6 \\
19 \pm 2 \\
5780 \pm 20 \\
9 \pm 1 \\
133 \pm 3 \\
3170 \pm 70 \\
2190 \pm 110 \\
62 \pm 14 \\
3860 \pm 560 \\
17 \pm 2\end{array}$ & $\begin{array}{l}23 \pm 5 \\
27 \pm 1 \\
6460 \pm 360 \\
10 \pm 1 \\
76 \pm 4 \\
3550 \pm 70 \\
2000 \pm 100 \\
46 \pm 1 \\
1795 \pm 135 \\
23 \pm 3\end{array}$ \\
\hline \multicolumn{6}{|l|}{ Burbank second harvest } \\
\hline $\begin{array}{l}\mathrm{AL} \\
\mathrm{B} \\
\mathrm{Ca} \\
\mathrm{Cu} \\
\mathrm{Fe} \\
\mathrm{K} \\
\mathrm{Mg} \\
\mathrm{Mn} \\
\mathrm{P} \\
\mathrm{Zn}\end{array}$ & $\begin{array}{l}23 \pm 10 \\
32 \pm 2 \\
4890 \pm 130 \\
8 \pm 1 \\
124 \pm 10 \\
26400 \pm 2200 \\
2530 \pm 30 \\
48 \pm 2 \\
3310 \pm 150 \\
21 \pm 1\end{array}$ & $\begin{array}{l}30 \pm 3 \\
31 \pm 2 \\
5180 \pm 220 \\
8 \pm 1 \\
123 \pm 15 \\
25100 \pm 100 \\
2660 \pm 80 \\
43 \pm 5 \\
3250 \pm 50 \\
20 \pm 1\end{array}$ & $\begin{array}{l}45 \pm 10 \\
29 \pm 1 \\
4800 \pm 280 \\
8 \pm 1 \\
125 \pm 7 \\
23800 \pm 2000 \\
2390 \pm 10 \\
58 \pm 1 \\
3090 \pm 10 \\
18 \pm 1\end{array}$ & $\begin{array}{l}37 \pm 2 \\
26 \pm 3 \\
4380 \pm 260 \\
8 \pm 1 \\
174 \pm 82 \\
22900 \pm 700 \\
2390 \pm 150 \\
94 \pm 4 \\
3180 \pm 240 \\
18 \pm 1\end{array}$ & $\begin{array}{l}38 \pm 1 \\
30 \pm 2 \\
5120 \pm 300 \\
9 \pm 1 \\
119 \pm 12 \\
24400 \pm 400 \\
2570 \pm 230 \\
86 \pm 18 \\
1231 \pm 27 \\
19 \pm 1\end{array}$ \\
\hline
\end{tabular}

(a) First and second harvests were after 55 days and 34 days of growth, respectively.

results from the CDT. However, in the second harvest concentrations of both $A 1$ and $M n$ were back to control levels, with only Fe remaining elevated.

Results for the first and second harvests from Maxey Flats soil were substantially more complex (Table 3.68 ). When relative humidity is the variable, the tissue concentrations of $A 1, B, C u, F e, K$, and $Z n$ decline in the first harvest, while $\mathrm{Ca}$ and $\mathrm{Mg}$ increase, and $\mathrm{Mn}$ remains constant. No trends within the relative humidity treatments are clearly apparent. Under rainout conditions, the concentration of al. 1 elements decrease except for 
TABLE 3.68. PLANT AVAILABILITY OF ELEMENTS FROM MAXEY FLATS SILT-LOAM SOIL FOLLOWING CONTAMINATION WITH RP/BR SMOKES AT A RANGE OF RELATIVE HUMIDITIES AND UNDER RAINOUT CONDITION (a)

\begin{tabular}{|c|c|c|c|c|c|}
\hline reatment/e & Tiss & de Concent & ration $(\mu \mathrm{g}$ & (gm dry wt) & \\
\hline $\begin{array}{l}\text { Maxey Flats } \\
\text { Treatment } \\
\text { Mass loading }\end{array}$ & $\begin{array}{c}\text { arvest } \\
53 \% \\
160 \\
\end{array}$ & $\begin{array}{l}27 \% \\
180 \\
\end{array}$ & $\begin{array}{l}89 \% \\
180 \\
\end{array}$ & $\begin{array}{l}\text { Rainout } \\
3000\end{array}$ & Control \\
\hline $\begin{array}{l}\mathrm{AL} \\
\mathrm{B} \\
\mathrm{Ca} \\
\mathrm{Cu} \\
\mathrm{Fe} \\
\mathrm{K} \\
\mathrm{Mg} \\
\mathrm{Mn} \\
\mathrm{P} \\
\mathrm{Zn}\end{array}$ & $\begin{array}{l}95 \pm 33 \\
27 \pm 1 \\
5980 \pm 680 \\
10 \pm 1 \\
114 \pm 34 \\
1460 \pm 220 \\
2340 \pm 140 \\
805 \pm 213 \\
1740 \pm 190 \\
50 \pm 8\end{array}$ & $\begin{array}{l}77 \pm 20 \\
26 \pm 1 \\
5900 \pm 160 \\
11 \pm 1 \\
98 \pm 13 \\
1500 \pm 120 \\
2260 \pm 10 \\
734 \pm 92 \\
2100 \pm 80 \\
47 \pm 10\end{array}$ & $\begin{array}{l}43 \pm 1 \\
30 \pm 3 \\
4980 \pm 320 \\
12 \pm 1 \\
85 \pm 2 \\
1390 \pm 230 \\
2090 \pm 10 \\
631 \pm 125 \\
2300 \pm 40 \\
38 \pm 2\end{array}$ & $\begin{array}{l}81 \pm 18 \\
26 \pm 1 \\
4420 \pm 460 \\
9 \pm 1 \\
112 \pm 17 \\
1460 \pm 10 \\
1480 \pm 260 \\
1060 \pm 160 \\
2460 \pm 600 \\
40 \pm 9\end{array}$ & $\begin{array}{l}159 \pm 3 \\
50 \pm 7 \\
4750 \pm 625 \\
22 \pm 10 \\
225 \pm 31 \\
29800 \pm 1450 \\
1505 \pm 120 \\
880 \pm 280 \\
1305 \pm 345 \\
75 \pm 14\end{array}$ \\
\hline Maxey Flats & harvest & & & & \\
\hline $\begin{array}{l}\mathrm{Al} \\
\mathrm{B} \\
\mathrm{Ca} \\
\mathrm{Cu} \\
\mathrm{Fe} \\
\mathrm{K} \\
\mathrm{Mg} \\
\mathrm{Mn} \\
\mathrm{P} \\
\mathrm{Zn}\end{array}$ & $\begin{array}{l}59 \pm 1 \\
37 \pm 1 \\
6150 \pm 150 \\
10 \pm 1 \\
185 \pm 12 \\
8600 \pm 600 \\
3210 \pm 190 \\
724 \pm 160 \\
2047 \pm 113 \\
50 \pm 3\end{array}$ & $\begin{array}{l}37 \pm 1 \\
40 \pm 3 \\
6810 \pm 690 \\
13 \pm 1 \\
109 \pm 4 \\
8700 \pm 100 \\
3540 \pm 200 \\
581 \pm 105 \\
2210 \pm 150 \\
50 \pm 1\end{array}$ & $\begin{array}{l}33 \pm 7 \\
45 \pm 1 \\
5890 \pm 670 \\
13 \pm 2 \\
143 \pm 6 \\
7800 \pm 400 \\
3190 \pm 130 \\
627 \pm 173 \\
2660 \pm 40 \\
51 \pm 4\end{array}$ & $\begin{array}{l}78 \pm 21 \\
38 \pm 6 \\
6280 \pm 800 \\
12 \pm 2 \\
165 \pm 36 \\
14800 \pm 3600 \\
2460 \pm 80 \\
1409 \pm 169 \\
3370 \pm 650 \\
68 \pm 10\end{array}$ & $\begin{array}{l}138 \pm 34 \\
233 \pm 11 \\
7355 \pm 1177 \\
64 \pm 2 \\
1857 \pm 275 \\
18370 \pm 5000 \\
2580 \pm 180 \\
1790 \pm 204 \\
2333 \pm 422 \\
215 \pm 20\end{array}$ \\
\hline
\end{tabular}

(a) First and second harvest were after 55 days and 34 days of growth, respectively.

$\mathrm{Ca}, \mathrm{Mg}$, and $\mathrm{Mn}$, which remain constant. An interesting observation can be made based on the phosphorus levels in treatments and controls. While there is a 30-fold difference in the soil phosphorus load, only a 2-fold difference was observed in tissue concentration. This observation supports the role of plant roots in regulating ion uptake, although the fate and interactions of the remaining phosphorus residing in these soils should be considered.

In the second harvest, basically similar trends in tissue composition were seen for the relative humidity treatments. Aluminum, B, Cu, Fe, Mn, and $\mathrm{Zn}$ were still low compared to controls. However, $K$ levels, although 
still depressed were beginning to increase, and $\mathrm{Ca}$ levels returned to control concentrations. Under rainout conditions, effects were comparable to the results from the first harvest. Potassium in particular returned to control levels.

These tissue data, while appearing to be quite complex and in many instances contradictory, represent the end result of a series of abiotic and biotic processes, including both soil and plant processes. In addition, apparent differences between data sets were further complicated by a range of experimental variables, including preplanting equilibration periods (CDT versus RFT and relative humidity), growth duration, mass loading rates, and the type and fertility level of the two soils used. A number of indirect effects of phosphorus smoke deposition to soils can be assumed or postulated. First, RP/BR smokes are acidic and will have more or less of an effect on sojl pH, depending on buffering capacity. Also, soil acidity, or increased $\mathrm{H}^{+}$ion, can cause a displacement of cations from cation exchange sites. The displaced cations could account for the observed increases in plant availability of mono and divalent cations such as $\mathrm{Ca}, \mathrm{Fe}, \mathrm{K}, \mathrm{Mg}, \mathrm{Mn}$, and $\mathrm{Zn}$, and possibly $\mathrm{Al}$. Acidity could also reduce the soil solubility of anions such as $B$. Secondly, the presence of high concentrations of soluble phosphorus in soils could form insoluble phosphorus complexes, particularly if the concentrations are high enough to exceed the anion exchange capacity of the soil. This, in fact, may account for the reduced levels of $\mathrm{Al}, \mathrm{Ca}, \mathrm{Fe}, \mathrm{Mg}, \mathrm{Mn}$, and $\mathrm{Zn}$. Several causative factors for the observed growth reductions can be postulated. First, in several instances the high levels of $A 1$ and/or $M n$ in tissues can be toxic to plants and result in growth reductions. Secondly, in several instances there is a dramatic imbalance in nutrients (i.e., $\mathrm{Ca}, \mathrm{K}, \mathrm{Mg}, \mathrm{Fe}$, and $\mathrm{Mn})$. The imbalance could also be metabolically disruptive. Finaliy, there still remains some question as to whether there are smoke components other than phosphates that remain in the system and induce some adverse effects.

Because of the inconsistencies in data interpretation, one additional data set was collected in an effort to place some of these mechanisms into perspective. In the wind speed test for RP/BR smoke, plants (not soils) were exposed to wind speeds of 0.5 to $10 \mathrm{mph}$. When the grasses were cut back for collection, it was clear that the $10 \mathrm{mph}$ treatment was severly affected and hardly any growth was exhibited. The $4.5 \mathrm{mph}$ treatment exhibited approximately a 50\% growth rate reduction, while the $0.5 \mathrm{mph}$ treatment appeared normal. At this point the blando brome was regrown and the shoot tissues were elementally analyzed. Table 3.69 shows the results of this study. It becomes quite clear from the phosphorus data that a substantial fraction of the foliar contaminants arising from direct smoke contamination were absorbed from the leaves and transported to the root of the grass. The stored phosphorus was then remobilized to the newly developing shoot. The remobilization increases with wind speed (i.e., mass loading). However, based on the behavior of the other elements, it appears that the root may also have secreted excess phosphorus to the soil and affected the availability of other elements. In this instance the availability of $A 1$ 
TABLE 3.69. CHANGES IN THE SHOOT CONTENT OF SEVERAL ELEMENTS FOLLOWING REGROWTH OF BLANDO BROME, FOLIARLY EXPOSED TO RP/BR SMOKES AT TWO WIND SPEEDS

\begin{tabular}{|c|c|c|c|}
\hline Element/treatment & \multicolumn{3}{|c|}{ Tissue concentration ( $\mu \mathrm{g} / \mathrm{gm}$ dry wt) } \\
\hline $\begin{array}{l}\text { Wind speed } \\
\text { Mass loading }\left(\mu \mathrm{g} \mathrm{P} / \mathrm{cm}^{2}\right)\end{array}$ & $\begin{array}{l}\text { Control } \\
0\end{array}$ & $\begin{array}{l}0.5 \mathrm{mph} \\
27\end{array}$ & $\begin{array}{l}4.5 \mathrm{mph} \\
640\end{array}$ \\
\hline $\begin{array}{l}\mathrm{Al} \\
\mathrm{B} \\
\mathrm{Ca} \\
\mathrm{K} \\
\mathrm{Mn} \\
\mathrm{Na} \\
\mathrm{P}\end{array}$ & $\begin{array}{l}126 \pm 10 \\
20 \pm 2 \\
4060 \pm 110 \\
19400 \pm 600 \\
188 \pm 10 \\
818 \pm 34 \\
888 \pm 39\end{array}$ & $\begin{array}{l}46 \pm 5 \\
22 \pm 3 \\
4080 \pm 80 \\
20000 \pm 300 \\
182 \pm 11 \\
1386 \pm 104 \\
1254 \pm 55\end{array}$ & $\begin{array}{l}19 \pm 3 \\
19 \pm 2 \\
5700 \pm 140 \\
23000 \pm 900 \\
103 \pm 9 \\
3420 \pm 215 \\
2560 \pm 134\end{array}$ \\
\hline
\end{tabular}

and $\mathrm{Mn}$ were substantially depressed, while concentrations of $\mathrm{Ca}, \mathrm{K}$, and $\mathrm{Na}$ are elevated. Roots generally do not have the capacity for holdup or storage of $\mathrm{Na}$, therefore we were most probably dealing with the effects of phosphorus secretion from roots. However, phosphate secreted from roots could not affect the cation exchange of $\mathrm{Na}$; only the $\mathrm{H}$ ion can affect the cation exchange. Thus, the phosphorus accumulation within the root may have caused a secretion of $\mathrm{H}^{4}$ ion (rather than butyl rubber in addition to P) from the root in an effort to balance charge distribution. If these assumptions are true, then much of the indirect effects data (elemental) can be explained as above.

\subsection{SOIL MICROBIAL EFFECTS}

In soil the transformation of ammonia to nitrate is accomplished by the combined efforts of two microbial genera: Nitrosomonas sp. which oxidizes ammonium to nitrite, and Nitrobacter sp., which further oxidizes nitrite to nitrate.

Ammonia exists as the cation $\mathrm{NH}_{4}{ }^{+}$in the soil, which is predominantly negatively charged, and is therefore held on the cation exchange sites and is relatively immobile. Plant roots obtain $\mathrm{NH}_{4}$ from soils either through diffusion or root-soil contact mechanisms. Nitrate $\left(\mathrm{NO}_{3}{ }^{-}\right)$, being negatively charged, is mobile in the soil and can move to plant roots in the transportation stream (mass flow). The latter mechanism is capable of supplying greater quantities of $N$ to the plant. A significant reduction in nitrification, hence readily available nitrogen, could limit plant growth in most soils.

When a thin lense of soil (0.4 mm depth) was exposed for 2 hours at an air velocity of $2 \mathrm{mph}$ and with phosphorus concentration of about $500 \mathrm{mg} / \mathrm{m}^{3}$ 
(range-finding test $A 3$, Table 3.70 ), a $75 \%$ reduction of the amount of nitrate produced in 14 days at 336 hours (Table 3.71 ) and a $90 \%$ reduction of the peak value of the formation of nitrite (Table 3.72) were observed in soil amended with 50 and $500 \mathrm{ppm}$ ammonium. The effect of the smoke on ammonium-oxidizing bacteria is seen in the extended lag period before a detectable increase in nitrite was observed for both unamended and ammonium-amended soil suspensions. The rate limiting step in the conversion of ammonium to nitrate is the formation of nitrite; therefore, the rate of nitrate formation is dependent on the activity of Nitrosomonas species. Considering the reduced activity of the Nitrosomonas species, reduced levels of the Nitrobacter species would also be expected. In unamended soil where the primary source of metabolizable nitrogen can either be exchangeable ammonium or mineralizable organic nitrogen, a $50 \%$ increase in nitrate and $30 \%$ decrease in the peak value of nitrite was observed. The reduced Nitrosomonas sp. activity is similar to the amended soil suspensions. The increased nitrate formation occurring at the same time as the decrease in nitrite, however, suggests that the high nitrate levels in soil exposed to smoke resulted from an increased heterotrophic conversion of organic nitrogen.

Exposure of soil to smoke decreases a portion of the soil microbial population, however; some organisms will remain viable due to protection in microsites, etc. The dead microbial biomass provides a readily decomposable substrate for the remaining live organisms, and during this process mineral $\mathrm{N}$ is released as $\mathrm{NH}_{4}{ }^{2}$. A viable but reduced population of nitrifying bacteria then oxidized the $\mathrm{NH}_{4}$ to $\mathrm{NO}_{3}$ - Jenkinson (1976) has demonstrated an increase in soil mineral ${ }^{4} \mathrm{~N}$ levels after fumigation with chloroform.

The influence of relative humidities of phosphorous smoke on soilnitrifying activities was evaluated with soil that had been amended with alfalfa, but not with ammonium. Table 3.73 and Table 3.74 summarize the effect of smoke on the production of nitrite and nitrate. Initial nitrite concentrations were relatively the same for all the soils. However, soil of thin lense $(0.4 \mathrm{~mm})$ showed a longer lag period of at least 3 days before an increase in nitrite was observed. Peak nitrite levels were markedly lower with decreasing soil lense thickness, indicating a reduced activity of Nitrosomonas sp. When measured immediately following exposure, the concentration of nitrate in all soil lenses was similar to the control soil. However, 57 days after exposure the nitrate in the control soil increased 16-fold, as did soil lenses of $1.0,2.0$ and $4.0 \mathrm{~mm}$, which increased from about 16 to 21 -fold. The most striking effects of smoke were observed in the thinnest soil lenses as the nitrifying activity either ceased or was negligible. Nitrifying activity was most affected by soil depth rather than the relative humidities of smoke exposure.

Painter (1970) and Focht et a1. (1975) have reported that a particularly important factor affecting nitrification is $\mathrm{pH}$. Favorable $\mathrm{pH}$ range for both Nitrosomonas sp. and Nitrobacter sp. is 7.0 to 9.0 . 
TABLE 3.70. PHYSICAL AND CHEMICAL VARIABLES OF RP/BR SMOKE TESTS FOR THE STUDY OF MICROBIOLOGICAL EFFECTS

\begin{tabular}{|c|c|c|c|c|c|c|c|c|c|c|c|}
\hline \multirow[b]{3}{*}{$\begin{array}{l}\text { Test } \\
\text { 10\# }\end{array}$} & \multirow[b]{3}{*}{ Date } & \multirow[b]{3}{*}{$\begin{array}{l}\text { Temp. } \\
\left({ }^{\circ} \mathrm{C}\right)\end{array}$} & \multirow{3}{*}{$\begin{array}{c}\text { Air } \\
\text { Velocity } \\
\text { (mph) }\end{array}$} & \multirow{3}{*}{$\begin{array}{c}\text { Exposure } \\
\text { Time } \\
\text { (hr) }\end{array}$} & \multirow{3}{*}{$\begin{array}{l}\text { Relative } \\
\text { Humidity } \\
\text { ( } \%)\end{array}$} & \multirow{3}{*}{$\begin{array}{l}\text { Deposition } \\
\text { Velocity on } \\
\text { Dry Surface } \\
(\mathrm{cm} \mathrm{sec}-1)\end{array}$} & \multirow{3}{*}{$\begin{array}{l}\text { Particle } \\
\text { Size } \\
\text { Distrib. } \\
\text { MMAD ( } / \mathrm{m})\end{array}$} & \multicolumn{4}{|c|}{ Mass Concentration } \\
\hline & & & & & & & & \multicolumn{2}{|c|}{ Particles, $\mathrm{mg} / \mathrm{m}^{3}$} & \multicolumn{2}{|c|}{ Phosphorus (a) } \\
\hline & & & & & & & & Fresh & $\begin{array}{l}\text { Desic- } \\
\text { cated }\end{array}$ & $\begin{array}{c}\text { Total } \\
\mathrm{mg}-\mathrm{P} / \mathrm{m}^{3}\end{array}$ & $\frac{\% 1 P}{P_{\text {tot }}}$ \\
\hline \multirow[t]{2}{*}{ RFT-A3 (b) } & $9-26-84$ & 24.0 & 2 & 2 & 25 & 0.052 & 0.76 & 1960 & $-\ldots(c)$ & $520\}$ & $\ldots(c)$ \\
\hline & & & & & & & & 2040 & & 530 & \\
\hline D6. 1 & $1-22-85$ & 22.0 & 2 & 2 & 25 & 0.031 & 1.56 & 2440 & 2290 & 630 & 30.0 \\
\hline D6.2 & $1-22-85$ & 21.7 & 2 & 2 & $60^{(d)}$ & 0.043 & 1.60 & 3060 & 2040 & 597 & 21.3 \\
\hline D7 & $1-23-85$ & 21.9 & 2 & 2 & $90^{(d)}$ & 0.034 & 1.90 & 4440 & 1510 & 425 & 15.7 \\
\hline
\end{tabular}

(a) P species measured by IC.

(b) Only one soil depth $(0.4 \mathrm{~mm})$ was exposed in this test.

(c) Data not available.

(d) Actual relative humidity is $56 \%$ for Test 06.2 and $84 \%$ for Test D7. 
TABLE 3.71. EFFECT OF RP/BR SMOKE ON THE MICROBIOLOGICAL CONVERSION OF AMMONIUM TO $\mathrm{NO}_{3}{ }^{-}$

\begin{tabular}{|c|c|c|c|c|c|c|}
\hline \multirow{3}{*}{$\begin{array}{l}\text { Time } \\
\text { (hr) }\end{array}$} & \multirow{2}{*}{\multicolumn{2}{|c|}{ Unamended soi 1}} & \multicolumn{4}{|c|}{ Amended soil } \\
\hline & & & \multicolumn{2}{|c|}{$50 \mathrm{ppm} \mathrm{NH}_{4}$} & \multicolumn{2}{|c|}{$500 \mathrm{ppm} \mathrm{NH}$} \\
\hline & Control & Smoke & Control & Smoke & Control & Smoke \\
\hline & & & & $0_{3}^{-(a)}$ & & \\
\hline 15 & $0.89 \pm 0.02$ & $0.82 \pm 0.04$ & $1.01 \pm 0.18$ & $0.89 \pm 0.01$ & $0.94 \pm 0.00$ & $0.85 \pm 0.01$ \\
\hline 38 & $1.25 \pm 0.08$ & $0.96 \pm 0.01$ & $1.05 \pm 0.06$ & $0.99 \pm 0.04$ & $1.07 \pm 0.04$ & $0.94 \pm 0.06$ \\
\hline 144 & $1.96 \pm 0.04$ & $2.08 \pm 0.18$ & $2.60 \pm 0.12$ & $1.70 \pm 0.10$ & $2.54 \pm 0.01$ & $1.46 \pm 0.13$ \\
\hline 216 & $2.15 \pm 0.04$ & $2.76 \pm 0.17$ & $5.17 \pm 0.40$ & $2.64 \pm 0.21$ & $5.49 \pm 0.36$ & $2.42 \pm 0.08$ \\
\hline 336 & $2.85 \pm 0.03$ & $4.01 \pm 0.27$ & $19.05 \pm 1.77$ & $4.42 \pm 0.35$ & $20.60 \pm 0.99$ & $3.70 \pm 0.01$ \\
\hline
\end{tabular}

TABLE 3.72. EFFECT OF RP/BR SMOKE ON THE MICROBIOLOGICAL CONVERSION OF AMMONIUM TO $\mathrm{NO}_{2}$

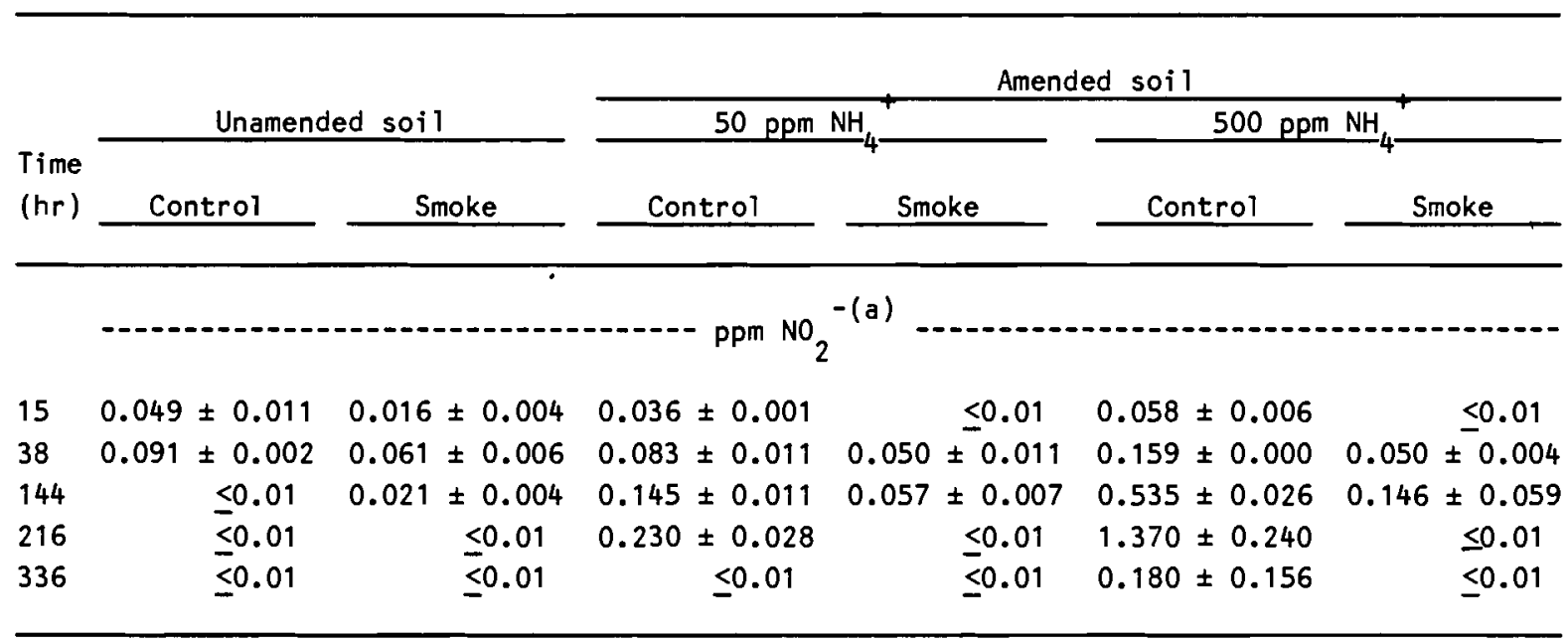

(a) Mean \pm S.D. $(n=2)$ 
TABLE 3.73. EFFECT OF RP/BR SMOKE ON NITRITE PRODUCTION

\begin{tabular}{|c|c|c|c|c|c|c|c|c|c|c|c|c|c|}
\hline \multirow{3}{*}{$\begin{array}{l}\text { Time } \\
\text { following } \\
\text { exposure } \\
\text { (days) }\end{array}$} & \multicolumn{8}{|c|}{$\begin{array}{l}\text { Humidity (q) } \\
60\end{array}$} & \multirow{2}{*}{\multicolumn{4}{|c|}{90}} & \multirow[b]{3}{*}{ Control } \\
\hline & \multicolumn{8}{|c|}{ Soil depth $(\mathrm{mm})$} & & & & & \\
\hline & 0.4 & 1.0 & 2.0 & 4.0 & 0.4 & 1.0 & 2.0 & 4.0 & 0.4 & 1.0 & 2.0 & 4.0 & \\
\hline \multicolumn{14}{|c|}{ Nitrite $(\mathrm{ppm})^{(\mathrm{a})}$} \\
\hline 0 & 0.038 & 0.035 & $\leq 0.02$ & $\leq 0.02$ & $\leq 0.02$ & 0.03 & $\leq 0.02$ & $\leq 0.02$ & $\leq 0.02$ & 0.03 & $\leq 0.02$ & $\leq 0.015$ & $\leq 0.02$ \\
\hline 1 & 0.083 & 0.21 & 0.18 & 0.18 & $\leq 0.05$ & 0.17 & 0.18 & 0.19 & $\leq 0.02$ & 0.17 & 0.17 & 0.16 & 0.16 \\
\hline 3 & 0.25 & 0.24 & 0.32 & 0.34 & $\leq 0.03$ & 0.18 & 0.25 & 0.31 & 0.076 & 0.20 & 0.21 & 0.23 & 0.31 \\
\hline 6 & 0.18 & 0.16 & 0.45 & 0.84 & $\leq 0.02$ & 0.08 & 0.25 & 0.57 & 0.084 & $\leq 0.02$ & 0.05 & 0.31 & 1.12 \\
\hline 10 & 0.039 & $\leq 0.02$ & 0.07 & 0.80 & $\leq 0.02$ & $\leq 0.02$ & 0.03 & 0.48 & 0.028 & $\leq 0.02$ & $\leq 0.02$ & 0.18 & 2.0 \\
\hline 15 & $\leq 0.02$ & $\leq 0.02$ & 0.12 & 7.1 & $\leq 0.02$ & $\leq 0.02$ & 0.06 & 2.00 & $\leq 0.02$ & $\leq 0.02$ & 0.10 & 3.91 & 6.4 \\
\hline 22 & $\leq 0.02$ & 0.097 & 0.06 & $\leq 0.06$ & $\leq 0.02$ & $\leq 0.02$ & 0.06 & $\leq 0.01$ & $\leq 0.02$ & $\leq 0.02$ & 0.04 & $\leq 0.01$ & $\leq 0.012$ \\
\hline 29 & $\leq 0.02$ & 0.041 & $\leq 0.02$ & $\leq 0.02$ & $\leq 0.02$ & $\leq 0.02$ & $\leq 0.02$ & $\leq 0.02$ & $\leq 0.02$ & $\leq 0.02$ & $\leq 0.02$ & $\leq 0.02$ & $\leq 0.02$ \\
\hline 57 & $\leq 0.02$ & $\leq 0.02$ & $\leq 0.02$ & $\leq 0.02$ & $\leq 0.02$ & $\leq 0.02$ & 0.03 & $\leq 0.02$ & $\leq 0.02$ & $\leq 0.02$ & $\leq 0.02$ & $\leq 0.02$ & 0.04 \\
\hline
\end{tabular}

(a) Single values. 
TABLE 3.74. EFFECT OF RP/BR SMOKE ON NITRATE PRODUCTION

\begin{tabular}{|c|c|c|c|c|c|c|c|c|c|c|c|c|c|}
\hline \multirow{3}{*}{$\begin{array}{l}\text { Time } \\
\text { foll lowing } \\
\text { exposure } \\
\text { (days) }\end{array}$} & \multicolumn{4}{|c|}{25} & \multicolumn{4}{|c|}{$\begin{array}{l}\text { Humidity }(8) \\
60\end{array}$} & \multirow{2}{*}{\multicolumn{4}{|c|}{90}} & \multirow[b]{3}{*}{ Control } \\
\hline & \multirow[b]{2}{*}{0.4} & \multirow[b]{2}{*}{1.0} & \multirow[b]{2}{*}{2.0} & \multirow[b]{2}{*}{4.0} & \multicolumn{4}{|c|}{ Soil depth $(\mathrm{mm})$} & \multirow[b]{2}{*}{0.4} & & & & \\
\hline & & & & & 0.4 & 1.0 & 2.0 & 4.0 & & 1.0 & 2.0 & 4.0 & \\
\hline \multicolumn{14}{|c|}{ Nitrate $(p p m)^{(a)}$} \\
\hline 0 & 3.8 & 3.6 & 3.2 & 3.4 & 3.7 & 3.6 & 3.0 & 3.4 & 3.8 & 3.3 & 3.7 & 3.5 & 3.9 \\
\hline 1 & 3.7 & 3.7 & 3.7 & 3.5 & 3.9 & 3.6 & 3.4 & 3.6 & 3.9 & 3.4 & 3.4 & 3.5 & 3.8 \\
\hline 3 & 2.9 & 3.6 & 3.7 & 3.1 & 3.5 & 3.4 & 3.0 & 3.3 & 3.6 & 3.3 & 3.4 & 3.5 & 3.7 \\
\hline 6 & 2.8 & 4.3 & 4.8 & 4.3 & 3.2 & 3.8 & 3.4 & 4.7 & 2.6 & 3.3 & 4.7 & 3.5 & 5.6 \\
\hline 10 & 2.9 & 5.6 & 8.4 & 9.0 & 3.3 & 4.5 & 4.7 & 9.9 & 2.6 & 5.6 & 5.6 & 5.9 & 9.7 \\
\hline 15 & 3.0 & 7.8 & 17.6 & 29.5 & 3.1 & 5.6 & 9.4 & 33.6 & 2.6 & 4.6 & 9.4 & 21.8 & 32.5 \\
\hline 22 & 3.6 & 18.0 & 46.8 & 47.1 & 3.5 & 8.4 & 23.2 & 41.8 & 2.7 & 7.3 & 18.8 & 42.1 & 41.9 \\
\hline 29 & 3.6 & 39.6 & 49.0 & 50.1 & 3.2 & 13.1 & 34.0 & 48.5 & 2.8 & 13.7 & 33.6 & 48.6 & 49.0 \\
\hline 57 & 5.0 & 66.2 & 63.1 & 64.1 & 4.1 & 60.0 & 63.3 & 63.6 & 3.9 & 52.9 & 63.8 & 63.5 & 62.9 \\
\hline
\end{tabular}

(a) Single values. 
Inhibition or slow rates of nitrification occurred at pH below 6.0. Table 3.75 lists the effects of smoke on soil pH. Lower pH in the thin soil reflects the increased phosphorus load on the soil. It is likely that phosphorus smoke inhibited soil nitrification by lowering soil pH to an unfavorable acidic range.

Inhibition of the nitrification process could lead to a reduction in the productivity level of the soil for plant growth. This may be especially true for a soil such as Burbank which is inherently low in fertility. However, soil depth to $2 \mathrm{~mm}$ is normally only a fraction of the soil horizon that contributes to nitrification and nitrogen cycling. Therefore, slower rates of nitrification in the 2-mm surface of soil due to smoke exposure might not be a major environmental impact.

Soil dehydrogenase assay has been recommended as an index of general soil microbial activity (Casida, 1967; Skujins, 1967). This assay was chosen for the smoke effect study because it measures the potential ability of a microbial community to decompose organic matter and to mineralize a representative carbon and/or nitrogen source to carbon dioxide (carbon mineralization) and ammonia (ammonification). Dehydrogenase assay was carried out using glucose as the substrate to study the effects on carbon mineralization. Casamino acids, another carbon source high in nitrogen, was used as substrate in the dehydrogenase assay to study the effects on ammonification.

In the range-finding study (see Table 3.70) enzyme activities were followed for 5 days. Soil dehydrogenase measured in the presence of casamino acids was reduced to less than detectable levels and remained reduced at least 5 days following exposure, whereas in the presence of glucose the activity showed a slight recovery from $0 \%$ to $6 \%$ in 5 days (Table 3.76). However, in the subsequent studies involving smoke of three relative humidities and soil of four different depths, the results varied. With the same soil lense $(0.4 \mathrm{~mm})$ exposed to smoke of similar humidity $(25 \%)$, dehydrogenase measured in the presence of glucose recovered to a smaller degree of $2 \%$ in 7 days, but declined below detectable levels after a prolonged incubation period of 56 days (Table 3.77 ). With the same soil, dehydrogenase measured in the presence of casamino acids showed peak recovery of only $4 \%$ in 14 days (Table 3.78 ). The variation in the recovery of dehydrogenase activity might be attributed to the variation in the physical and chemical properties of the smoke runs. As shown in Table 3.70 , at the same humidity of $25 \%$, ranging-finding test $A 3$ had lower mass concentration in terms of total particles or total phosphorus than the other test runs.

Tables 3.77 and 3.78 also show that dehydrogenase activity increases with increasing soil depth. With the $4.0-\mathrm{mm}$ soil lense, smoke effects were least evident. Nevertheless, there was still a $20 \%$ to $25 \%$ decrease in the casamino acids-amended soil and about a $60 \%$ to $40 \%$ decrease in glucose- amended soil. When measured immediately following exposure, 
TABLE 3.75. EFFECT OF RP/BR SMOKE ON SOIL pH

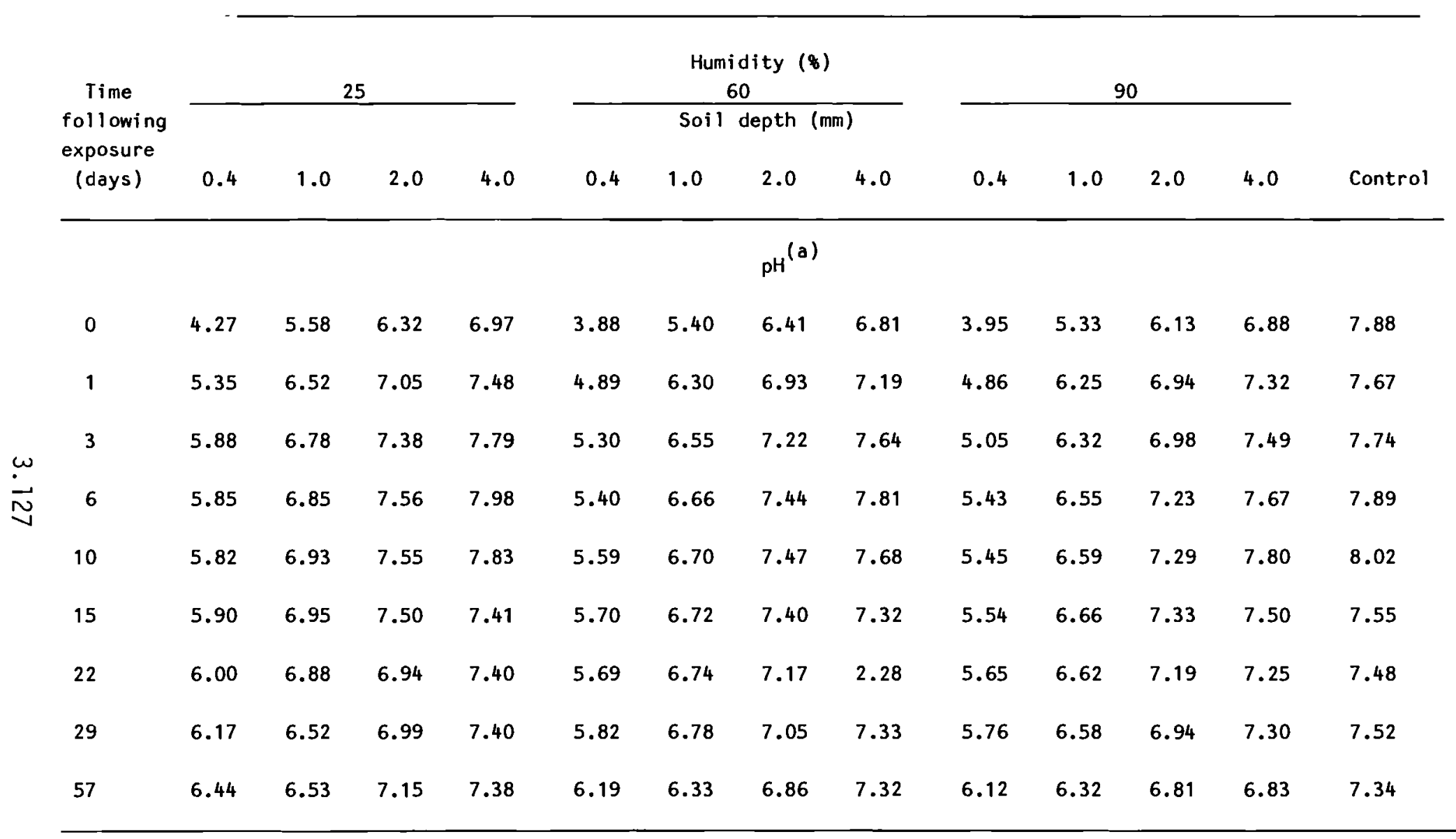

(a) Single values. 
TABLE 3.76. EFFECTS OF RP/BR SMOKE ON SOIL ENZYME ACTIVITY

\begin{tabular}{cccc}
\hline $\begin{array}{l}\text { Time following } \\
\text { exposure (days) }\end{array}$ & Phosphatase & $\begin{array}{c}\text { Dehydrogenase } \\
\text { (glucose-amended soil) }\end{array}$ & $\begin{array}{c}\text { Dehydrogenase } \\
\text { (casamino acids } \\
\text { amended soil) }\end{array}$ \\
\hline & \multicolumn{3}{c}{ Activities (\% of control)(a) } \\
\cline { 2 - 4 } 0 & $41 \pm 4$ & 0 & 0 \\
1 & $58 \pm 7$ & 0 & 0 \\
5 & $45 \pm 4$ & $6 \pm 3$ & 0 \\
\hline
\end{tabular}

(a) Mean \pm S.D. $(n=3)$.

ammonification, with the exception of $0.4-\mathrm{mm}$ soil at $60 \%$ humidity, reached peak value in 2 weeks and then decreased and showed no sign of leveling off in 56 days (Table 3.78). Carbon mineralization, with the exception of $4.0-\mathrm{mm}$ soil at $25 \%$ humidity, peaked at an earlier period of one week and seemed either to remain at the same level or slightly reduced level (Table 3.77).

Organic matter can be an important source of biologically available phosphorus in soil. Assimilation by plants and microorganisms of phosphate from organic phosphate compounds in soil is preceded by their hydrolys is by extracellular phosphatases. There are three classes of this hydrolytic enzyme: the alkaline, the acid, and the neutral phosphatase. In this study phosphatase was assayed in a slightly alkaline buffer and no attempt was made to distinguish the three phosphatases, which have different pH optima.

Soil phosphatase activity measured in soil exposed to the range-finding test $\mathrm{A} 3$ smoke run was reduced by about $50 \%$ immediately following exposure and remained at that level for at least 5 days (see Table 3.76 ). Table 3.79 shows that a comparable result was obtained with other smoke runs. Immediately following exposure, phosphatase measured in the thinnest soil lense was reduced by $50 \%, 40 \%$, and $30 \%$ of the control at humidities of $25 \%, 60 \%$, and $90 \%$, respectively, whereas in the thickest soil lense, minimal or no effect was observed. However, with prolonged incubation time following exposure, phosphatase activity gradual1y decreased. For the $0.4-\mathrm{mm}$ thick soil lense exposed to smoke of $90 \%$ humidity, phosphatase diminished to a less than detectable level 28 days after exposure. 
TABLE 3.77. EFFECT OF RP/BR SMOKE ON SOIL DEHYDROGENASE ACTIVITY (GLUCOSE-AMENDED SOILS)

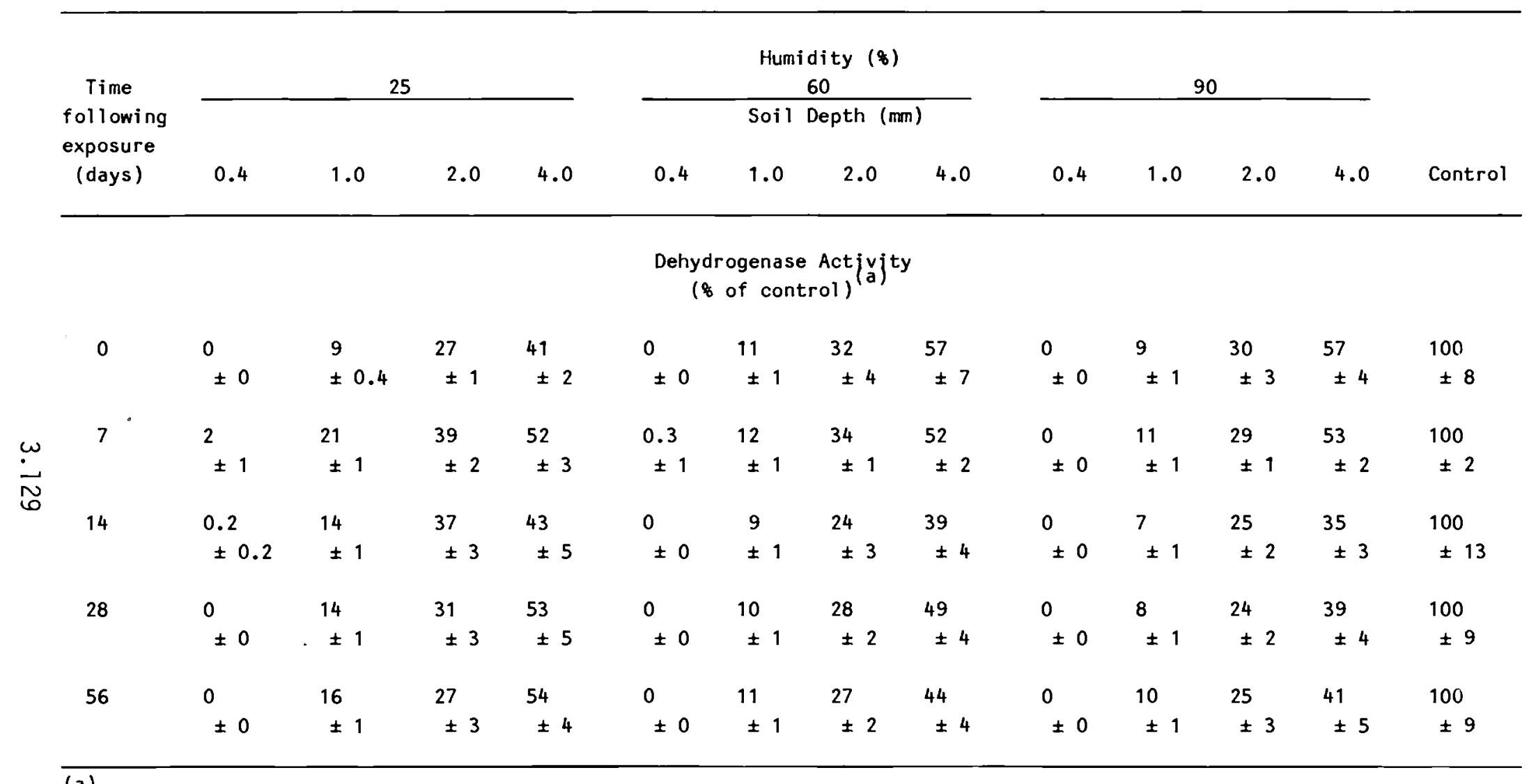

(a) Mean \pm S.D. $(n=3)$. 
TABLE 3.78. EFFECT OF RP/BR SMOKE ON SOIL DEHYDROGENASE ACTIVITY (CASAMINO ACIDS-AMENDED SOIL)

\begin{tabular}{|c|c|c|c|c|c|c|c|c|c|c|c|c|c|}
\hline \multirow{3}{*}{$\begin{array}{l}\text { Time } \\
\text { following } \\
\text { exposure } \\
\text { (days) }\end{array}$} & \multicolumn{4}{|c|}{25} & \multicolumn{4}{|c|}{$\begin{array}{l}\text { Humidity ( } 8) \\
60\end{array}$} & \multicolumn{4}{|c|}{90} & \multirow[b]{3}{*}{ Control } \\
\hline & & & & & \multicolumn{4}{|c|}{ Soil Depth (mm) } & & & & & \\
\hline & 0.4 & 1.0 & 2.0 & 4.0 & 0.4 & 1.0 & 2.0 & 4.0 & 0.4 & 1.0 & 2.0 & 4.0 & \\
\hline \multicolumn{14}{|c|}{$\begin{array}{l}\text { Dehydrogenase Activity } \\
\qquad(\% \text { of control) }\end{array}$} \\
\hline 0 & $\begin{array}{l}0.3 \\
\pm 0.01\end{array}$ & $\begin{array}{l}22 \\
\pm 1\end{array}$ & $\begin{array}{l}58 \\
\pm 6\end{array}$ & $\begin{array}{l}82 \\
\pm 5\end{array}$ & $\begin{array}{l}0 \\
\pm 0\end{array}$ & $\begin{array}{l}14 \\
\pm 1\end{array}$ & $\begin{array}{l}41 \\
\pm 3\end{array}$ & $\begin{array}{l}75 \\
\pm 6\end{array}$ & $\begin{array}{l}0 \\
\pm 0\end{array}$ & $\begin{array}{l}14 \\
\pm 2\end{array}$ & $\begin{array}{l}47 \\
\pm 1\end{array}$ & $\begin{array}{l}74 \\
\pm 2\end{array}$ & $\begin{array}{l}100 \\
\pm 5\end{array}$ \\
\hline 7 & 2 & 27 & 55 & $\begin{array}{l}74 \\
+3\end{array}$ & $\begin{array}{l}0.1 \\
\pm 0.2\end{array}$ & 21 & 54 & $\begin{array}{l}73 \\
\pm 2\end{array}$ & $\begin{array}{l}0 \\
+0\end{array}$ & $\begin{array}{l}19 \\
\pm 1\end{array}$ & 50 & $\begin{array}{l}79 \\
\pm 2\end{array}$ & $\begin{array}{l}100 \\
\pm 2\end{array}$ \\
\hline 14 & $\begin{array}{l}4 \\
\pm 0.3\end{array}$ & $\begin{array}{l}37 \\
\pm 2\end{array}$ & $\begin{array}{l}74 \\
\pm 3\end{array}$ & $\begin{array}{l}81 \\
\pm 4\end{array}$ & $\begin{array}{l}0 \\
\pm 0\end{array}$ & $\begin{array}{l}28 \\
\pm 4\end{array}$ & $\begin{array}{l}61 \\
\pm 3\end{array}$ & $\begin{array}{l}83 \\
\pm 3\end{array}$ & $\begin{array}{l}0 \\
\pm 0\end{array}$ & $\begin{array}{l}29 \\
\pm 2\end{array}$ & $\begin{array}{l}56 \\
\pm 3\end{array}$ & $\begin{array}{l}85 \\
\pm 2\end{array}$ & $\begin{array}{l}100 \\
\pm 4\end{array}$ \\
\hline 28 & ${ }^{3} \pm 0.1$ & $\begin{array}{l}32 \\
\pm 2\end{array}$ & $\begin{array}{l}52 \\
\pm 5\end{array}$ & $\begin{array}{l}77 \\
\pm 4\end{array}$ & ${ }^{1} \pm 0.03$ & $\begin{array}{l}25 \\
\pm 1\end{array}$ & $\begin{array}{l}60 \\
\pm 6\end{array}$ & $\begin{array}{l}75 \\
\pm 4\end{array}$ & 1 & $\begin{array}{l}24 \\
\pm 2\end{array}$ & $\begin{array}{l}56 \\
\pm 5\end{array}$ & $\begin{array}{l}71 \\
\pm 4\end{array}$ & $\begin{array}{l}100 \\
\pm 5\end{array}$ \\
\hline 56 & ${ }^{2} \pm 0.3$ & $\begin{array}{l}29 \\
\pm 0.5\end{array}$ & $\begin{array}{l}49 \\
\pm 3\end{array}$ & $\begin{array}{l}69 \\
\pm 3\end{array}$ & $\begin{array}{l}1 \\
\pm 0.1\end{array}$ & $\begin{array}{l}18 \\
\pm 0.4\end{array}$ & $\begin{array}{l}46 \\
\pm 1\end{array}$ & $\begin{array}{l}68 \\
\pm 2\end{array}$ & $\begin{array}{l}0 \\
\pm 0\end{array}$ & $\begin{array}{l}18 \\
\pm 0.2\end{array}$ & $\begin{array}{l}52 \\
\pm 3\end{array}$ & $\begin{array}{l}74 \\
\pm 3\end{array}$ & $\begin{array}{l}100 \\
\pm 0\end{array}$ \\
\hline
\end{tabular}


TABLE 3.79. EFFECT OF RP/BR SMOKE ON SOIL PHOSPHATASE ACTIVITY

\begin{tabular}{|c|c|c|c|c|c|c|c|c|c|c|c|c|c|}
\hline \multirow{2}{*}{$\begin{array}{l}\text { Time } \\
\text { following } \\
\text { exposure } \\
\text { (days) }\end{array}$} & \multicolumn{4}{|c|}{25} & \multicolumn{4}{|c|}{$\begin{array}{l}\text { Humidity (8) } \\
60\end{array}$} & \multicolumn{4}{|c|}{90} & \multirow[b]{2}{*}{ Control } \\
\hline & 0.4 & 1.0 & 2.0 & 4.0 & 0.4 & 1.0 & 2.0 & 4.0 & 0.4 & 1.0 & 2.0 & 4.0 & \\
\hline \multicolumn{14}{|c|}{$\begin{array}{l}\text { Phosphatase Actiyify } \\
(\% \text { of control) }\end{array}$} \\
\hline 0 & $\begin{array}{l}54 \\
\pm 3\end{array}$ & $\begin{array}{l}78 \\
\pm 4\end{array}$ & $\begin{array}{l}91 \\
\pm 4\end{array}$ & $\begin{array}{l}105 \\
\pm 5\end{array}$ & $\begin{array}{l}40 \\
\pm 4\end{array}$ & $\begin{array}{l}65 \\
\pm 4\end{array}$ & $\begin{array}{l}73 \\
\pm 3\end{array}$ & $\begin{array}{l}95 \\
\pm 6\end{array}$ & $\begin{array}{l}28 \\
\pm 1\end{array}$ & $\begin{array}{l}55 \\
\pm 4\end{array}$ & $\begin{array}{l}75 \\
\pm 5\end{array}$ & $\begin{array}{l}90 \\
\pm 5\end{array}$ & $\begin{array}{l}100 \\
\pm 6\end{array}$ \\
\hline 7 & $\begin{array}{l}51 \\
\pm 3\end{array}$ & $\begin{array}{l}67 \\
\pm 4\end{array}$ & $\begin{array}{l}77 \\
\pm 5\end{array}$ & $\begin{array}{l}97 \\
\pm 8\end{array}$ & $\begin{array}{l}46 \\
\pm 3\end{array}$ & $\begin{array}{l}70 \\
\pm 4\end{array}$ & $\begin{array}{l}82 \\
\pm 6\end{array}$ & $\begin{array}{l}94 \\
\pm 8\end{array}$ & $\begin{array}{l}30 \\
\pm 2\end{array}$ & $\begin{array}{l}49 \\
\pm 2\end{array}$ & $\begin{array}{l}66 \\
\pm 7\end{array}$ & $\begin{array}{l}90 \\
\pm 8\end{array}$ & $\begin{array}{l}100 \\
\pm 6\end{array}$ \\
\hline 14 & $\begin{array}{l}33 \\
\pm 3\end{array}$ & $\begin{array}{l}51 \\
\pm 5\end{array}$ & $\begin{array}{l}60 \\
\pm 3\end{array}$ & $\begin{array}{l}67 \\
\pm 5\end{array}$ & $\begin{array}{l}33 \\
\pm 4\end{array}$ & $\begin{array}{l}53 \\
\pm 5\end{array}$ & $\begin{array}{l}57 \\
\pm 3\end{array}$ & $\begin{array}{l}73 \\
\pm 5\end{array}$ & $\begin{array}{l}18 \\
\pm 1\end{array}$ & $\begin{array}{l}38 \\
\pm 2\end{array}$ & $\begin{array}{l}59 \\
\pm 3\end{array}$ & $\begin{array}{l}73 \\
\pm 5\end{array}$ & $\begin{array}{l}100 \\
\pm 7\end{array}$ \\
\hline 28 & $\begin{array}{l}20 \\
\pm 4\end{array}$ & $\begin{array}{l}41 \\
\pm 3\end{array}$ & $\begin{array}{l}53 \\
\pm 6\end{array}$ & $\begin{array}{l}68 \\
\pm 5\end{array}$ & $\begin{array}{l}12 \\
\pm 2\end{array}$ & $\begin{array}{l}34 \\
\pm 4\end{array}$ & $\begin{array}{l}55 \\
\pm 4\end{array}$ & $\begin{array}{l}68 \\
\pm 5\end{array}$ & $\begin{array}{l}0 \\
\pm 0\end{array}$ & $\begin{array}{l}24 \\
\pm 3\end{array}$ & $\begin{array}{l}45 \\
\pm 5\end{array}$ & $\begin{array}{l}62 \\
\pm 5\end{array}$ & $\begin{array}{l}100 \\
\pm 10\end{array}$ \\
\hline 56 & $\begin{array}{l}19 \\
\pm 2\end{array}$ & $\begin{array}{l}44 \\
\pm 3\end{array}$ & $\begin{array}{l}52 \\
\pm 5\end{array}$ & $\begin{array}{l}62 \\
\pm 2\end{array}$ & $\begin{array}{l}14 \\
\pm 1\end{array}$ & $\begin{array}{l}37 \\
\pm 4\end{array}$ & $\begin{array}{l}45 \\
\pm 2\end{array}$ & $\begin{array}{l}62 \\
\pm 3\end{array}$ & $\begin{array}{l}0 \\
\pm 0\end{array}$ & $\begin{array}{l}25 \\
\pm 2\end{array}$ & $\begin{array}{l}45 \\
\pm 5\end{array}$ & $\begin{array}{l}56 \\
\pm 2\end{array}$ & $\begin{array}{l}100 \\
\pm 5\end{array}$ \\
\hline
\end{tabular}


The gradual decrease in phosphatase enzyme activity in soil may be related to the increase in orthophosphate concentrations over the same period. Orthoposphate is an end product in the phosphatase-catalyzed reactions, and can act as a competitive inhibitor for this class of enzymes. As orthophosphate concentrations decrease through natural processes the phosphatase activity in the soil will likely be restored.

Judging from the general trend of decreased enzyme activity with increased smoke humidity, it appeared that humidity-related properties such as deposit velocity, mass concentration, etc., as listed in Table 3.70, all influenced smoke toxicity on soil microbial activities.

Figure 3.33 depicts the general trends of effects on soil phosphatase by smoke screens at 25,60 and $90 \%$ relative humidities. This indicates a reduced level of phosphatase associated with the exposed thin soil surface and remained reduced for at least 8 weeks.

Figures 3.34 and 3.35 illustrate the trends of smoke effects on soil dehydrogenase. Smoke effects were most severe in the thin soil layer in that virtually all of the dehydrogenase activity (with glucose, Figure 3.34 , or casamino acids, Figure 3.35 , as substrate respectively) ceased to function. Carbon mineralization decreased following exposure, but was able to recover to a small extent after 2 weeks. In some instances with a thicker soil layer, ammonification showed enhancement before leveling off.

Figure 3.36 demonstrates the erratic trends of soil nitrification activity resulting from phosphorus smoke exposure. However, the trends indicate a severe inhibition in surface soil after exposure, but were able to regain activity after 2 weeks.

The extent of the impact of phosphorous smokes on soil microbial activity and subsequent environmental implications will be dependent on soil type, seasonal variation, and the frequency of exposure to the smokes. Soil physical and chemical factors that can influence the effect smokes have on soil microbial activity include particle size and porosity, which can determine the depth to which the effects occur, and initial soil pH and buffer capacity. The phosphorous smokes can reduce soil pH. The extent of this reduction will be dependent on the buffering capacity of the soil, and the impact on soil microbial activity will be dependent on the initial soil $\mathrm{pH}$. The soil microflora can adapt to different pHs, therefore a soil that is initially in the acid range may not be as severely affected by exposure to phosphorous smoke than a soil with a high $\mathrm{pH}$, such as the Burbank soil.

Seasonal fluctuations in temperature and moisture determine microbial activity in soil. Exposure to phosphorous smoke in the spring when soil microbial activity is often at a peak (favorable moisture and temperature conditions) would be more critical than during periods when the soil is dry or cold. The Burbank soil also showed a capacity to recover microbial activity after smoke exposure. Repeated exposure could have more serious and long-lasting effects on the soil microbial activity and the ability of that soil to interact with the rest of the ecosystem in a normal capacity. 

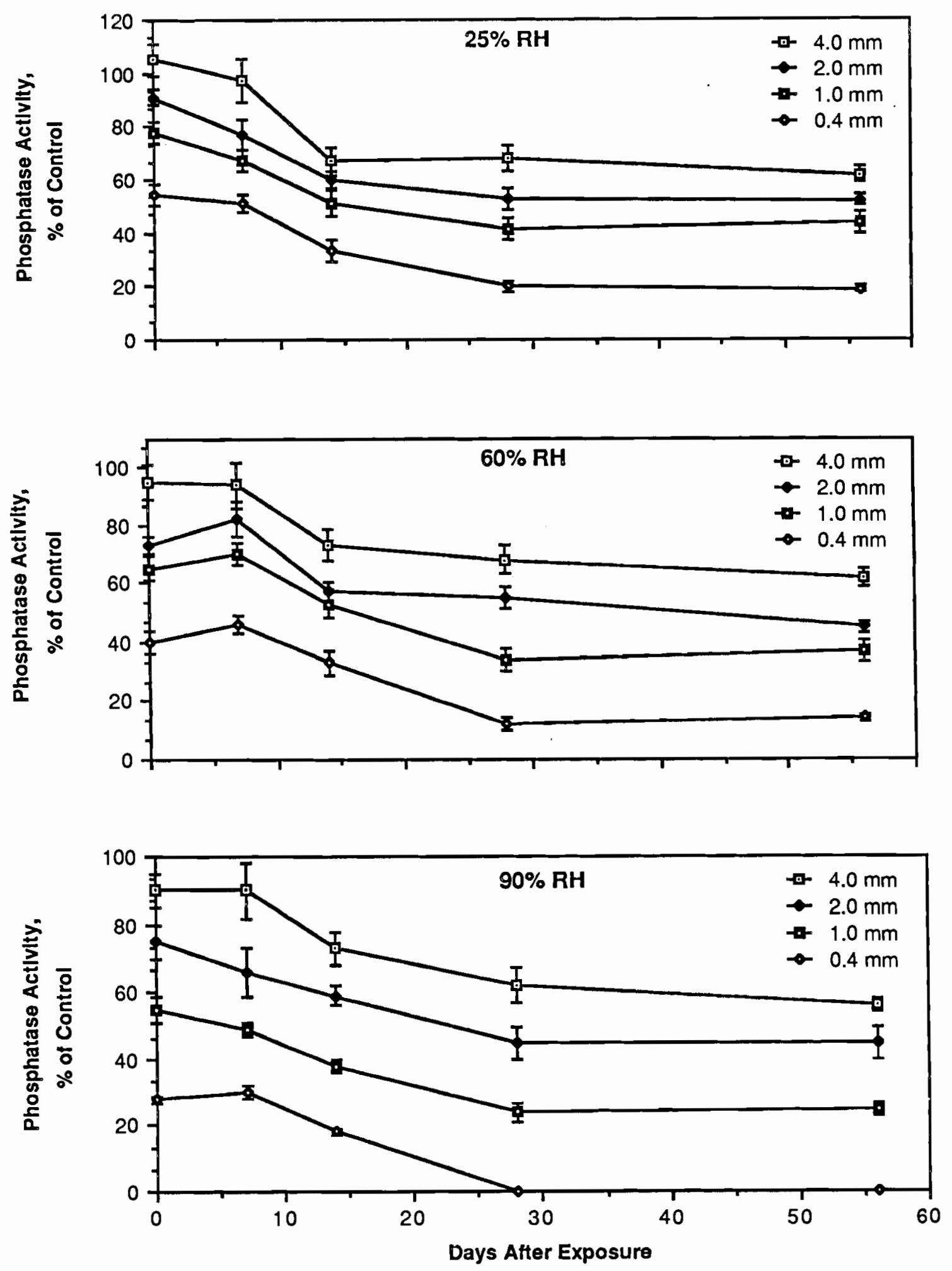

FIGURE 3.33. SOIL PHOSPHATASE ACTIVITY FOLLOWING RP/BR SMOKES EXPOSURES OF SOIL LENSES OF 4.0,2.0, 1.0, AND $0.4 \mathrm{~mm}$ THICKNESS AT RELATIVE HUMIDITY OF 25,60 , AND $90 \%$. ERROR BARS REPRESENT STANDARD DEVIATIONS, $n=3$ 

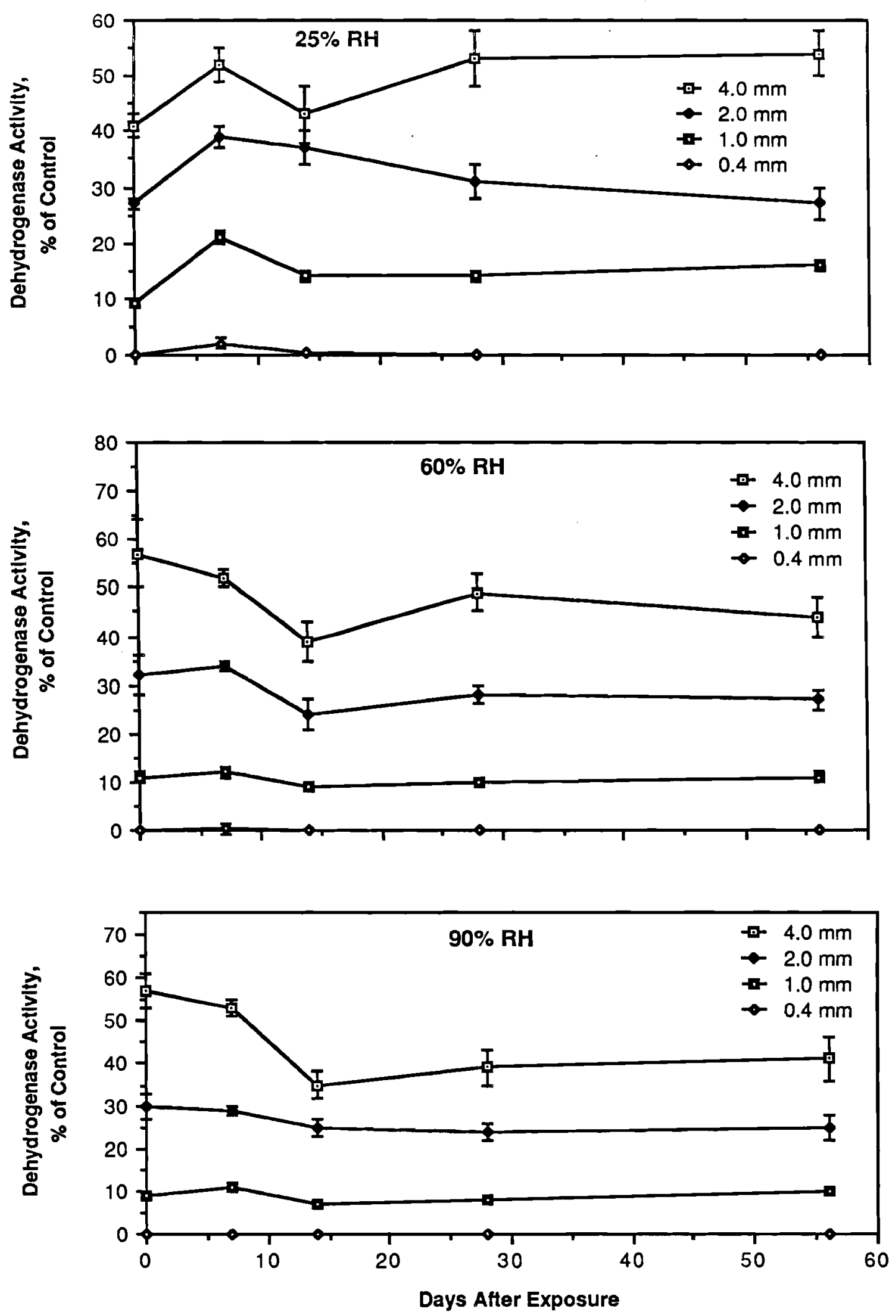

FIGURE 3.34. SOIL DEHYDROGENASE ACTIVITY (IN GLUCOSE AMENDED SOIL) FOLLOWING RP/BR SMOKE EXPOSURE OF SOIL LENSES OF 4.0, 2.0, 1.0, AND $0.4 \mathrm{~mm}$ THICKNESS AT RELATIVE HUMIDITY OF 25, 60, AND $90 \%$. ERROR BARS REPRESENT STANDARD DEVIATIONS, $n=3$ 

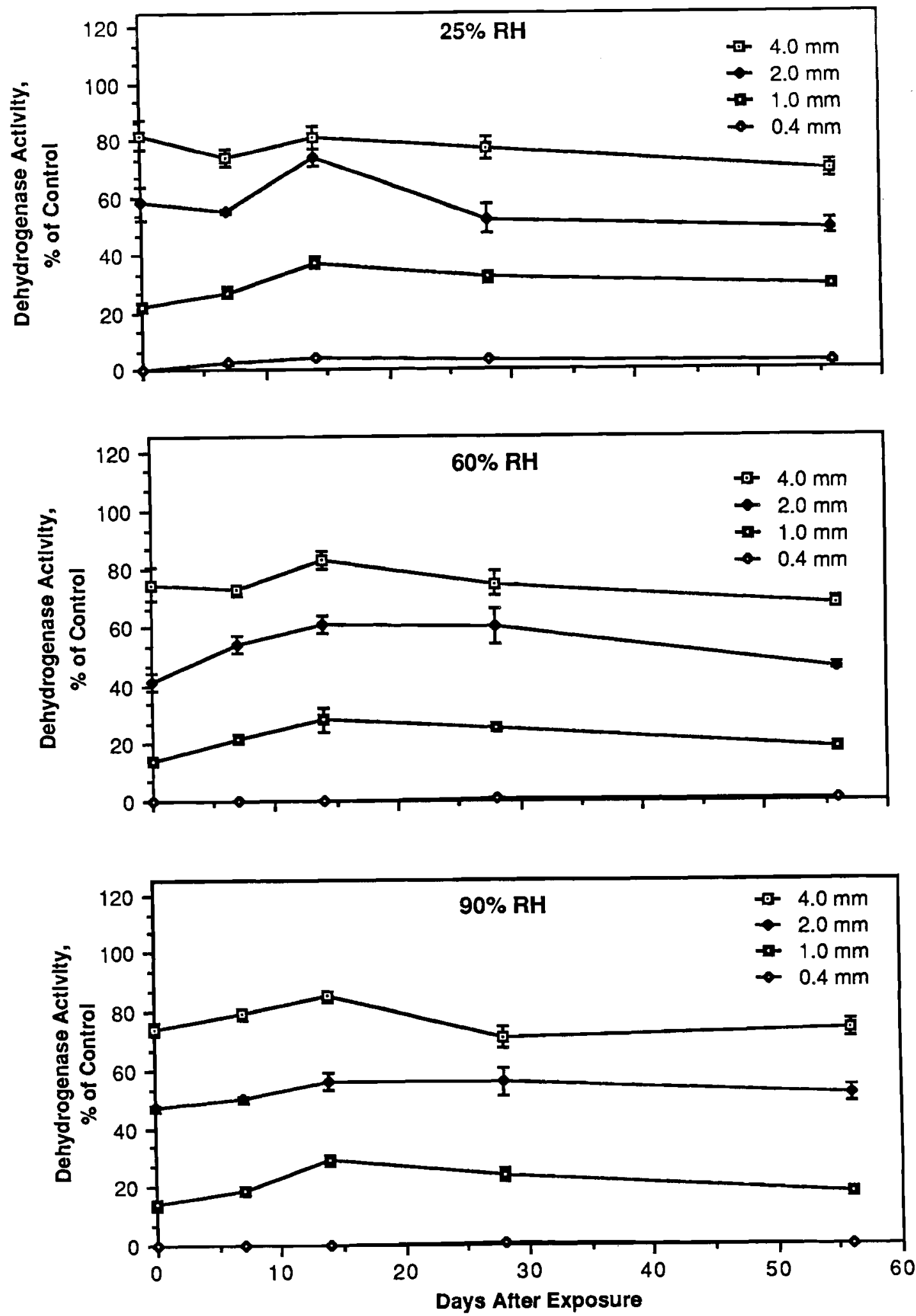

FIGURE 3.35. SOIL DEHYDROGENASE ACTIVITY (IN CASAMINO ACIDS AMENDED SOIL) FOLLOWING RP/BR SMOKE EXPOSURE OF SOIL LENSES OF $4.0,2.0$, 1.0 , AND $0.4 \mathrm{~mm}$ THICKNESS AT RELATIVE HUMIDITY OF $25, \cdot 60$, AND $90 \%$. ERROR BARS REPRESENT STANDARD DEVIATIONS, $n=3$ 

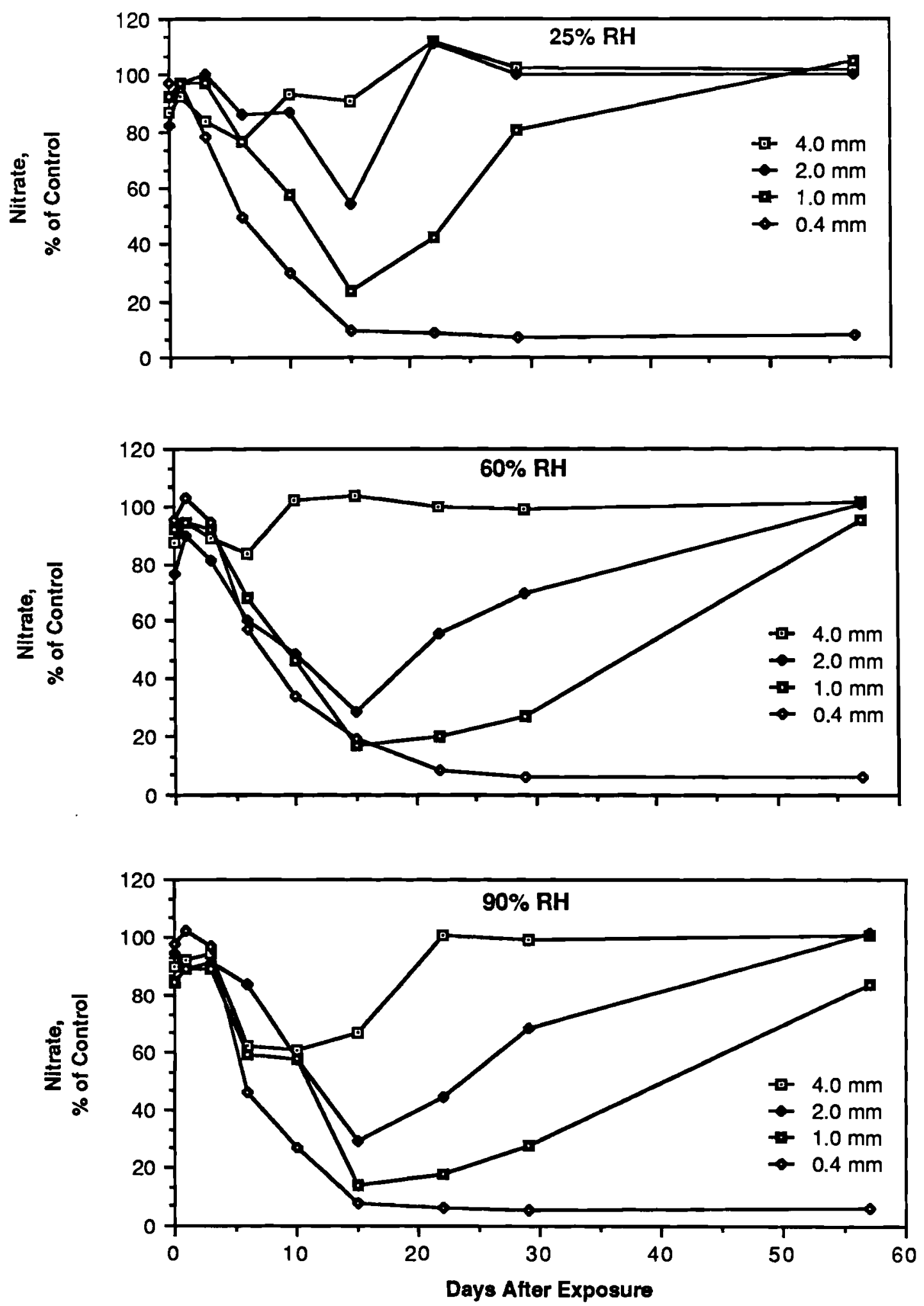

FIGURE 3.36. SOIL NITRIFICATION ACTIVITY FOLLOWING RP/BR SMOKE EXPOSURE OF SOIL LENSES OF $4.0,2.0,1.0$, AND $0.4 \mathrm{~mm}$ THICKNESS AT RELATIVE HUMIDITY OF 25,60 , AND. $90 \%$ 


\subsection{CONCLUSIONS}

A limited number of sites are used in the United States for testing obscurant smokes and for troop training exercises. Since these sites are unique from the standpoint of topography and environment, it is in the national interest to protect their physical and biological characteristics, thereby assuring their long-term usefulness and availability. Information on the environmental behavior, fate, and effects of obscurant smokes is necessary to adequately assess the long-term impacts of obscurant smoke use.

This study has been designed to simulate, under controlled laboratory conditions, the combustion, delivery, deposition, chemical fate and potential biological effects of red phosphorus/butyl rubber (RP/BR) and white phosphorus (WP) smokes. Various atmospheric, environmental, and biological variables are used to determine resulting environmental impacts, and studies were conducted using a range of exposure and post-exposure variables. The variables used were either controlled or varied, and included relative humidity, wind speed, temperature, smoke concentration, and exposure duration. In addition, key parameters including boundary conditions, turbulence, and particle size distributions within the exposure test section of the wind tunnel were used to extrapolate data to field situations. The use of a wind tunnel, compared to static laboratory exposure systems, allows for dynamic exposure scenarios that can more closely simulate important environmental variables and processes. In this study, this approach provides an integrated view of smoke chemistry, atmospheric transport, and deposition at approximately $1 \mathrm{~km}$ from a generator or source.

\subsection{PHYSICAL AND CHEMICAL CHARACTERISTICS OF AIRBORNE PHOSPHORUS SMOKES}

Variations in experimental and chemical methods used by PNL and other researchers to generate and collect smoke aerosol (Brazell et al. 1984, Katz et a1. 1981, Spanggord et a1. 1985) have led to some conflicting observations that may not necessarily be reproduced under actual field conditions. Based on our aerosol studies, we conclude that phosphorus speciation is affected by humidity and aerosol age (time to water contact), whether speciation results from direct deposition onto foliage, soils, lakes and streams, or by rainout and runoff. Hydrolysis will also be affected by the resulting solution environment generated by the wetting techniques, and the availability of agents causing complexation or precipitation. Particle size is a function of parameters including age and humidity, and so will reflect the corresponding distributions on a more limited scale. Wind speed may have a minor effect on species distribution, but would most likely be outweighed by the moisture-related responses.

Since combustion and hydrolys is reactions are expected to be temperature dependent, future work should include studies at potential field temperatures $\left(\angle 0^{\circ} \mathrm{C}\right.$ to $40^{\circ} \mathrm{C}$ or more), and the corresponding actual 
moisture content ranges covered by relative humidity values. Since the environmental impact of these aerosols may be dependent on individual chemical species that are in turn dependent on age and environmental influence, accurate prediction of the relative impact of field use of phosphorus obscurants would require such measurements.

\subsection{IMPACT OF PHOSPHORUS SMOKES ON SOIL CHEMISTRY}

Although phosphorus speciation effects on leachates of exposed soils indicated that the soils can accelerate the hydrolysis rate of the higher polyphosphates and possibly alter the mechanistic pathway of the hydrolysis, the soils did change as a result of phosphorus aerosol deposition. Phosphorus aerosol depositions result in an increased acidic impact on soils, which may exceed the buffering capacity at the very surface of the soils. The increased solubility of Al observed from several surface soils was not due to an acid or phosphate effect, and is therefore presumed to be due to the presence of one or more condensed phosphates. Interaction of trace metals with phosphorus species could contribute to leachability and subsequent migration of those metals. The phosphorus amendment is subject to precipitation and adsorption removal, which is highly dependent on soil type. The effects of phosphorus aerosol depositions on surface soil appeared to be mitigated with increased soil volume, so changes in solubilized species will likely be minimal on a field scale. Phosphorus depositions may actually be beneficial to nutrient-poor surface soils. However, the potential exists for elevated levels of soluble components resulting from runoff into streams and lakes. Future work should include studies of the effects of codispersion of phosphorus aerosol with dust particulate from surface soil types.

\subsection{IMPACT OF PHOSPHORUS SMOKES ON SOIL MICROFLORA}

Phosphorus smoke effects on the soil microbial community were evaluated using four principal microbiological parameters: nitrification, carbon mineralization, ammonification and an extracellular enzyme, phosphatase. Variables in the smoke exposure tests included soil depth $(0.4$ to $4.0 \mathrm{~mm})$ and relative humidities, which ranged from $25 \%$ to $90 \%$. Results indicated the environs of the soil surface and near surface would be most susceptible to toxic effects of smoke because the major portion of the phosphorus load was in the soil surface. Based on the response surfaces (see Figures 3.33 through 3.36 ), it appears the effects of phosphorus smoke on indigenous soil micro-organisms in soil at or near the surface may be severe and persistent. Nevertheless, with increasing soil depth, deleterious effects are less intense and appear to be transient. Smoke/humidity interactions, when related to other aerosol properties such as particle size distribution and phosphorus mass concentration, may have some effects, although to a lesser extent, on the indigenous soit micro-organisms.

It is apparent from these studies that obscurants can have a serious impact on soil microbial communities and their activities. The degree and 
1ongevity of the effects are dependent on a number of factors, with soil type being a key factor. Future studies should address the issue of soil type as the sites where phosphorus smoke obscurants may be used vary in climate and geology, and hence vary in the types of soils that exist on them.

\subsection{FOLIAR CONTACT TOXICITY: DIRECT EFFECTS}

In considering the contact toxicity of phosphorus smokes to plants, whether in the field or under laboratory conditions, it is difficult to evaluate toxicity response based only on air concentration and exposure duration since a wide range of parameters affect the transfer of smoke residues from the air column to foliar or soil surfaces. This difficulty has been alleviated in this study by using the actual received dose (i.e., mass loading) as the absolute measure of chemical insult. Therefore, the influence of a wide range of modifying variables can be evaluated including mass loading (range-finging test series), relative humidity, wind speed, the influence of plants to compensate for cumulative dose episodes [cumulative dose test (CDT) series], post-exposure leaching, and dosing during simulated rainout conditions. Wind speed was shown to have the most pronounced effect on mass loading and therefore on phytoxocity. Mass loading increases almost logarithmically as wind speed is increased from 2 to $10 \mathrm{mph}$. In addition, once a mass loading value is obtained and the exposure duration and air concentration are known, a deposition velocity value can be calculated. The deposition velocity value can be readily used in a predictive mode to determine mass loading to plant foliage under field conditions, assuming that wind speed, relative humidity, air concentration, and exposure duration are known for the field situation. Deposition velocity data obtained for soils can be used in a similar manner.

Numerous observations can be made concerning the toxicity of phosphorus smokes to native vegetation:

1. The dose/response relationships for RP and WP smokes are generally similar for the five plant species studied.

2. Application of a post-exposure simulated rainfall tends to ameliorate phosphorus effects by removing a substantial fraction of the dose.

3. Relative humidity has a variable influence on toxicity; increased relative humidity increases toxicity in ponderosa pine and sagebrush, but has little consistent effect on sagebrush, blando brome or bushbean. This may be a function of the absorptive capacity of foliar cuticles characteristic of individual species.

4. There is a pronounced increase in mass loading and therefore toxicity response at wind speeds in excess of 4 to $6 \mathrm{mph}$.

5. Plants receiving a series of nine consecutive dosings over a threeweek period appear to compensate for the cumulative dose, resulting in minimal phytotoxic response compared with single large dose events. 
6. With the exception of bushbean, each of plant species, when severely impacted to the point of near defoliation, exhibited secondary bud activity and recovered within 30 to 45 days post-exposure. This would indicate that toxicity is generally localized to the impacted foliage, and that periodic, severe effects are transient and can be tolerated by the plant.

\subsection{RESIDUAL AND INDIRECT SOIL/PLANT EFFECTS}

While the adverse environmental impacts resulting from contact toxicity from RP/BR and WP smokes appear to be transient, additional studies suggest that the recurrent use of phosphorus smokes may have long-term impacts on plant performance at heavily used training sites. These studies include the residual effects studies where foliarly exposed grasses were cut back and allowed to regrow, and the indirect effects studies where soils were contaminated with phosphorus smokes and subsequently seeded with grass. In the residual effects studies performed in the cumulative dose test and wind speed test series, second harvest biomass results indicate that some component of the smoke residuals deposited to the foliage was absorbed and transported to the root, resulting in significant biomass reductions during the second regrowth. The effect was much more pronounced for RP/BR treatments than WP

treatments. A similar effect was noted in the indirect effects studies where soils were contaminated prior to planting. However, because the two soils used varied in fertility, effects on first harvest data were somewhat masked. The effect is however, clearly observed in the results from the relative humidity test series for RP/BR smokes. This aspect of the environmental impact of phosphorus smokes can result in reduced vigor of selected plant species, and should be further investigated.

\subsection{EXTRAPOLATION OF LABORATORY DATA TO FIELD SCENARIOS: PREDICTIVE CAPABILITIES}

An adequate data base must be developed for individual smokes to evaluate the environmental impact of obscurant smoke use. Data and efforts based on previous and continuing laboratory and field investigations must be integrated to define important, if not controlling, processes. In this study we attempted to integrate and interrelate those processes (atmospheric, environmental, and biological) thought to be important in defining the interaction of phosphorus smokes with receptor surfaces in the environment. The dose based on mass loading was quantified and the responses based on individual variables were evaluated to provide a basis for extrapolating laboratory data to field situations. Figure 4.1 presents examples of three dimensional data extrapolation for the toxicity response (Daubenmire Index) of both ponderosa pine and sagebrush to phosphorus smokes, against a series of variables. The variables include mass loading, relative humidity and post-exposure simulated rainfall. From the response surface, it is clear that foliar mass loading is a major factor in toxicity. At a given mass loading, high and low levels of relative humidity have an adverse effect on the response, probably because of 
speciation of the phosphorus, while precipitation events (i.e., rainfall) can ameliorate the intensity of the adverse effects. It is also apparent that morphologic characteristics of the leaf surface can play a role in limiting or ameliorating the intensity of the impact (see Figures 3.13 through 3.15 for Electron Micrographs showing differences in leaf surfaces between pine and sagebrush).

The ease with which this type of response surface characterization can be applied to field scenarios depends on the basis used for establishing dose/response relationships. In this study, we have generated values for deposition velocity based on air concentration and mass loading (foliar and soil) that can be applied readily to the field situation. For example, the length of time a smoke test could be conducted without defoliating a stand of ponderosa pine ( $D R=7$ ) located $8-\mathrm{km}$ down wind could be readily calculated based on the air concentration at that point, the deposition velocity for that canopy type, relative humidity and wind speed. It is this predictive approach based on precise laboratory or field data that will be most useful in the future. 

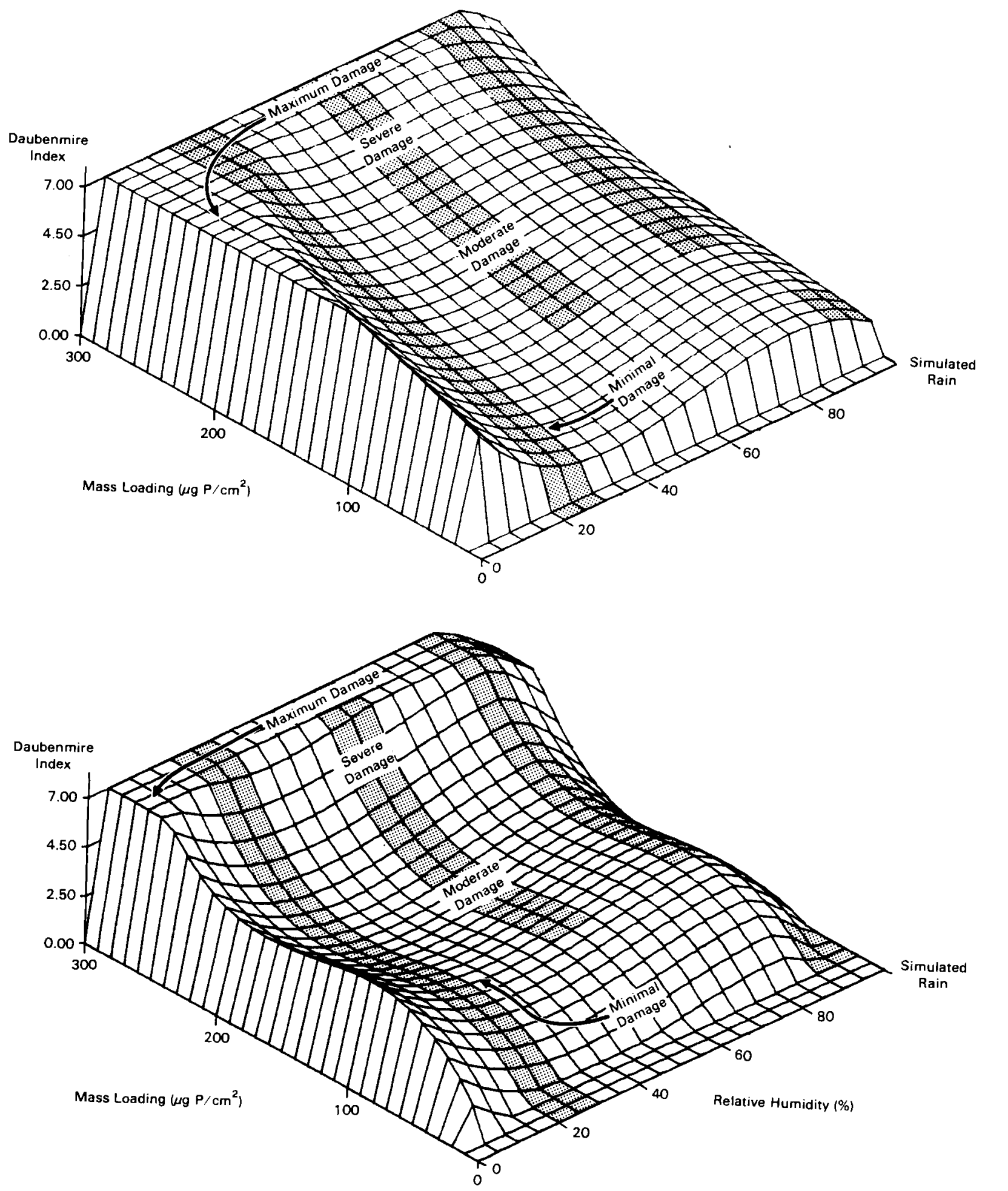

FIGURE 4.1 RESPONSE SURFACE FOR PONDEROSA PINE (top) AND SAGEBRUSH (below) 


\subsection{REFERENCES}

Ballou, J.E. 1981. Chemical Characterization and Toxicological Evaluation of Airborne Mixture. Final Summary Report, AD-A 102678. Battelle, Pacific Northwest Laboratories, Richland, WA. DAMD17-79-C9160.

Berkheiser, V.E., J.J. Street, P.S.C. Rao, and T.L. Yuan. 1980. "Partitioning of Inorganic Orthophosphate in Soil-Water Systems." Also available as Journal Article No. 2396 from the Agr. Exp. Station, University of Florida, Gainesville, FL, CRC Critical Reviews in Environmental Control pp. 179-224.

Brazel1, R.S., R.W. Holmberg, and J.H. Moneyhun. 1984. "Application of High Performance Liquid Chromatography-Flow Injection Analys is for the Determination of Polyphosphoric Acids in Phosphorus Smokes." $\mathrm{J}$. Chromatrgr. 290:163-172.

Brazell, R.S., J.H. Moneyhun, and R.W. Holmberg. 1984. Chemical Characterization and Toxicologic Evaluation of Airborne Mixtures. Final Summary Report. Oak Ridge National Laboratory, Oak Ridge, TN. DE-AC05-840R21400.

Burton, F.G., M.L. Clark, R.A. Miller, and R.E. Schirmer. 1982. "Generation and Characterization of Red Phosphorus Smoke Aerosols for Inhalation Exposure of Laboratory Animals." Am. Ind. Hyg. Assoc. J. 43.

Carlon, H.R., D.H. Anderson, M.E. Milham, T.L. Tarnove, R.H. Frickel, and I. Sindoni. 1977. "Infrared Extinction Spectra of Some Common Liquid Aerosols." Applied Optics 16(6).

Casida, L.E., Jr. 1967. "Microbial Metabolic Activity in Soil as Measured by Dehydrogenase Determinations." Appl. Environ. Microbiol. $34: 630-636$.

Cataldo, D.A., T.R. Garland, R.E. Wildung. 1981. "Foliar Retention and Leachability of Submicron Plutonium and Americium Particles." $\mathrm{J}$ Environ. Qual. 10:31-37.

DeFord, H.S., M.L. Clark, and J.R. Decker. 1982. "A Laboratory-Scale Conveyor/Metering Device and Combustor for Generating Smoke from Solids at a Uniform Rate." Am. Ind. Hyg. Assoc. J. 43(10):764-766.

Dixon, J.B. and S.B. Weed. 1977. Minerals in Soil Environments. Soil Science Society of America, Madison, Wisconsin.

Focht, D.D., and A.C. Chang. 1975. "Nitrification and Denitrification Processes Related to Waste Water Treatment." Advances in Applied Microbiology 19:153-186. 
Gillespie, G.R., and H.F. Johnstone. 1955. "Particle-Size Distribution in Some Hygroscopic Aerosols." Chemical Engineering Progress 51(2).

Halmann, M., editor. 1972. Analytical Chemistry of Phosphorus Compounds. Wiley-Interscience, New York.

Hedley, M.J., J.W.B. Stewart, and B.S. Chauhan. 1982. "Changes in Inorganic and Organic Soil Phosphorus Fractions Induced by Cultivation Practice and by Laboratory Incubations." Soil Sci. Soc. Am. P. $46: 970-976$.

Holmberg, R.W., and J.H. Moneyhun. 1982. "A System for the Continuous Generation of Phosphorus Aerosol From Red Phosphorus-Butyl Rubber." Conf-820468-1. Oak Ridge National Laboratory. Sponsored by the U.S. Department of Defense.

Jenkinson, D.S. 1976. "The Effect of Biocidal Treatments on Metabolism in Soil. IV. The Decomposition of Fumigated Organisms in Soil." Soil Biol. Biochem. 8:203-208.

Kafkafi, U. 1972. Soil Phosphorus. In M. Halmann, editor. Analytical Chemistry of Phosphorus Compounds. Wiley-Interscience, NY.

Katz, S., A. Snelson, R. Butler, W. Bock, N. Rajendron, and S. Relwani. 1981. Physical and Chemical Characterization of Military Smokes, Part II I: White Phosphorus-Felt Smokes. Final Summary Report AD A1156557. IIT Research Institute, Chicago, IL.

Klein, D.A., T.C. Loh and R.L. Goulding. 1971. "A Rapid Procedure to Evaluate the Dehydrogenase Activity of Soils Low in Organic Matter." Soil Biol. Biochem. 3:385-387.

Klein, D.A., et al. 1979. "Role of Soil Microorganisms as Indicators and Possible Controlling Factors in Plant Succession Processes on Retorted Shale and Disturbed Soils." In C.W. Cook, editor. Rehabilitation Potential and Practice of Colorado $0 i l$ Shale Lands. Colorado State University, Fort Collins, C0.

Kudeyarova, A.Y. and M.Z. Kvaratskheliya. 1984. "Contribution of Inorganic Polyphosphates to Migration of Elements in a Grey Forest Soi1, USSR." Geoderma 34:251-259.

Lai, M.G. and D.H. Rosenblatt. 1977a. Determination of Ultramicro Quantities of Elemental Phosphorus in Water by Neutron Activation Analysis. NSWC/MOL-TR-77-49. Naval Surface Weapons Center, Silver Spring, MD.

Lai, M.G. and D.H. Rosenblatt. 1977b. Identification of Transformation Products of White Phosphorus in Water. NSWC/WOL-TR-76-103. NavaT Surface Weapons Center, Silver Spring, MD. 
Ligotke, M.W., D.A. Cataldo, P. Van Voris, and C.M. Novich. 1986. "Analysts Use Wind Tunnel to Study Particle Behavior in the Environment." Research and Development 28(6):82-85.

Meixner, R.E. and M.J. Singer. 1985. "Phosphorus Fractions from a Chronosequence of Alluvial Soils, San Joaquin Valley, California." Soil Science $139(1): 37-46$.

Milham, M.E., D.H. Anderson, R.H. Frickel, and T.L. Tarnove. 1977. New Findings on the Nature of WP/BR Smokes. Technical Report ARCSL-TR-77067. Aberdeen Proving Ground, MD.

Painter, H.A. 1970. "A Review of Literature on Inorganic Nitrogen Metabolism in Microorganisms." Water Research 4:393-450.

Poston, T.M., R.M. Bean, B.L. Thomas, K.M. McFadden, and M.L. Clark. 1986. Acute Toxicity of Smoke Screen Materials to Aquatic Organisms, White Phosphorus-Felt, Red Phosphorus-Butyl Rubber and SGF No. 2 Fog 0 il. Final Summary Report. Pacific Northwest Laboratory, Richland, WA. Project Order No. 84PP4800.

Riemann, W. III, and J. Beukenkamp. 1961. "Phosphorus." I.M. Kilthoff, P.J. Elving, E.B. Sande11, eds. Treatise on Analytical Chemistry. pp. 317-402. Interscience Publishers, Inc., N.Y.

Shinn, J.H., S.A. Martins, P.L. Cederwall, and L.B. Gratt. 1985. A First-Order, Environmental Screening and Ranking of Army Smokes and Obscurants. Phase I Report. Lawrence Livermore National Laboratory, Livermore, $C A$.

Skujins, J. 1967. "Extracellular Enzymes in Soil." Crit. Rev. Microbiol. $4: 383-421$.

Spanggord, R.J., R. Rewick, T. Chou, R. Wilson, R.T. Podoll, T. Mill, R. Parnas, R. Platz, and D. Roberts. 1985. Environmental Fate of White Phosphorus/Felt and Red Phosphorus/Butyl Rubber Military Screening Smokes. Draft Final Report. SRI Internationa T, MenTo Park, CA. DAMD 17-82-C-2320.

Stott, D.E., W.A. Dick, and M.A. Tabatabai. 1985. "Inhibition of Pyrophosphatase Activity in Soils by Trace Elements." Soil Sci. $139(2): 112-117$.

Tabatabai, M.A., and J.M. Bremner. 1969. "Use of p-nitrophenyl Phosphate for Assay of Soil Phosphatase Activity." Soil Biol. Biochem. $1: 301-307$.

Tarnove, T.L. 1980. Studies of the Chemistry of the Formation of Phosphorus-Derived Smokes and their Implication for Phosphorus Smoke Munitions. ARCSL-TR-80049. U.S. Army Armament Research and Development Command, Chemical Systems Laboratory, Aberdeen Proving Ground, MD. 
Thilo, E., and W. Wieker. 1954. Z. Anorg. Allg. Chem. 277:27-33.

Van Voris, P., M.W. Ligotke, D.A. Cataldo, T.R. Garland, K.M. McFadden, J.E. Rogers, D.W. Carlile, and S.W. Li. 1985. "Transport, Transformation, and Ecological Effects of Phosphorus Smokes in an Environmental Wind Tunnel." Volume II of the Proceedings of the Smoke/Obscurants Symposium IX. Adelphi, MD, April 23-25, 1985. Office of the Project Manager Smoke/Obscurants, Aberdeen Proving Ground, MD. 2:593-642.

Van Voris, P., M.W. Ligotke, K.M. McFadden, D.A. Cataldo, and T.R. Garland. 1986. "Use of a Toxic and Hazardous Aerosol Research Facility to Evaluate Fate and Effects of Army Smoke Screen Materials." Proceedings of the 28th Conference on Analytical Chemistry in Energy Technology. Knoxville, TN, October 1-3, 1985. Analytical Chemistry Division, Oak Ridge National Laboratory, Oak Ridge, TN. pp. 3-8.

Van Wazer, J.R., E.J. Griffith, J.E. McCullough. 1954. "Analys is of Phosphorus Compounds. Automated pH Titration of Soluble Phosphates and Their Mixtures." Anal. Chem. 26(11):1755-1759.

Van Wazer, J.R. 1958. "Phosphorus and Its Compounds." Vol. 1, Chemistry. Interscience Publishers, Inc., N.Y.

Wasti, K., K.J.T. Abaidoo, and J.E. Villaume. 1978. "Occupational Health and Safey Aspects of Phosphorus Smoke Compounds." Technical Report ADA056019. U.S. Army Medical Research and Development Command, Fort Detrick, Frederick, MD.

Weiner, J.T., G. Affleck, J. Preston, J. Lucey, J. Manthei, and F. Lee. 1977. The Acute Effects of Single Exposures to United Kingdom Red Phosphorus Screening Smoke in Rats, Guinea Pigs, Rabbits, and Dogs. Technical Report ARCSL-TR-77052. Aberdeen Proving Ground, MD.

Yamaguchi H., T. Nakamura, Y. Hirai and S. Ohashi. 1979. "High-performance Liquid Chromatographic Separation of Linear and Cyclic Condensed Phosphates." J Chroma. 172: 131-140. 
No. of

Copies

OFFSITE

25 Commander

U.S. Army Biomedical Research and Development Laboratory

ATTN: SGRD-UBZ-C

Fort Detrick

Frederick, MD 21701-5010

2 Commander

U.S. Army Medical Research and Development Command

ATTN: SGRD-RMI -S

Fort Detrick

Frederick, MD 21701-5012

Dean

School of Medicine

Uniformed Services University

of the Health Sciences

4301 Jones Bridge Road

Bethesda, MD 20814-4799

Commandant

Academy of Health Sciences

U.S. Army

ATTN: AHS-CDM

Fort Sam Houston, TX 78234-6100

Commander

U.S. Army Environmental Hygiene Agency

ATTN: HSHD-HD-L (Librarian)

Aberdeen Proving Ground, MD 21010

2 DOE Technical Information Center
No. of

Copies

ONSITE

DOE Richland Operations Office

J. J. Sutey

46 Pacific Northwest Laboratory

D. W. Dragnich

J. A. Stottlemyre

P. C. Hays

P. Van Voris (25)

D. A. Cataldo

M. W. Ligotke

T. R. Garland

K. M. McFadden

J. K. Fredrickson

S. W. Li

R. M. Bean

B. L. Thomas

D. W. Carlile

R. G. Riley

R. E. Wildung

Publishing Coordination (2)

Technical Report Files (5) 